\title{
EXPERIMENT AND SIMULATION OF THE ACOUSTIC SIGNATURE OF FATIGUED-CRACKED GEARS IN A TWO-STAGE GEARBOX
}

\author{
A Thesis \\ presented to \\ the Faculty of California Polytechnic State University, \\ San Luis Obispo
}

\author{
In Partial Fulfillment \\ of the Requirements for the Degree \\ Master of Science in Mechanical Engineering
}

By

Matthew James Ostiguy

December 2014 
(C) 2014

Matthew James Ostiguy

ALL RIGHTS RESERVED 


\section{COMMITTEE MEMBERSHIP}

TITLE:

AUTHOR:

DATE SUBMITTED:

COMMITTEE CHAIR:

COMMITTEE MEMBER:
Experiment and Simulation of the Acoustic Signature of

Fatigued-Cracked Gears in a Two-Stage Gearbox

Matthew James Ostiguy

December 2014

Dr. Tom Mackin

Professor of Mechanical Engineering

Dr. Jim Meagher

Professor of Mechanical Engineering

COMMITTEE MEMBER: Dr. Xi (Julia) Wu

Associate Professor of Mechanical Engineering 


\begin{abstract}
Experiment and Simulation of the Acoustic Signature of Fatigued-Cracked Gears in a

Two-Stage Gearbox

Matthew James Ostiguy
\end{abstract}

\begin{abstract}
This thesis focuses on the development of a health monitoring system for gearbox transmissions. This was accomplished by developing and understanding a twostage gearbox computer model that emulates an actual gearbox test rig. The computer model contains actual gearbox geometry, flexible shafts, bearings, gear contact forces, input motor torque, output brake torque, and realistic gearbox imbalance. The gear contact force of each gear stage and the input bearing translational acceleration were the main outputs compared between a healthy gearbox and damaged gearbox computer model. The damage of focus was a fatigue crack on the input pinion gear. A sideband energy ratio comparison yielded the computer simulation accurately modeled the difference between a healthy and damaged gearbox. The next step in this study involved the development of a repeatable procedure to initiate and propagate a fatigue crack at the tooth root in an actual spur gear. A damaged spur gear allows for a future comparison of an actual healthy and damaged gearbox system in the lab. A custom fatigue fixture was designed and manufactured for a Martin S1224BS 1 spur gear. The fatigue crack was initiated by position control fatigue testing which deflects the gear tooth a set amplitude for a number of cycles. Over the length of the test, the load that the tooth can withstand in bending decreases as damage begins to occur. Once the max load on the gear has dropped by a significant percentage (5-15\%) a crack has initiated and begun to propagate across the tooth face. The use of a scanning electron microscope confirmed the presence a fatigue crack.
\end{abstract}

Keywords: Gearbox health-monitoring, multi-body dynamic gearbox model, spur gear fatigue crack, spur gear fatigue testing, sideband energy ratio, gearbox fatigue damage 


\section{ACKNOWLEDGMENTS}

I would like to take this time to thank the Cal Poly San Luis Obispo Mechanical Engineering department for providing an excellent Graduate Program and allowing this thesis to be possible.

Thank you to Professor Tom Mackin and Professor Xi (Julia) Wu for providing me with the tools necessary to complete this study and being available whenever possible for questions and advice on any problems I was encountering.

I am grateful for the help provided by the Material Engineering Department at Cal Poly, especially help from Professor Trevor Harding, Professor Blair London, and Professor Richard Savage. Also input provided by Kirk Fields of UCSB is much appreciated.

I thank my fellow engineering students, Sam Kaplan, Rene Sawatzky, Deep Shah, Kyle Texeira, and Eric Griess for assisting me at various points throughout my thesis.

Lastly I would like to thank my parents Stephen and Jeanette, and my girlfriend, Kelsee, for supporting me during this journey in completing my Master's degree. Without all the names mentioned above this would not have been possible and I am forever grateful for everyone's contribution and help. 


\section{TABLE OF CONTENTS}

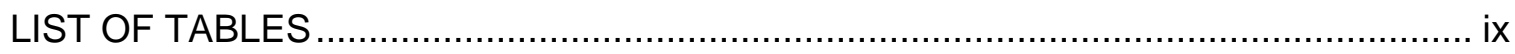

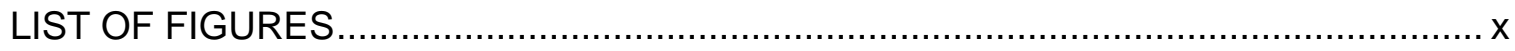

LIST OF ABBREVIATIONS ..............................................................................ii

1 INTRODUCTION

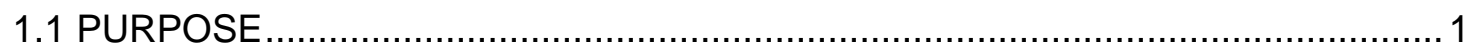

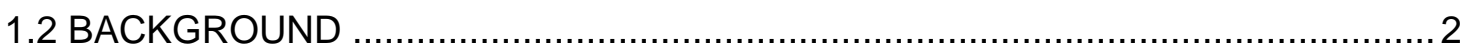

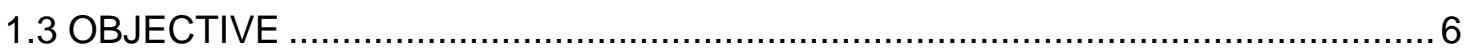

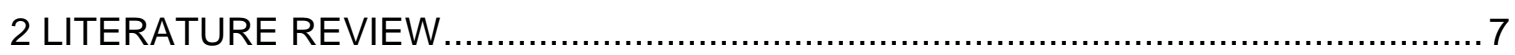

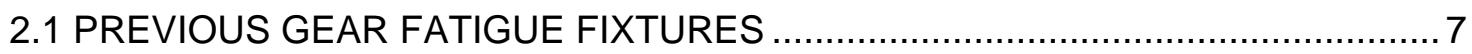

2.2 PREVIOUS ACOUSTIC SENSING TECHNIQUES ….......................................

2.3 PREVIOUS GEARBOX DAMAGE DETECTION STUDIES …...........................13

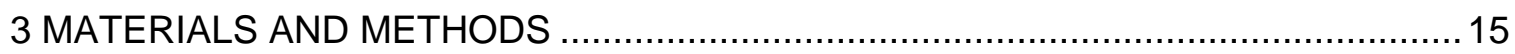

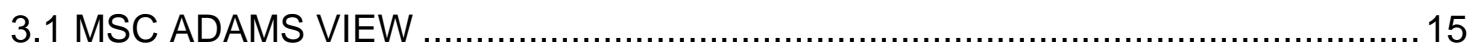

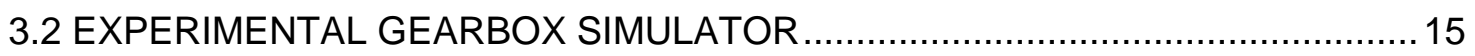

3.2.1 SPECIFIC COMPONENT DETAILS ……………................................16

3.3 GEARBOX DAMAGE DETECTION - SIDEBAND ENERGY RATIO................... 18

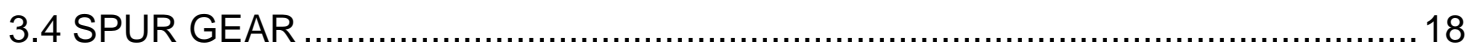

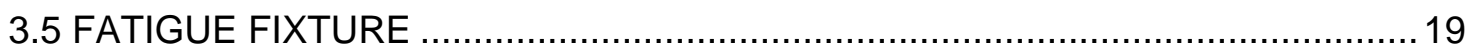

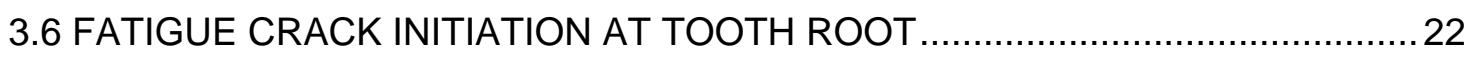

3.6.1 PRE-FATIGUE TESTING CALCULATIONS ……….................................22

3.6.2 INSTRON FATIGUE TESTING SET-UP AND PARAMETERS ...................25

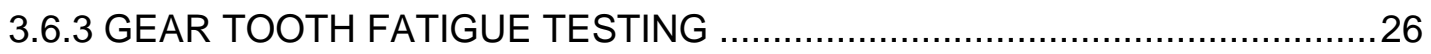

3.6.4 FATIGUE TESTING POST PROCESSING TECHNIQUES .........................29 
4 ONE-STAGE FIXED AXIS GEARBOX COMPUTER SIMULATION

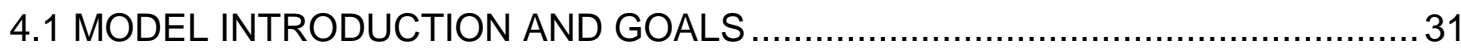

4.2 ONE-STAGE GEARBOX MODEL DEVELOPMENT AND RESULTS ..................31

4.2.1 RIGID BODY MODEL DEVELOPMENT AND RESULTS ............................ 32

4.2.2 FLEXIBLE SHAFT MODEL DEVELOPMENT AND RESULTS .....................37

4.2.3 BEARING MODEL DEVELOPMENT AND RESULTS $\ldots \ldots \ldots \ldots \ldots \ldots \ldots \ldots \ldots . . \ldots \ldots$

5 TWO-STAGE FIXED AXIS GEARBOX COMPUTER MODEL ............................... 44

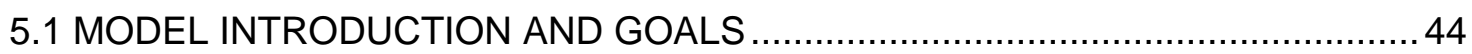

5.2 TWO-STAGE GEARBOX MODEL DEVELOPMENT AND RESULTS ................ 45

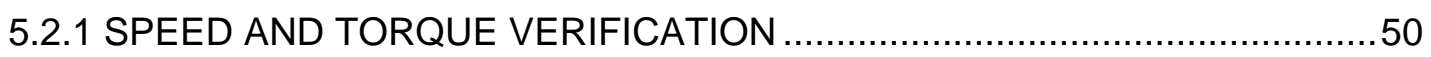

5.2.2 GEAR CONTACT FORCE ANALYSIS AND COMPARISON ........................52

5.2.3 BEARING ACCELERATION ANALYSIS ..................................................55

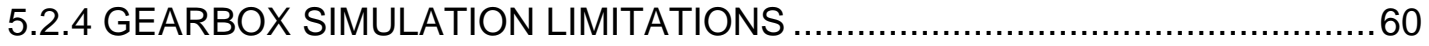

5.3 TWO-STAGE DAMAGE GEARBOX MODEL AND RESULTS .........................61

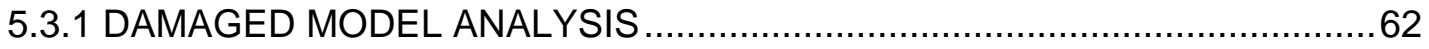

5.3.2 DAMAGED AND HEALTHY SIDEBAND ENERGY RATIO COMPARISON ..67

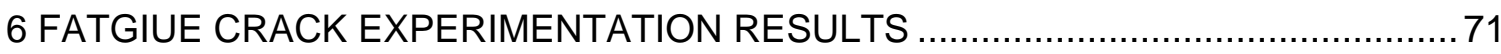

6.1 EXPERIMENTAL MAX TANGENTIAL LOAD ........................................ 71

6.2 LOAD CONTROL FATIGUE TESTING RESULTS ................................... 71

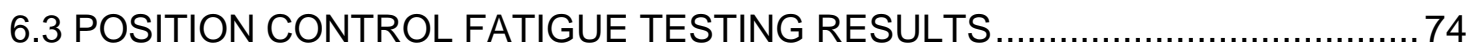

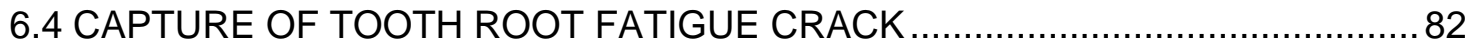

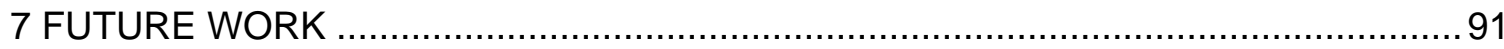

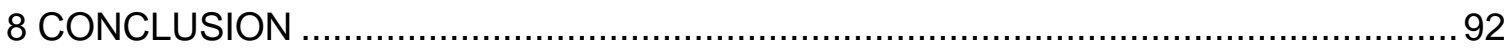




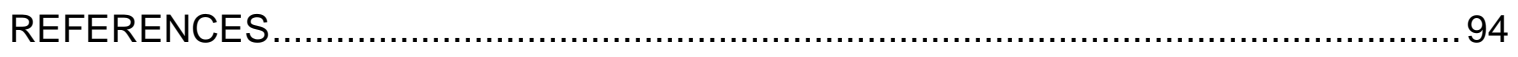

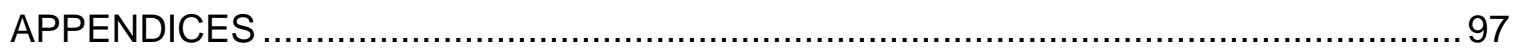

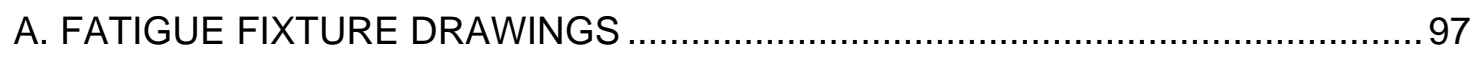

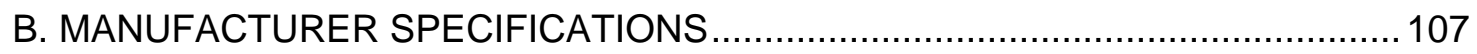

C. POSITION CONTROL PLOTS AND BEARING ACCELERATION FFT PLOTS .. 112

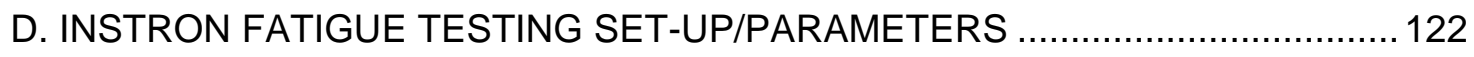

E. INPUT/OUTPUT TORQUE FOR USE IN ADAMS TUTORIAL ......................... 123

F. ABAQUS MNF GENERATION FOR USE IN ADAMS TUTORIAL .................... 126

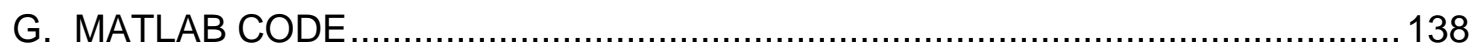

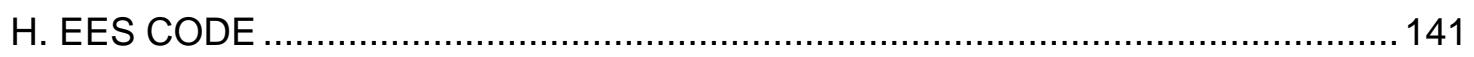




\section{LIST OF TABLES}

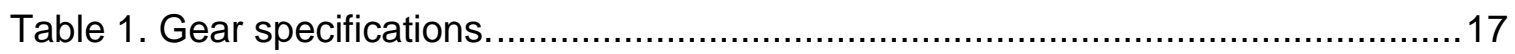

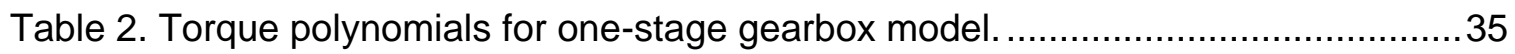

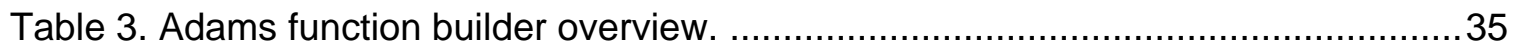

Table 4. First stage gear contact force properties.............................................. 36

Table 5. Gear contact force FFT amplitude comparison........................................42

Table 6. Torque curves for two-stage gearbox model.........................................46

Table 7. Gear mesh frequency harmonics for two-stage gearbox simulation. ...............54

Table 8. Common factor for sub and super-harmonic gear mesh frequencies. .............54

Table 9. Sub and super-synchronous gear mesh frequencies...............................57

Table 10. Gear contact force SER comparison ..................................................68

Table 11. Bearing 1 translational acceleration magnitude SER comparison. .................69

Table 12. Last five cycle analysis for Gear 6 fatigue testing. .................................. 80

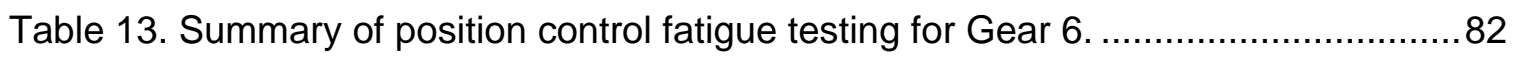

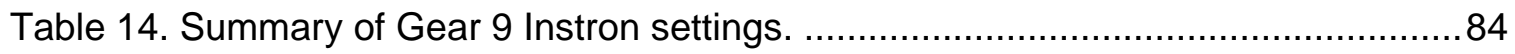




\section{LIST OF FIGURES}

Figure 1. Gear types: spur gear, helical gear, bevel gear, worm gear [11] ...................

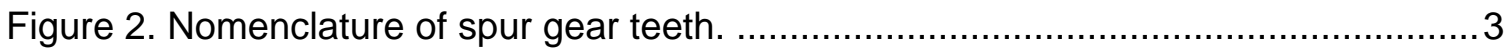

Figure 3. (a) Fatigue crack in gear tooth root [9]. (b) Complete tooth fracture [10] ..........4

Figure 4. SAE J1619 spur gear fatigue test fixture [20]. ..................................... 7

Figure 5. ASME Gear Research Institute spur gear fatigue fixture [2] ........................ 8

Figure 6. (a) CAD model of fatigue fixture (b) Fixture loaded in fatigue tester [3]..........9

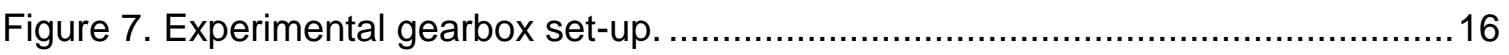

Figure 8. Anvil applying normal load to gear tooth...............................................20

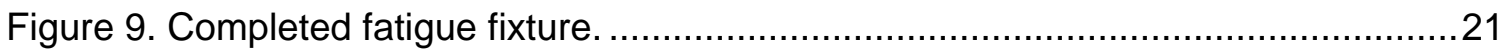

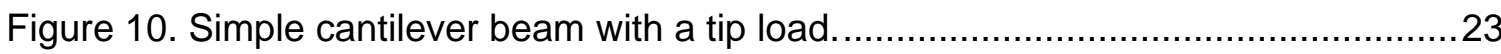

Figure 11. Fatigue fixture secured into Instron for fatigue testing. .............................26

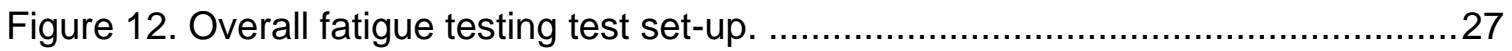

Figure 13. Digital microscope attached and aimed at anvil-tooth contact.....................27

Figure 14. Image captured during fatigue testing from digital microscope...................28

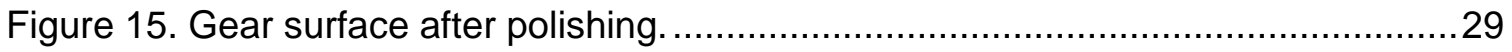

Figure 16. Gear tooth surface comparison between factory and polished surface........29

Figure 17. Scanning electron microscope (SEM) used to view fracture surface.............30

Figure 18. NEMA Design AC motor torque curves. .................................................. 33

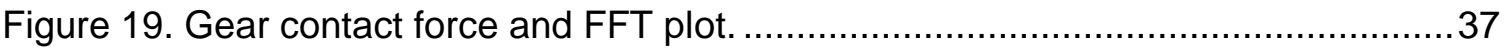

Figure 20. Revolute joint contact forces for flexible shaft model. .................................40

Figure 21. Single-stage gearbox model with flexible shafts and bearings. ..................41

Figure 22. Bearing forces for the single-stage gearbox model. .................................43

Figure 23 Bearing 1 force FFT for the single-stage gearbox model..............................43

Figure 24. CAD model of gearbox components developed using Solidworks.................45 
Figure 25. Input and output torque curves for two-stage gearbox model. 46

Figure 26. Input shaft mesh, 0.125 inch quadratic tetrahedral elements. 48

Figure 27. SKF 6004-2Z bearing used for the two-stage gearbox [13]. 49

Figure 28. Two-stage dynamic gearbox model with flexible shafts and bearings. .50

Figure 29. Shaft angular velocities for two-stage gearbox model. .51

Figure 30. Input and output torque for the two-stage gearbox model. .51

Figure 31. First stage contact force and FFT analysis for gearbox model. .53

Figure 32. First and second stage GMF of first stage contact force analysis. 53

Figure 33. Second stage contact force and FFT analysis for gearbox model......... 54

Figure 34. Bearing 1 magnitude acceleration and frequency between peaks. 55

Figure 35. Bearing 1 magnitude acceleration FFT analysis 0-2000 Hz. 57

Figure 36. Bearing 1 magnitude acceleration FFT analysis $0-500 \mathrm{~Hz}$. 58

Figure 37. Magnitude of bearing forces from healthy gearbox simulation. 59

Figure 38. Fatigue crack model of pinion, S1224BS 1. 61

Figure 39. First stage gear contact force comparison .63

Figure 40. Second stage gear contact force comparison 64

Figure 41. Damaged model Bearing 1 acceleration comparison 0-2000 Hz. 65

Figure 42. Bearing 1 acceleration magnitude comparison. 66

Figure 43. Damaged model Bearing 1 acceleration comparison $0-500 \mathrm{~Hz}$ 70

Figure 44. Typical load versus time plot cyclic loading of a single tooth. 72

Figure 45. Gear 2 - Tooth 4 fracture side surface. Tooth loaded on right side. 73

Figure 46. Typical beginning test results during test on Gear 4 - Tooth $1 \ldots \ldots \ldots \ldots \ldots \ldots . . .75$

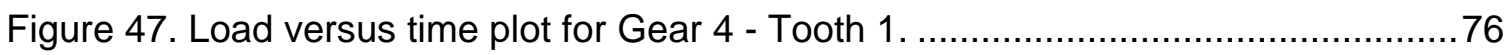

Figure 48. Final minutes of position-controlled fatigue loading for Gear 6 -Tooth $1 \ldots . . .78$

Figure 49. Final minutes of position-controlled fatigue loading for Gear 6 -Tooth $2 \ldots \ldots .78$ 
Figure 50. Final minutes of position-controlled fatigue loading for Gear 6 -Tooth $3 \ldots . . .79$

Figure 51. Final minutes of position-controlled fatigue loading for Gear 6 -Tooth $4 \ldots . . .79$

Figure 52. Max load for each cycle of fatigue testing for Gear 6 - Tooth $1 \ldots \ldots \ldots \ldots \ldots \ldots . . . . . . . .11$

Figure 53. (a) Fatigue crack at 20x magnification and (b) 600x magnification..............83

Figure 54. Final 6 minutes of Gear 9 - Tooth 2 crack propagation test....................... 85

Figure 55. Final 32 minutes of Gear 9 - Tooth 3 crack propagation test....................... 86

Figure 56. Tooth root crack on Gear 9 -Tooth 2 at $40 x$ mag. ................................... 87

Figure 57. Tooth root crack on Gear 9 -Tooth 2 at 150x mag................................. 88

Figure 58. Tooth root crack initiation site on Gear 9 -Tooth 2 at $300 x$ mag. ..................88

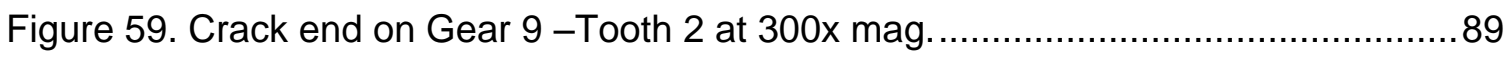

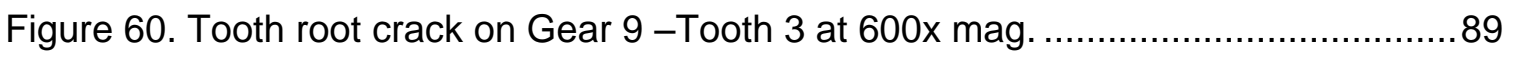

Figure 61. Tooth root crack initiation site on Gear 9 -Tooth 3 at 1200x mag. ................90 


\section{LIST OF ABBREVIATIONS}

$\begin{array}{ll}\text { AE } & \text { Acoustic Emission } \\ \text { EDS } & \text { Energy Dispersive Spectroscopy } \\ \text { SEM } & \text { Scanning Electron Microscope } \\ \text { Mn } & \text { Manganese } \\ \text { GMF } & \text { Gear Mesh Frequency } \\ \text { FFT } & \text { Fast Fourier Transform } \\ \text { MPC } & \text { Multi-Point Constraint } \\ \text { SER } & \text { Sideband Energy Ratio } \\ \text { BPFI } & \text { Ball Pass Frequency Inner-Race }\end{array}$




\section{INTRODUCTION}

\subsection{PURPOSE}

The importance of gears in machinery cannot be overstated. They provide essential power transfer in configurable directions at remarkably high efficiency $(70-99 \%$ depending upon gear type and relative angles of the axels) [16]. These high efficiencies are likely why so little progress has been made in the development of new advanced manufacturing and novel processing methods. Even so, as we strive to make more durable machinery at lower costs, with greater specific power outputs, there is a growing need to provide insight on the mechanistic underpinnings of wear and failure of gears. Gears are so essential and prevalent in our machine systems that the failure of a single tooth could cause catastrophic failures. Regardless of the gearbox application the gears within them are selected using the same design principles and failure modes identified some 30 years ago [17]. More often than not catastrophic failure occurs without warning and causes serious damage. The technology is now available to develop an advanced early-warning system for gear damage so a system can be shut down and repaired before catastrophic failure. This approach extends the knowledge base of structural health monitoring into the domain of geared systems. As such, the goal of this thesis was to demonstrate the concept that we can not only detect the early stages of gearbox damage, but pinpoint the individual damaged component within a complex multi-stage gearbox. This was carried out by combining theory and experiment to identify the changes in vibration spectra that occur with fatigue cracking on a single tooth on an individual gear embedded in a multi-stage gearbox. 


\subsection{BACKGROUND}

Rotational reduction systems, including gears, have played a major role in energy conversion since the dawn of the industrial age. The need to impart rotation from one axis to another, to change the orientation of the axes, and to reduce/upgrade the rotational velocity of shafts led to the development of a host of gear systems. These include; spur, helical, bevel, and worm gears, Figure 1. Spur gears, simplest of the gear types, have teeth parallel to the axis of rotation and are used to transmit motion from one shaft to a parallel shaft. Helical gears, have teeth inclined to the axis of motion and can be used in the same types of applications as spur gears but were designed to run more quietly at higher rpms. Even though helical gears are often less noisy than spur gears, the inclined teeth develop thrust and bending couples that spur gears do not experience. Bevel gears have teeth formed on conical surfaces and are generally used for applications that involve transmitting rotary motion between intersecting shafts. Lastly, worm gears are used to transmit rotary motion between nonparallel and nonintersecting shafts. [8]
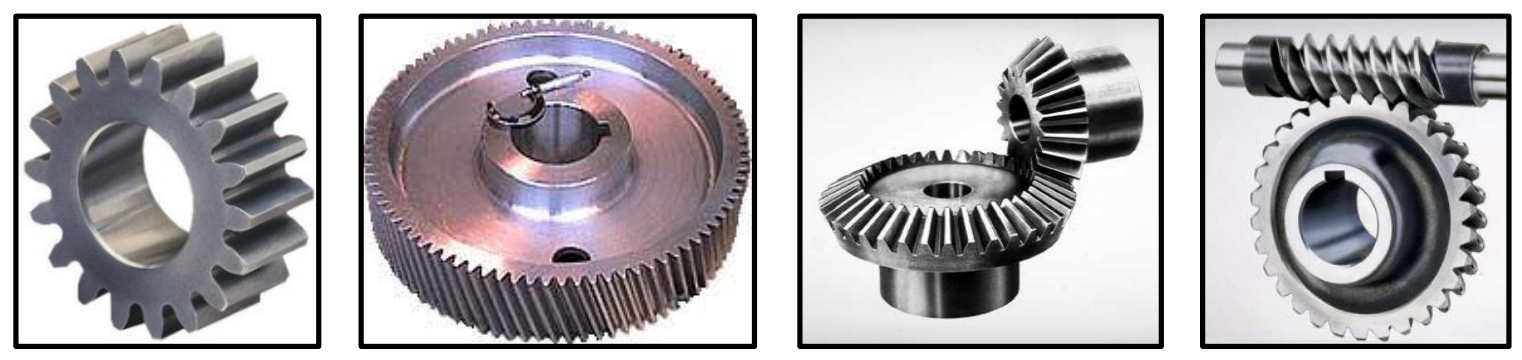

Figure 1. Gear types: spur gear, helical gear, bevel gear, worm gear [11]

The spur gear is the most common gear type and was chosen, for simplicity, as the gear of focus in this thesis. Although the spur gear is the simplest type of gear, there is an essential nomenclature that is used to describe the geometry. The pitch circle is a theoretical concentric circle that intersects the teeth of a gear at the points where the teeth mesh with another gear. The diameter of this circle is called the pitch diameter and 
a majority of calculations are based upon it. The circular pitch $(p)$ is the distance from a point on one tooth to a corresponding point on an adjacent tooth measured along the pitch circle. The diametral pitch $(P)$ is the ratio of the number of teeth on the gear to the pitch diameter. The module $(\mathrm{m})$ is the ratio of the pitch diameter to the number of teeth. The addendum (a) is the radial distance between the top land and the pitch circle while the dedendum (b) is the radial distance from the bottom land to the pitch circle, Figure 2.

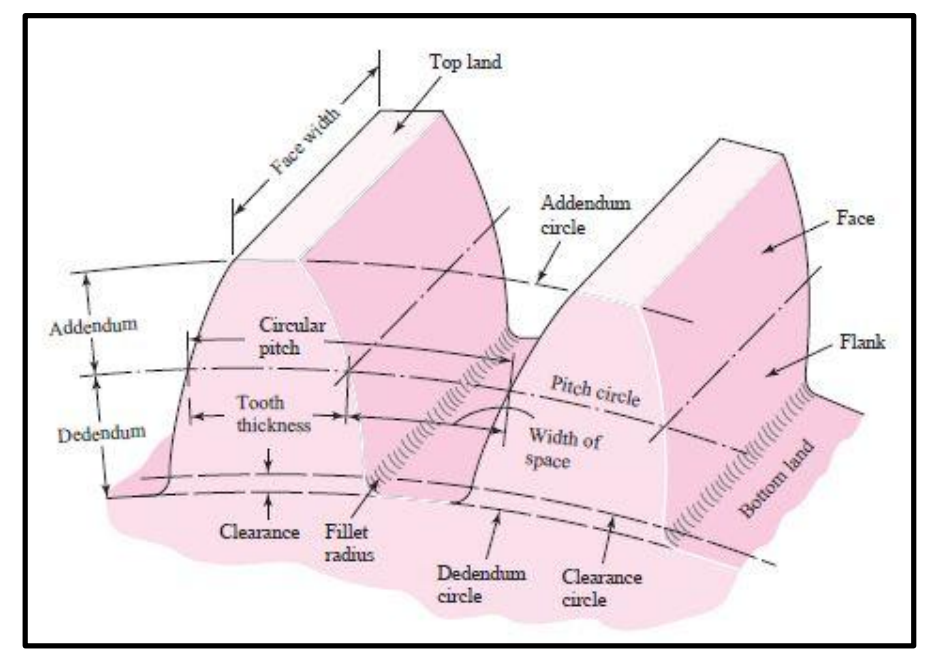

Figure 2. Nomenclature of spur gear teeth.

Gears suffer from four common failure mechanisms; breakage, wear, pitting, and scoring [3]. Each mode of failure has its own specific characteristics but the most common failure mode, and the focus of this study, is breakage through fatigue. Tooth breakage is defined as the fracture of a whole tooth or substantial part of a tooth. The most common causes for such a failure include overload and cyclic stressing beyond the endurance limit. The bending fatigue breakage occurs in several steps. First, there is crack initiation at a specific high-stress location on the tooth. Following initiation, the crack propagates, sub-critically, through the tooth, Figure 3a. The crack initiation phase is normally much longer than the crack propagation phase [3]. Eventually, the crack reaches a critical length and catastrophic failure occurs, Figure $3 b$. 


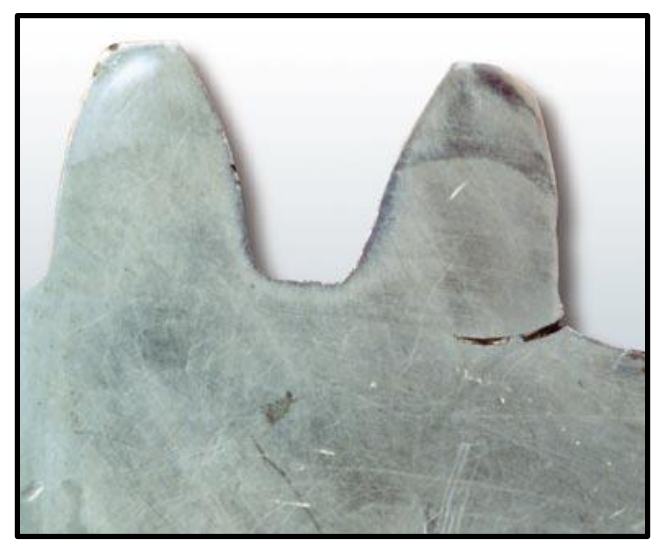

(a)

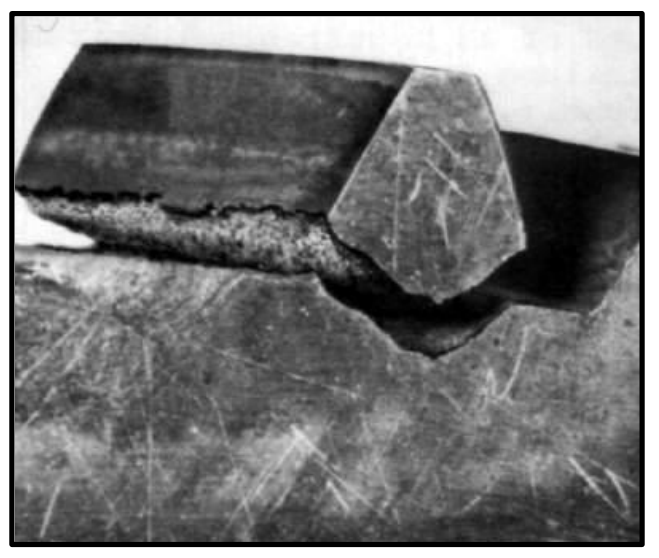

(b)

Figure 3. (a) Fatigue crack in gear tooth root [9]. (b) Complete tooth fracture [10]

The most common site for fatigue crack growth is at the tooth root fillet, due to the high stress concentration. High cycle fatigue is typically associated with cycles greater than 1000 and at a stress amplitudes less than the gross yield stress.

Two key industries suffer the bulk of gear damage: aviation and wind power. Both use complicated gear boxes, and both are financially intolerant of down-time. This is especially acute in helicopters, where gear failure can have life-threatening consequences. The performance of helicopters is constantly increasing and the gearboxes that support this performance are subject to increasing demands for specific strength and high-reliability [1]. Since tooth breakage can cause catastrophic failure of a helicopter transmission, leading to the loss of the aircraft and loss of life, the need for drivetrain diagnostics is ever apparent. Investigations have shown that 32 percent of fatigue failure accidents in rotorcraft were due to engine and transmission component failure [4]. In order to improve the safety of the rotorcraft industry a reliable health monitoring system needs to be developed. Ideally this system can successfully detect the onset of gear fatigue cracks in order to provide pilots warning of impending damage or failure. Ideally, such a system would lead to the replacement of damaged gears 
before full tooth breakage. Also the health monitoring system could help reduce maintenance costs by accurately diagnosing the current state of health of the gearboxes and not causing premature replacements of parts and unnecessary downtime of the aircraft [6].

The technology that is commonly used to detect damage within machinery is vibration analysis. With this technology, sensors are placed in precise locations so vibration signals can be detected in the $\mathrm{X}, \mathrm{Y}$, or Z-axis. Once data is collected it is processed to generate a detailed interpretation of the signal. Although vibration analysis is very valuable, it can often be quite complicated and difficult to attain a reliable diagnosis. $\mathrm{A}$ new technology that has a lot of potential and worth in the health monitoring industry is acoustic emission (AE). Acoustic emission uses sound waves that are generated from within a material that undergoes shock, impact, friction, cracking, or an external force. If these sound waves can be detected then it would be possible to detect impending failure before massive damage occurs. For example, through the use of an AE sensor a developing fatigue crack in a spur gear could be detected before the failure of the gear tooth. The fields in which vibration analysis and $A E$ can be applied are very similar but $\mathrm{AE}$ allows for early detection of damage whereas vibration analysis can only detect when damage has already occurred. In the early days of AE highly trained technicians were needed to analyze AE signals but, as the technology matured, automated signal processing have been put in place. The increasing availability of sophisticated AE opens the door to its use in many new applications. One great aspect of acoustic emission is that it can be used while machinery is operating. Unlike vibration analysis this allows for the diagnosis of problems in real time. Another benefit to $A E$ is that an effective signal is attained after a very short period of measurement. Typically in vibration analysis the 
machine would have to run at a constant speed for an extended period of time in order to obtain a meaningful average signal for comparison to damaged signals. This process is true for $\mathrm{AE}$ sensors but the time it takes to acquire a meaningful signal is much lower. The continued development and exploration of AE will only lead to new and improved health monitoring systems for machinery [12].

\subsection{OBJECTIVE}

The main goal of this study is to develop a practical approach to the detection of early onset of damage in gearbox transmissions. This goal was accomplished in several steps: First, research was conducted to develop and understand a detailed computer model of a two-stage fixed axis gearbox. This was used to simulate the behavior of an experimental gearbox in our laboratory. It was developed to operate as similarly as possible to the actual gearbox. Once completed and validated by comparison to the experimental gearbox, damaged gears were introduced into the model. A simulation will be run again and results from the damaged model shall be analyzed. The damage to be studied is a fatigue crack at the root of a single tooth on the pinion on the input shaft. The work done in this thesis was the first step in this process. In a later study these models will be validated and compared to the actual gearbox. Another main goal of this study is to produce a repeatable procedure to initiate and propagate a fatigue crack at the tooth root in an actual spur gear. Without a gear with a fatigue crack, a damaged gearbox comparison cannot be accomplished. Vibration analysis and acoustic emission data are to be used to compare the model to the actual experimentation results for both the healthy and damaged studies. 


\section{LITERATURE REVIEW}

\subsection{PREVIOUS GEAR FATIGUE FIXTURES}

Gear tooth fatigue is not a new concept and several researchers have developed a number of test fixtures to facilitate gear fatigue testing. More recent gear tooth fatigue fixtures have been based on the SAEJ1619 fatigue test fixture shown in Figure 4.

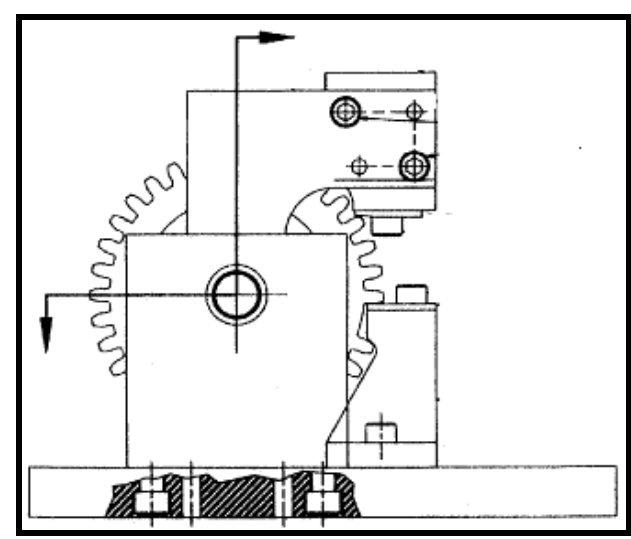

Figure 4. SAE J1619 spur gear fatigue test fixture [20].

In this set-up, the upper anvil loads the test gear at the tooth tip. A lower anvil applies resisting load and prevents the gear from rotating. The fixture is held together by a base and a support shaft that maintains anvil alignment. Load is applied through a large ball bearing to eliminate misalignment and to align the applied force with the support anvils. The downside to this design is that one must remove a gear tooth, prior to testing, to allow clearance between the support anvil and the tooth root. Since our goal is to introduce sub-critical fatigue cracks into a gear that will be placed into a functioning transmission, this fixture is not suitable for this study. The ASME Gear Research Institute developed a similar design for investigating the bending fatigue resistance of spur gear teeth, Figure 5 [2]. 


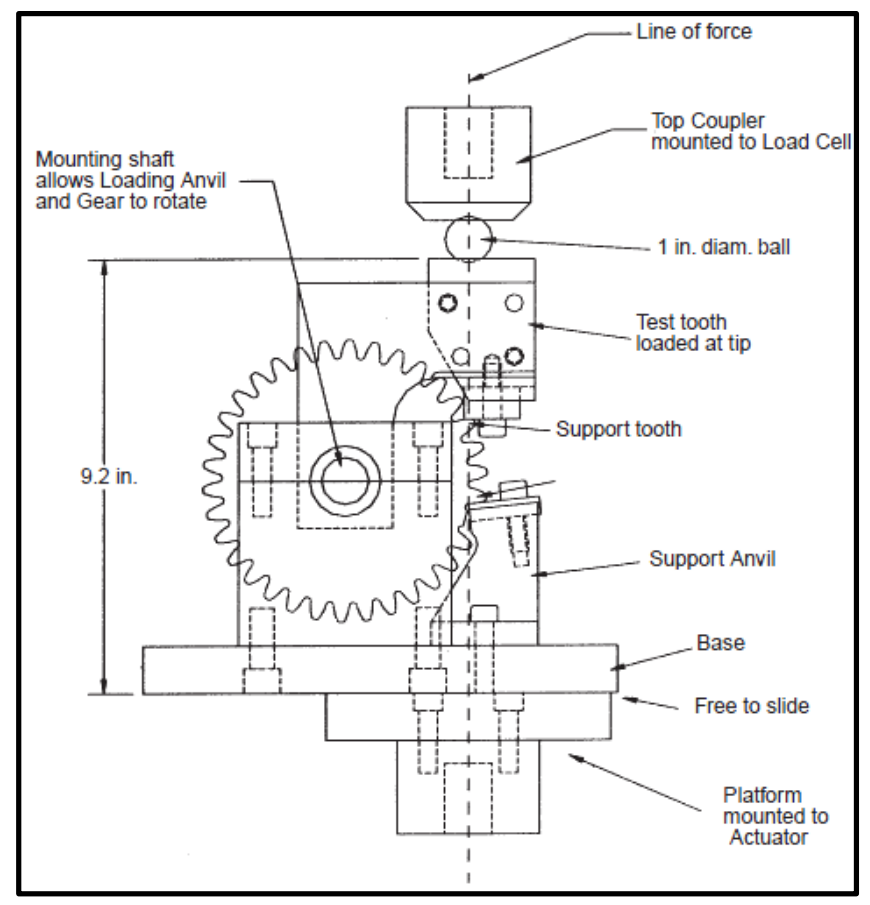

Figure 5. ASME Gear Research Institute spur gear fatigue fixture [2]

[1] Gasparini, Mariani, Gorla, Filippini, and Rosa analyzed bending fatigue tests of helicopter case carburized gears and explored the use of two common types of fatigue test fixtures. The first fixture utilizes a set-up similar to SAE J1619 and is common in gear tooth testing in the United States. In this fixture, the test gear is supported by a pin while one tooth is loaded and a second tooth acts as a reaction tooth. The second test method, which is more common throughout Europe, loads two teeth at the same time. When loading two teeth, the gear does not require any type of support pin and both teeth have equal and opposite applied forces. The fatigue fixture used by Gasparini et al [1] encompassed both of these methods.

Nenadic, Nenad G. and Thurston [3] manufactured a fatigue fixture specifically developed for seeding fatigue cracks in gears to increase the likelihood of tooth breakage, Figure 6 . Their fixture secured a single spur gear between two steel plates and used an anvil to apply load on a single gear tooth. They used an anvil width larger 
than the face width of the gear and made of tool steel. The anvil gear surface interface meshes at a 5 degree angle in order to ensure the load is applied properly. The gear is located using a shaft and key that also ensures proper orientation. Three inter-locking gear teeth were used to resist rotation and to assure that no other teeth, besides the one under load, were damaged. We found this set-up to be the most robust and purposebuilt fatigue crack-initiating fixture. The design lessons learned from this fixture were expanded upon in the design of the fatigue fixture used for the present study.

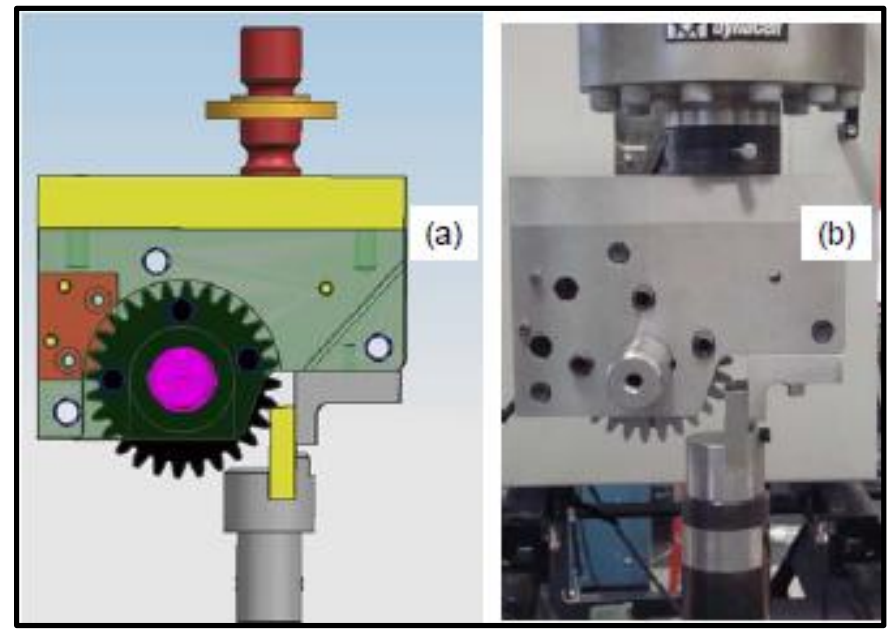

Figure 6. (a) CAD model of fatigue fixture (b) Fixture loaded in fatigue tester [3].

\subsection{PREVIOUS ACOUSTIC SENSING TECHNIQUES}

Research on acoustic detection of fatigue cracks in gears has been attempted with varying amounts of success. Many acoustic techniques successfully identify a difference between a healthy and damaged gear but are not able to localize the location as well as the type of damage. Zakrajsek and Lewicki utilized methods that processed vibration data in real time. The spur gears used in this research were notched in the fillet region of a single tooth to initiate a fatigue crack. A test rig was then used to fail the gear in bending. The spur gear then ran on shaft at $10,000 \mathrm{rpm}$ and meshed with another 
gear in the test rig. An accelerometer mounted on the shaft provided the vibration data. In total, 4 different methods were investigated, denoted as FM4, NA4, NB4, and a demodulation technique [4].

The FM4 method was developed by Stewart to detect isolated damage on gear teeth by detecting a change in the vibration pattern. The theory behind this method is that the change in vibration pattern is caused from damage on a limited number of gear teeth in the gearbox system. The difference signal between a non-damaged and damaged-gear train are constructed by first removing regular meshing harmonics from the timeaveraged signal. The regular meshing harmonics include: shaft frequency and harmonics, primary meshing frequency and harmonics and first order sidebands. Using the difference signal a fourth normalized statistical moment (normalized kurtosis) is applied. The criteria for a gear in good condition was a normalized kurtosis value of 3 . If one or two teeth, however, are damaged then the normalized kurtosis value will is greater than 3 [4].

The NA4 and NB4 methods were developed at NASA Lewis Research Center. The idea behind NA4 is that it can detect the onset and progression of damage. In the NA4 technique a residual signal is constructed by removing all regular meshing components, then "the fourth statistical moment of the residual signal is then divided by the current run time averaged variance of the residual, raised to the second power." The calculation normalizes the kurtosis and "with this method, the changes in the residual signal are constantly being compared to weighted baseline for the" good condition system. Under normal conditions the kurtosis value is 3 . Similar to with the NB4 method, "the same operation to normalize the kurtosis" occurs. The biggest difference between the two is 
that, "NB4 uses the envelope of a band passed segment of the signal." Using band-pass filters and the Hilbert transform, a complex time signal is created. The envelope is the magnitude of this complex time signal gives insight into reoccurring transient in the loading. The importance of this finding is that damaged teeth cause transient load fluctuations which are observed in the signal envelope. A value of 3 in NB4 represents normal operating conditions [4].

Another demodulation technique results in detecting local gear defects such as a fatigue crack. In theory this method works by having the gear tooth defect produce sidebands that "modulate the dominant meshing frequency." With the Hilbert transform and using the real and imaginary parts of the complex time signal, the instantaneous phase is estimated from filtered sidebands. The instantaneous phase will be dominated by a gear that has a fatigue crack [4]. This study did provide some results. For thin-rimmed gears, all four methods showed no early detection of fatigue cracks but only showed results immediately before complete fracture. For full rim spur gears, all four methods gave earlier indication of fatigue cracks before complete fracture actually took place. Each method had a different reaction to the fatigue crack and provided varying kurtosis values. NA4 and NB4 methods gave the earliest reactions to the fatigue crack [4].

F.K. Choy, D.H. Mugler, and J. Zhou also investigated damage detection techniques of spur gears. In their research the Wigner-Ville Distribution (WVD) method and the Wavelet Transform were compared using a gear train simulation and actual experimental data taken from a gear test rig at NASA Glen Research Center. The WVD method "provides a relationship between time and frequency during the period of the time window that is not present in standard Fourier spectral analysis." WVD has the 
capability to display any phase and magnitude changes present in the system. The wavelet transform "also provides a time-frequency analysis of an input signal," but this application is linear [6]. The results of this study yielded that the wavelet transform gave a more "direct quantification of the tooth damage" than the WVD did in both the simulation and experimental test. In the experimental runs, a healthy spur gear, a spur gear with one damaged tooth, a spur gear with two consecutive damaged teeth, and a spur gear with three consecutive damaged teeth were utilized. The wavelet transform clearly indicated an increase in magnitude with an increase in damage. The WVD did not provide enough significant changes in conjunction with gear damage for the gear train simulation or experimental tests [6].

Acoustic emission has been gaining some momentum in recent years in becoming a non-destructive method for health diagnosis on rotating machinery [8]. Acoustic emission is defined as a sound wave that is produced when a material undergoes an internal stress change as a result of an external force. Research performed by Toutounzakis, Tan, and Mba [18] utilized spur gears and a test-rig gearbox. Acoustic emission sensors were placed on the pinion and the bearing casing. The gearbox rig was run with three different torque settings $0 \mathrm{~N}-\mathrm{m}, 55 \mathrm{~N}-\mathrm{m}$, and $110 \mathrm{~N}-\mathrm{m}$. Two types of gear damage were also tested, a small pitch-line defect, and a large addendum defect. The results of the experiment were concluded as "unsatisfactory" but the system did respond to the gear damages just not in a consistent manner. For the small pitch-line defect, the r.m.s. values increased as load increased but for the large addendum defect, the r.m.s. values decreased with an increase in load. Although this study did not provide definitive results it did shed light on the possibility of using acoustic emission for detecting gear damage. 
In 2009, research by Eftekharnejad and Mba [19] investigated the use of AE as a fault detection method for use with helical gears. In their experiment, a wide-band AE sensor was fixed on the pinion gear of the test rig and an accelerometer was mounted on a bearing for comparison purposes. The test rig was run at various loads for hours at a time to let the system dynamically settle and so that defect-free $\mathrm{AE}$ and vibrational data could be collected. Defects were added to a single gear tooth using a drill. After the first seeded defect was created and tested, the defect was increased in size on the same tooth without removing the gear from the test rig. In all, seven different levels of defects were tested. Overall the AE r.m.s levels rose for increasing defect size. Between a couple defect sizes small drops were noted but then an increase was seen with the next defect size up. The vibration data in comparison remained relatively constant from defect to defect but the two sensors were not in the same locations within the test rig so this comparison may not be completely valid. In conclusion, changes in AE were detected with change in gear defects unlike experiments in the past. Also it was clear that changes in $\mathrm{AE}$ values have a much higher impact when placed on the gear than using an accelerometer on the bearing.

\subsection{PREVIOUS GEARBOX DAMAGE DETECTION STUDIES}

In the study "Frequency-domain Analysis of a Two-Stage Planetary Gear with Combined Backlash and Tooth Damage Nonlinearities" a joint time frequency analysis was performed in order to see a difference between a healthy and damaged planetary gearbox dynamic computer model. The joint time frequency analysis focuses on transient start-up conditions and demonstrates how the frequency content of the gear contact force evolves over time. On a 3D Fast Fourier Transform plot the gear contact force, frequency, and time are plotted. A comparison between the healthy and damaged planetary gearbox revealed that the healthy model had very clear and distinct vibration 
patterns when the contact force increased during the start-up acceleration and the damaged model had much more broadband noise that dominated the start-up condition. This analysis was purely observational and no distinct analytical method was used. [28]

A follow-up to the previous study was conducted by Brain Fang and focused on "CAE Methods on Vibration-based Health Monitoring of Power Transmission Systems". In Fang's study, different methods to analyze power transmissions for the presence of damage were examined. Both sideband energy ratio and joint time frequency analysis were utilized on a practical two-stage planetary gear system. Sideband energy ratio is a patent pending technique developed by Bentley Nevada and was specifically designed for gear tooth damage within a machine causing vibration. This analytical technique uses an algorithm that outputs a single value to determine if a gear system is damaged or not. Both the sideband energy ratio technique and the joint time frequency analysis were determined to be a possible acoustic emission detection method for observing the difference between a healthy and damaged system for a twostage planetary gearbox transmission. [29] 


\section{MATERIALS AND METHODS}

\subsection{MSC ADAMS VIEW}

MSC Adams View is a popular multi-body dynamics software that provides a tool to "study the dynamics of moving parts, and to analyze how loads and forces are distributed throughout mechanical systems" [15]. A tool such as Adams View allows for simulation to be done prior to building mechanical systems, leading the designer to uncover flaws and areas of concern before time and money are spent on creating actual prototypes. "Engineers can evaluate and manage complex interactions between disciplines including motion, structures, actuation, and controls" [15]. MSC Adams View was the software chosen for developing a dynamic computer model of the gearbox in our experimental dynamic simulator.

\subsection{EXPERIMENTAL GEARBOX SIMULATOR}

The experimental gearbox that is a main focus of this study was purchased from Spectra Quest, Inc. This Gearbox Dynamics Simulator was designed and built with the purpose of studying signatures of common gearing faults. It allows for controlled experiments on a simulator that emulates real world machinery and provides a nice platform to learn about preventive maintenance. This lab set-up is available to students in the California State Polytechnic Mechanical Engineering vibrations laboratory. The current lab set-up, Figure 7, consists of an AC Motor and variable speed drive, speed control interface box for external PC control, optical speed sensor, parallel shaft two stage fixed axis gearbox, loading mechanism (brake with controller), ADRE 408 data acquisition system, and a laptop computer. 


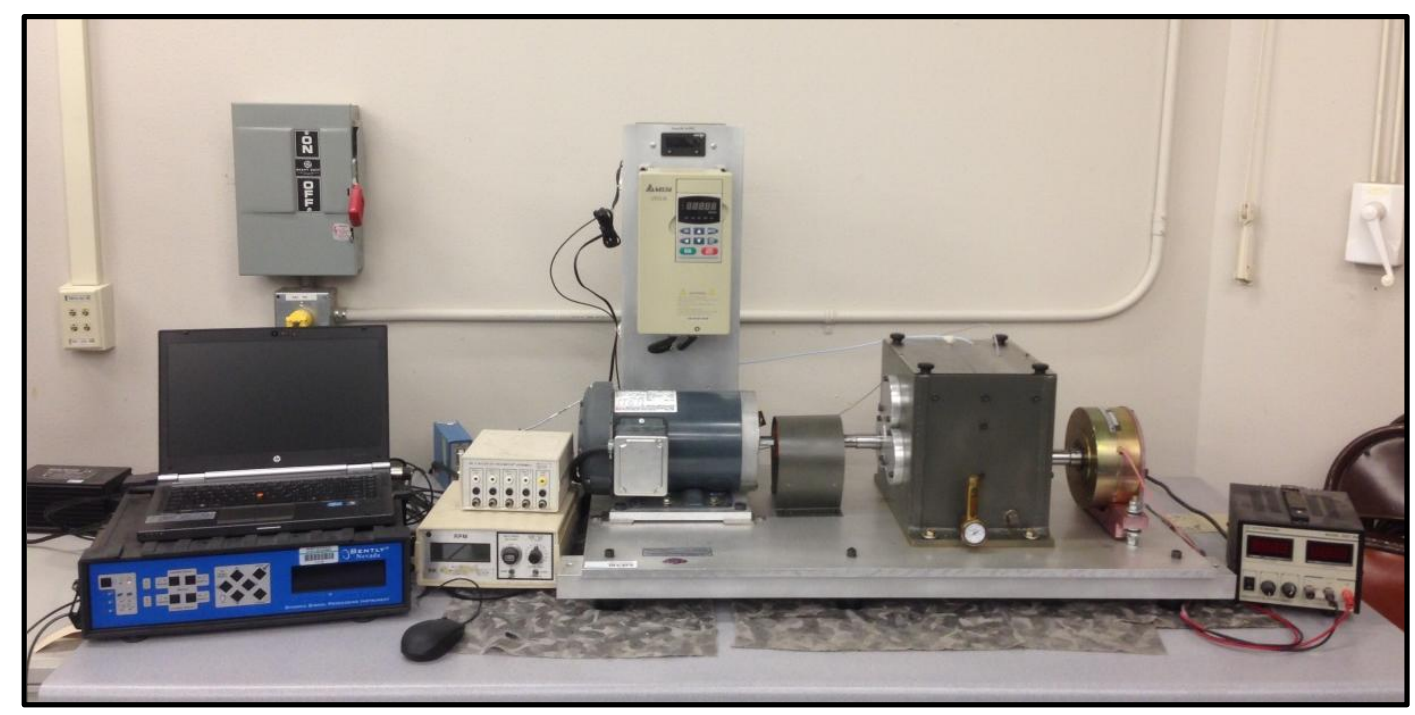

Figure 7. Experimental gearbox set-up.

\subsubsection{SPECIFIC COMPONENT DETAILS}

The AC Motor is a Marathon Electric D396 general purpose motor with a speed range from 0-3600 RPM. The D396 is a 3 HP, 2-pole, 3-phase motor and is approximately 13 inches in length.

The actual gearbox portion of the dynamic simulator is approximately of 10.5 " $\mathrm{x}$ $8.5^{\prime \prime} \times 10^{\prime \prime}$ in volume. There are a total of three shafts, two mating gear pairs, and six bearings. The input shaft is approximately 13 inches in length and has a nominal diameter of 1 inch but steps down to $3 / 4$ inches for the bearings. The intermediate shaft is approximately 8.5 inches in length and the output shaft is approximately 10.5 inches in length. Both the intermediate shaft and output shaft have the same nominal diameter and step as the input shaft. Each shaft is fitted with two MB manufacturing ER-10K bearings. Each bearing has eight, 0.3125 inch diameter, rolling elements and a ball pitch diameter of 1.319 inches. The bore of the bearing is $3 / 4$ of an inch. 
The four gears in the gearbox housing are made by Martin. A summary of each gear is listed in Table 1 and manufacturer specification pages are located in Appendix B. All the dimensions listed for the gearbox shafts are close estimations since the actual gearbox was not disassembled to get exact measurements. The bearing and gear values are accurate as they are given manufacturer specifications.

Table 1. Gear specifications.

\begin{tabular}{|c|c|c|}
\hline \multicolumn{3}{|c|}{ Stage 1} \\
\hline Part No. & S1224BS 1 & S1260 \\
\hline Description & Pinion, Input Shaft & Gear, Intermediate Shaft \\
\hline Pressure Angle, $\varphi \quad$ (deg) & 14.5 & 14.5 \\
\hline Pitch Diameter, d (in) & 2 & 5 \\
\hline Diametral Pitch, $\mathbf{P}$ (teeth/in) & 12 & 12 \\
\hline Face Width, $\mathrm{F}$ & 0.75 & 0.75 \\
\hline Number of Teeth & 24 & 60 \\
\hline \multicolumn{3}{|c|}{ Stage 2} \\
\hline Part No. & S1236 & S1248 \\
\hline Description & Pinion, Intermediate Shaft & Gear, Output Shaft \\
\hline Pressure Angle, $\varphi \quad$ (deg) & 14.5 & 14.5 \\
\hline Pitch Diameter, d (in) & 3 & 4 \\
\hline Diametral Pitch, $\mathbf{P} \quad$ (teeth/in) & 12 & 12 \\
\hline Face Width, F & 0.75 & 0.75 \\
\hline Number of Teeth & 36 & 48 \\
\hline
\end{tabular}




\subsection{GEARBOX DAMAGE DETECTION - SIDEBAND ENERGY RATIO}

Sideband energy ratio (SER) is a patent pending technique developed by Bentley Nevada and was specifically designed for gear tooth damage within a machine causing vibration. The algorithm is calculated by summing the first six sideband amplitudes on each side of the center gear mesh frequency and dividing it by the amplitude of the center gear mesh frequency, Eqn 3.1. For a healthy gearbox the SER value is typically much less than 1 , while damaged gearboxes shall exceed 1 . Sidebands are thought to be a good measure of gearbox damage because they occur as a result of amplitude modulation around a center frequency and a damaged tooth is a root cause of this phenomenon. As damage within a gearbox system progresses more sidebands should be present around the center mesh frequency and the amplitude of these sidebands should increase, ultimately causing the rise in SER. The sidebands of interest in a damaged system are determined by Eqn 3.2. Gear mesh frequency sidebands are modulated by, $\omega_{s}$, which is the frequency of the shaft on which the damaged gear is present. The gear mesh frequency is $\omega_{G M}$, and $\mathrm{n}$ is any whole number integer. This phenomenon gives insight into which stage the damage is present in a multi-stage gearbox. [24]

$$
\begin{gathered}
S E R=\frac{\sum_{i=1}^{6} \text { sideband amplitude }_{i}}{\text { center mesh frequency amplitude }} \\
\omega_{G M} \pm n\left(\omega_{s}\right)
\end{gathered}
$$

\subsection{SPUR GEAR}

The Martin S1224BS 1 steel spur gear is the gear into which we introduced fatigue damage. Prior to testing, we conducted materials analysis to determine the alloy composition. We measured a surface hardness of 29-32 HRC, while energy dispersive spectroscopy was used to measure the composition. Five different locations were tested 
showing $1.7 \%$ atomic percent Manganese (Mn). Using the hardness and composition data, as well as published data on Manganese-Steel Alloys, we determined the steel used in this particular gear is an AISI 1300 series alloy with AISI 1340 affording the best match to the measured hardness and chemical composition.

\subsection{FATIGUE FIXTURE}

We used a specially designed fatigue fixture to introduce sharp, natural fatigue cracks at the root of a single gear tooth on our chosen spur gears. Our design was based upon the fatigue fixture developed by Nenadic, Nenad G. and Thurston [3]. The goal of our fatigue experiments was to produce a natural fatigue crack in a specific gear tooth root. To accomplish this we designed our fixture to hold a gear and load a single tooth using an instrumented fatigue testing machine. Our fatigue fixture consisted of 6 unique parts: a front cover, back plate, alignment shaft, an anvil, an anvil guide, and a top connector. A key design constraint was that the fixture had to mount within our existing Instron machine.

To ensure that load would be applied normal to the gear tooth face the anvil face was designed to match the involute profile of the gear, resulting in an anvil angle at $13.75^{\circ}$ from the horizontal, Figure 8. The spur gear has a surface hardness of 29-32 HRC, thus the anvil surface had to have a greater HRC to prevent damage to the anvil surface during testing. The anvil was fabricated from 17-4 PH stainless steel with a nominal HRC of 32. To increase the surface hardness of the anvil, it was subjected to a one hour postfabrication heat treatment at $900^{\circ} \mathrm{F}$ followed by air cooling, increasing the HRC to between 40 and 47. 


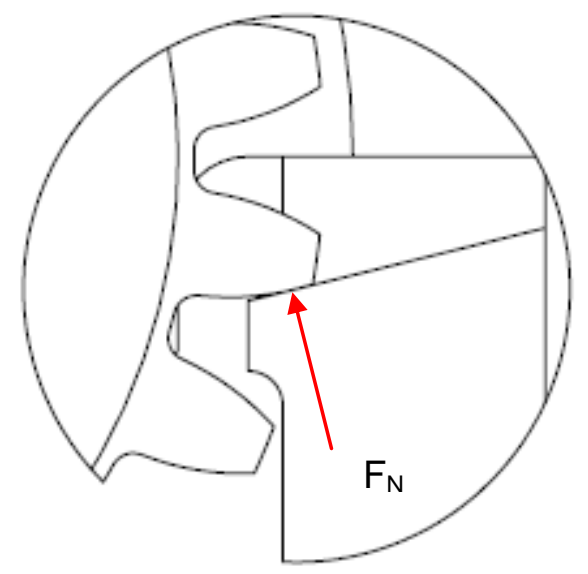

Figure 8. Anvil applying normal load to gear tooth.

To ensure that the fixture would also withstand fatigue testing, all parts (besides the anvil) were made of general low carbon steel. The gear is aligned and held fast using a custom shaft secured by the back plate and front cover, Figure 9. The back plate was machined with a square cut to match the machined end of the gear-mounting shaft. This was done to prevent rotation of the shaft during testing as well as to prescribe proper alignment between the gear tooth and loading anvil. The gear-mounting shaft was fabricated from a fully keyed 1045 steel shaft purchased from McMaster. One end of the shaft was machined square to fit securely into a matching hole fabricated into the back plate of the fixture. The spur gear is slid onto the shaft and aligned using a key way. The key way prevents the gear from rotating on the shaft under load, while the square shaft end and matching plate mount prevent the shaft from rotating. Once the alignment shaft is fitted with the spur gear and key way, the back and front plates are fastened together. A unique clover design implemented into the front cover allows the alignment shaft to be rotated every $90^{\circ}$. This design feature allows testing of four different teeth on a single spur gear, but also assures secure fixturing during the fatigue test. Four $1 / 4$ "-20 socket head cap screws, washers, and four nylon-insert nuts are used to hold the front and back plates together. 


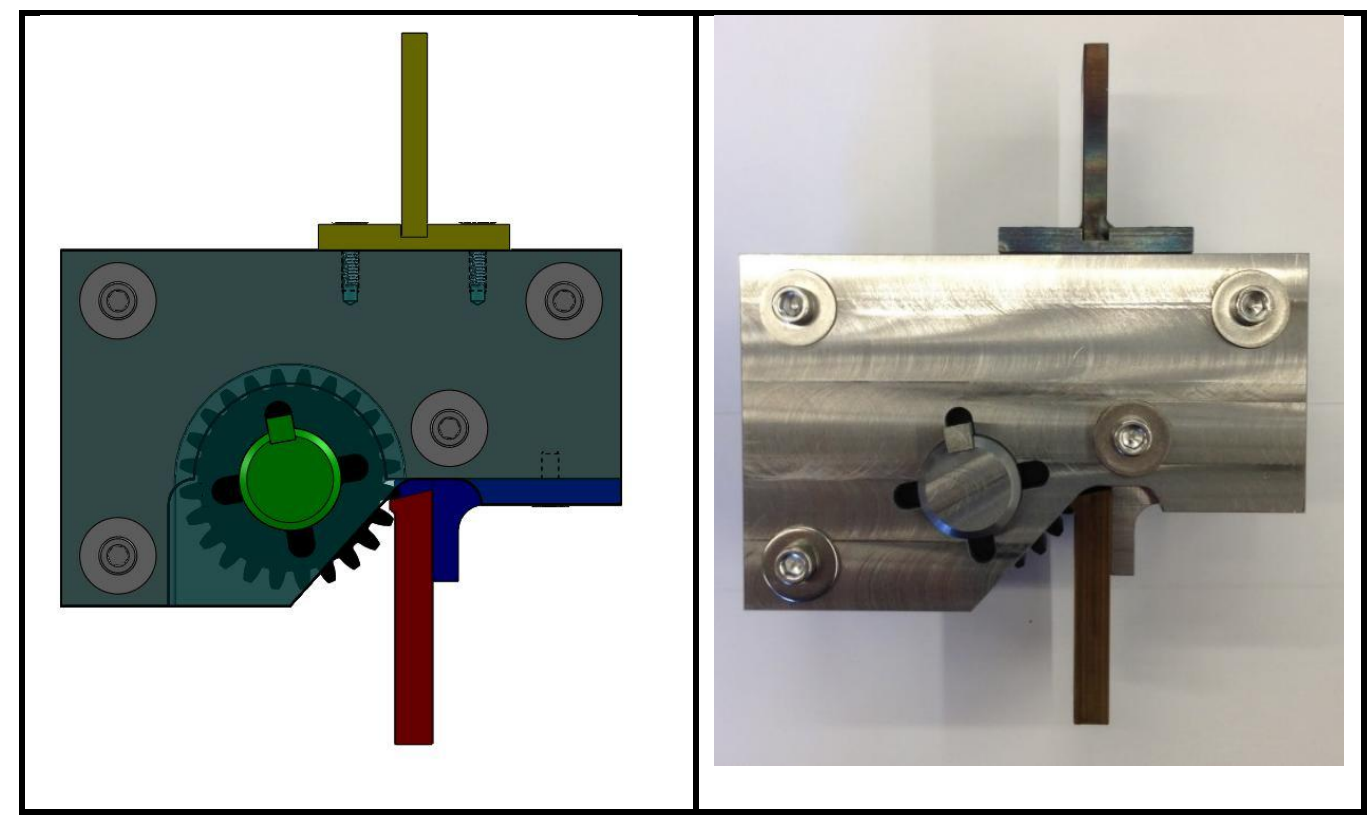

Figure 9. Completed fatigue fixture.

After the initial design, there was concern that the alignment shaft could back out from the square receiver hole due to vibration during testing. To prevent this, a bolt with a large washer was added so the shaft could not move longitudinally during testing. Given that the contact area between the anvil and gear tooth is small, the anvil slipping on the gear tooth also became an area of concern. To prevent this, an anvil guide was created that attaches to the bottom of the back plate and creates a bearing surface into which the anvil is pressed so it cannot slip off of the gear tooth. A secondary benefit of the anvil guide is that the right plane of the anvil will remain parallel with the right plane of the fixture. Once the two halves are connected and the anvil guide is in place, the top connector is attached with four 8-32 stainless steel socket head cap screws. The sole purpose of the top connector is to provide a way to mount the fixture into the top jaw of the Instron. 


\subsection{FATIGUE CRACK INITIATION AT TOOTH ROOT}

In order to produce a sharp fatigue crack in the tooth root, an Instron 1330 Series Servo Hydraulic Fatigue Testing Machine was used in conjunction with the fatigue fixture described in the previous section. The machine was fixtured with a 20,000 lbf load cell and 2160 controller. Test data was collected with a custom LabVIEW program running on a desktop computer.

\subsubsection{PRE-FATIGUE TESTING CALCULATIONS}

Prior to testing, calculations were conducted to determine the anticipated failure loads and fatigue thresholds associated with the subject gear teeth. A theoretical max tangential load $\left(\mathrm{W}_{\mathrm{t}}\right)$ was calculated using the Lewis bending equation [8]. Lewis treated the gear tooth as a simple cantilever beam and estimated the resulting bending stress, Eqn 3.3, Figure 10. Using similar triangles Eqn 3.3 is converted to 3.4 using the diametral pitch. In this Equation, $\mathrm{W}_{\mathrm{t}}$ is the transmitted tangential tooth load (lbf), $\mathrm{P}$ is the diametral pitch (teeth/in), $\mathrm{F}$ is the face width (in), and $\mathrm{Y}$ is the tooth form factor. The Martin S1224BS 1 spur gear has 24 teeth so this yields a tooth form factor of 0.302 for a $14-1 / 2^{\circ}$ full depth involute profile loaded at the tip [14]. Since the spur gear geometry is known, and the bending stress is assumed to equal the ultimate stress of the gear material, the calculated theoretical max load is $1925 \mathrm{lbf}$, allowing an anticipated load level for direct comparison to experiment. Eqn 3.5 outputted the max deflection for a cantilever beam for the associated max tangential. The anticipated upper bound to the tip deflection, using a $1925 \mathrm{lbf}$ tip load, is $2.3 \times 10^{-4} \mathrm{in}$. This can be used as a basis for position control during experiments on the gear. 


$$
\begin{gathered}
\sigma_{b}=\frac{M}{I / c}=\frac{6 W_{t} l}{F t^{2}} \\
\sigma_{b}=\frac{W_{t} P}{F Y} \\
\delta_{\max }=\frac{F l^{3}}{3 E I} \\
l=\frac{t^{2} P}{6 Y} \\
I=\frac{1}{12} b h^{3}
\end{gathered}
$$

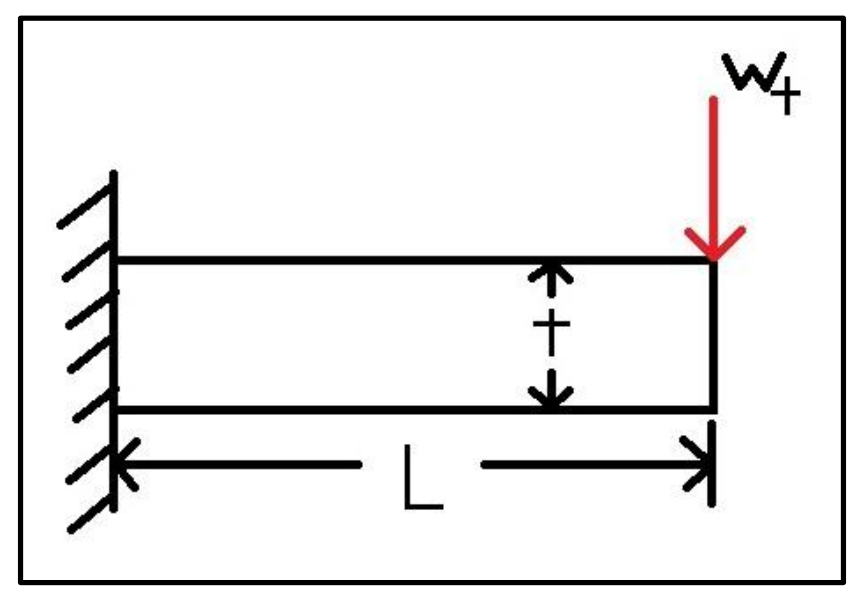

Figure 10. Simple cantilever beam with a tip load.

The number of cycles required to initiate a fatigue crack in the tooth root of the Martin spur gear was not known a priori. But to determine a reasonable set of loading conditions, several experimental design parameters were considered. First, in the interest of testing time, we chose to test in the lower third of the high cycle fatigue regime, choosing 10,000 cycles as a reasonable count. Once 10,000 cycles was chosen, we back-calculated to determine the required tangential gear tooth load. These calculations require an estimation of the fatigue strength of the gear tooth based upon a modified version of Basquin's law, Eqn 3.8. Following the procedures developed by 
Shigley [8], the fitting parameters for Basquin's law can be related to the ultimate strength $\left(\mathrm{S}_{\mathrm{ut}}\right)$ and endurance strength $\left(\mathrm{S}_{\mathrm{e}}\right)$, using Eqns 3.9 and 3.10. The tensile ultimate strength of AISI 13400 Alloy Steel is $102 \mathrm{ksi}$.

$$
\begin{gathered}
S_{f}=a N^{b} \\
a=\frac{\left(f S_{u t}\right)^{2}}{S_{e}} \\
b=-\frac{1}{3} \log \left(\frac{f S_{u t}}{S_{e}}\right)
\end{gathered}
$$

The endurance strength of the material was unknown so it had to be calculated using an acceptable procedure that employs Marin factors [8], again, as developed by Shigley, [8], Eqn 3.10. Though there are a range of Marin modification factors, we used only $k_{a}$ and $k_{b}$, with all other factors assumed equal to 1 . The "a" and "b" in Eqn 3.11 were taken from Table 6-2 in Shigley's Mechanical Engineering Design $9^{\text {th }}$ ed [8].

$$
\begin{gathered}
S_{e}=k_{a} k_{b} k_{c} k_{d} k_{e} k_{f}\left(0.5 S_{u t}\right) \\
k_{a}=\mathrm{a}\left(S_{u t}\right)^{b} \quad \mathrm{a}=1.34, \mathrm{~b}=-0.085 \\
k_{b}=(d / 0.3)^{-0.107}=0.879 d^{-0.107} \text { for } 0.11 \leq \mathrm{d} \leq 2 \mathrm{in} .
\end{gathered}
$$

The estimated endurance strength of the Martin S1224BS 1 spur gear is $46.96 \mathrm{ksi}$. Using this value, an ultimate stress of $102 \mathrm{ksi}$ and $\mathrm{N}$ equal to 10,000 cycles, the fatigue strength of the spur gear was estimated to be $70.68 \mathrm{ksi}$. For fully reversed loading conditions the fatigue strength equals the fully-reversed stress and using Eqn 3.14 and Eqn 3.15, a maximum stress and thus a maximum tangential tooth load can be estimated for a finite number of cycles. 


$$
\begin{aligned}
& \sigma_{m}, \sigma_{a}=\left|\frac{\sigma_{\max } \pm \sigma_{\min }}{2}\right| \\
& \sigma_{\text {rev }}=\frac{\sigma_{a}}{1-\sigma_{m} / S_{u t}}
\end{aligned}
$$

To avoid dynamic effects during fatigue testing the anvil must never lose contact with the gear tooth surface. Therefore, we chose a minimum stress of $25 \mathrm{ksi}$ corresponding to a minimum tangential tooth load of $472 \mathrm{lbf}$. Once this value is assumed, we must employ a mean stress correction factor to adjust the fatigue lifetime. We did so using the Goodman mean stress correction leading to a max stress of $88 \mathrm{ksi}$ corresponding to a max tangential tooth load of $1650 \mathrm{lbf}$. Using this approach, and assigning a fatigue lifetime of 10,000 cycles, we calculate a minimum tangential force of $472 \mathrm{lbf}$ and a maximum tangential force of $1650 \mathrm{lbf}$. For convenience of changing of any number of the factors associated with these calculations, all equations were entered into Engineering Equation Solver (EES). A copy of this code is located in Appendix $\mathrm{H}$.

\subsubsection{INSTRON FATIGUE TESTING SET-UP AND PARAMETERS}

To eliminate inconsistencies and possible sources of error a specific procedure was developed when loading the fatigue fixture into the Instron. With all components of the fatigue fixture securely fitted, the top jaw of the Instron is lowered until the anvil can be accurately aligned in the bottom jaw and subsequently clamped, Figure 11. Both the load and position controller were utilized in this study and each had specific parameters for use in their respective fatigue tests. In general a $1.5 \mathrm{~Hz}$ half-sine waveform was used in fatigue testing. For the fatigue fixture loading procedure and specific load and position control parameters see Appendix D. 


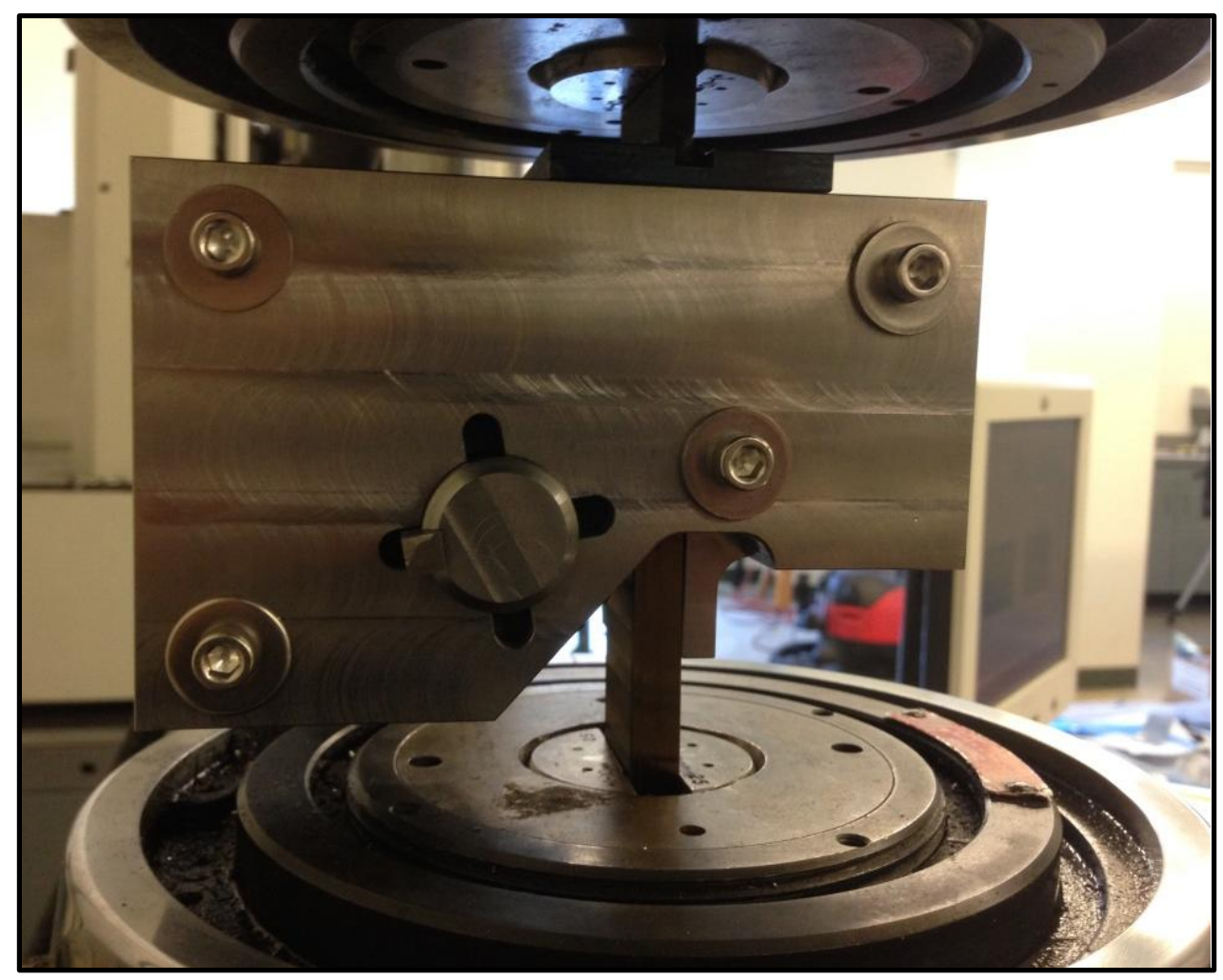

Figure 11. Fatigue fixture secured into Instron for fatigue testing.

\subsubsection{GEAR TOOTH FATIGUE TESTING}

In addition to setting up the Instron machine with the correct parameters several additional steps were taken to image the fatigue crack formation during testing. A small digital microscope was attached directly to the fatigue fixture and focused at the contact between the anvil and the gear tooth, Figure 13. The microscope is supplied with a stand that we attached to the Instron with double-sided tape, allowing the lens to be adjusted to the optimum angle and position, Figure 14. This camera has 50x optical zoom and 200x digital zoom at 2.0 megapixels. LED lights surround the lens and illuminate the viewing area. A manual focus and light dimmer help make the digital output as clear as possible. The camera connects to the computer through a USB cable enabling simple image and video capture. Specifications for the camera are shown in Appendix B. 


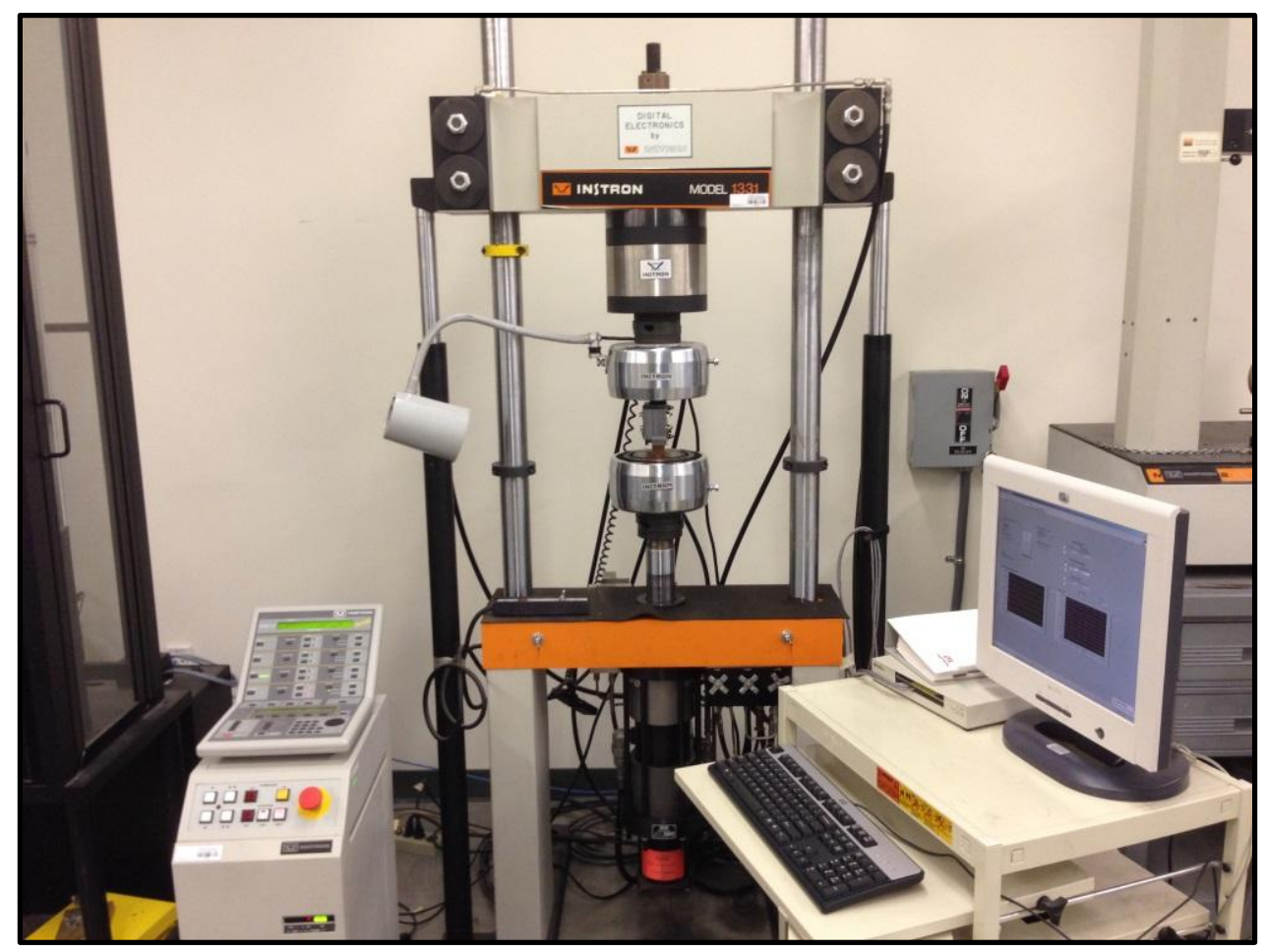

Figure 12. Overall fatigue testing test set-up.

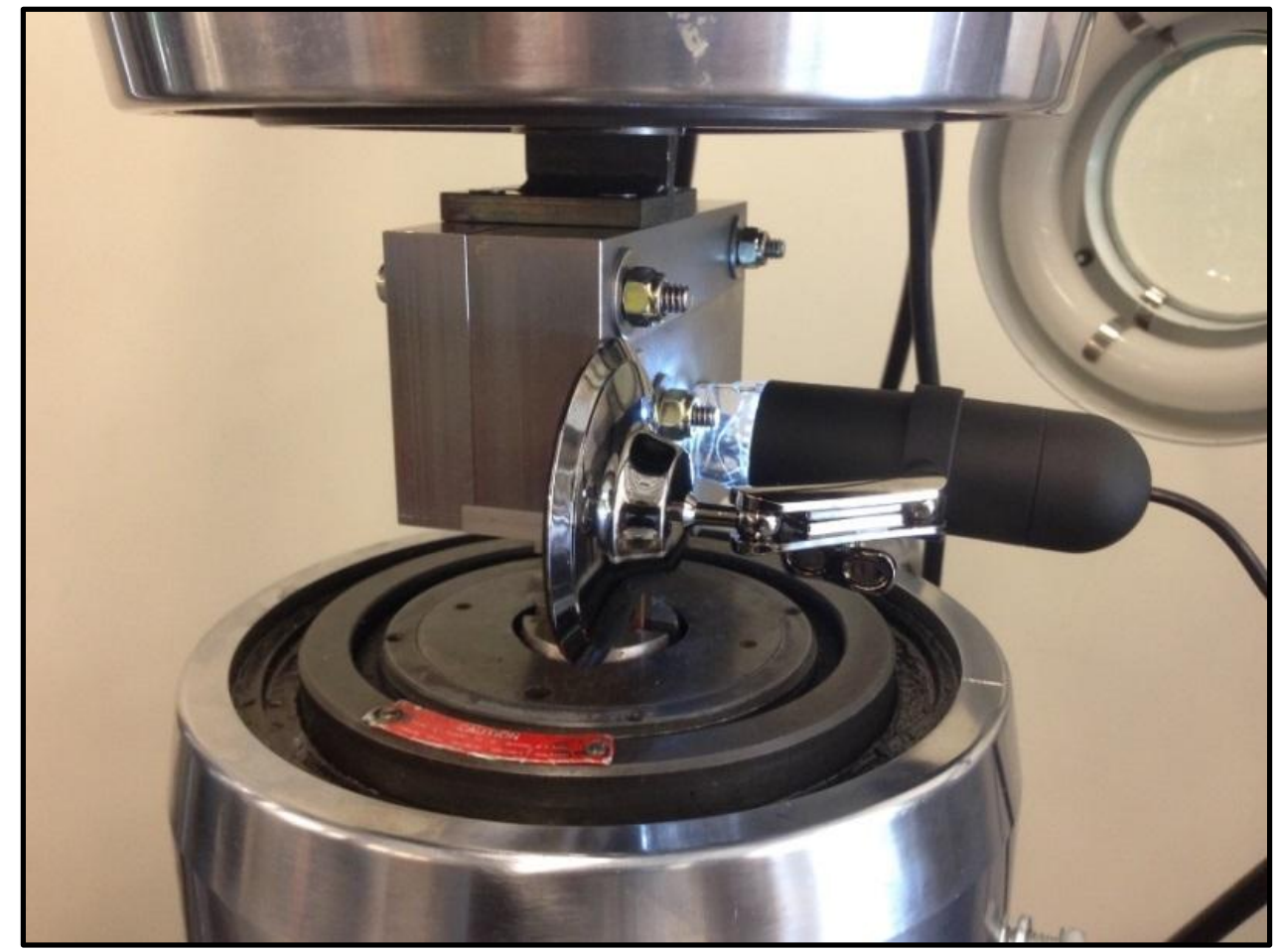

Figure 13. Digital microscope attached and aimed at anvil-tooth contact. 


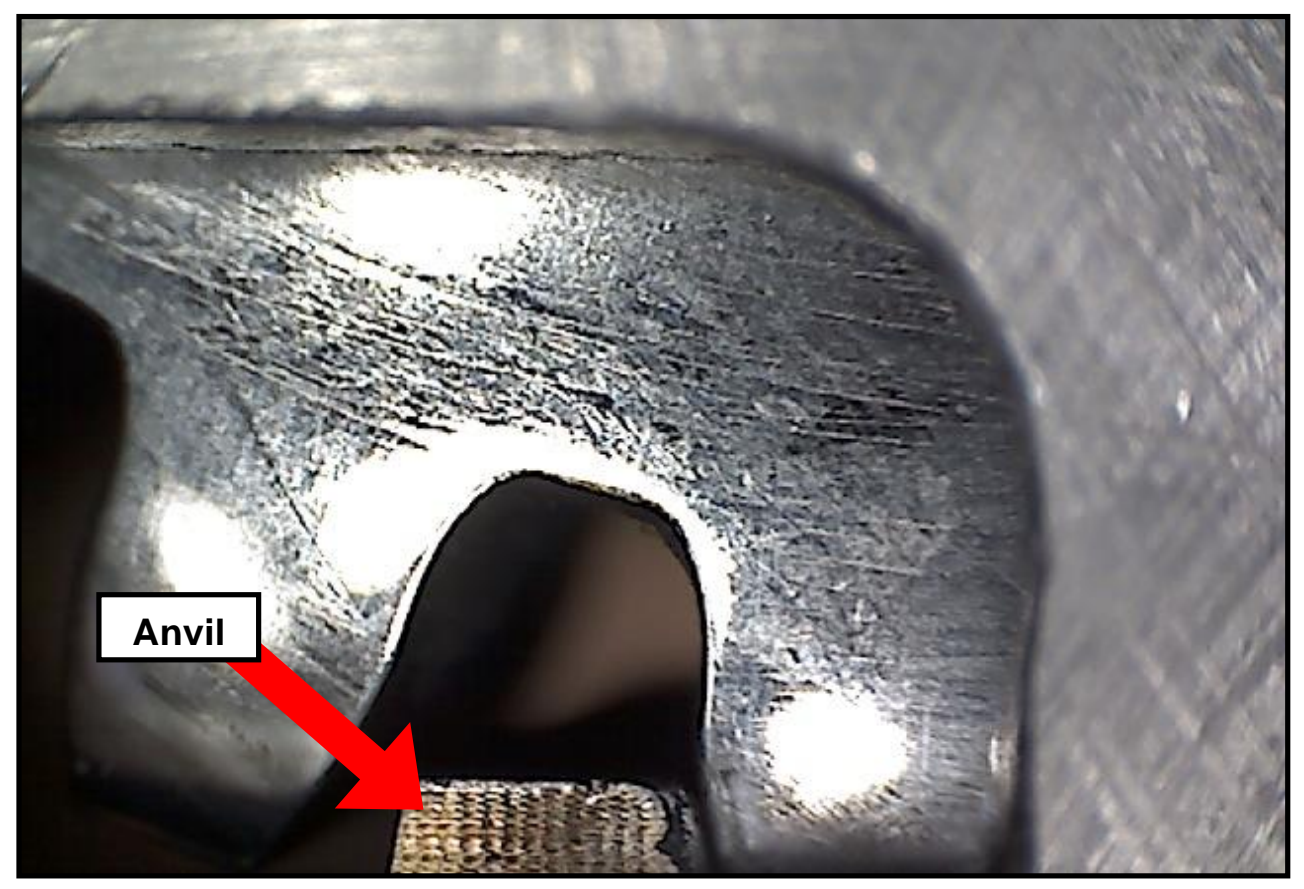

Figure 14. Image captured during fatigue testing from digital microscope.

The Martin spur gear is shipped from the manufacturer with a very rough surface finish. In addition to this, the black color of the gear provides insufficient contrast to view any possible fatigue cracks. To improve the surface quality and enhance our ability to detect the fatigue crack, we polished the back surface of the gear. This resulted in a clean finish that made crack detection much easier. The gear was polished in steps by chucking the gear in a hand lathe and sanding the back face of the gear. A series of grit was used beginning with 80 , followed by 150 grit, 220 grit, and finally 400 grit. During sanding, linear and rotational motion was alternated to avoid polishing marks and to not round any edges of the gear teeth. After sanding, white compound polish was loaded into a cloth polishing wheel. Lastly blue compound polish was used to attain a mirror finish, Figures 15 and 16. 


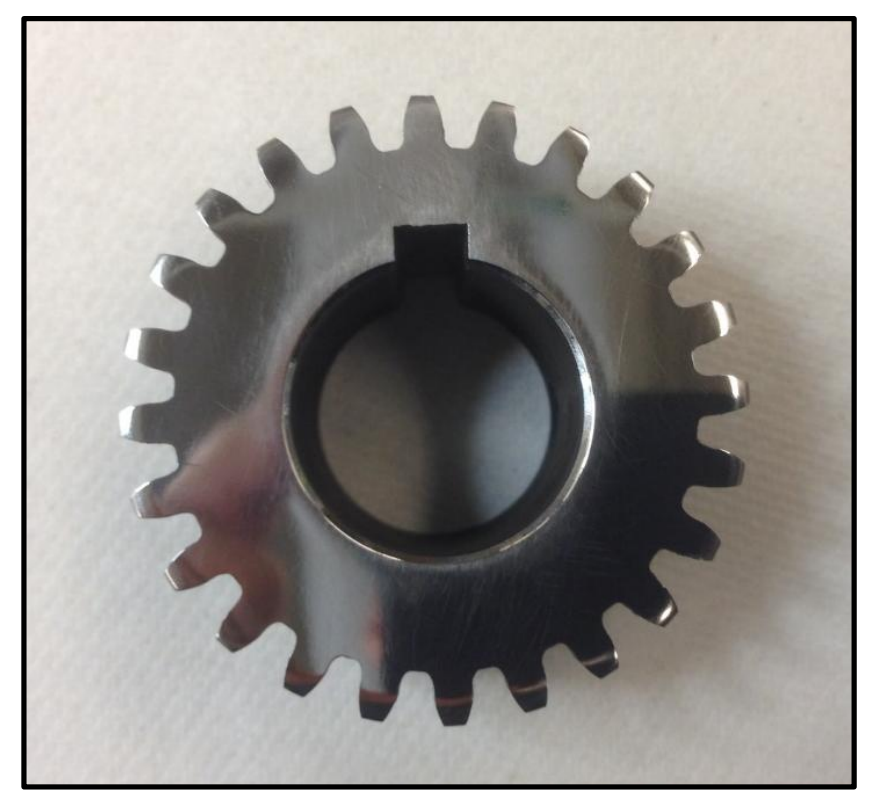

Figure 15. Gear surface after polishing.
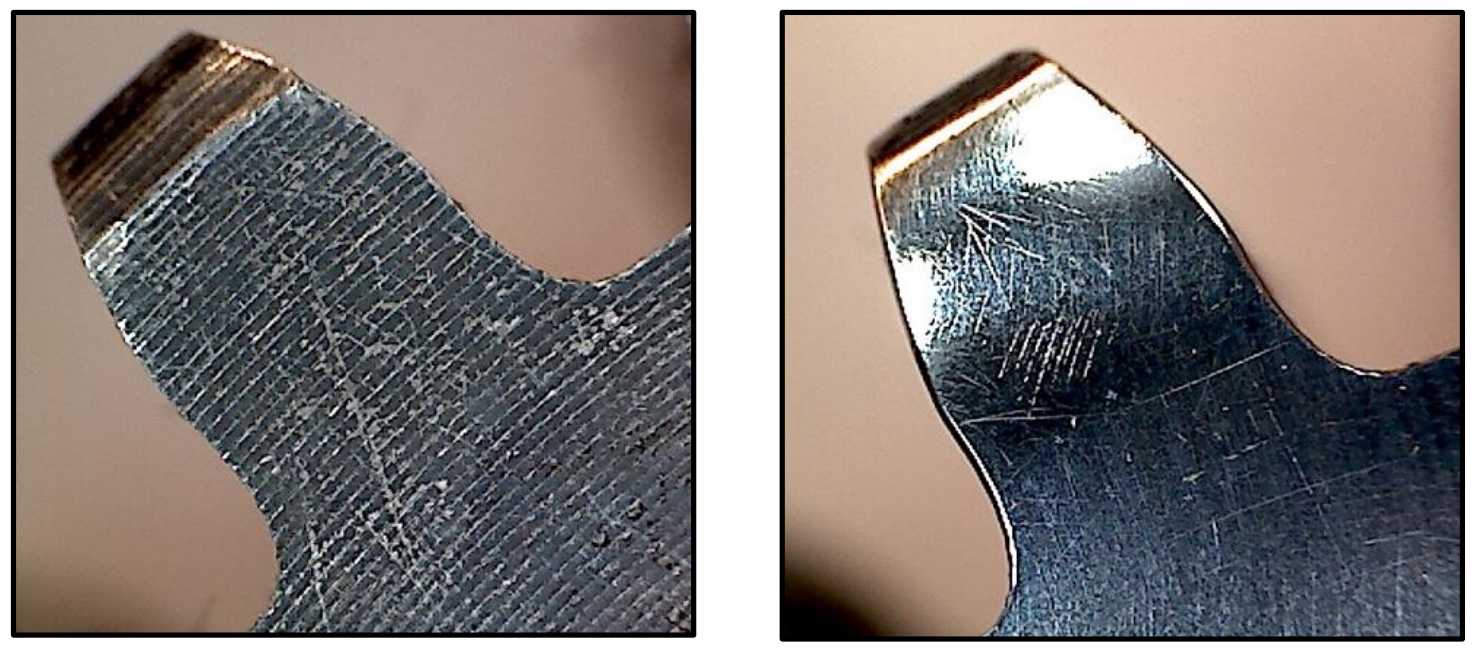

Figure 16. Gear tooth surface comparison between factory and polished surface.

\subsubsection{FATIGUE TESTING POST PROCESSING TECHNIQUES}

The LabVIEW program that collects data during fatigue testing is programmed to output a text file when testing is concluded. Depending on the sample rate selected and the length of the test the output file can vary dramatically in size. In order to manage and analyze such large file sizes, we developed a custom program in Matlab for post 
processing. For each test a plot of the crosshead position versus time and load versus time were plotted. Specifically for position control tests, code was written that determined the peak load for each cycle and then plotted this value versus the data point number corresponding with it. This was useful because it could show the trend of the peak load for every cycle and the change in compliance of the tooth as damage occurred. We proposed using the change in tooth compliance as a means of 'measuring' fatigue damage in the tooth, details of which will be presented in a later section.

Scanning Electron Microscopy (SEM) was used to validate the presence of fatigue cracks at the tooth root. We used a FEI scanning electron microscope, model, Quanta 200, Figure 17, under high vacuum and $20 \mathrm{kV}$ to image the gears.

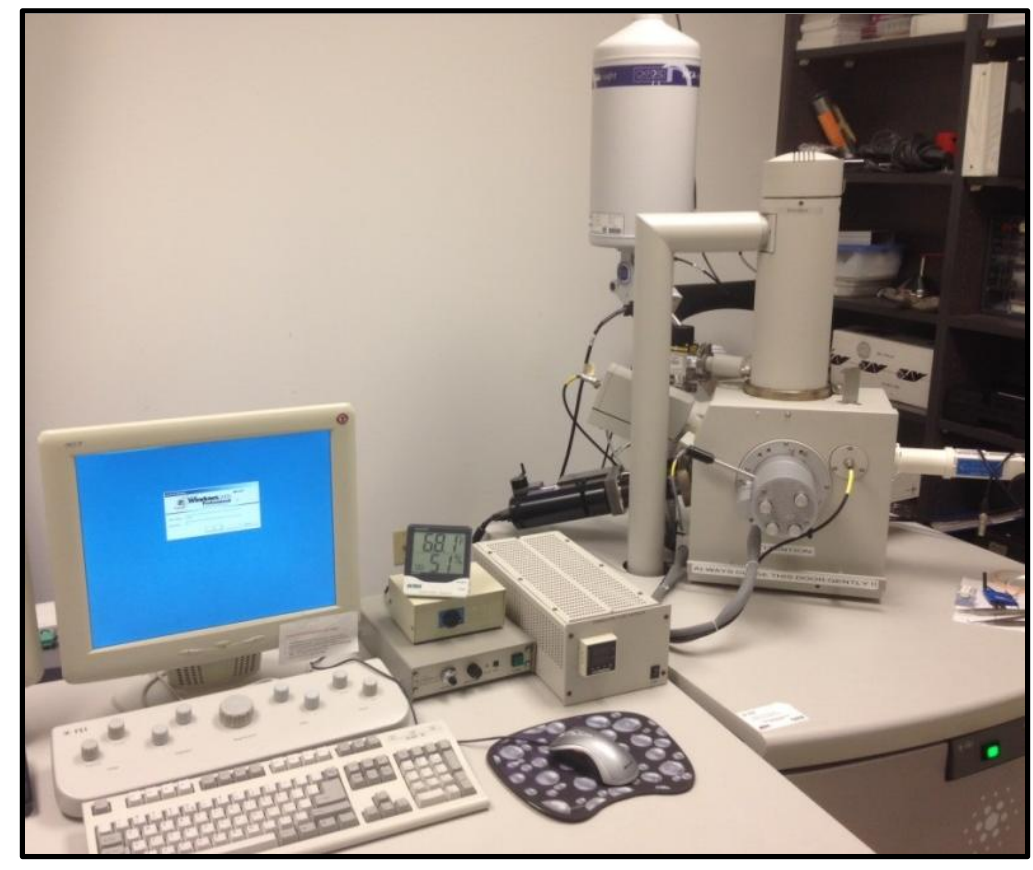

Figure 17. Scanning electron microscope (SEM) used to view fracture surface. 


\section{ONE-STAGE FIXED AXIS GEARBOX COMPUTER SIMULATION}

\subsection{MODEL INTRODUCTION AND GOALS}

To better develop health monitoring systems it would prove useful to have a validated working gearbox computer model to run simulations rather than having to conduct all testing with an experimental gearbox. A computer model can prove to be an efficient use of time to help determine what type of damage and how that type of damage can be detected in a gearbox. The main goal of the single-stage gearbox model was to familiarize with the MSC Adams software before the development of the entire two-stage gearbox model. Once the model was formulated and fully understood the knowledge behind developing the single-stage gearbox could be transferred into the construction of the two-stage gearbox model.

\subsection{ONE-STAGE GEARBOX MODEL DEVELOPMENT AND RESULTS}

. This one-stage model was built in three steps. The first step was to develop a rigid body gearbox model. This model is an ideal case with no imbalance and all parts are assumed rigid. Step two converted the gearbox shafts into flexible bodies and step three added bearings to the model. The rigid model construction began with a quick simplification of the actual gearbox system. The major simplification was reducing the number of gear stages to one. The keyways and setscrews were removed to lower the part count and to remove imbalance from the system. The keyway and step features were removed from each gearbox shaft and the keyway slots were removed from both gears. The main purpose for this upfront simplification was to reduce computation time while learning which settings best incorporated all the necessary elements of the gearbox. A simulation was run after every small change to see how the model was 
affected. With quick simulation times multiple settings and configurations were tested so that the most accurate system could was found.

\subsubsection{RIGID BODY MODEL DEVELOPMENT AND RESULTS}

The input shaft, output shaft, pinion, and gear were 3D solid modeled using Solidworks. Both shafts are 0.9842 inches $(25 \mathrm{~mm})$ in diameter, while the input shaft is 12 inches long and the output shaft is 8.5 inches long. The gears in this model are the same as the first stage in the gearbox dynamic simulator. A solid model assembly was generated and the mating gears were positioned to have the proper backlash. The center-to-center distance between the two mating gears was calculated with a provided Matlab code found in Appendix G. The center-to-center distance that provided the correct backlash for the first stage gear pair is 3.52516 inches. With all components in the proper orientation, the assembly was saved as a Parasolid (.x_t) file. English units (inch, Ibm, Ibf, deg, sec) were selected for this model, and the default geometry display was adjusted to allow for more detailed components to be imported properly. The model construction began with importing the parasolid assembly file. Each gear was fixed to the appropriate shaft using a lock joint constraint. A single revolute joint constraint was attached to the geometric center of each shaft and this allowed rotation about the $z$-axis but constrained all other rotations and translations. Next the all parts were assigned with the default Adams steel material properties, Table 2. The rotation of the input shaft was controlled by attaching a motion constraint to a revolute joint at the end of the input shaft. The motion constraint rotates the input shaft through the use of an input step function. The step function begins at zero and ramps up to max angular velocity in 0.5 seconds. 
Table 2. Adams View steel material properties.

\begin{tabular}{|l|l|}
\hline Modulus of Elasticity & $3.00228 \times 10^{7} \mathrm{Ibf} / \mathrm{in}^{2}$ \\
\hline Poisson's Ratio & 0.29 \\
\hline Density & $0.28183 \mathrm{lbf} / \mathrm{in}^{2}$ \\
\hline
\end{tabular}

Next torque forces were applied to the input and output shafts. Remember the experimental gearbox is powered by a Marathon Electric AC Motor and so the input torque applied to the input shaft varies with speed. Since the actual speed-torque curve of the AC Motor was unavailable, an estimated curve was developed. From speaking with the manufacturer, the motor is NEMA Design B and the no-load torque and full-load torque were specified as $7.5 \mathrm{lbf}-\mathrm{ft}$ and $4.5 \mathrm{lbf}-\mathrm{ft}$ respectively. Using these values a torque curve was estimated by matching the shape of a nominal NEMA Design B motor torque curve, Figure 18, with the values provided from the manufacturer. Once enough data points were estimated a polynomial curve fit was calculated in Matlab.

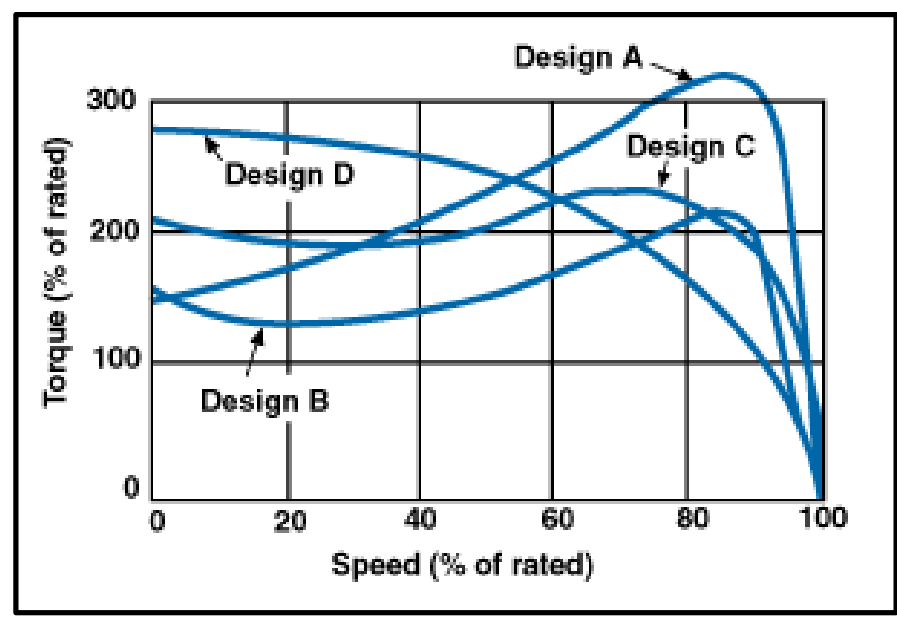

Figure 18. NEMA Design AC motor torque curves.

To ensure the input torque varied with speed, multiple steps had to be taken. First, the angular velocity of the input shaft was measured. This was done by using a point-topoint measure in Adams. The measure calculated the difference in angular velocity between a geometric marker located at the pinion center of mass and a marker attached 
to the ground. This measure has the units of deg/s so the second step was to create a function measure that converted the angular velocity measure into revolutions per minute. The angular velocity in rpm was then the independent variable of another function measure that contained a 6-degree polynomial characteristic torque curve. Lastly an IF statement was utilized to ensure the value computed by the characteristic torque curve was used correctly. This IF statement ensured that as long as the value outputted from the characteristic curve was greater than zero it would be an appropriate value for the input torque. Next the output torque characteristic curve was developed using equation (5.1) which relates output torque to the input torque $\left(T_{1}\right)$, input speed $\left(\Omega_{1}\right)$, output speed $\left(\Omega_{2}\right)$, and efficiency $(\mathrm{n})$. For each data point in the input torque curve a data point was calculated for the output torque curve. The output torque was plotted with the independent variable being the speed of the input shaft, thus, for every time step in the simulation the input and output torque was calculated based upon the current angular velocity of the input shaft. The efficiency of the mating gear pair was computed using a Matlab code provided in Appendix G. The efficiency is determined from the mating gear pair geometry such as outside diameter, pitch diameter, pressure angle, and gear ratio.

$$
T_{2}=\frac{n \Omega_{1} T_{1}}{\Omega_{2}}
$$


Table 2. Torque polynomials for one-stage gearbox model.

\begin{tabular}{|l|r|l|r|}
\hline \multicolumn{2}{|c|}{ Input Torque } & \multicolumn{2}{c|}{ Output Torque } \\
\hline $\mathrm{a}_{0}$ & 87.6731773876 & $\mathrm{a}_{0}$ & 2.1174701686 \\
\hline $\mathrm{a}_{1}$ & $-2.2795650160 \mathrm{E}-02$ & $\mathrm{a}_{1}$ & 1.7258040506 \\
\hline $\mathrm{a}_{2}$ & $-1.2110334782 \mathrm{E}-04$ & $\mathrm{a}_{2}$ & $-5.6420190062 \mathrm{E}-03$ \\
\hline $\mathrm{a}_{3}$ & $2.2015535665 \mathrm{E}-07$ & $\mathrm{a}_{3}$ & $8.4235315226 \mathrm{E}-06$ \\
\hline $\mathrm{a}_{4}$ & $-1.3029514819 \mathrm{E}-10$ & $\mathrm{a}_{4}$ & $-6.8070458278 \mathrm{E}-09$ \\
\hline $\mathrm{a}_{5}$ & $3.4269338431 \mathrm{E}-14$ & $\mathrm{a}_{5}$ & $3.2088480983 \mathrm{E}-12$ \\
\hline $\mathrm{a}_{6}$ & $-3.4659857554 \mathrm{E}-18$ & $\mathrm{a}_{6}$ & $-8.8361910464 \mathrm{E}-16$ \\
\hline & & $\mathrm{a} 7$ & $1.3191890370 \mathrm{E}-19$ \\
\cline { 2 - 4 } & & a8 & $-8.2724964965 \mathrm{E}-24$ \\
\cline { 2 - 4 } & &
\end{tabular}

Table 3. Adams function builder overview.

\begin{tabular}{|c|c|c|}
\hline Function Use & Adams Function Format & Description \\
\hline Input Motion & $\operatorname{STEP}\left(x, x_{0}, h_{0}, x_{1}, h_{1}\right)$ & $\begin{array}{l}x \text {, independent variable. } \\
x_{0}, \text { value of } x \text { which the step } \\
\text { begins to ramp up. } h_{0} \text {, intial } \\
\text { value of } h . x_{1} \text {, value fo } x \text { at } \\
\text { which step reaches } h_{1} \text {. } \\
h_{1} \text {, max value of } h\end{array}$ \\
\hline $\begin{array}{l}\text { Input/Output Torque } \\
\text { Characteristic Curve }\end{array}$ & $\operatorname{POLY}\left(x, x_{0}, a_{0}, a_{1}, \ldots ., a_{30}\right)$ & $\begin{array}{l}x, A \text { real variable that } \\
\text { specifies the independent } \\
\text { variable. } x_{0} \text { a real variable } \\
\text { that specifies a shift in the } \\
\text { polynomial. } a_{0}, a_{1}, \ldots \ldots, a_{30}, \\
\text { polynomial coeffcients }\end{array}$ \\
\hline Input/Output Torque & $\begin{array}{l}\mathrm{IF} \text { (expression 1: expression 2, } \\
\text { expression3, expression 4) }\end{array}$ & $\begin{array}{l}\text { If the value of } \exp 1 \text { is }<0 \text {, IF } \\
\text { evaluated using } \exp 2 \text {. If } \\
\text { value exp } 1=0 \text {, IF evaluated } \\
\text { using exp } 3 \text {. If the value of } \\
\text { exp } 1>0 \text {, IF evaluated using } \\
\text { exp } 4 \text {. }\end{array}$ \\
\hline
\end{tabular}

The last force applied in the model was a gear contact force between the two rigid gears.

Within this contact force: stiffness, damping, penetration depth, and force exponent were defined, Table 4 . The stiffness refers to the material stiffness that is used to calculate a normal force for the impact model. The damping property is that of the contacting 
material and penetration depth defines the depth at which Adams turns on full damping. Lastly, the force exponent models normal force as a non-linear spring-damper and if the penetration depth is the instantaneous penetration between the contacting geometry, Adams calculates the contribution of the material stiffness to the instantaneous normal force [22]. With all necessary constraints in place, a simulation was run for 2.0 seconds with a time step of 0.0001 seconds.

Table 4. First stage gear contact force properties.

\begin{tabular}{|l|l|}
\hline Stiffness & $2.7697958518 \times 10^{7} \mathrm{lbf} /$ in \\
\hline Damping & $2.8550735774 \mathrm{lbf}-\mathrm{s} /$ in \\
\hline Penetration Depth & $3.93700787 \times 10^{-5} \mathrm{in}$ \\
\hline Force Exponent & 2.2 \\
\hline
\end{tabular}

To ensure the basic rigid model was valid checks were conducted. First, the angular velocity of the input shaft/pinion $\left(\Omega_{1}\right)$ and output shaft/gear $\left(\Omega_{2}\right)$ were compared to theoretical calculations. These values matched and so the model accurately transferred motion form one shaft to the other. Next, the input $\left(T_{1}\right)$ and output $\left(T_{2}\right)$ torques were compared to the estimated calculated torque curves. The curves matched and so the measure and function measure set-ups within Adams were properly modeled. The final check compared theoretical and actual gear mesh frequencies (GMF). The gear mesh frequency was calculated using Eqn (5.2). The theoretical gear mesh fundamental frequency for this gear pair is $408 \mathrm{~Hz}$ and the FFT plot shown in Figure 19 showed a GMF spike at $408 \mathrm{~Hz}$. The other peaks on the FFT plot were harmonics of the GMF. 


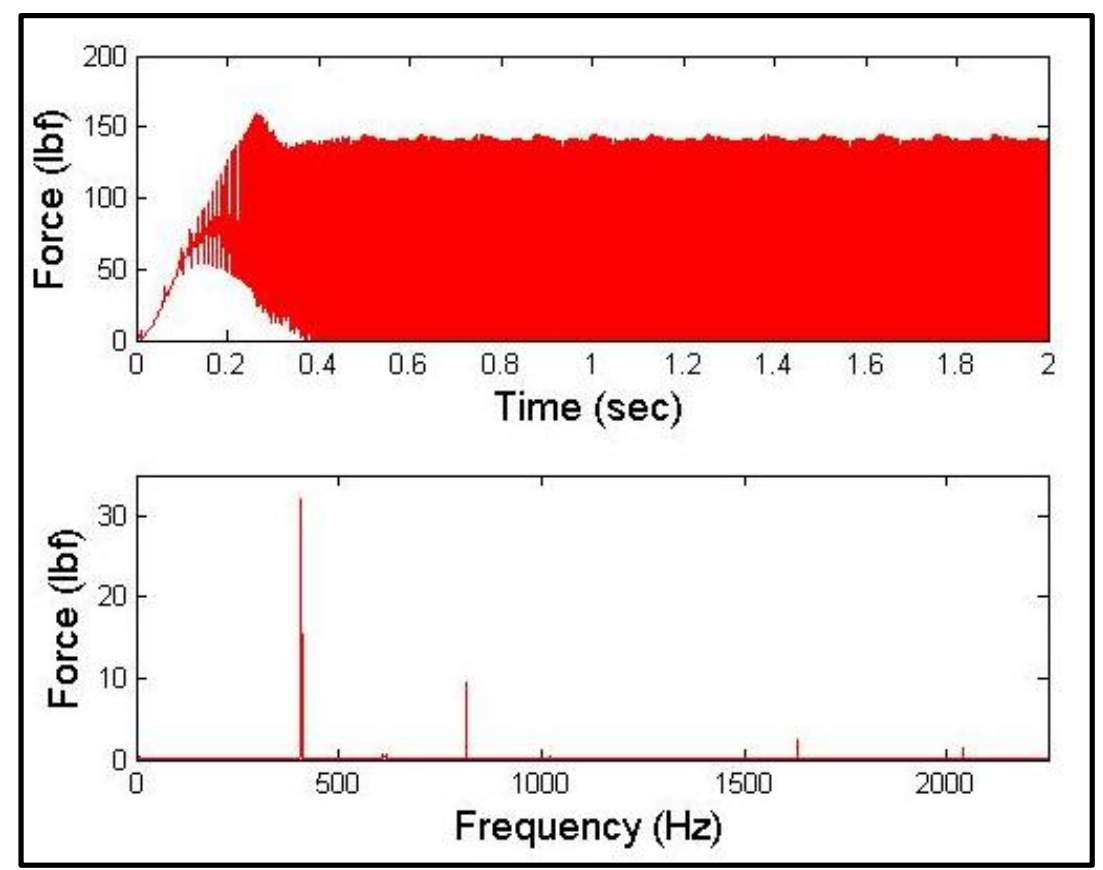

Figure 19. Gear contact force and FFT plot.

\subsubsection{FLEXIBLE SHAFT MODEL DEVELOPMENT AND RESULTS}

In this model the two shafts were converted from rigid bodies to flexible bodies.

This conversion can be done within the Adams View program using the ViewFlex module or using an outside finite element solver such as Abaqus. The rigid body is converted into a flexible body through the use of an MNF (Modal Neutral File) and contains all the necessary flexible body information [21]. One key component of this is the interface nodes, which are the nodes that forces and other bodies are connected to. For, example the outside surface nodes at which a gear connects to the shaft should be constrained so that the body can transfer force in the correct manner. To get a visualization of the forces being exerted on each shaft for the mating gear pair, revolute joints were attached at every future bearing location. Having this joint present would allow forces in the $\mathrm{x}$ and $\mathrm{y}$-direction to be analyzed and then compared to bearing forces in the next step. 
Adams ViewFlex is an automatic flexible body generation module that converts a rigid body into a flexible body through MNF generation. This module is convenient since the mesh can be created within Adams without the help of an external FEA software but the usability may prove difficult. The advanced settings within ViewFlex, control the element type, element shape, element order, element size, and growth rate. In addition to this, attachment nodes locations and multi-point constraints can be created. This is important because the nodes surrounding the bearing sites, gear locations, and force attachment points must transfer forces and moments between other components in Adams. Adams ViewFlex proved to not be the best way of generating the MNF for this study.

Instead of using the ViewFlex module, the MNF was generated through Abaqus, an external FEA software. Although this process may take more effort, the result was more accurate for use with this gearbox model. The MNF generation process begins with creating a modal analysis study in Abaqus. A data check outputs a Job.inp file and this contains all the necessary information from the Abaqus model. This information is extracted and imported into three separate .inp files and through the Abaqus command window a modal neutral file is generated. The custom inp files used for the MNF generation process were developed by Rene Sawatzky for use in his study, "Vibration Based Planetary Gear Analysis and Damage Detection" [27]. The .inp were modified to fit the needs of this present study. A full explanation of the process required for developing the MNF using Abaqus is in Appendix F.

To validate the Abaqus MNF generation process for use in Adams, two quick tests were conducted. An MNF was developed for a simple circular cylinder 12 inches in length with a 1 inch diameter. Once imported in Adams, one end of the shaft was fixed while the 
other end was left free and had a $500 \mathrm{lbf}$ load applied to the center of the face. Through a simulation the maximum deflection of the shaft was measured to be 0.205 inches which was very close to the theoretical value of 0.202 inches. The Adams model was within $2 \%$ of the theoretical value and so generation of the modal neutral file using Abaqus for Adams was validated. In addition to the deflection test, a torsion test was conducted and a very similar result was found. The shaft angle of twist computed in Adams was less than $2 \%$ from a computed theoretical value. Each shaft in the one-stage model utilized a linear hexahedral element with a seed size of 0.125 inches. For the input shaft a beam type multipoint constraint (MPC) was created for the input torque, both bearing locations, and the gear location [21]. Remember these MPC's are necessary to transfer force from a rigid part to a flexible part. The steel material properties of each shaft in Abaqus were the same material properties in Adams

To verify the flexible shaft model operated in the same manner as the rigid model, the angular velocities of both shafts and the input and output torques were compared. These values matched the previous step and so the flexible shaft model was still in working order. Next the contact force between the meshing gear pair was compared. For the fundamental GMF, first, and third harmonic of the gear mesh frequency the force amplitude decreased from the rigid body model which was expected. In theory the flexible shaft model should have a lower gear contact force because the shaft is now acting like a spring or damper and absorbing some of the force created by the meshing gear pair [26]. 
As mentioned earlier, a revolute joint was attached to each shaft at a bearing location.

Figure 20 displays the force at each joint. These forces will be compared to bearing forces from the next model.

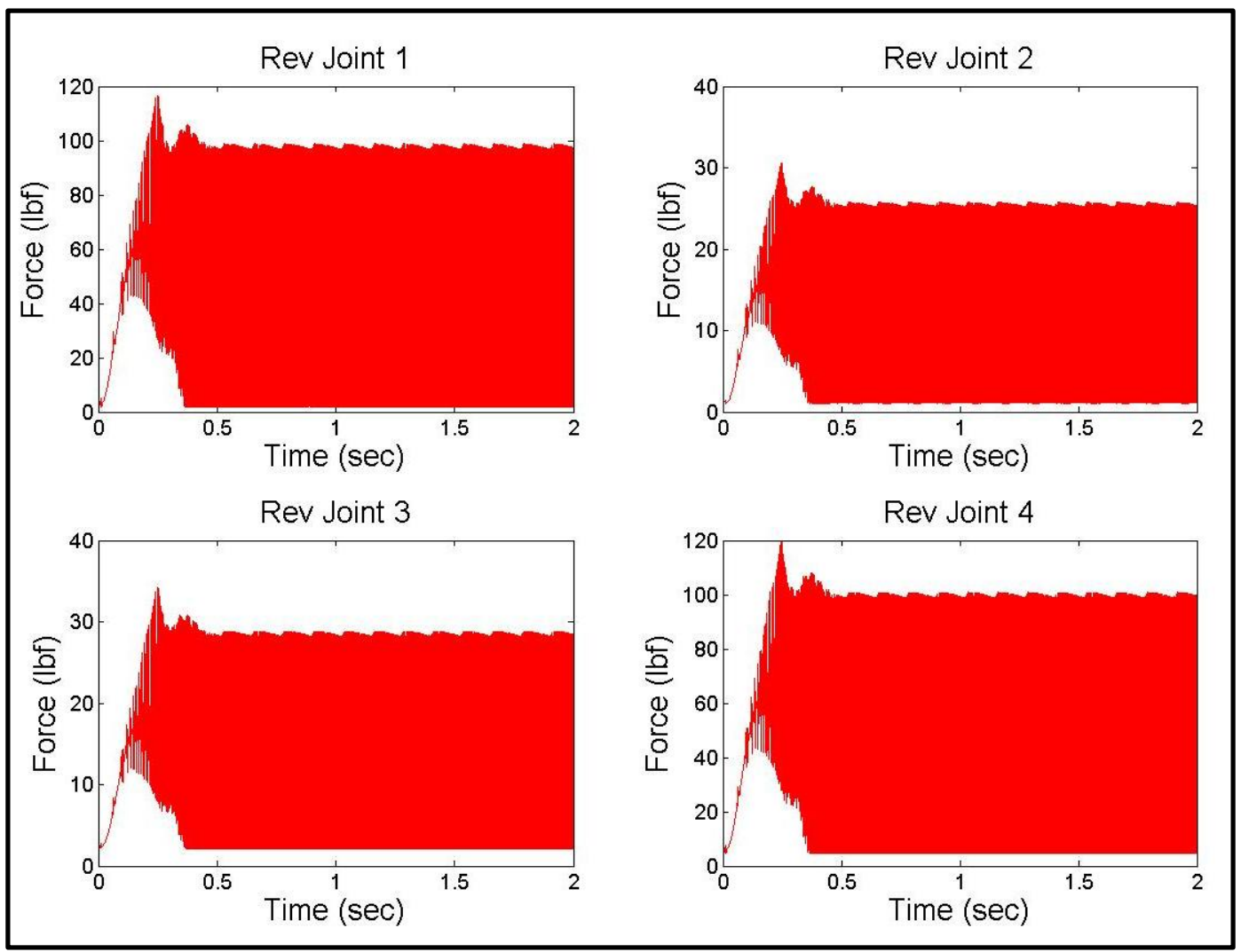

Figure 20. Revolute joint contact forces for flexible shaft model.

\subsubsection{BEARING MODEL DEVELOPMENT AND RESULTS}

The next step in the model development was adding bearings. Adams View 2013.2 has a bearing module that accurately predicts the effects of bearing elements on the overall system performance. The bearing module includes an accurate representation of the bearing stiffness, internal dimensions, offsets, misalignments, and clearances [22]. To attach the bearings to the flexible shafts, dummy parts were created. Dummy parts are necessary because bearings can only be attached to rigid parts in Adams and the shafts are flexible in this step of the model. Extremely small, $1 \mathrm{~mm}$ 
radius, spheres were created at each bearing location and a lock joint connected the dummy part to its respective shaft. Each dummy part was assigned a dummy material and this material has an extremely low density so it does not affect the model. When the bearings were inserted, the dummy part was selected as the shaft and the bearing housing was ground. Once all four bearings were added to the model, the revolute joints at each bearing location were deactivated. If this is not done, the model will be over constrained and not run properly.

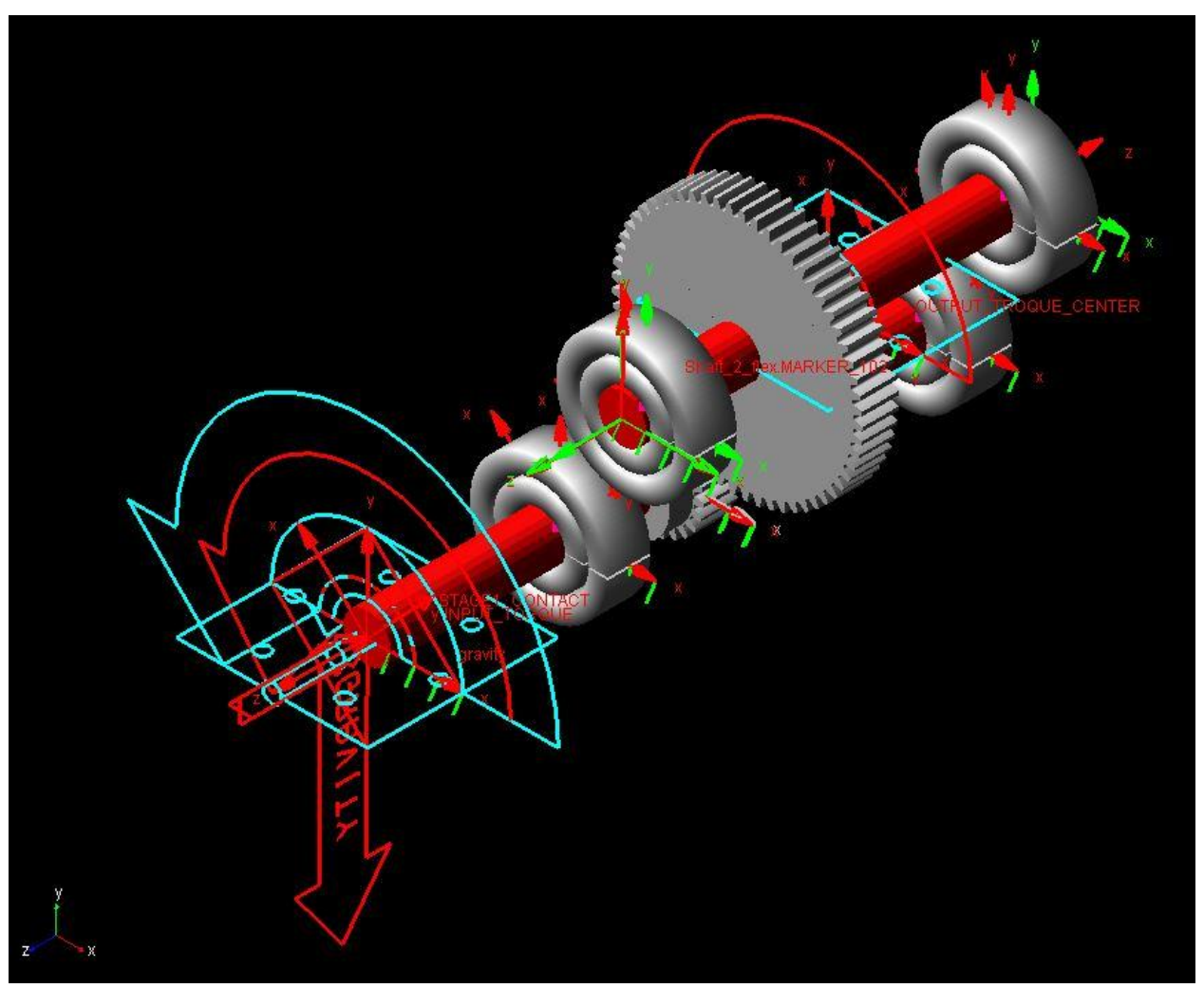

Figure 21. Single-stage gearbox model with flexible shafts and bearings.

The addition of bearings to the one-stage gearbox model caused the gear contact force peaks on the FFT plot to decrease once again. The force amplitude at the fundamental GMF was recorded to be $25.43 \mathrm{lbf}$. This is a dramatic decrease from the previous step but the second, third, and fourth harmonic increased a small amount. Table 5 compares the amplitude of the gear contact force for the first four harmonics of the GMF. 
Table 5. Gear contact force FFT amplitude comparison.

\begin{tabular}{|c|c|c|c|c|}
\hline \multirow{2}{*}{ Model } & \multicolumn{4}{|c|}{ Force Amplitude (Ibf) } \\
\cline { 2 - 5 } & $\mathbf{1 X ~ G M F}$ & $\mathbf{2 X ~ G M F}$ & 3X G MF & 4X GMF \\
\hline Rigid & 32.03 & 9.37 & 0.48 & 2.47 \\
\hline Flexible Shaft & 30.83 & 2.23 & 1.72 & 1.55 \\
\hline $\begin{array}{c}\text { Flexible Shaft } \\
\text { w/ Bearings }\end{array}$ & 25.43 & 2.89 & 1.99 & 1.81 \\
\hline
\end{tabular}

Bearings forces were also analyzed to see if the data output was accurate. All four bearing forces plotted over time had a somewhat sinusoidal shape, Figure 22. The force at bearing 1 looked to be accurate as the overall magnitude of the force was lower than the force experienced on the revolute joint at the same location for the flexible shaft model. Bearing 2 also seemed to be accurate has the force was of similar magnitude to the revolute joint at the same location and the general shape of the force plot was similar to bearing 2. Bearing 3 and 4 however looked to be inaccurate. Although a nice sinusoidal shape was present the force was two orders of magnitude higher than the other bearings in the model. The reason for this could be the way the MPC was defined for the output torque. The MPC constraint for the output torque and bearing 4 seemed to overlap and the overall effect of this is unknown. An FFT analysis of the Bearing 1 force was plotted and peaks were located at the fundamental GMF, harmonics of the GMF, and sidebands surround these peaks, Figure 23. The ability to use type of analysis gave a possible way to analyze the difference between a healthy and damaged system. 

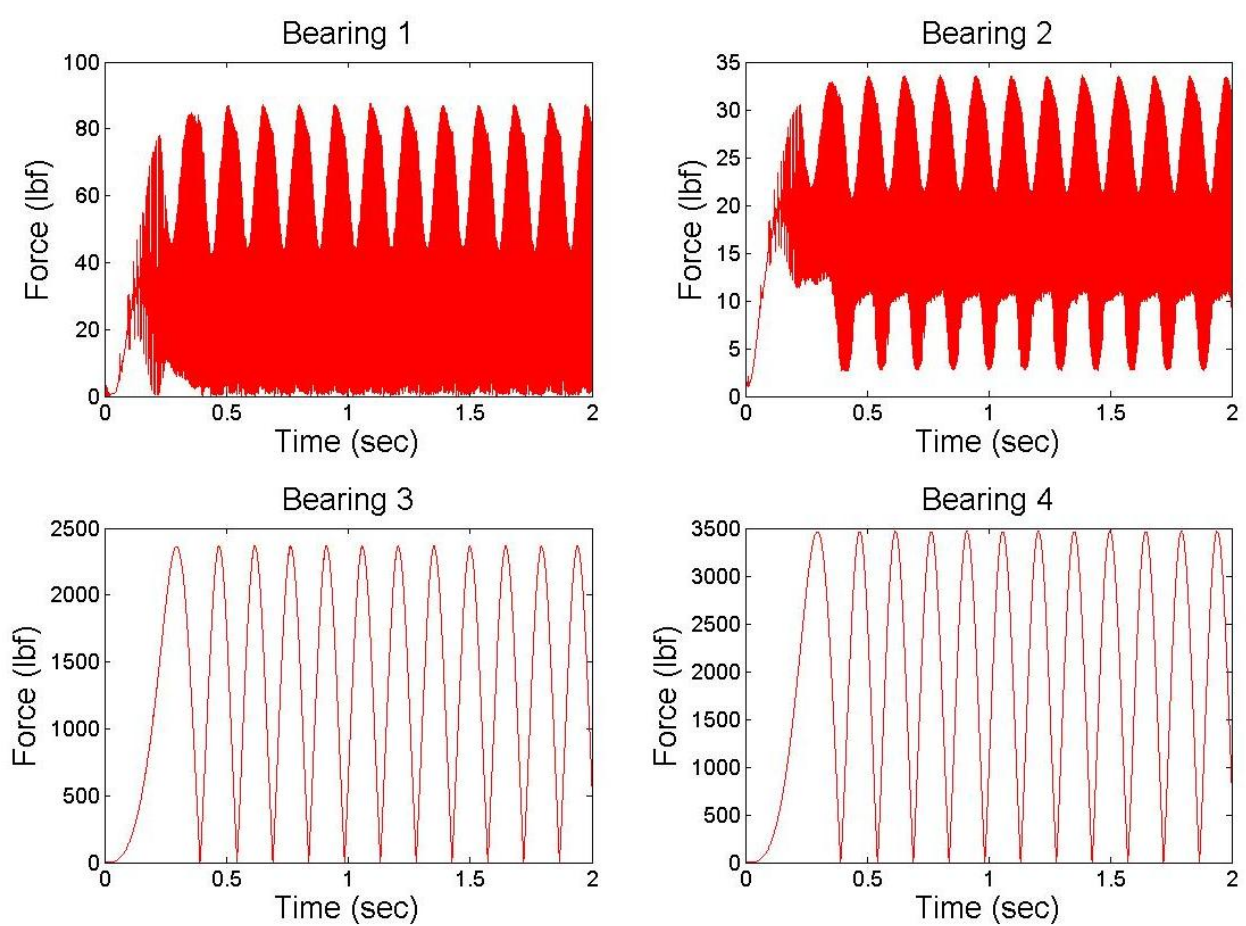

Figure 22. Bearing forces for the single-stage gearbox model.

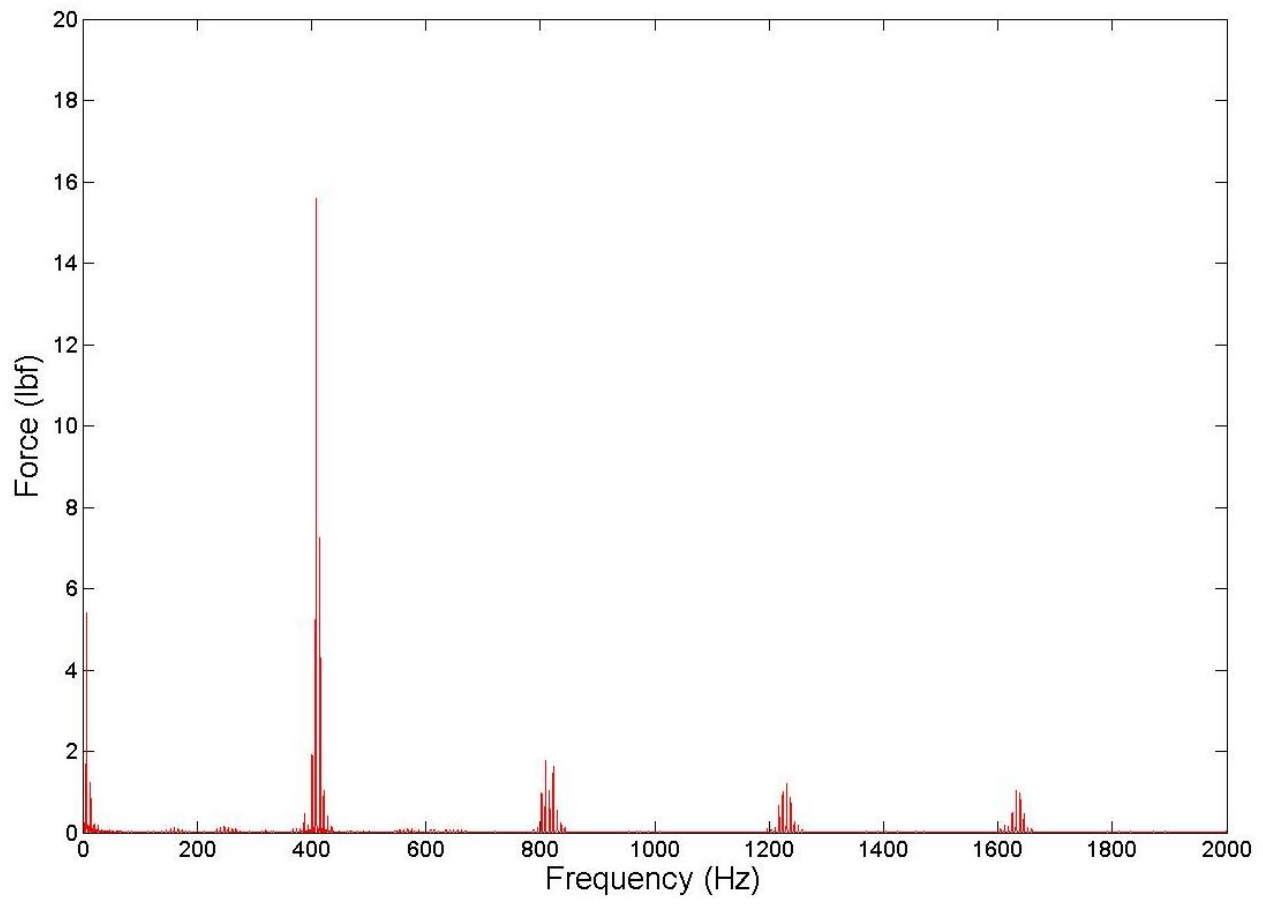

Figure 23 Bearing 1 force FFT for the single-stage gearbox model. 


\section{TWO-STAGE FIXED AXIS GEARBOX COMPUTER MODEL}

\section{$\underline{5.1 \text { MODEL INTRODUCTION AND GOALS }}$}

The goal of the two-stage gearbox model was to emulate the real experimental gearbox in our vibrations lab. To mimic the vibration signature, the gearbox simulation must include flexible shafts, bearings, gear contact forces between meshing gear pairs, bearing forces, and motor input torque and output torque. A very similar developmental

process as the one-stage gearbox model was undertaken to develop the two-stage fixed axis gearbox model. The two-stage gearbox model has very comparable geometry to the actual gearbox. Shaft imbalances, all four gears, shaft keys, and set screws were included. The only differences between the CAD model, Figure 24, and the actual gearbox are small geometry differences in the shafts. Instead of the steps on the shaft ends being $3 / 4$ " they were made to be $20 \mathrm{~mm}(0.7874$ "). The bore diameter of the chosen bearing in the Adams bearing module are $20 \mathrm{~mm}$ and thus the step of the shafts must match this. The exact location of the step along the shaft and the length on the shaft was unknown and so it was estimated. To have the geometry of the shafts match exactly the actual gearbox would have to be disassembled so measurements could be acquired. 


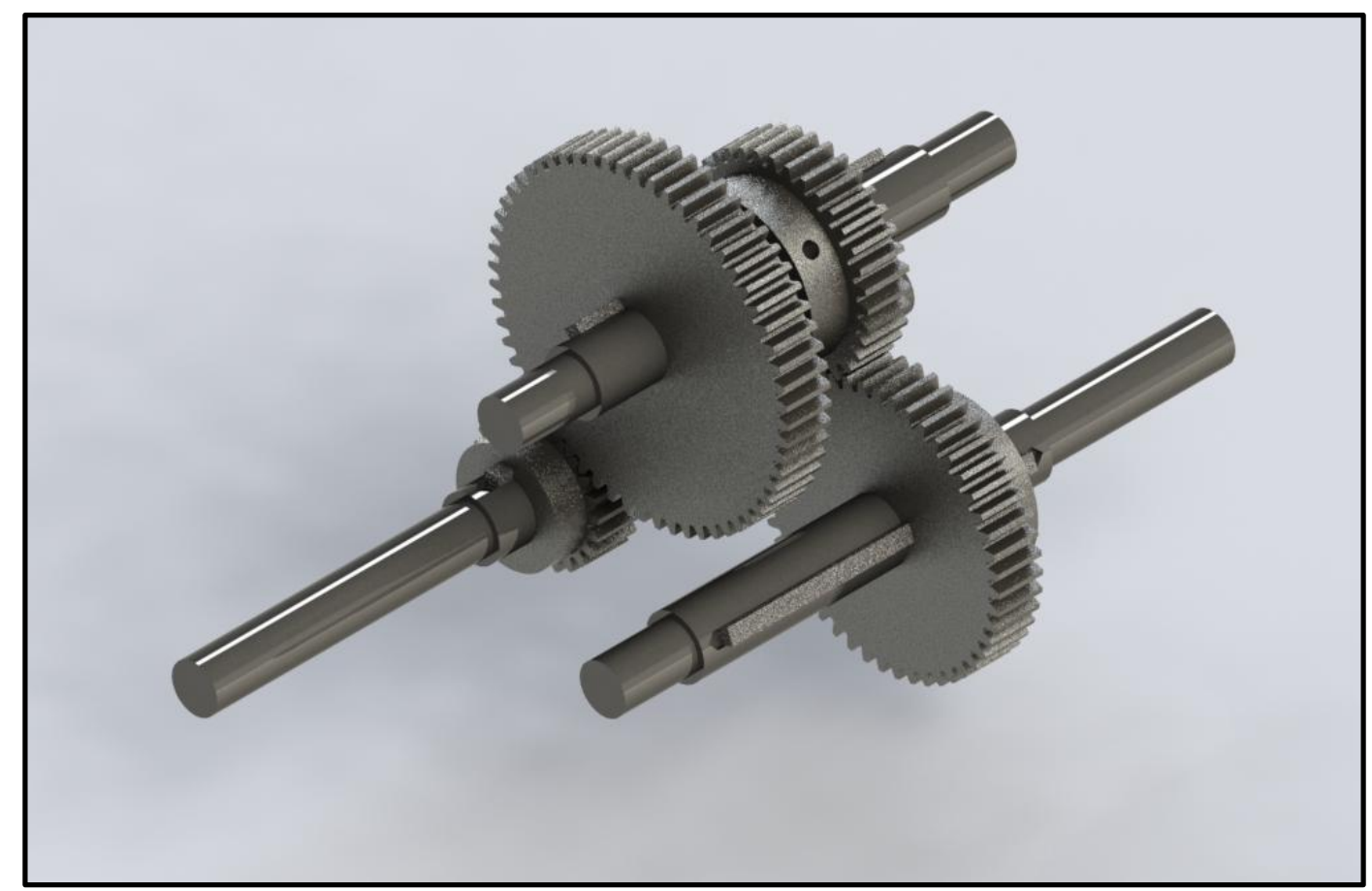

Figure 24. CAD model of gearbox components developed using Solidworks.

\subsection{TWO-STAGE GEARBOX MODEL DEVELOPMENT AND RESULTS}

In the same manner as the single-stage model, the two-stage solid model was imported with a parasolid file. A lock joint constraint attached the gears, shaft keys, and set screws to each shaft and revolute joint constraints were applied to each shaft. The input shaft motion utilized the same step function that ramps up from zero to a maximum angular velocity in 0.5 seconds. All parts were given the default Adams steel material properties.

The torque curve for the input motor torque was equivalent to the single-stage model but the output torque curve changed with the addition of a second stage. The second stage now meant the input and output shaft rotate in the same direction and the output torque characteristic curve was developed using equation (5.1). With two meshing gear pairs, the efficiency is a product of the gear efficiency from the first gear pair and the second 
gear pair. The gear-train efficiency for the two-stage gearbox is $94.6 \%$. Figure 25 shows the input and output torque curve used for the gearbox simulation and Table 6 has the characteristic curve polynomial coefficients for each curve.
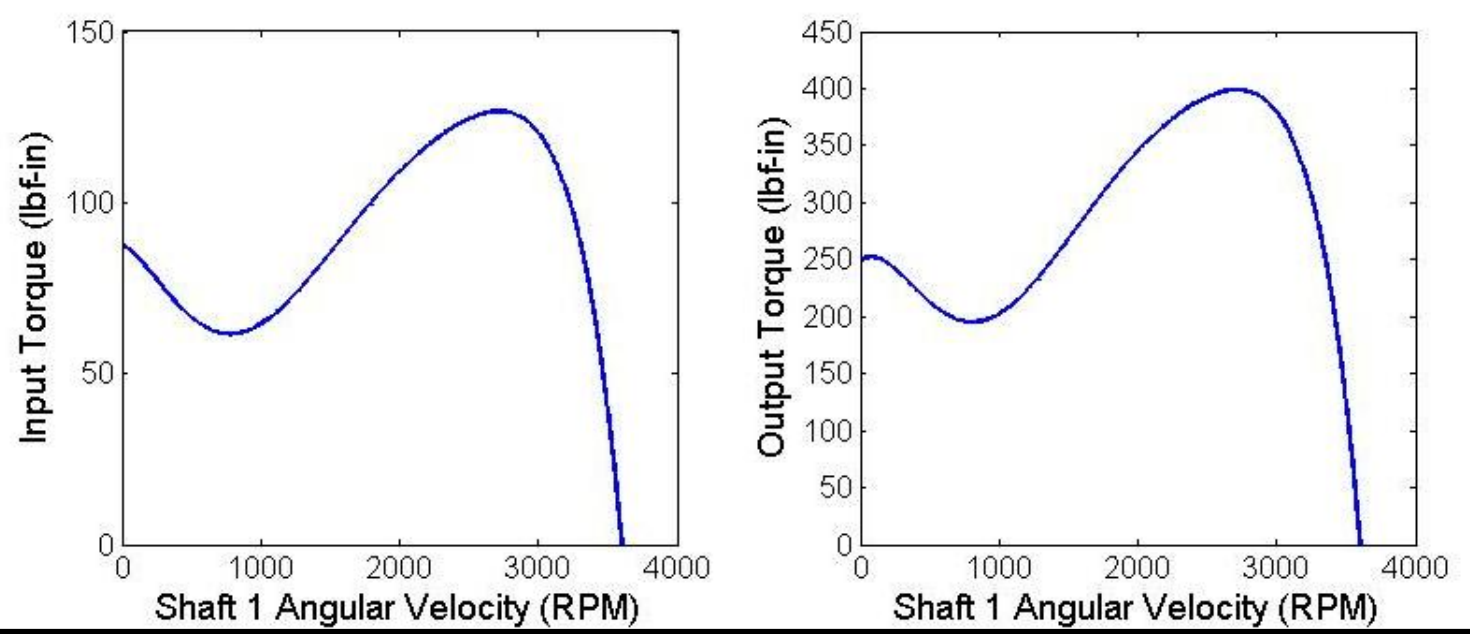

Figure 25. Input and output torque curves for two-stage gearbox model.

Table 6. Torque curves for two-stage gearbox model.

\begin{tabular}{|l|r|l|r|}
\hline \multicolumn{2}{|c|}{ Input Torque } & \multicolumn{2}{c|}{ Output Torque } \\
\hline $\mathrm{a}_{0}$ & 87.6731773876 & $\mathrm{a}_{0}$ & 249.0391000000 \\
\hline $\mathrm{a}_{1}$ & $-2.2795650160 \mathrm{E}-02$ & $\mathrm{a}_{1}$ & $9.0217745000 \mathrm{E}-02$ \\
\hline $\mathrm{a}_{2}$ & $-1.2110334782 \mathrm{E}-04$ & $\mathrm{a}_{2}$ & $-6.9451147192 \mathrm{E}-04$ \\
\hline $\mathrm{a}_{3}$ & $2.2015535665 \mathrm{E}-07$ & $\mathrm{a}_{3}$ & $9.6715521360 \mathrm{E}-07$ \\
\hline $\mathrm{a}_{4}$ & $-1.3029514819 \mathrm{E}-10$ & $\mathrm{a}_{4}$ & $-5.3003784020 \mathrm{E}-10$ \\
\hline $\mathrm{a}_{5}$ & $3.4269338431 \mathrm{E}-14$ & $\mathrm{a}_{5}$ & $1.3346835517 \mathrm{E}-13$ \\
\hline $\mathrm{a}_{6}$ & $-3.4659857554 \mathrm{E}-18$ & $\mathrm{a}_{6}$ & $-1.3035634218 \mathrm{E}-17$ \\
\hline
\end{tabular}


The same contact force stiffness, damping, penetration depth, and force exponent as the one-stage model were used for each gear pair contact force in the two-stage model. To verify the basic parameters of the gearbox model worked properly, a simulation was run with the initial rigid model for 2.0 seconds with a 0.0001 second time step. The angular velocities of each shaft and the input/output torque characteristics curves matched theoretical.

Next each shaft was converted into a flexible part. For the input shaft, multi-point constraints were created for the input torque application, the pinion gear, and both bearings. The intermediate shaft has MPCs for both bearing locations, and the second and third gear in the gear train. Lastly the output shaft has a MPC for the output torque application, the output gear, and both bearing locations. In this model the output shaft is longer than that of the single-stage model and thus the MPC for the last bearing and the output torque no longer overlap. The more complicated shaft geometry in the present model, require a much different mesh than previously used. The 0.125 inch linear hexahedral elements were no longer suitable because Abaqus could not mesh the shaft geometry with this type of element. The more complicated shafts required a quadratic tetrahedral element with a seed size of 0.125 inches, Figure 26 . In the previous singlestage model, only the linear hexahedral element was verified with tests in Adams. To verify the tetrahedral element was valid for MNF use in Adams, a 12 inch shaft with a 1 inch diameter was meshed with the 0.125 inch quadratic tetrahedral element. A simple beam deflection test was conducted and the difference between the Adams results and theoretical values was $3.2 \%$. 


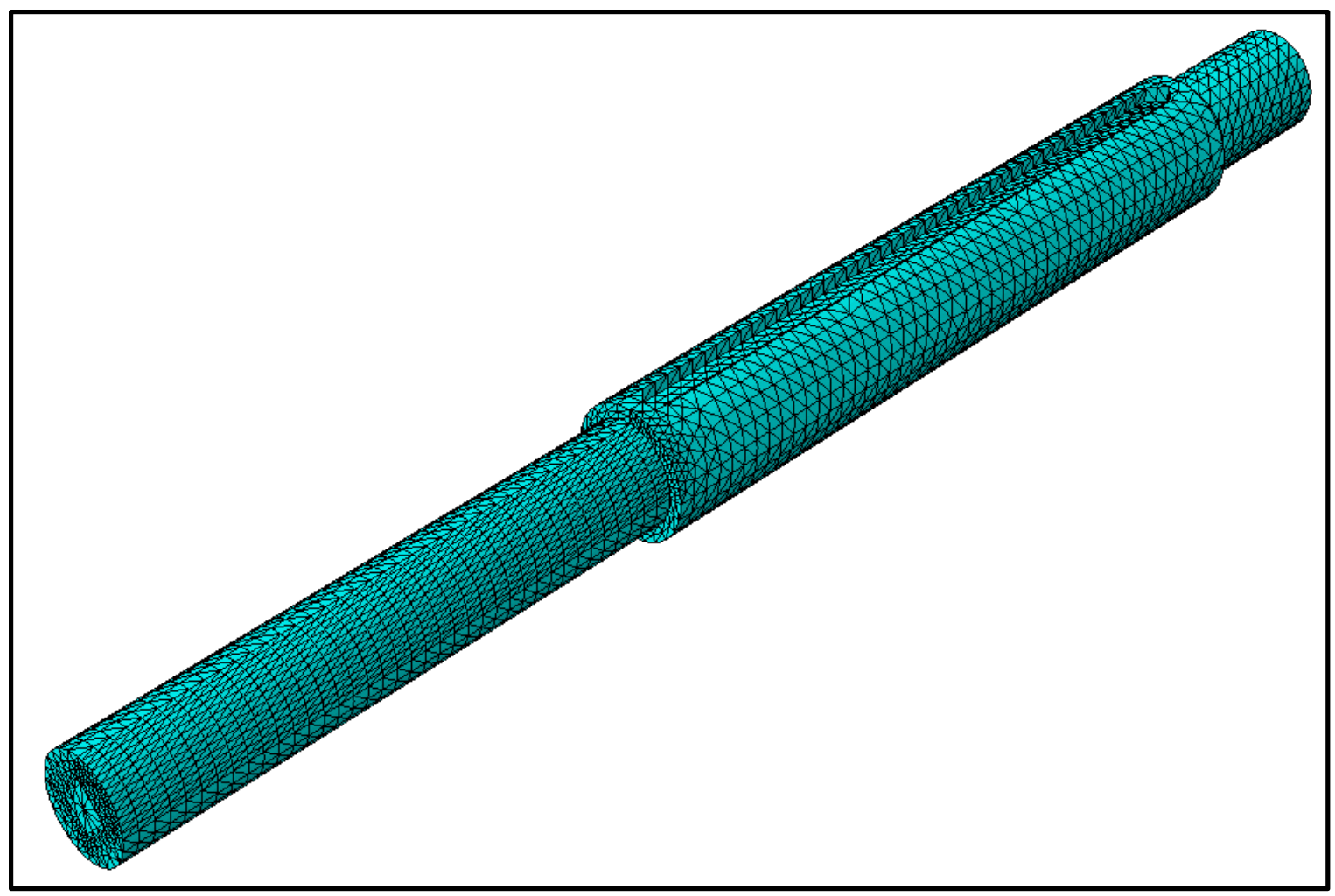

Figure 26. Input shaft mesh, 0.125 inch quadratic tetrahedral elements.

Spherical dummy parts with a dummy material were created in the same manner as the single-stage model and each dummy part was locked to the shafts at each bearing location. Next all six bearings were created with the Adams bearing module. As mentioned previously the bearings in the actual gearbox are $3 / 4$ " bore ER-10K bearings. The bearing module in Adams does not have the exact bearing type and size as the actual gearbox so a similar bearing was sought out. In order to reduce the scope of bearings to compare, the SKF brand was chosen. The SKF 6004-2Z bearing, Figure 27, is similar to the ER-10K. It has eight rolling elements that are 0.26925 inches in diameter and a ball pitch diameter of 1.22071 inches [23]. The main difference between the SKF $6002-2 Z$ and the ER-10K is that the SKF bearing does not have an insert designed for a set screw locking it to the shaft. 


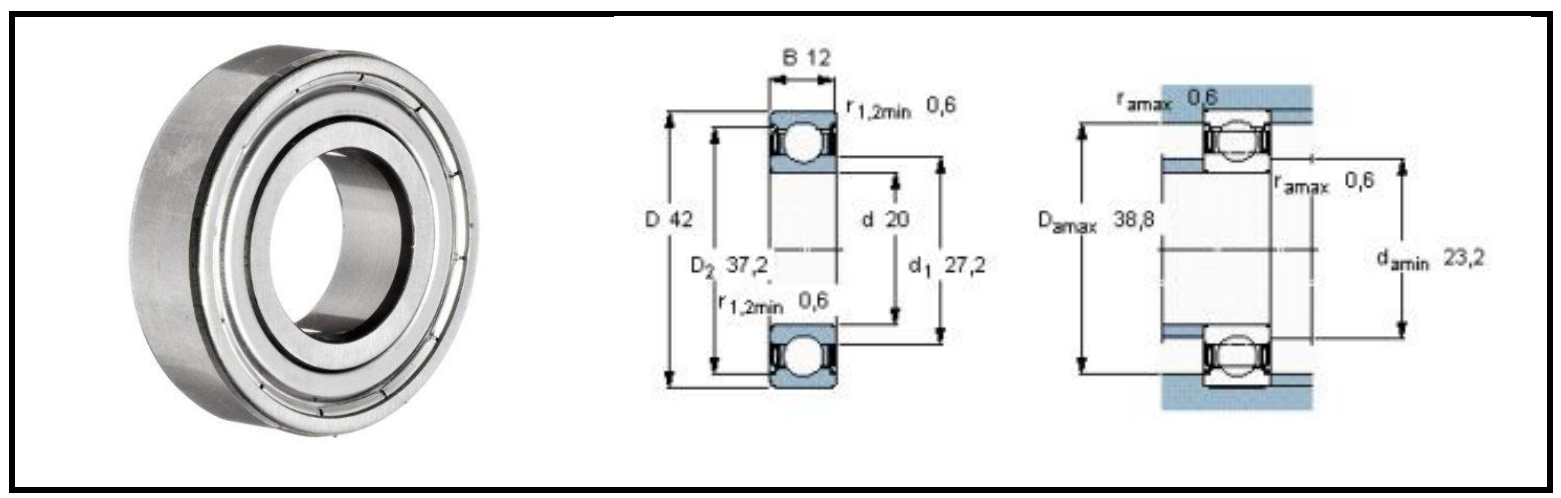

Figure 27.SKF 6004-2Z bearing used for the two-stage gearbox [13].

The simulation time for the two-stage gearbox was chosen to be 1.5 seconds because the file is more complicated than the one-stage model and a lower simulation time leads to a shorter computation time. With a 0.0001 second time step the model took approximately 3 hours to run with four processors utilized. Before the simulation was run a model verification analysis was done to ensure no redundant constraints were present. 


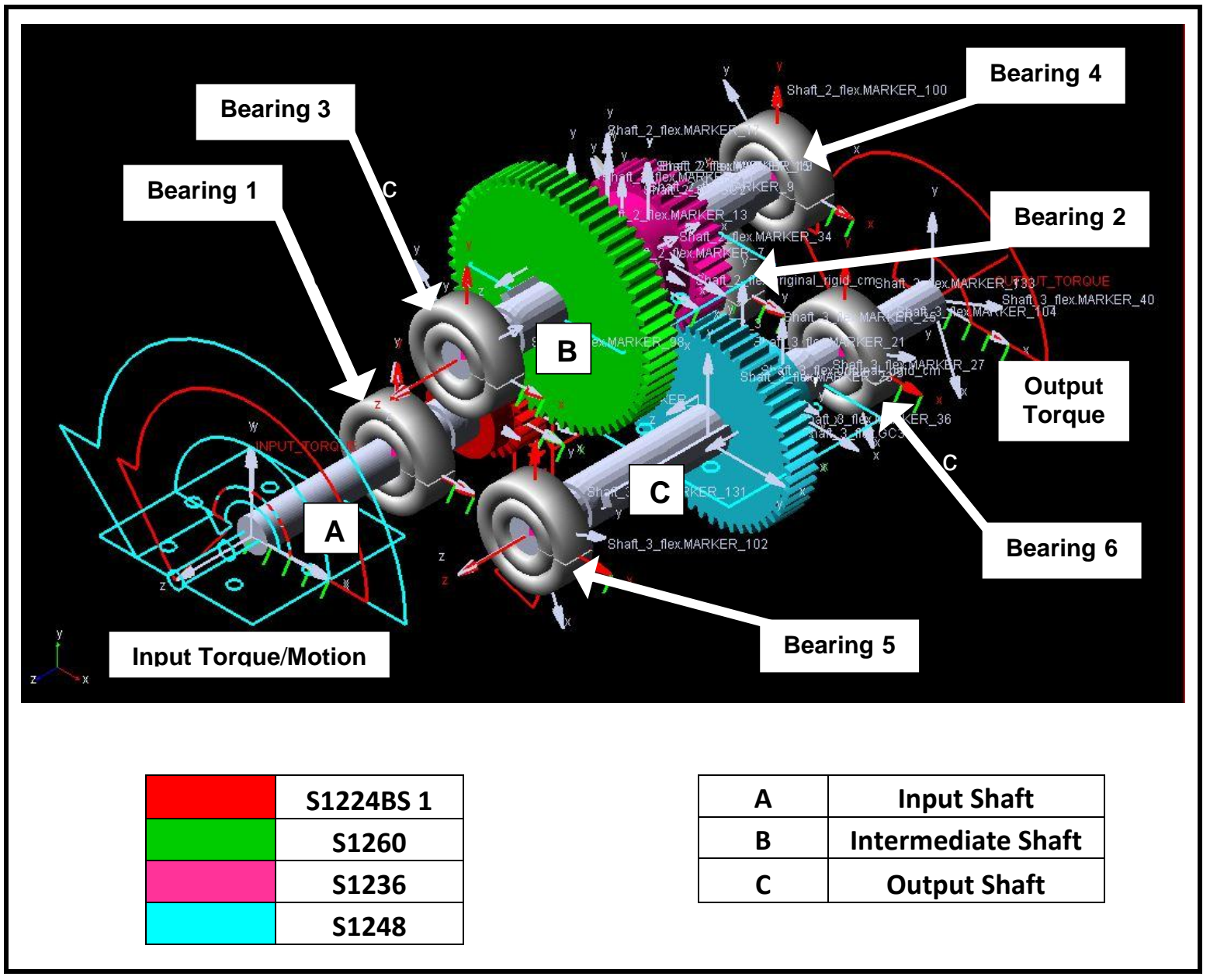

Figure 28. Two-stage dynamic gearbox model with flexible shafts and bearings.

\subsubsection{SPEED AND TORQUE VERIFICATION}

To ensure the completed two-stage gearbox model functioned properly, shaft angular velocities were compared to theoretical values. The input speed was set to reach a maximum angular velocity of $1020 \mathrm{rpm}$. The theoretical angular velocity of the intermediate shaft and the output shaft should be $408 \mathrm{rpm}$ and $306 \mathrm{rpm}$ respectively. Figure 29 verifies the angular velocities determined from the dynamic simulation match theoretical when steady-state operation is reached. The theoretical steady-state input torque and output torque should approximately be $64.7 \mathrm{lbf}$-in and $203.8 \mathrm{lbf}-\mathrm{in}$ respectively. These values match the torques derived from the model, Figure 30. 


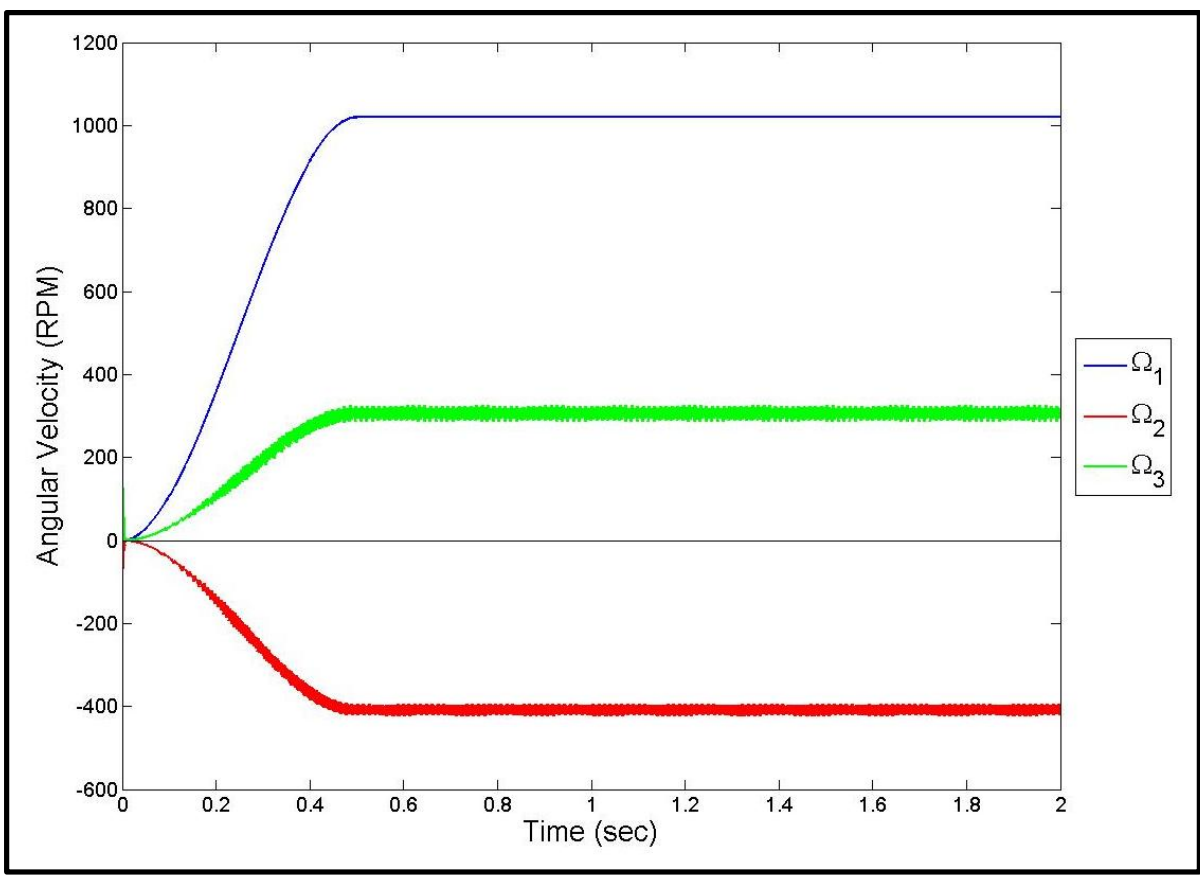

Figure 29. Shaft angular velocities for two-stage gearbox model.

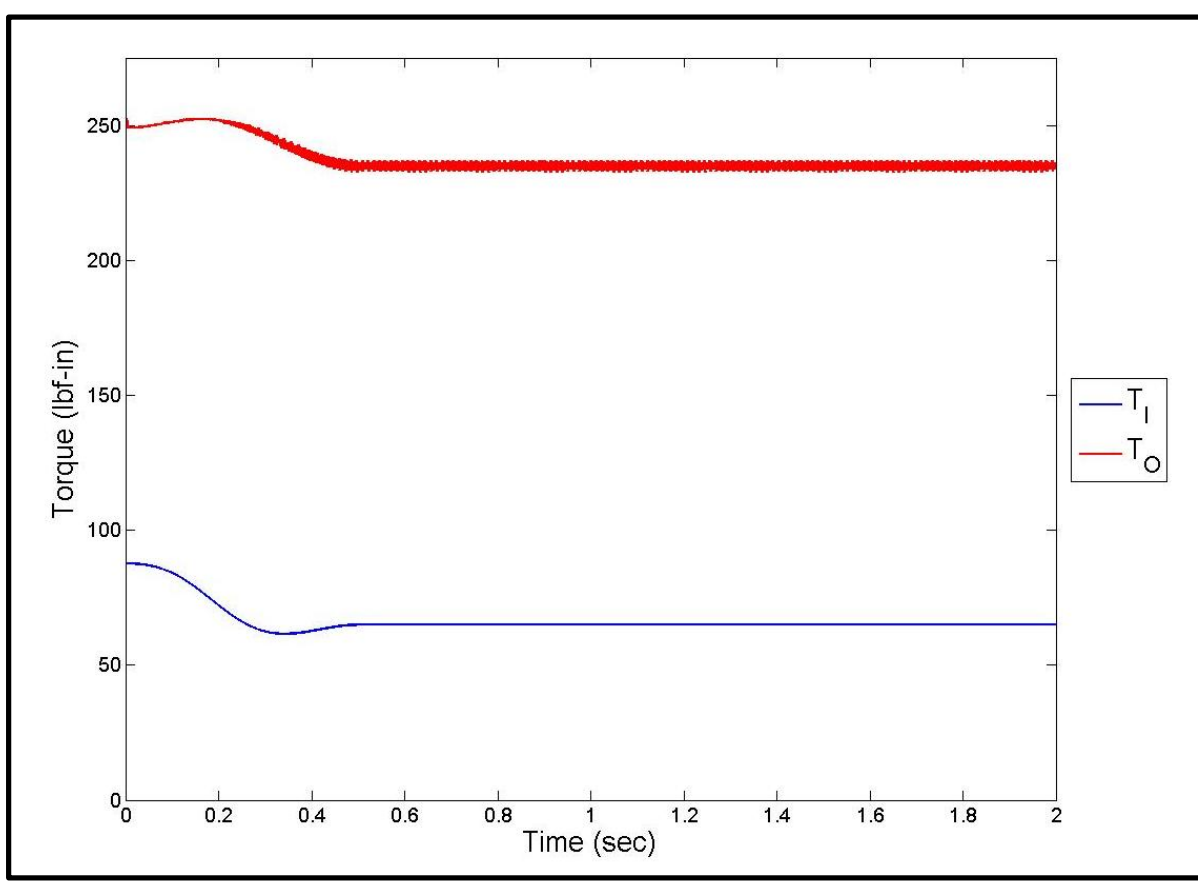

Figure 30. Input and output torque for the two-stage gearbox model. 


\subsubsection{GEAR CONTACT FORCE ANALYSIS AND COMPARISON}

The gear contact force for each meshing gear pair was analyzed in order to verify this method as a possible comparison technique between a healthy and damaged model. With the presence of the two gear stages the fundamental gear mesh frequency of each stage was present in the respective contact force FFT plot, Figure 31 and 33. Table 7 lists the fundamental gear mesh frequency and the first three harmonics for the first and second stage gear mesh frequencies within a 0-2000 Hz frequency range. The fundamental (1X) gear mesh frequency for the first and second stage were $408 \mathrm{~Hz}$ and 244.8 Hz respectively. At each GMF peak, sidebands were also present. These sidebands occur at approximately $6.8 \mathrm{~Hz}$ above and below the first and second stage GMF. For example, the first stage 1X GMF had sidebands present at $401 \mathrm{~Hz}$ and 415 $\mathrm{Hz}$. The $6.8 \mathrm{~Hz}$ sideband could be caused by the speed of the intermediate shaft. The input shaft and pinion were rotating at $1020 \mathrm{rpm}(17 \mathrm{~Hz})$ during steady state operation and this caused the intermediate shaft and first stage output gear to rotate at $408 \mathrm{rpm}$ $(6.8 \mathrm{~Hz})$. Since the intermediate shaft was part of the first and second stage these sidebands were present in the FFT analysis of the first and second stage gear contact force. In the contact force FFT some other peaks were present that were not GMFs or sidebands associated with them. For example a peak was present every $163 \mathrm{~Hz}$. A subsynchronous harmonic of second stage GMF is $163 \mathrm{~Hz}$ and this was determined by computing the gear pair common factor. The common factor between the gear pair on the first stage and the gear pair on the second stage is 12 , Table 8 . A sub-harmonic was determined by the fraction $\mathrm{n} / \mathrm{CF}$, where $\mathrm{CF}$ is the gear pair common factor and $\mathrm{n}$ is any whole integer. The gear contact force FFT analysis for both gear stages proved to be a viable data set to compare a healthy and damage model as there were many peaks to compare and identify if any change occurred. 


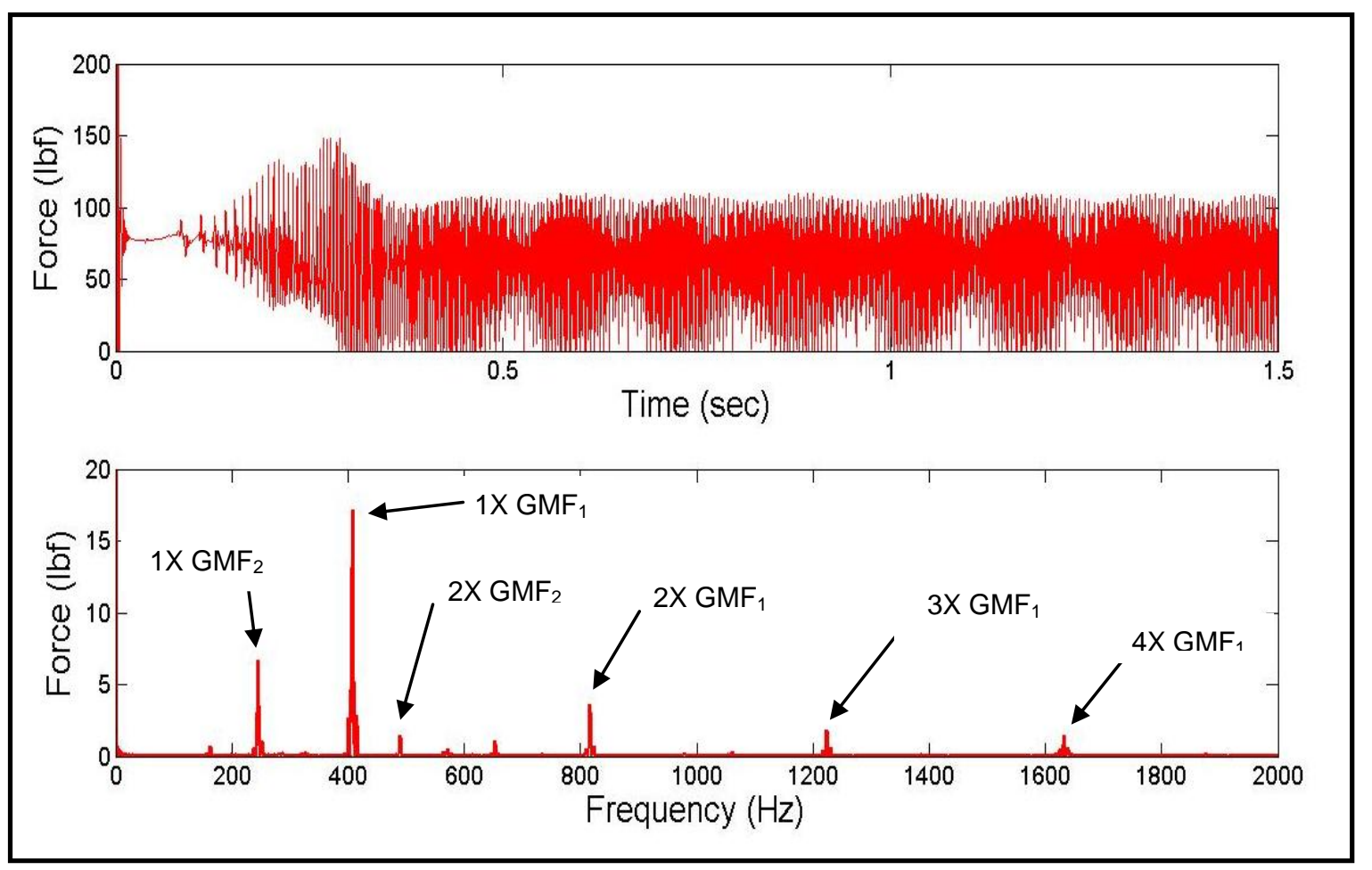

Figure 31. First stage contact force and FFT analysis for gearbox model.

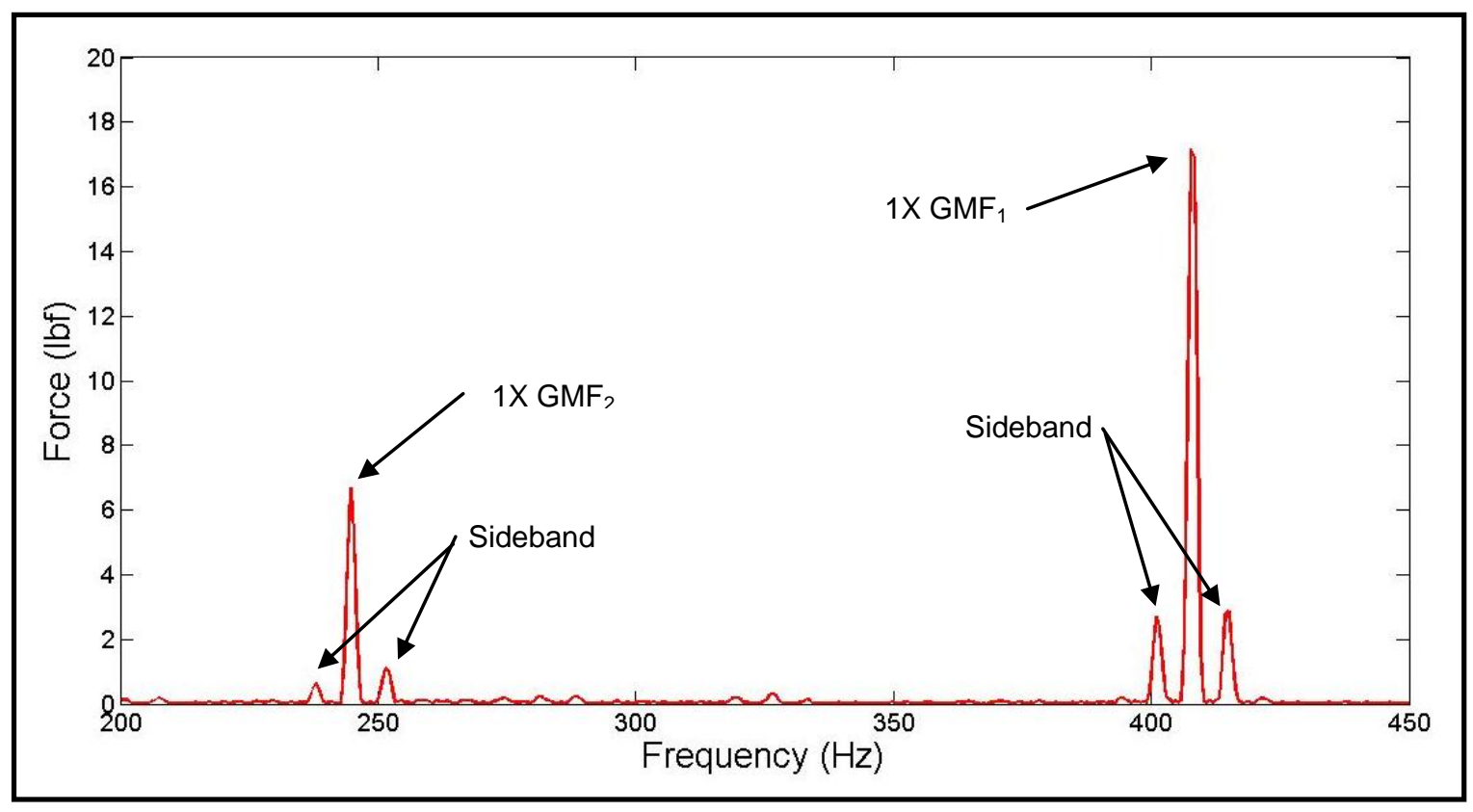

Figure 32. First and second stage GMF of first stage contact force analysis. 

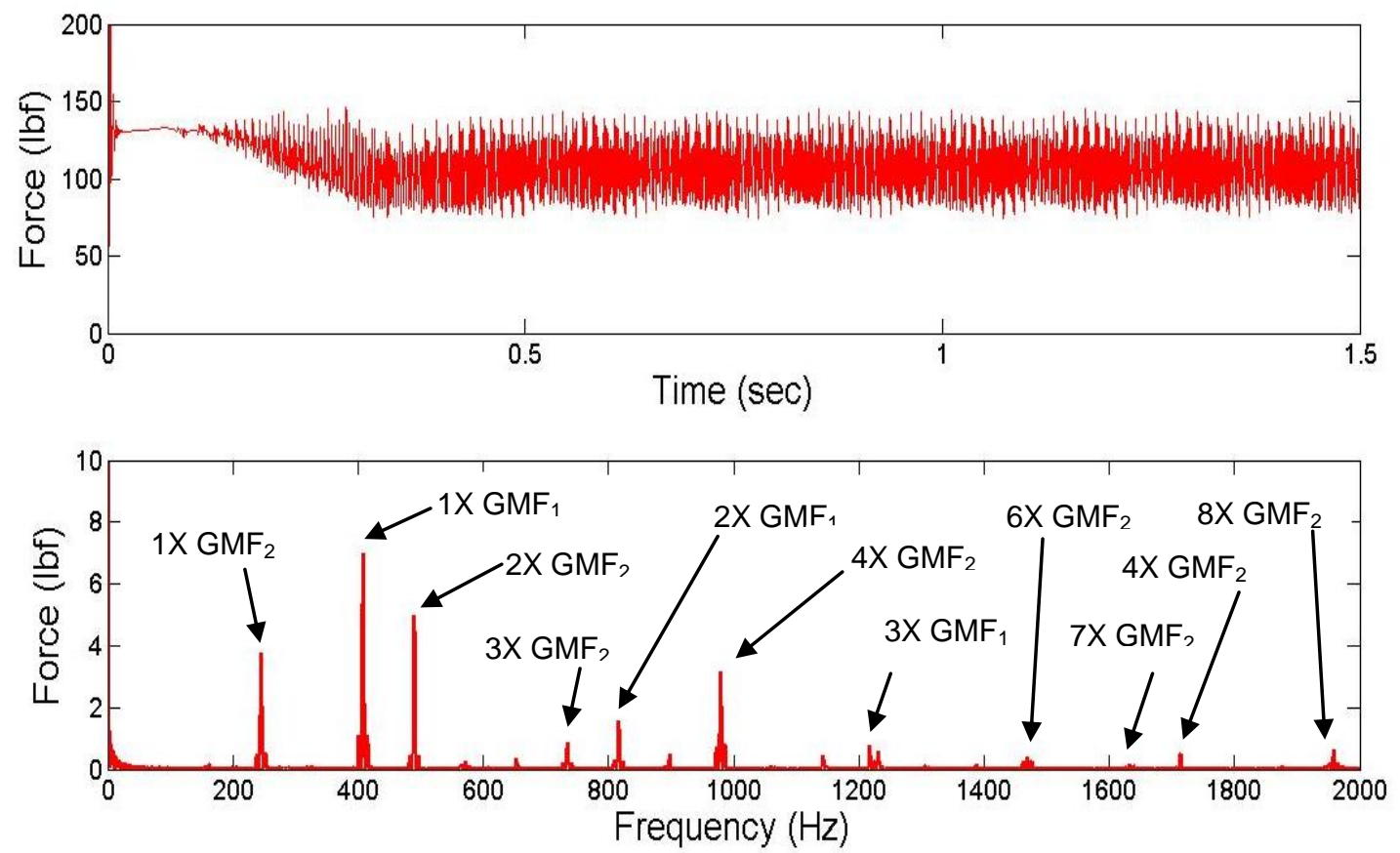

Figure 33. Second stage contact force and FFT analysis for gearbox model.

Table 7. Gear mesh frequency harmonics for two-stage gearbox simulation.

\begin{tabular}{|c|c|c|}
\cline { 2 - 3 } \multicolumn{1}{c|}{} & \multicolumn{2}{c|}{ Gear Mesh Frequency (Hz) } \\
\cline { 2 - 3 } \multicolumn{1}{c|}{} & First Stage & Second Stage \\
\hline $\mathbf{1 X}$ & 408 & 244.8 \\
\hline $\mathbf{2 x}$ & 816 & 489.6 \\
\hline $\mathbf{3 X}$ & 1224 & 734.4 \\
\hline $\mathbf{4 X}$ & 1632 & 979.2 \\
\hline $\mathbf{5 X}$ & - & 1224 \\
\hline $\mathbf{6 X}$ & - & 1468.8 \\
\hline $\mathbf{7 X}$ & - & 1713.6 \\
\hline $\mathbf{8 X}$ & - & 1958.4 \\
\hline
\end{tabular}

Table 8. Common factor for sub and super-harmonic gear mesh frequencies.

\begin{tabular}{|c|c|c|c|c|c|}
\hline \multirow{2}{*}{ Stage } & Gear & $\begin{array}{c}\text { Number } \\
\text { of Teeth }\end{array}$ & Factor & $\begin{array}{c}\text { Common } \\
\text { Factor }\end{array}$ & $\begin{array}{c}\text { Uncommon } \\
\text { Factor }\end{array}$ \\
\hline \multirow{2}{*}{1} & S1224BS 1 & 24 & $2 \times 2 \times 2 \times 3$ & \multirow{2}{*}{12} & 2 \\
\cline { 2 - 4 } & S1260 & 60 & $2 \times 2 \times 3 \times 5$ & & 5 \\
\hline \multirow{2}{*}{2} & S1236 & 36 & $2 \times 2 \times 3 \times 3$ & \multirow{2}{*}{12} & 3 \\
\cline { 2 - 6 } & S1248 & 48 & $2 \times 2 \times 3 \times 4$ & \\
\hline
\end{tabular}




\subsubsection{BEARING ACCELERATION ANALYSIS}

On the actual experimental gearbox an accelerometer or other type of acoustic emission sensor shall be placed on the bearing housing to collect data on the overall health of the gearbox. Due to this, the most relevant data to analyze from the two-stage gearbox simulation was the bearing accelerations. Figure 34 displays the magnitude of the translational bearing acceleration experienced by Bearing 1 versus time. Since the damaged system will contain a fatigue crack on the pinion and Bearing 1 was the closest bearing to the pinion, the analysis of Bearing 1 shall be the main comparison between the healthy and damaged system. The translational acceleration magnitude experienced by the bearing has a sinusoidal waveform and the frequency of the peaks was approximately $6.8 \mathrm{~Hz}$. It is a safe assumption to say that the bearing force was modulated by the speed of the intermediate shaft. The bearing acceleration and FFT plots of the remaining five bearings are in Appendix $\mathrm{C}$. The other plots show the same phenomenon as Bearing 1.

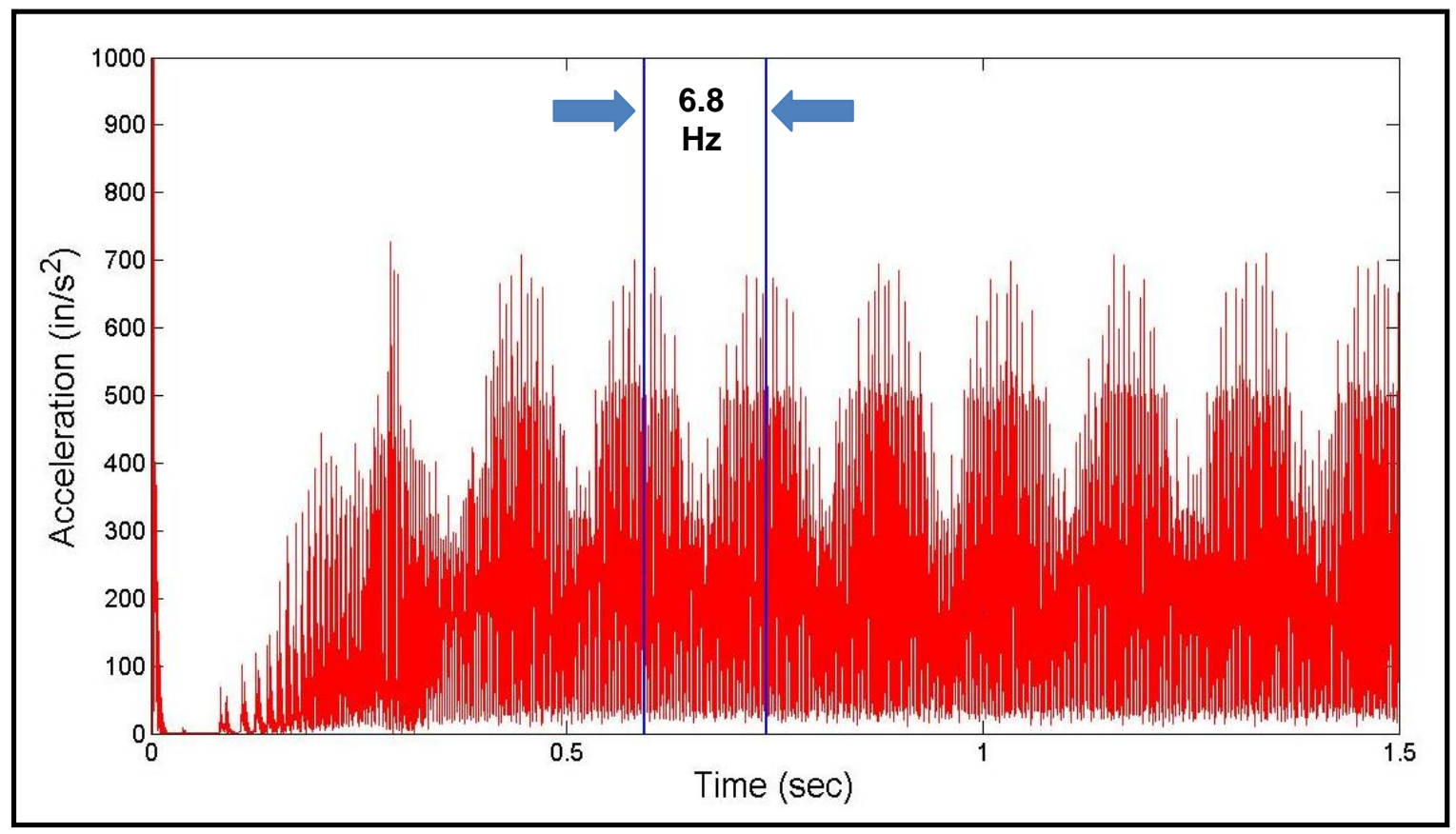

Figure 34. Bearing 1 magnitude acceleration and frequency between peaks. 
Bearing 1 had the highest acceleration magnitude of all six bearings in the gearbox. During steady-state operation, the peak acceleration was around $709 \mathrm{in} / \mathrm{s}$. Bearing 1 was closest to the motor input and the pinion which drives the entire gearbox. Bearing 2 experiences the second highest acceleration with a steady-state peak of $182 \mathrm{in} / \mathrm{s}$. This value was significantly lower than the Bearing 1 acceleration magnitude. Bearing 3 had the higher acceleration magnitude on the intermediate shaft and had a similar peak to Bearing 2 at $196 \mathrm{in} / \mathrm{s}$. The acceleration magnitude at Bearing 4 significantly drops once again and had a peak acceleration of $16 \mathrm{in} / \mathrm{s}$. The final two bearings on the output shaft had the lowest acceleration magnitudes. Bearing 5 and 6 had an acceleration magnitude of $1.7 \mathrm{in} / \mathrm{s}$ and $2.3 \mathrm{in} / \mathrm{s}$ respectively. Similar to the gear contact force an FFT analysis of the translational acceleration magnitude was plotted. Peaks were present at the fundamental GMF and harmonics of the first and second stage gear mesh frequencies. Sub and super-harmonics of the second-stage GMF were present as well. For example in Figure 35, the sub-synchronous peaks of $81.63 \mathrm{~Hz}$ and $163.3 \mathrm{~Hz}$ and the supersynchronous peak of $326.6 \mathrm{~Hz}$ are present. Each acceleration peak on the FFT plot also has multiple sidebands that differ by approximately $6.8 \mathrm{~Hz}$ to the left and right, Figure 36 . The peak that does not have any sidebands was the peak at $6.8 \mathrm{~Hz}$, the intermediate shaft frequency. 
Table 9. Sub and super-synchronous gear mesh frequencies.

\begin{tabular}{|c|c|c|c|c|c|}
\hline \multicolumn{3}{|c|}{ Sub-Synchronous } & \multicolumn{3}{c|}{ Super-Synchronous } \\
\hline $\mathbf{n}$ & GMF 1 & GMF2 & $\mathbf{n}$ & GMF 1 & GMF 2 \\
\hline 1 & 34 & 20.4 & 13 & 442 & 265.2 \\
\hline 2 & 68 & 40.8 & 14 & 476 & 285.6 \\
\hline 3 & 102 & 61.2 & 15 & 510 & 306 \\
\hline 4 & 136 & 81.6 & 16 & 544 & 326.4 \\
\hline 5 & 170 & 102 & 17 & 578 & 346.8 \\
\hline 6 & 204 & 122.4 & 18 & 612 & 367.2 \\
\hline 7 & 238 & 142.8 & 19 & 646 & 387.6 \\
\hline 8 & 272 & 163.2 & 20 & 680 & 408 \\
\hline 9 & 306 & 183.6 & 21 & 714 & 428.4 \\
\hline 10 & 340 & 204 & 22 & 748 & 448.8 \\
\hline 11 & 374 & 224.4 & 23 & 782 & 469.2 \\
\hline
\end{tabular}

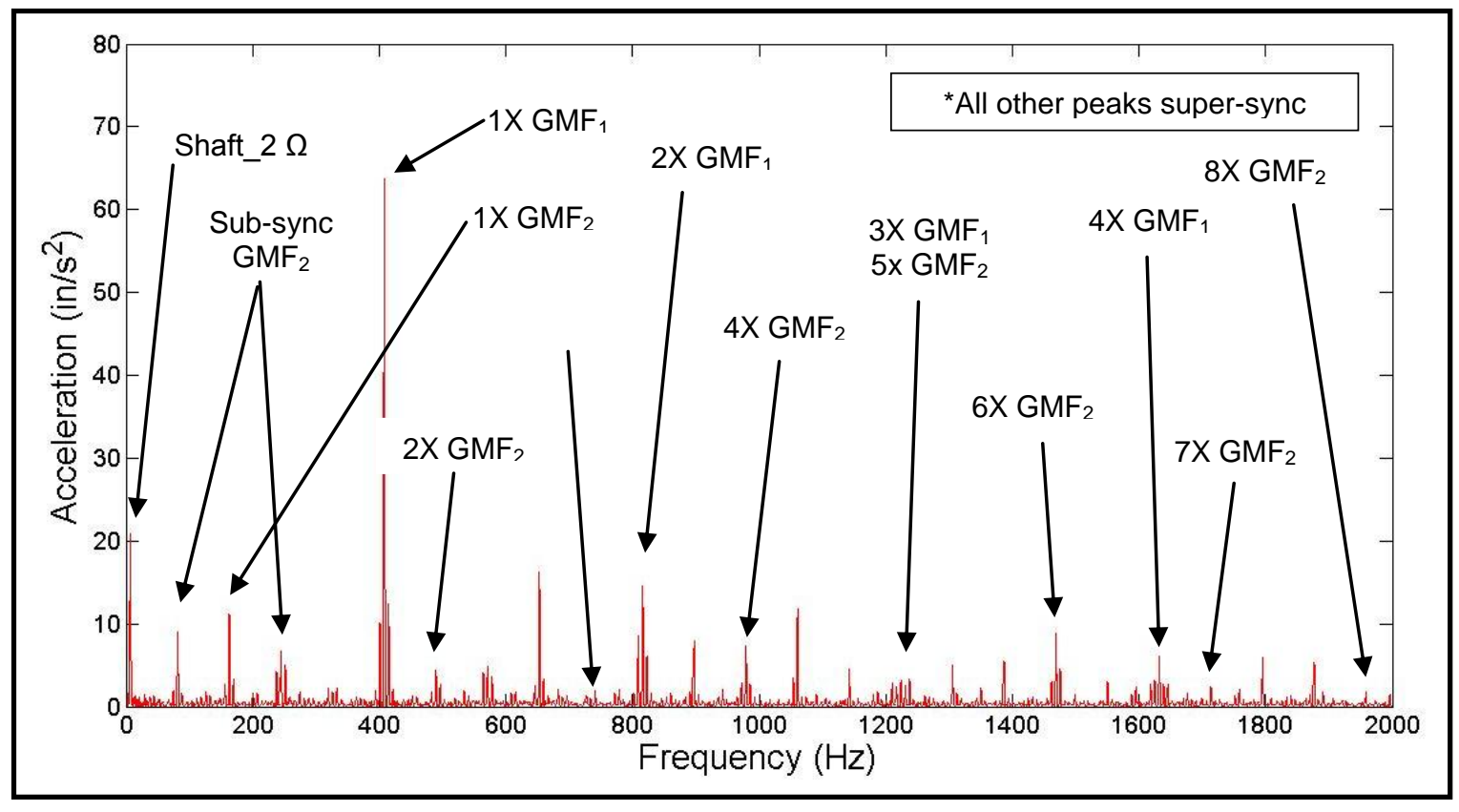

Figure 35. Bearing 1 magnitude acceleration FFT analysis 0-2000 Hz. 


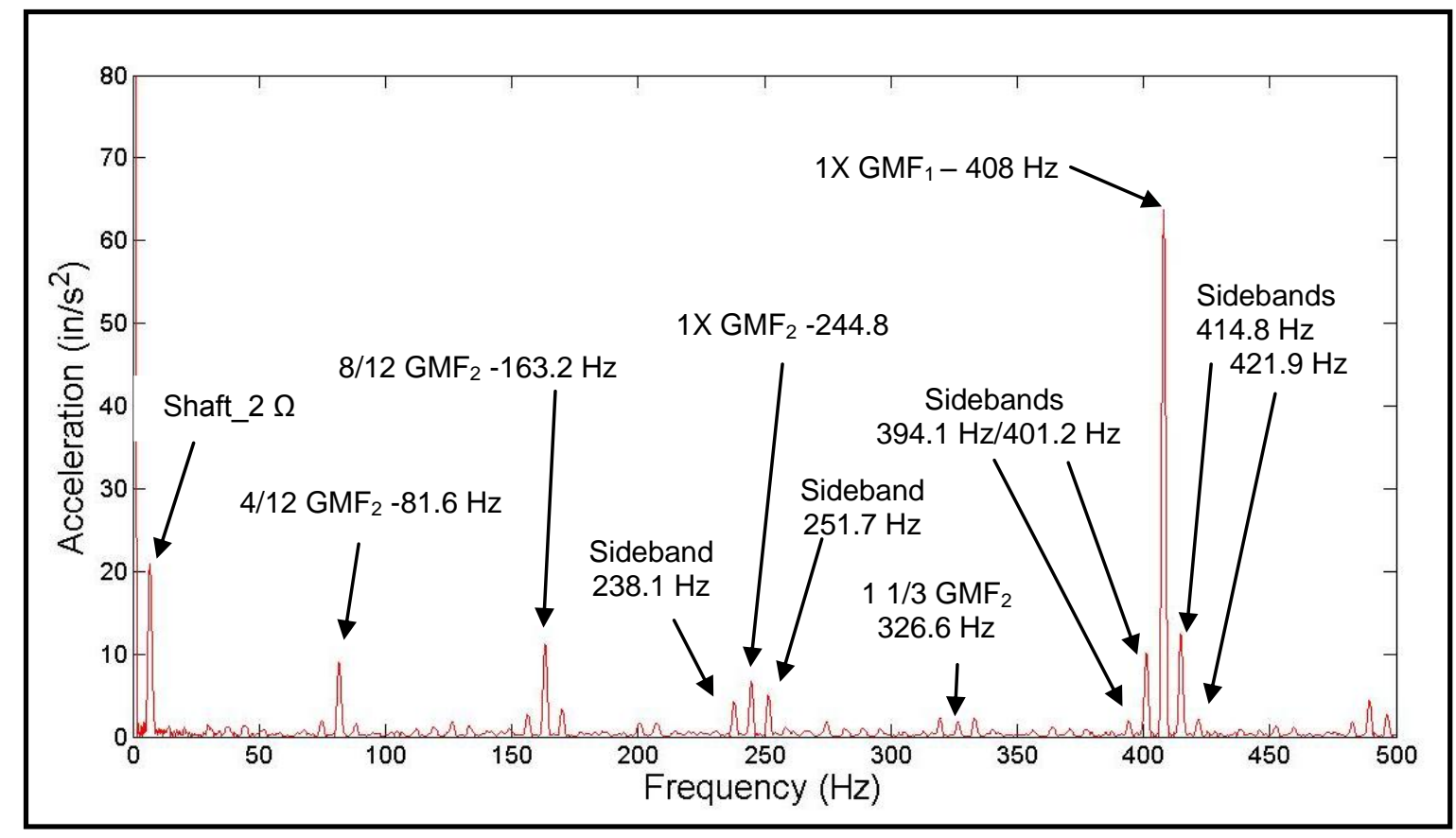

Figure 36. Bearing 1 magnitude acceleration FFT analysis 0-500 Hz.

The bearing force magnitude experienced by all six bearings in the healthy gearbox simulation was analyzed in addition to the bearing acceleration, Figure 37 . Just as in the acceleration analysis, Bearing 1 has the highest bearing force. This result was as expected since force equals mass times acceleration. Thus the bearing order from the highest force to the lowest force was the same as the bearing acceleration order. The bearing forces had a sinusoidal waveform and Bearing 6 had a very clear representation of this. The frequency between bearing force peaks once steady-state was reached was approximately $6.8 \mathrm{~Hz}$. It was concluded that the bearing translation acceleration data would be a very useful comparison tool between a healthy and damaged gearbox model. 


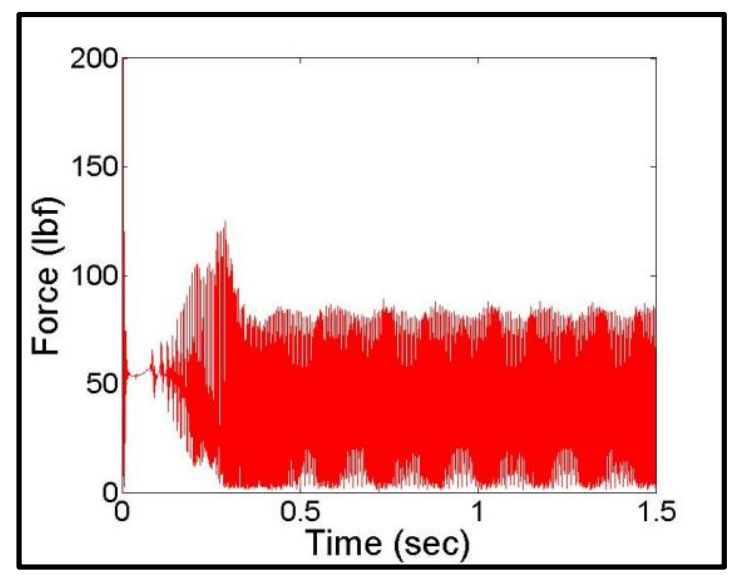

(a) Bearing 1

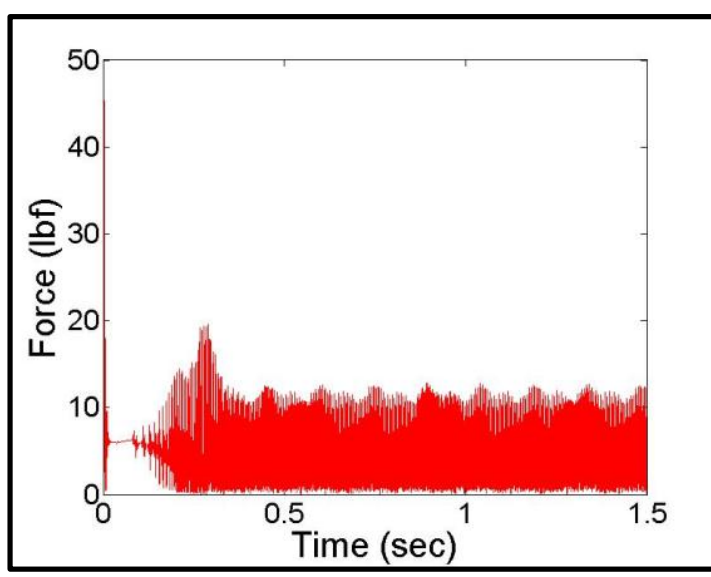

(c) Bearing 3

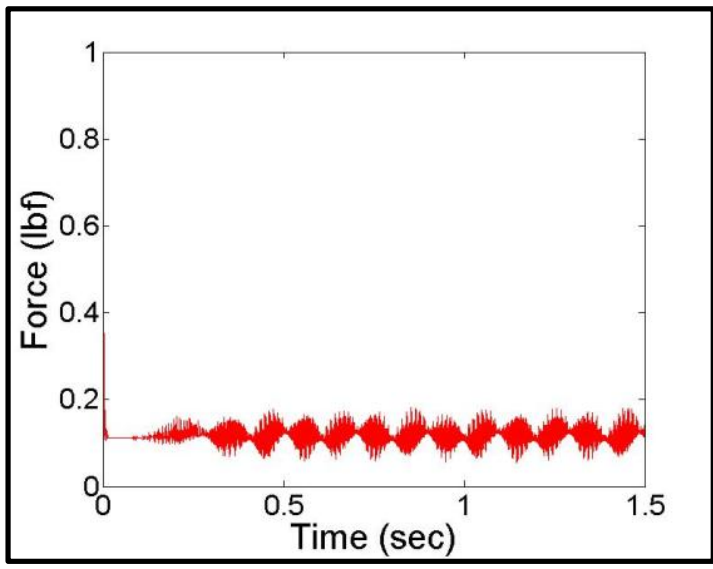

(e) Bearing 5

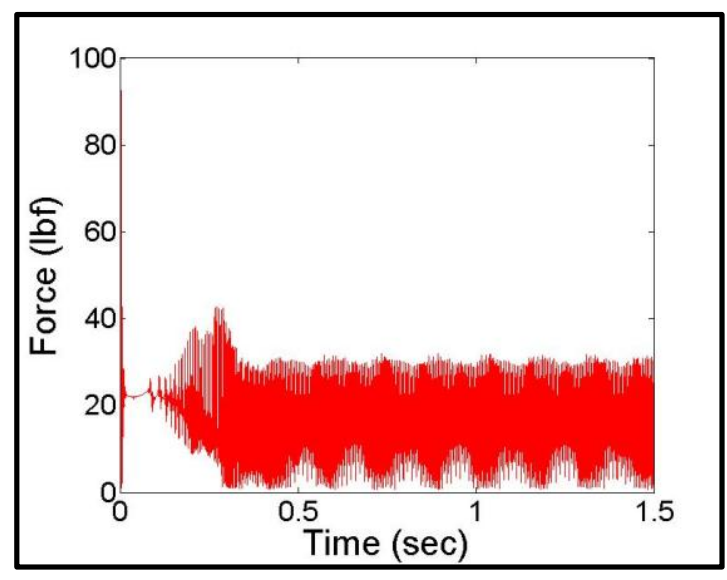

(b) Bearing 2

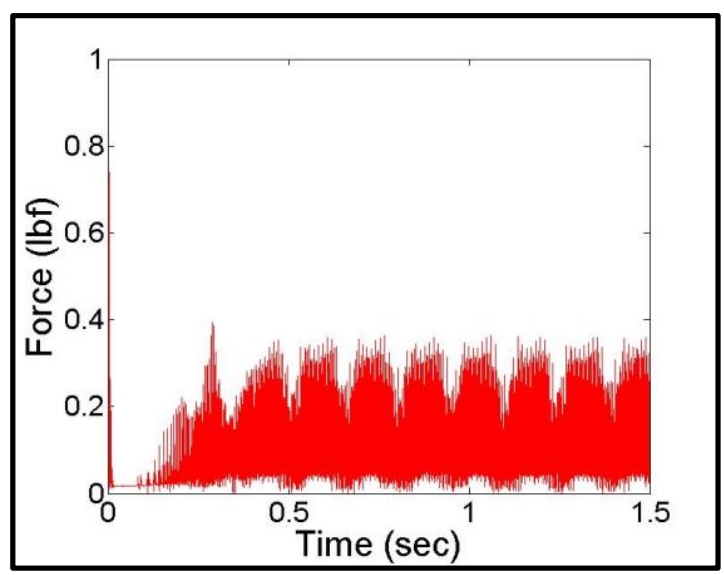

(d) Bearing 4

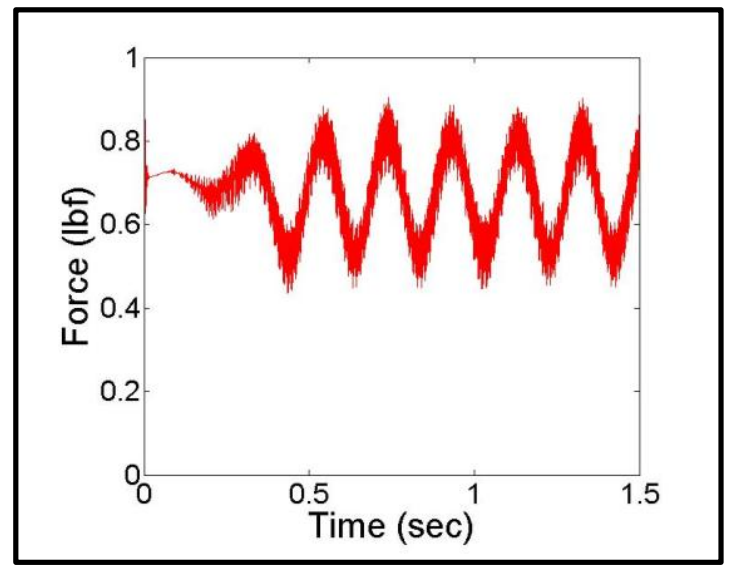

(f) Bearing 6

Figure 37. Magnitude of bearing forces from healthy gearbox simulation. 


\subsubsection{GEARBOX SIMULATION LIMITATIONS}

One frequency missing from the gearbox simulation bearing acceleration FFT plot is the ball pass frequency of the bearing in the system. In the model the ground was selected as the bearing housing, thus the outer race of the bearing is fixed leaving the inner race to rotate. A possible frequency that could show up in the FFT plot is the inner race ball pass frequency (BPFI). This frequency is computed from Eq (6.1) and it is a function of the inner race speed (s), the pitch diameter $\left(P_{d}\right)$, the ball diameter $\left(B_{d}\right)$, number of rolling elements $\left(\mathrm{N}_{\mathrm{b}}\right)$, and the contact angle $(\phi)$. Since the two-stage gearbox has three rotating shafts, there are three possible inner race ball pass frequencies. For the input shaft, intermediate shaft, and output shaft the calculated ball pass frequencies are $56.91 \mathrm{~Hz}, 22.60 \mathrm{~Hz}$, and $16.95 \mathrm{~Hz}$. Neither of these frequencies or harmonics of the BPFI are evident on any bearing acceleration FFT plot.

$$
B P F I=s\left(\frac{N_{b}}{2}\right)\left(1+\frac{B_{d} \cos (\varnothing)}{P_{d}}\right)
$$




\subsection{TWO-STAGE DAMAGE GEARBOX MODEL AND RESULTS}

The damaged gearbox model was created with fatigue damage as the main focus. A fatigue crack was modeled into the pinion gear (S1224BS 1) on the input shaft, Figure 38. This crack was created in the Solidworks pinion CAD model using a spline sketch on the back face of the gear tooth and the $2 \mathrm{D}$ crack geometry was extrude cut through the entire gear tooth face. The damaged pinion was imported into the damage gearbox model using a parasolid file. In order to directly compare the damaged model to the healthy model the same simulation time and time step was utilized, 1.5 seconds with 0.0001 second time step. This model took approximately 3 hours to compute.

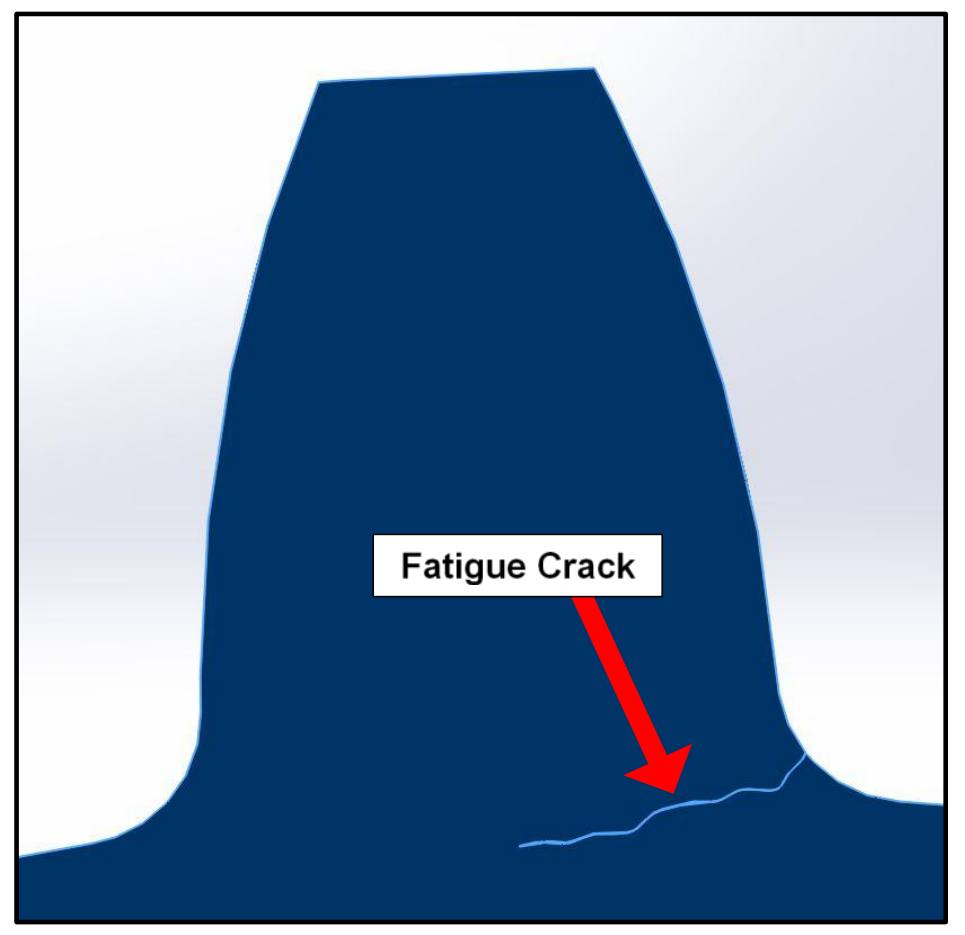

Figure 38. Fatigue crack model of pinion, S1224BS 1. 


\subsubsection{DAMAGED MODEL ANALYSIS}

The gear contact force and bearing accelerations were analyzed from the damaged model. Figure 39 and 40 compare the first and second stage gear contact forces to the healthy model contact forces. The same first and second stage GMFs and sub-synchronous and super-synchronous harmonic peaks were evident on the damaged model gear contact force FFT plots. From direct observation many more sidebands were present on each gear mesh frequency fundamental frequency and harmonics. Overall the first and second stage gear contact force and gear mesh frequency peaks on the FFT plot were of very similar magnitude to the healthy model. The only key difference observed was the increased amount of sidebands. Remember Bearing 1 serves as the bearing for direct comparison between the healthy and damaged model. Just as observed in the gear contact forces the Bearing 1 translational acceleration magnitude had an increased amount of sidebands surrounding each gear mesh frequency peak on the FFT plot, Figure 41 . The Bearing 1 acceleration was of similar magnitude to the healthy model but the accelerations peaks were slightly higher. A key difference was that the Bearing 1 acceleration magnitude peaks occurred every $17 \mathrm{~Hz}$ instead of $6.8 \mathrm{~Hz}$ as in the healthy model, Figure 42 . This $17 \mathrm{~Hz}$ represented the input shaft frequency and this could have been an indication as to which shaft the damage was present. 


\section{HEALTHY MODEL}
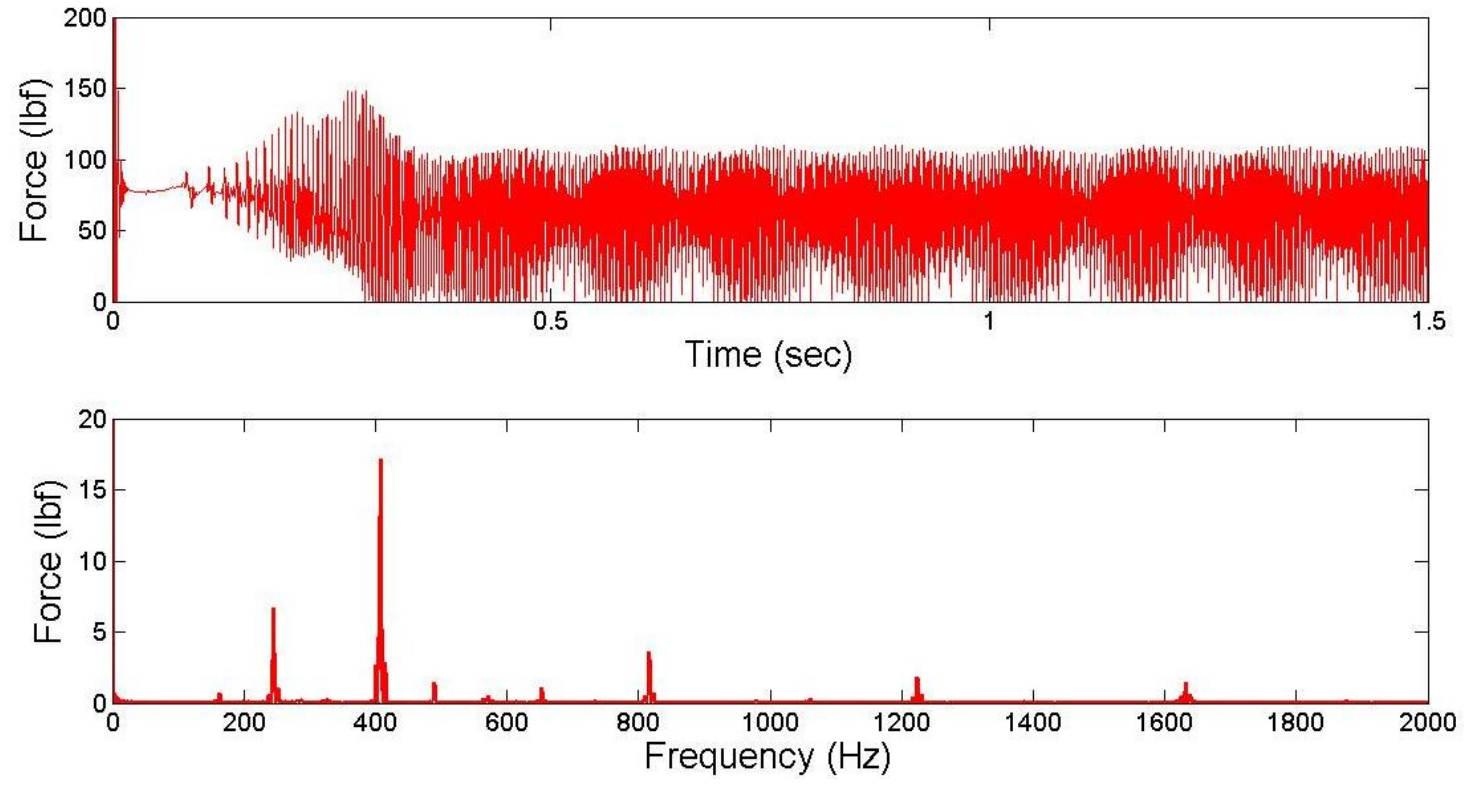

DAMAGED MODEL

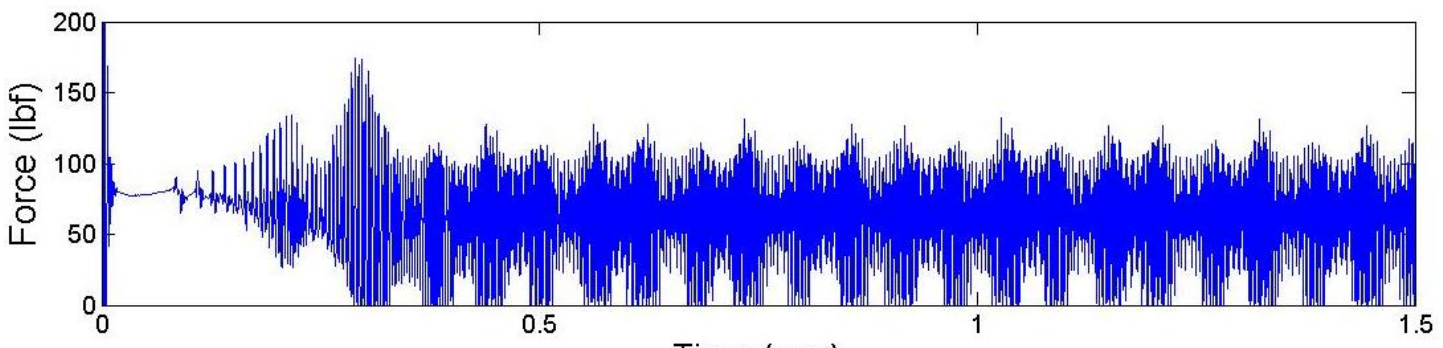

Time (sec)

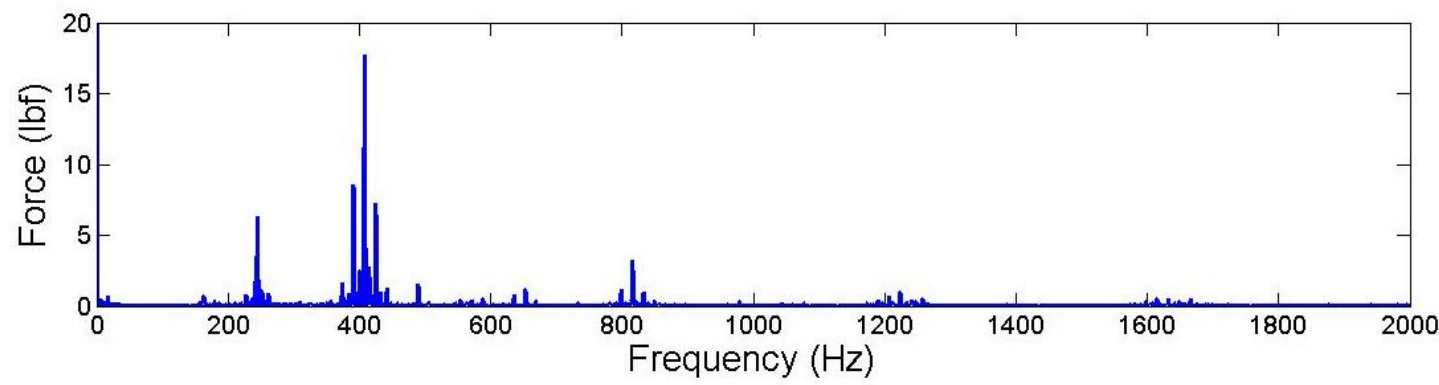

Figure 39. First stage gear contact force comparison. 


\section{HEALTHY MODEL}
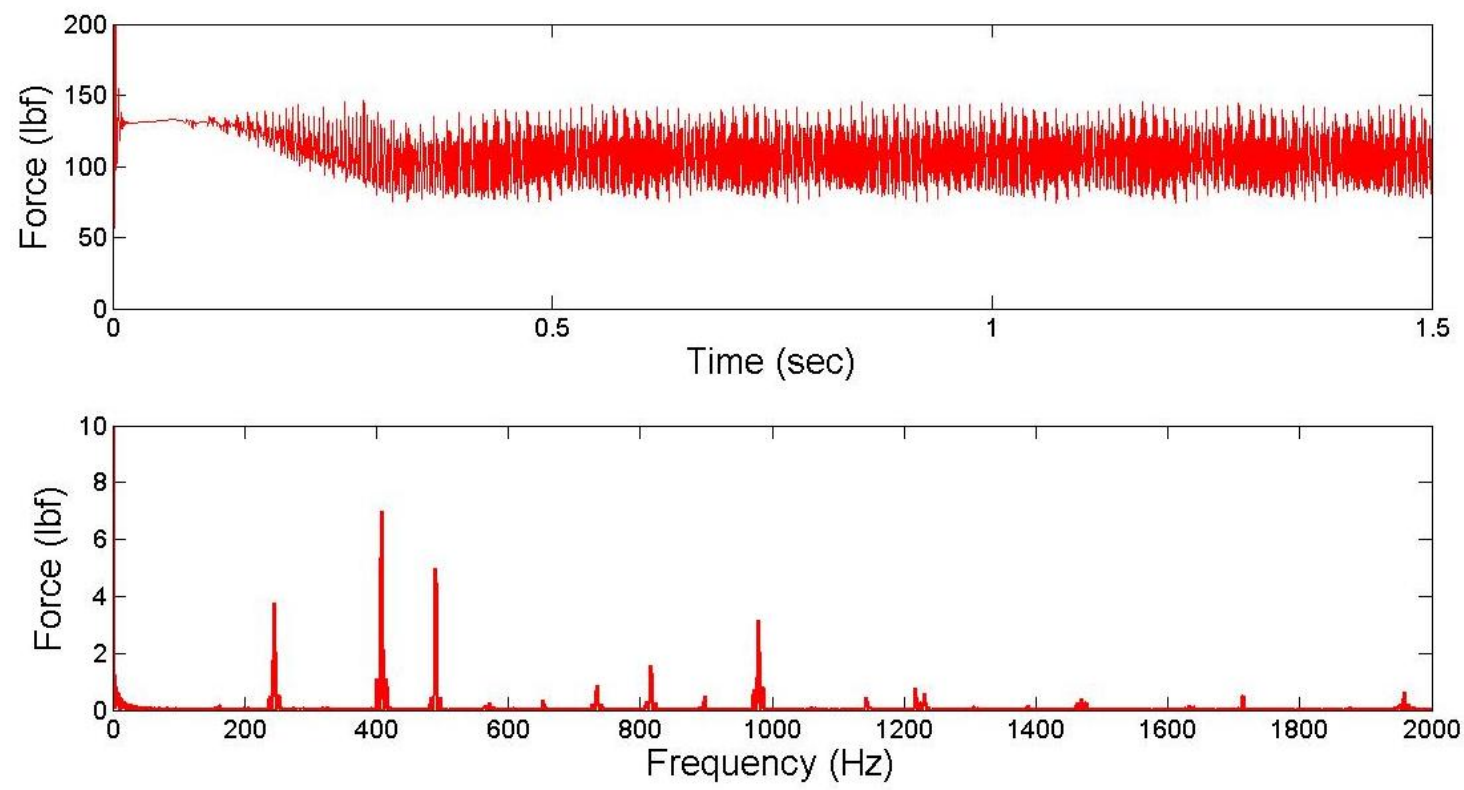

DAMAGED MODEL
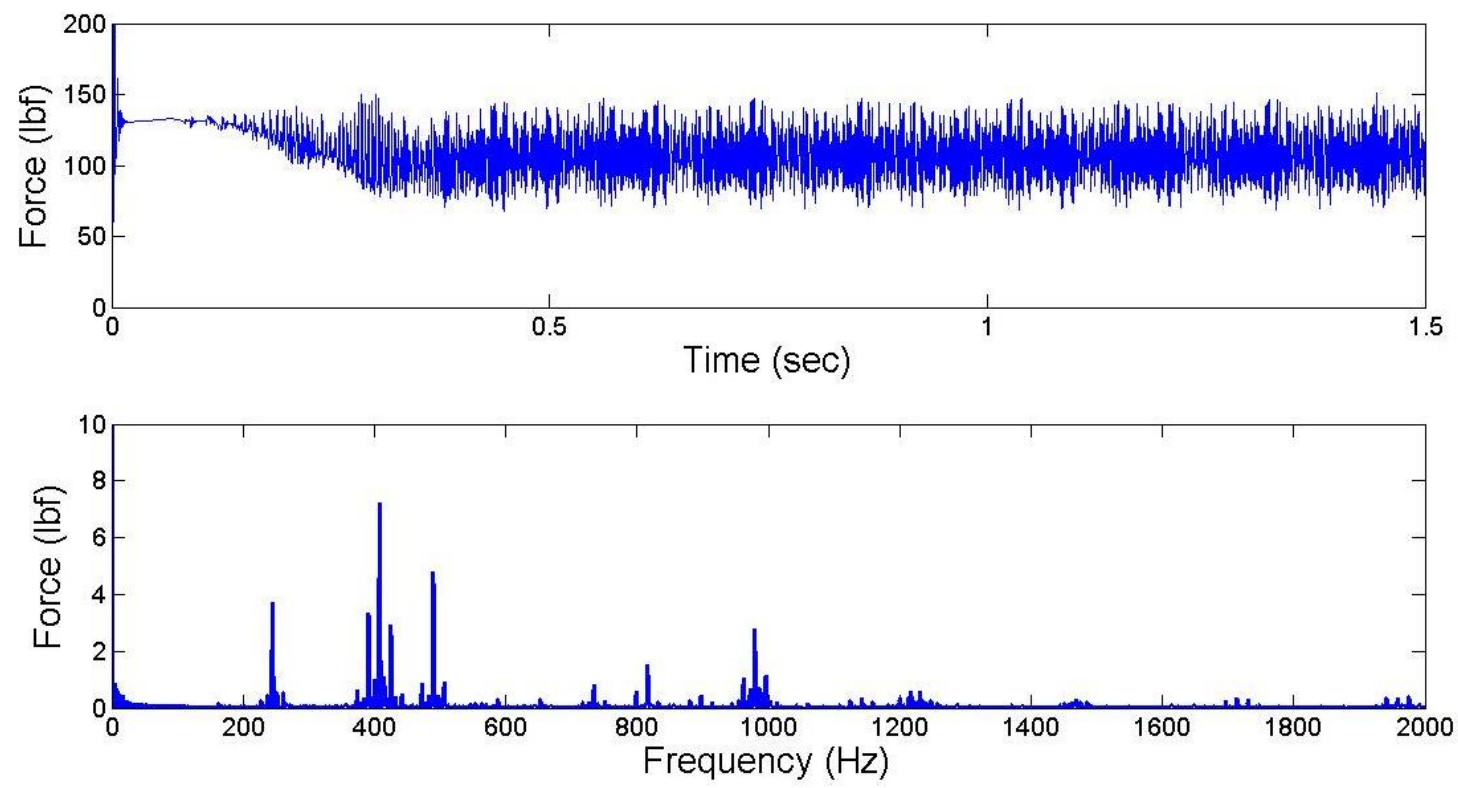

Figure 40. Second stage gear contact force comparison. 


\section{HEALTHY MODEL}

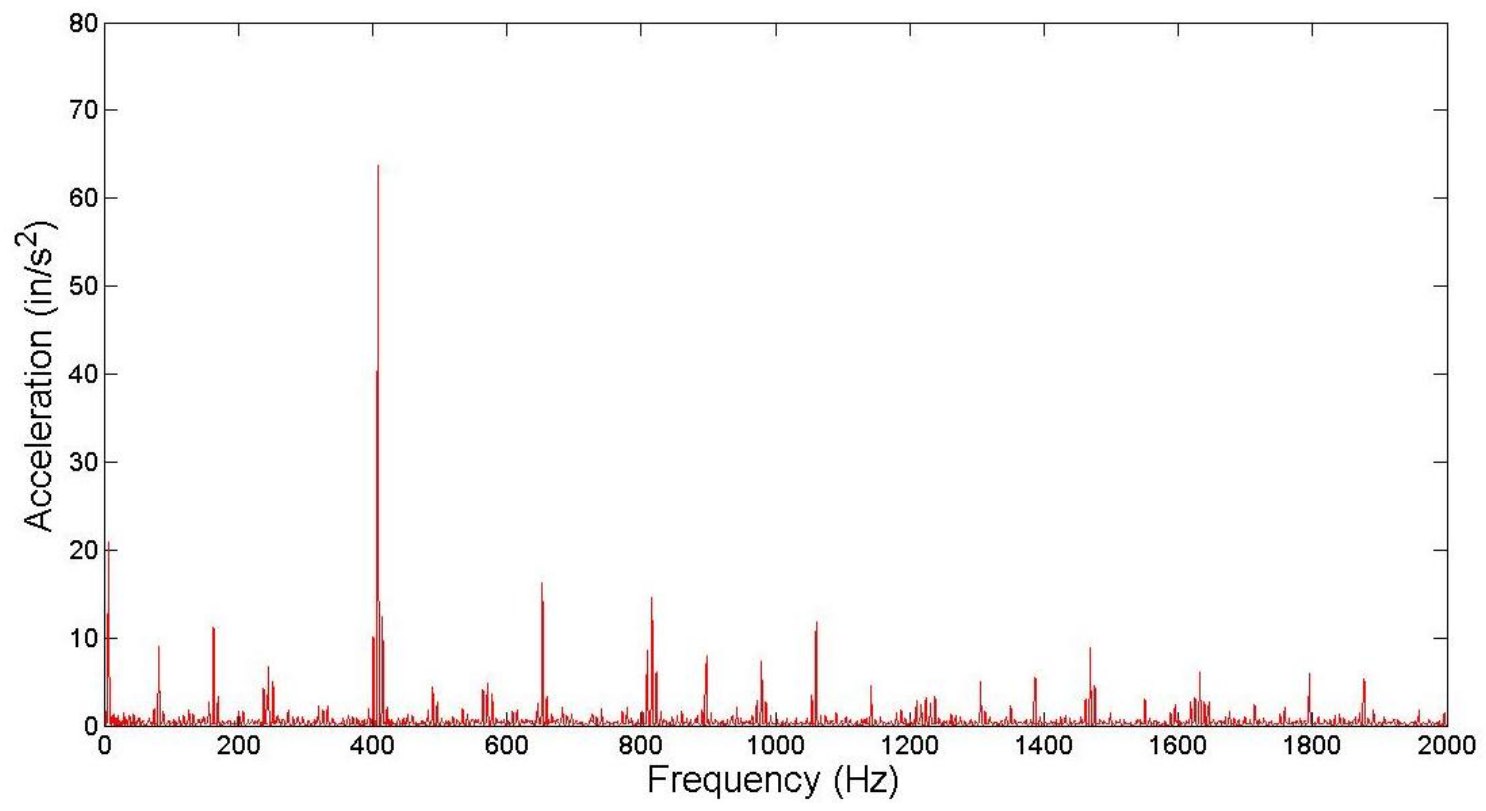

DAMAGED MODEL

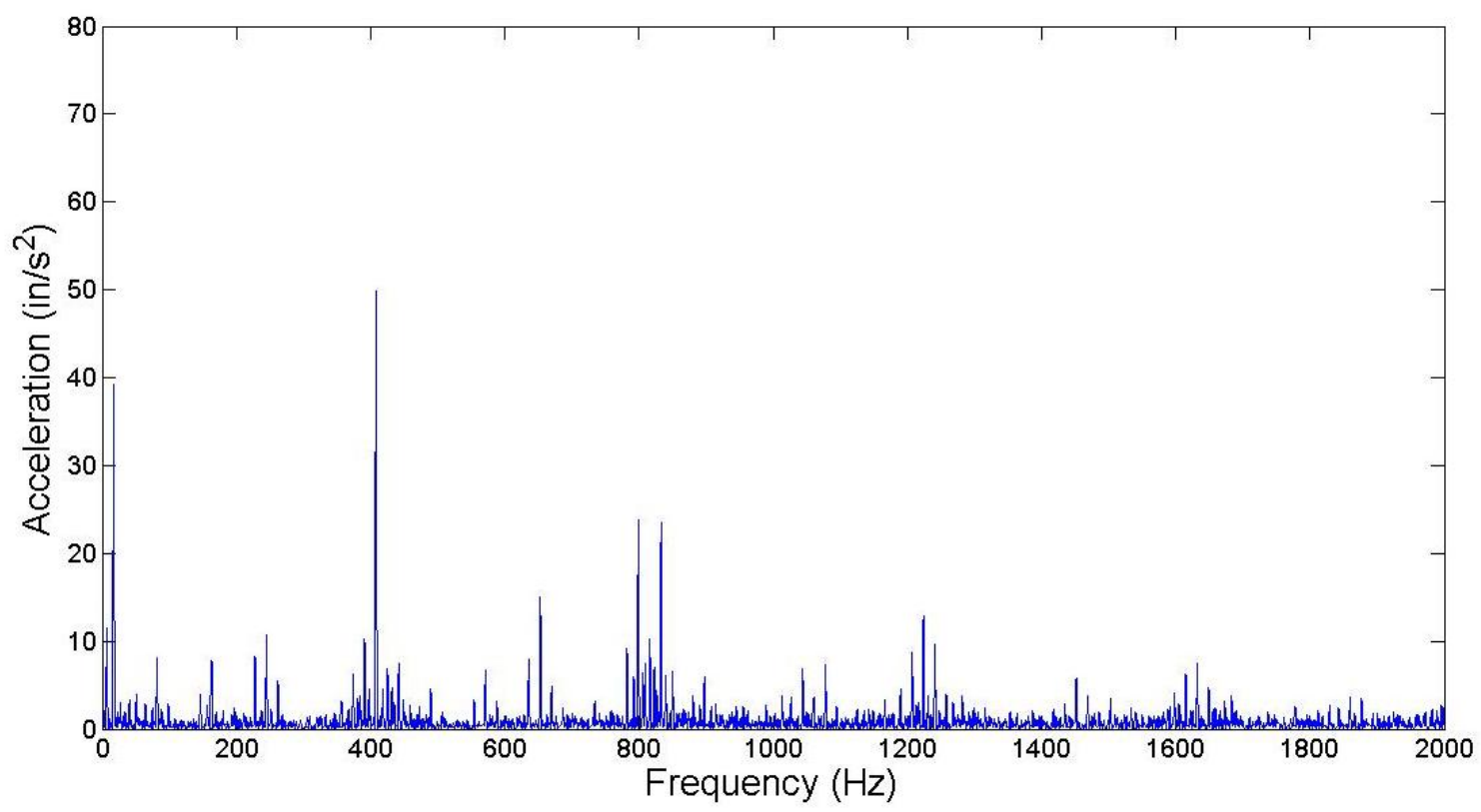

Figure 41. Damaged model Bearing 1 acceleration comparison $0-2000 \mathrm{~Hz}$. 
HEALTHY MODEL

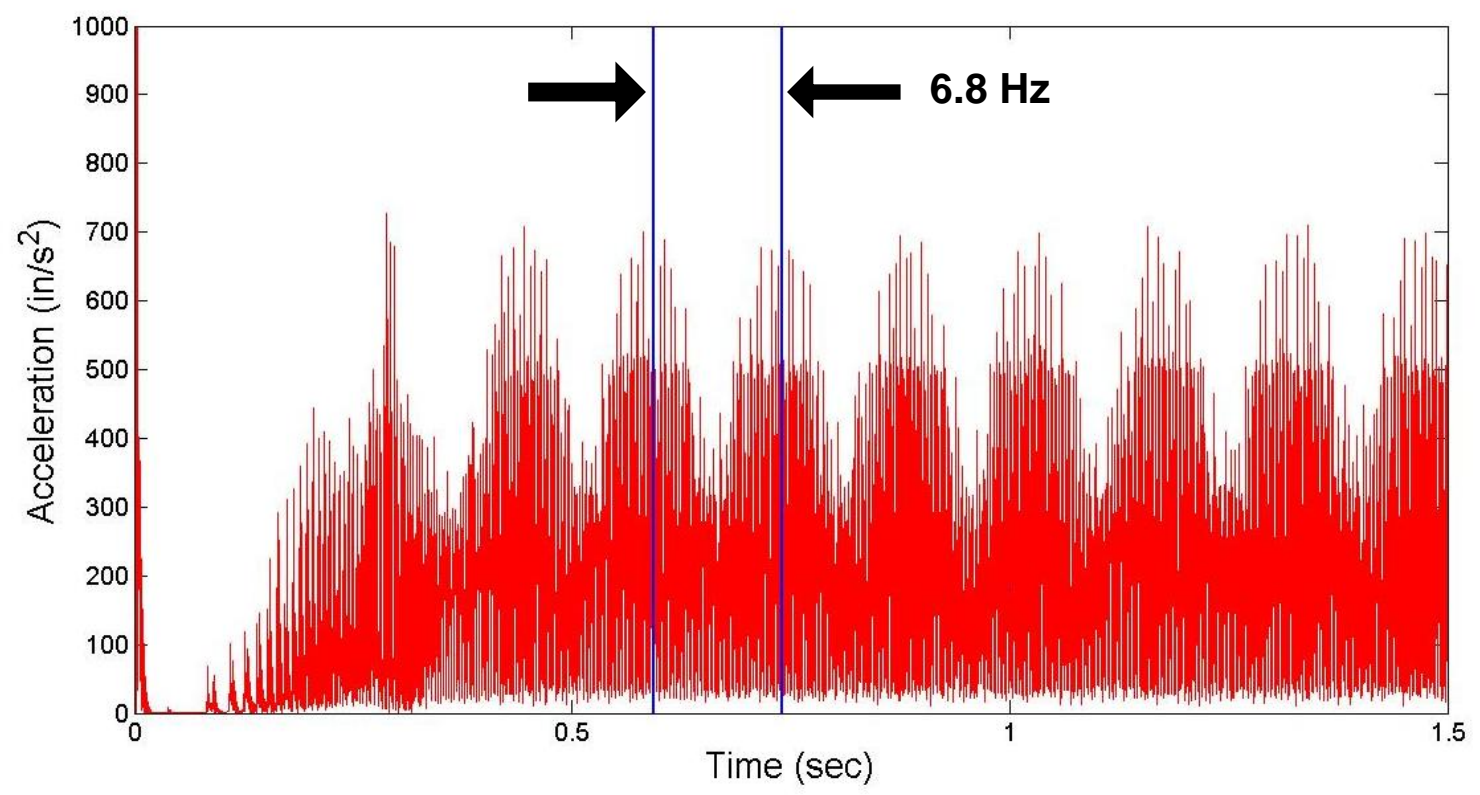

DAMAGED MODEL

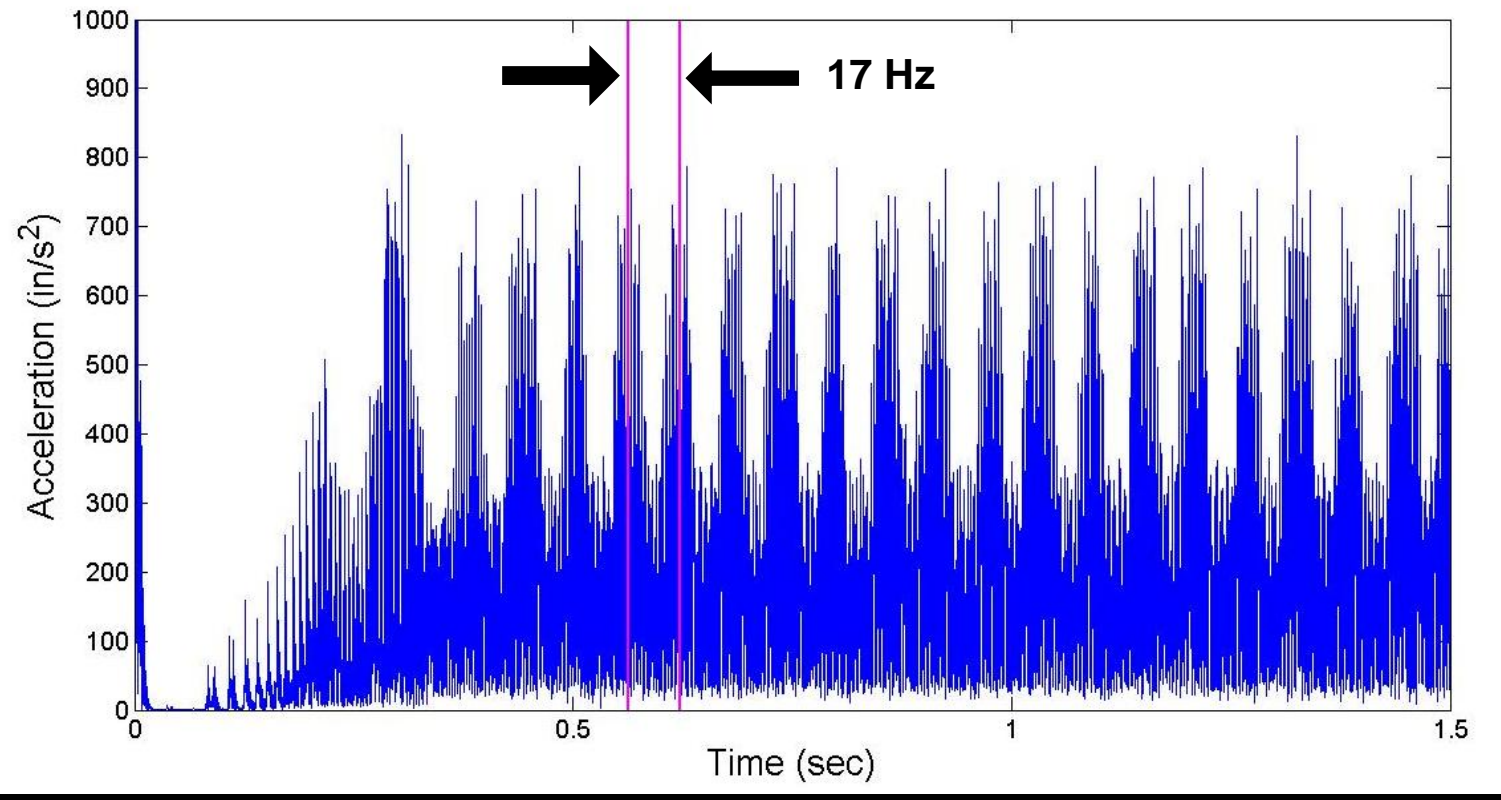

Figure 42. Bearing 1 acceleration magnitude comparison. 


\subsubsection{DAMAGED AND HEALTHY SIDEBAND ENERGY RATIO COMPARISON}

As mentioned previously, the sideband energy ratio (SER) serves as a

mathematical tool to analyze the presence of damage within a gearbox. The SER for the gear contact forces were calculated for the healthy and damaged model, Table 10. For each gear stage FFT analysis the fundamental frequency and first three harmonics of the first stage GMF and second stage GMF sideband energy ratio was compared. As expected the healthy model yielded an SER value less than 1 for each GMF peak. This confirms no damage was present and that the healthy model is accurate in this manner.

On the first stage gear contact force FFT plot, the first stage GMF fundamental frequency and first three harmonics yielded an SER value greater than 1. The second stage GMF had a SER value lower than 1 for the fundamental frequency and first harmonic while the second and third harmonic were greater than 1. Even though the fundamental frequency and first harmonic had a lower SER value, it still increased dramatically from the healthy model and thus indicated some type of change due to damage. The average SER value for the first stage GMF frequencies were higher than the SER values for the second stage GMF frequencies. This observation gave insight into which stage the damage was present and thus the model works accurately in this way. 
On the second stage gear contact force FFT plot, the first stage GMF was over 1 for the fundamental frequency, second harmonic, and third harmonic. The SER value for the second stage GMF frequencies was less than 1 but there was still a significant increase from the healthy model value. Just as in the first stage SER analysis, the average SER value for the contact force was higher for the first stage GMF frequencies than the second stage GMF frequencies.

Table 10. Gear contact force SER comparison

\begin{tabular}{|c|c|c|c|c|c|c|c|c|c|}
\hline \multirow{2}{*}{$\begin{array}{c}\text { GEARBOX } \\
\text { STAGE }\end{array}$} & \multirow{2}{*}{ MODEL } & \multicolumn{6}{|c|}{ GMF $\mathbf{1}$} & \multicolumn{4}{c|}{ GMF $\mathbf{2}$} \\
\cline { 3 - 10 } & & $\mathbf{1 X}$ & $\mathbf{2 X}$ & $\mathbf{3 X}$ & $\mathbf{4 X}$ & $\mathbf{1 X}$ & $\mathbf{2 X}$ & $\mathbf{3 X}$ & $\mathbf{4 X}$ \\
\hline \multirow{2}{*}{1} & HEALTHY & 0.02 & 0.08 & 0.10 & 0.02 & 0.12 & 0.25 & 0.24 & 0.26 \\
\cline { 2 - 11 } & DAMAGED & 1.13 & 1.08 & 2.42 & 4.55 & 0.47 & 0.92 & 3.02 & 2.11 \\
\hline \multirow{2}{*}{2} & HEALTHY & 0.10 & 0.20 & 0.78 & 0.92 & 0.18 & 0.12 & 0.22 & 0.24 \\
\cline { 2 - 10 } & DAMAGED & 1.1 & 0.82 & 3.16 & 5.87 & 0.34 & 0.48 & 0.91 & 0.97 \\
\hline
\end{tabular}

Figure 43 shows a closer comparison of the Bearing 1 acceleration magnitude FFT analysis between the healthy and damaged model. It was quite obvious to see the increased number of sidebands surrounding the GMF peaks and thus it was expected that the SER value for the damaged model would be much greater than the healthy model. Once the calculation was completed the increase in SER value was confirmed, Table 11. On the bearing acceleration FFT plot, the SER associated with the first stage GMF was less than 1 for fundamental frequency but significantly greater than 1 for the first three harmonics. The SER value associated with fundamental frequency of the first stage GMF increased significantly from the healthy model even though the value is still less than 1. Just as in the contact force analysis the average SER value associated with the first stage GMF was higher than the average SER value of the second stage GMF. This confirmed once again that the damage within the gearbox was present on the first stage. 
Table 11. Bearing 1 translational acceleration magnitude SER comparison.

\begin{tabular}{|c|c|c|c|c|c|c|c|c|c|c|}
\hline \multirow{2}{*}{ MODEL } & \multicolumn{4}{|c|}{ GMF $\mathbf{1}$} & \multirow{4}{*}{ Gvg. } & \multicolumn{4}{|c|}{ GMF 2 } & \multirow{2}{*}{ Avg. } \\
\cline { 2 - 7 } & $\mathbf{1 X}$ & $\mathbf{2 X}$ & $\mathbf{3 X}$ & $\mathbf{4 X}$ & & $\mathbf{1 X}$ & $\mathbf{2 X}$ & $\mathbf{3 X}$ & $\mathbf{4 X}$ & \\
\hline HEALTHY & 0.35 & 0.31 & 0.34 & 0.20 & 0.30 & 0.10 & 0.20 & 0.20 & 0.20 & 0.17 \\
\hline DAMAGED & 0.87 & 6.42 & 2.48 & 3.04 & 3.20 & 1.28 & 1.29 & 1.84 & 6.78 & 2.80 \\
\hline
\end{tabular}

To calculate the SER, only the peaks present at $\omega_{G M} \pm n\left(\omega_{S}\right)$ were analyzed. Peaks at other frequencies were disregarded because these peaks may not have been sidebands of the GMF but simply sub or super-harmonics of the GMF. The sub and superharmonics themselves may also have sidebands in the FFT analysis so it was important to be consistent in which peaks were included in the SER comparison. If the damage in the gearbox was unknown then the sidebands present would also be an indication of which stage the damage was present because the location of the sidebands is dependent upon the shaft speed the damage is on. In this present study the damage location was already known and so the appropriate sidebands to analyze were known previously. 


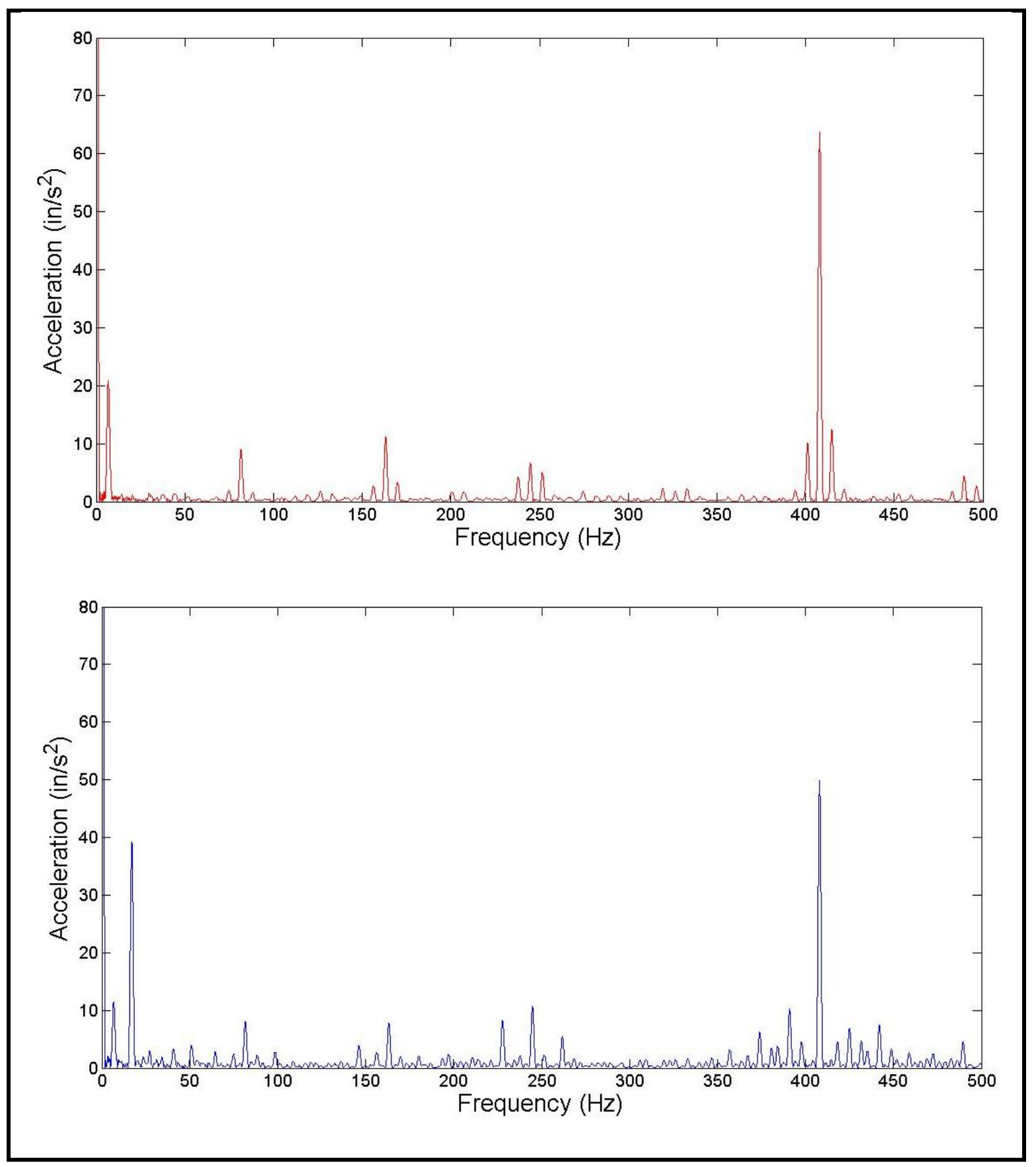

Figure 43. Damaged model Bearing 1 acceleration comparison 0-500 Hz. 


\section{FATGIUE CRACK EXPERIMENTATION RESULTS}

\subsection{EXPERIMENTAL MAX TANGENTIAL LOAD}

Experiments were conducted to measure the quasi-static strength of individual gear teeth as well as the fatigue strength. With a sample secured in the fixture a single ramp load was applied at a rate of $10 \mathrm{lbf}$ per second. A total of three trials were conducted leading to an experimentally measured gear tooth failure loads of $3707 \mathrm{lbf}$, $3700 \mathrm{lbf}$, and $3939 \mathrm{lbf}$. All three trails were conducted on different teeth on the same gear specimen. The average max tangential tooth load for bending failure is approximately $3800 \mathrm{lbf}$. This number is significantly higher than the theoretically calculated value of $1925 \mathrm{lbf}$. Recall that the theoretical calculations treat the gear tooth as a simplified beam while the geometry is quite different. In addition, the ultimate stress used in the Lewis bending equation is that of the parent gear material ignoring the hardened outer surface that may have occurred in the manufacturing process.

\subsection{LOAD CONTROL FATIGUE TESTING RESULTS}

To experimentally measure the fatigue strength of the Martin S1224BS 1 spur gear cyclic loading was applied as follows. Experiments were conducted on four teeth on each of three different gears, labeled; Gear 1, Gear 2, and Gear 3.

Theoretical load calculations, as described previously, were used to assign maximum and minimum applied tooth loads of $1650 \mathrm{lbf}$ and $472 \mathrm{lbf}$, respectively. These values were chosen to create fatigue failures in the vicinity of 10,000 cycles. Due to the inaccuracy of the quasi-static max tangential tooth load test, we raised the maximum fatigue load to $2000 \mathrm{lbf}$ instead of $1650 \mathrm{lbf}$. The minimum tangential tooth force was selected to be $400 \mathrm{lbf}$. On Gear 1 we fatigued 4 different teeth to $6000,8000,10000$, 
and 12000 cycles. None of these teeth experienced breakage during these tests. The Instron machine was set to load control with a half-sine waveform at an amplitude of $1600 \mathrm{lbf}$ and a frequency of $1.5 \mathrm{~Hz}$. The set point was $400 \mathrm{lbf}$, providing the desired load range of 400 to $2000 \mathrm{lbs}$. A typical load-time plot is shown in Figure 44 . The half-sine wave in the Instron controller allows the user to set the minimum load point and the amplitude is referenced from that value. This assured no loss of contact with the tooth during testing.

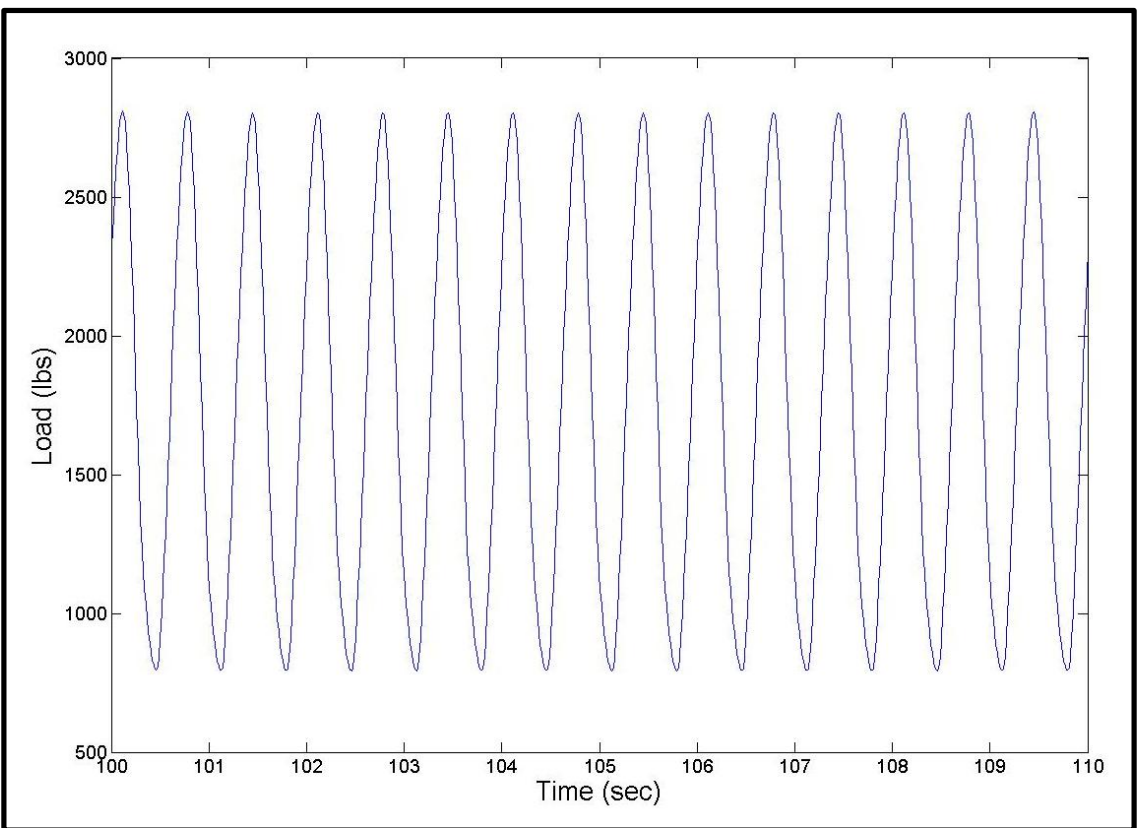

Figure 44. Typical load versus time plot cyclic loading of a single tooth.

Even after close examination in the SEM, we found no evidence of fatigue cracks after the initial round of testing. Given the anticipated fatigue strengths, we expected to find fatigue cracks in the gears, but found no such damage. Even after exceeding the 10,000 cycle anticipated lifetimes for the given loading, we found no damage after 12,000 cycles. 
In an attempt to initiate fatigue cracks, we raised the maximum and minimum tangential tooth loads to $2800 \mathrm{lbf}$ and $800 \mathrm{lbf}$ for Gear 2. This increase in load also increases the mean stress on the gear tooth. The same waveform was used as the previous test. Teeth 1 through 4 on Gear 2, were loaded for 10000, 12500, 15000, and 20000 cycles, respectively. Once again with this loading condition and number of cycles, we saw no evidence of fatigue cracking. We placed the gear back in the fixture and carried on testing tooth 4 . This tooth had already experienced 20,000 load cycles, and we continued testing over the same load range until failure at 33445 cycles, Figure 45 . In an attempt to 'capture' a fatigue crack at the root of a tooth, we set limits for total numbers of cycles on the remaining three teeth on Gear 2. We established cycle goals for Tooth 1 through 3 of 27000,29000 , and 31000 total cycles.

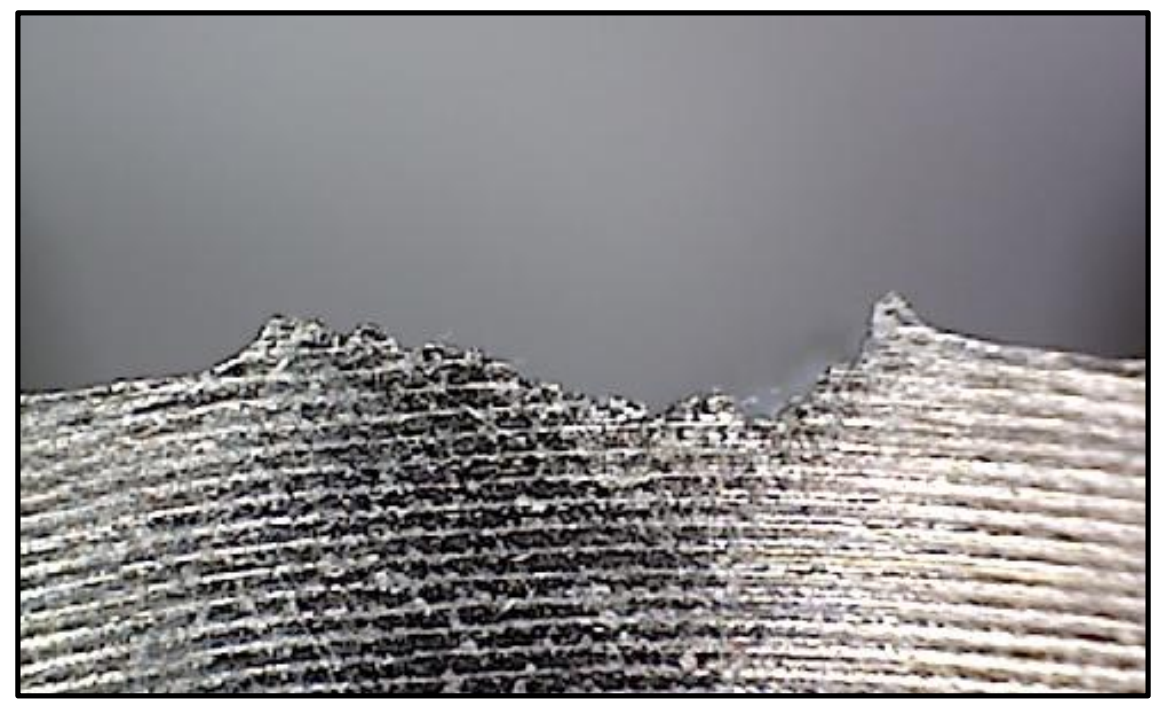

Figure 45. Gear 2 - Tooth 4 fracture side surface. Tooth loaded on right side.

Tooth 1 was successfully tested to 27000 cycles while teeth 2 and 3 failed. Tooth 2 failed at a total of 24488 cycles and Tooth 3 failed at 22128 cycles. Tooth 1 was analyzed with the naked eye and no visible cracks were noticed. The only visible change was the surface of the gear tooth had slight scuffing and discoloration at the contact point with the loading anvil. SEM examination revealed no cracks at the tooth root. The 
cycles to failure for Tooth 2 and 3 are dramatically lower than those for Tooth 4 , demonstrating the inherent variability of fatigue testing.

Since load control testing had proven successful for running a spur gear tooth to fatigue failure we attempted to create an S-N curve for these materials. The mean stress on Gear 3 was kept the same but the maximum and minimum tangential tooth load was changed to $3200 \mathrm{lbf}$ and $400 \mathrm{lbf}$. Three teeth in total were tested with this loading condition and failures occurred at 4609, 3626, and 3933 cycles. The tooth failures for this round of testing showed less scatter amongst the three trials, but we could not reliably capture a fatigue crack in a gear tooth using load control.

\section{$\underline{6.3}$ POSITION CONTROL FATIGUE TESTING RESULTS}

Our experience using load-control fatigue testing led us to hypothesize that position control would show a distinct change in compliance after fatigue crack initiation. If we could detect that compliance, we surmised that we could terminate a test and, therefore, capture a sub-critical fatigue crack in the gear. The gears used to test this hypothesis were labeled Gear 4, 5, 6. 8 and 9.

The first round of position control testing was run on Gear 4 - Tooth 1. Cyclic Loading was conducted in position control with a half-sine waveform at an amplitude of 0.02 inches and a frequency of $1.5 \mathrm{~Hz}$. The set-point of this test was 0.01 inches, yielding a max position of 0.03 inches and a minimum of 0.01 inches. Although the Instron actuator is moving a total of 0.02 inches in every cycle, the actual tooth deflection is much less due to the compliance of the fatigue fixture. Typical load- and position-time curves near the beginning of these tests are shown in Figure 46. 
Tooth 1 on Gear 4 failed in 1628 cycles, revealing a key feature in the load-time curve. Through the bulk of the test, the applied position control, 0.01 inch to 0.02 inch, corresponded to minimum and maximum loads of $65 \mathrm{lbf}$ and $3000 \mathrm{lbf}$, respectively. In the last 100 cycles, the loads, both max and min, began to decrease with every cycle. This trend continued until the tooth failed completely in bending fatigue. During the final 10-20 cycles the decrease in load became quite pronounced, Figure 47.

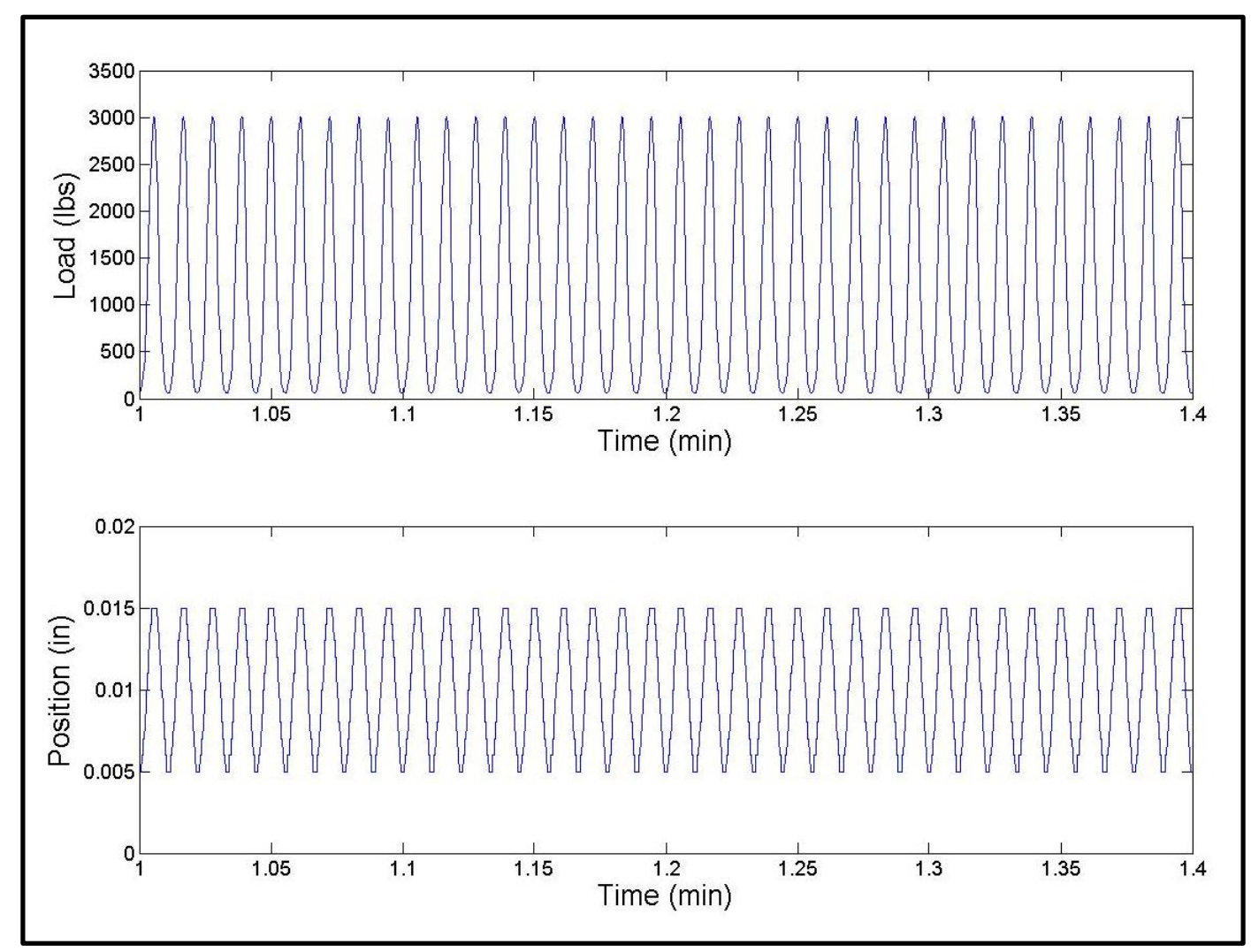

Figure 46. Typical beginning test results during test on Gear 4 - Tooth 1. 


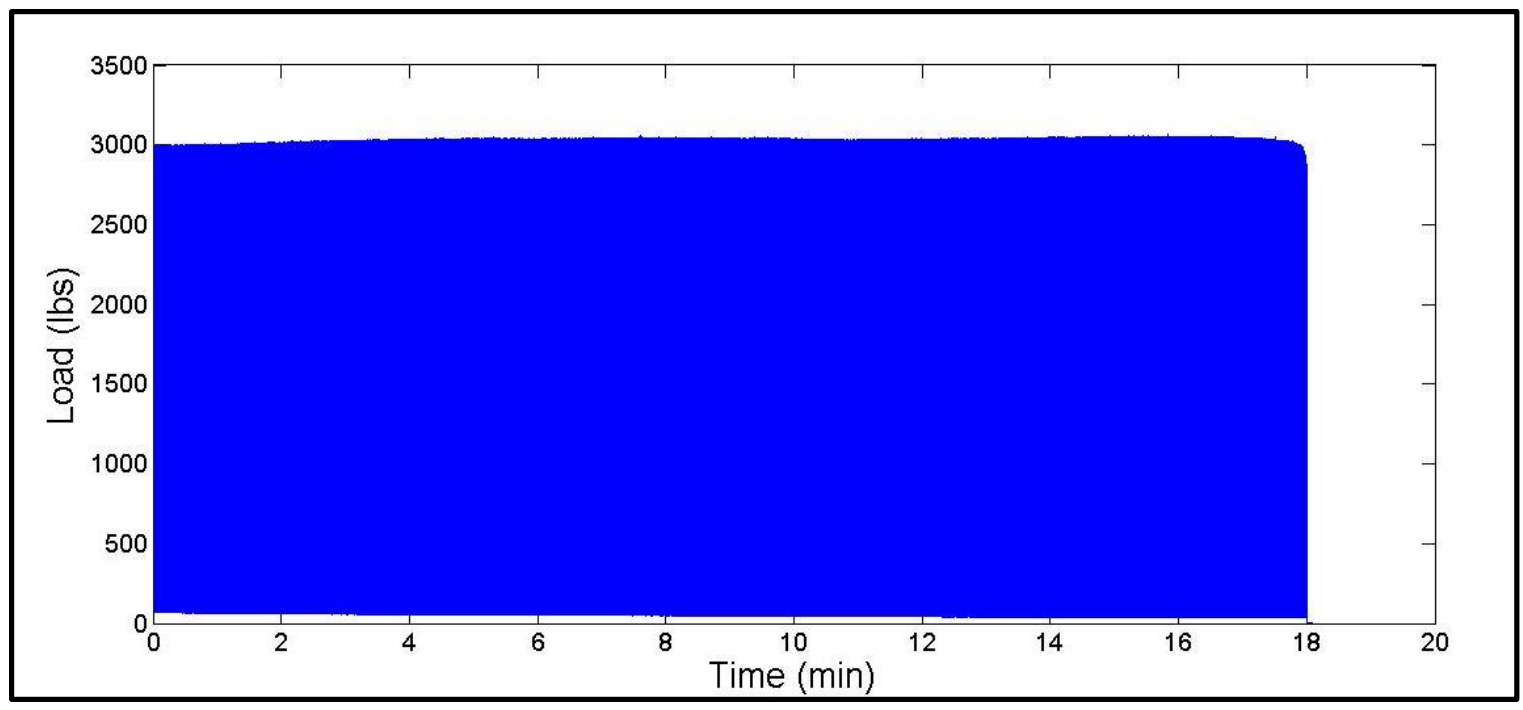

Figure 47. Load versus time plot for Gear 4 - Tooth 1.

For Tooth 2, the position amplitude was changed to -0.016 inches. The same set-point was used as the Tooth 1 test. The tooth was fatigue tested and Tooth 2 failed in 4672 cycles. With a smaller load on the gear tooth, more cycles were required to fail Tooth 2 . The position amplitude for Tooth 3 was decreased once more to -0.014 inches. The setpoint remained the same at -0.01 inches. In this test, Tooth 3 failed after 15865 cycles. For both Tooth 2 and Tooth 3 the same phenomenon was seen in the load versus time plot. In an effort to verify the phenomenon shown on Gear 4 was not just a fluke but a consistent experimental finding, a similar round of testing was conducted on Gear 5 and Gear 6. On Gear 5 some different settings and a procedures were tested to try and develop a consistent test bed for Gear 6 . Before the anvil is clamped into the bottom jaw the lower crosshead is double-checked that it is at the zero position. When the jaw clamps onto the anvil, the anvil is just slightly touching the gear tooth. On Gear 5 a setpoint of -0.007 inches was determined to give a static set-point load of approximately $200 \mathrm{lbf}$. Since there is variability among the gear teeth and how the anvil is clamped into 
the bottom jaw, it was made sure that the set point of -0.007 inches equated to a set point load of $-150 \mathrm{lbf}$ to $-200 \mathrm{lbf}$ for every test.

On Gear 6, the relationship between the position amplitude and the number of cycles to failure were thoroughly investigated. For each gear tooth in this test a position set point of 0.007 was used and the position amplitude changed for each test. For Tooth 1 through 4 the amplitude was $0.02,0.018,0.016$, and 0.014 inches respectively. Tooth 1 failed at 2245 cycles, Tooth 2 failed at 3200 cycles, Tooth 3 failed at 4291 cycles, and Tooth 4 failed at 9042 cycles. Consistent with expectation and as seen in Gear 4, as the position amplitude decreased, the number of cycles to failure increased. The steadystate load during each test did not necessarily decrease however. For Tooth 1 the max load on the gear tooth was $2130 \mathrm{lbf}$ but when the position amplitude was decreased for Tooth 2 the maximum load actually increased to 2516 lbf. For Tooth 3, the max load was $2540 \mathrm{lbf}$. This again shows variability in each gear tooth and the manufacturing process used to create the Martin S1224BS 1 spur gear. Figures 48 through 51 plot load verses displacement for Tooth 1, 2, 3, and 4 during the last few minutes of each test. Figures 48-52 show clearly how the load drops off at the end of each test. We shall show, using post-test SEM, that this drop in load is directly related to the presence of fatigue cracks. 


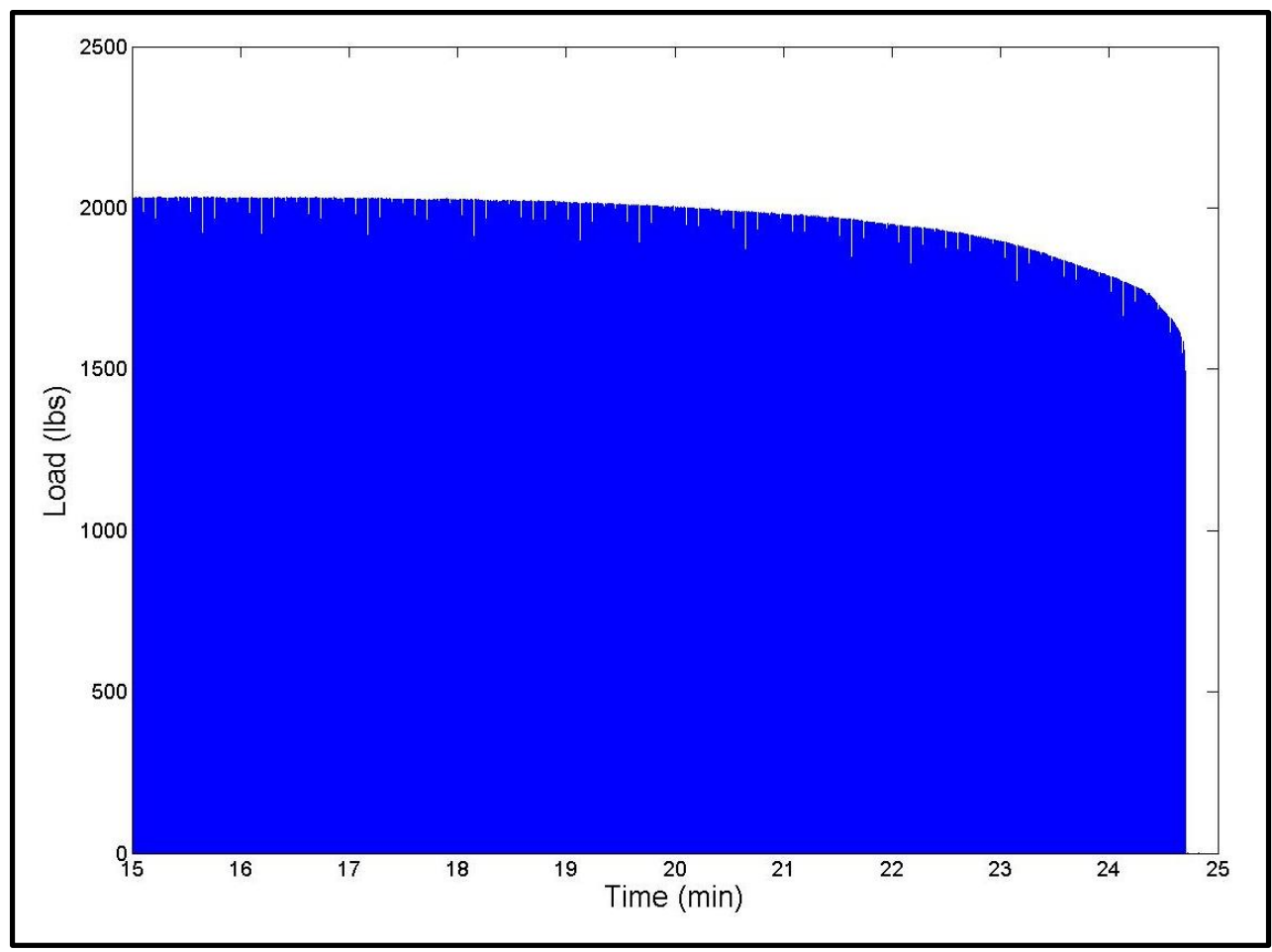

Figure 48. Final minutes of position-controlled fatigue loading for Gear 6 -Tooth 1.

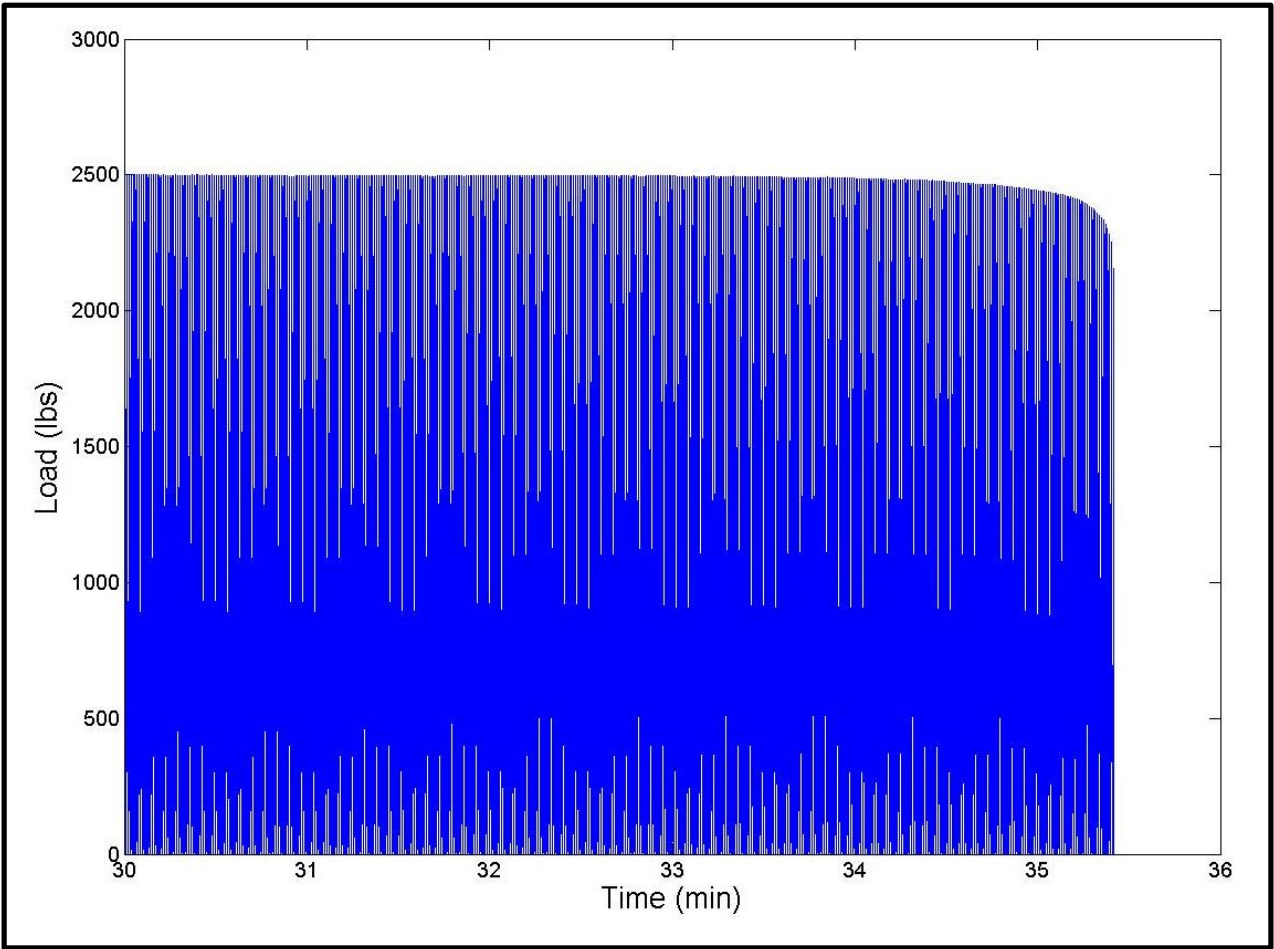

Figure 49. Final minutes of position-controlled fatigue loading for Gear 6 -Tooth 2. 


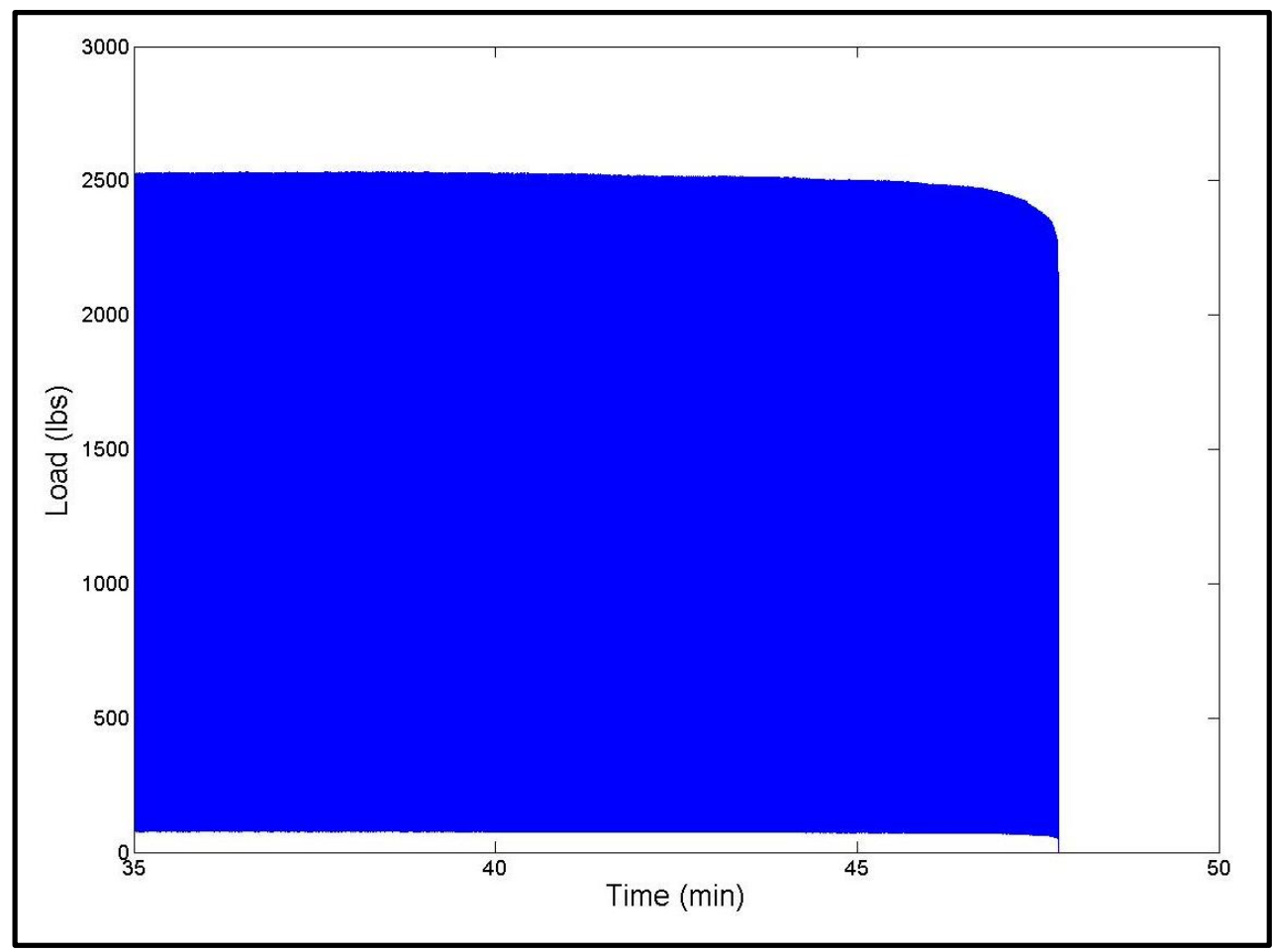

Figure 50. Final minutes of position-controlled fatigue loading for Gear 6 -Tooth 3.

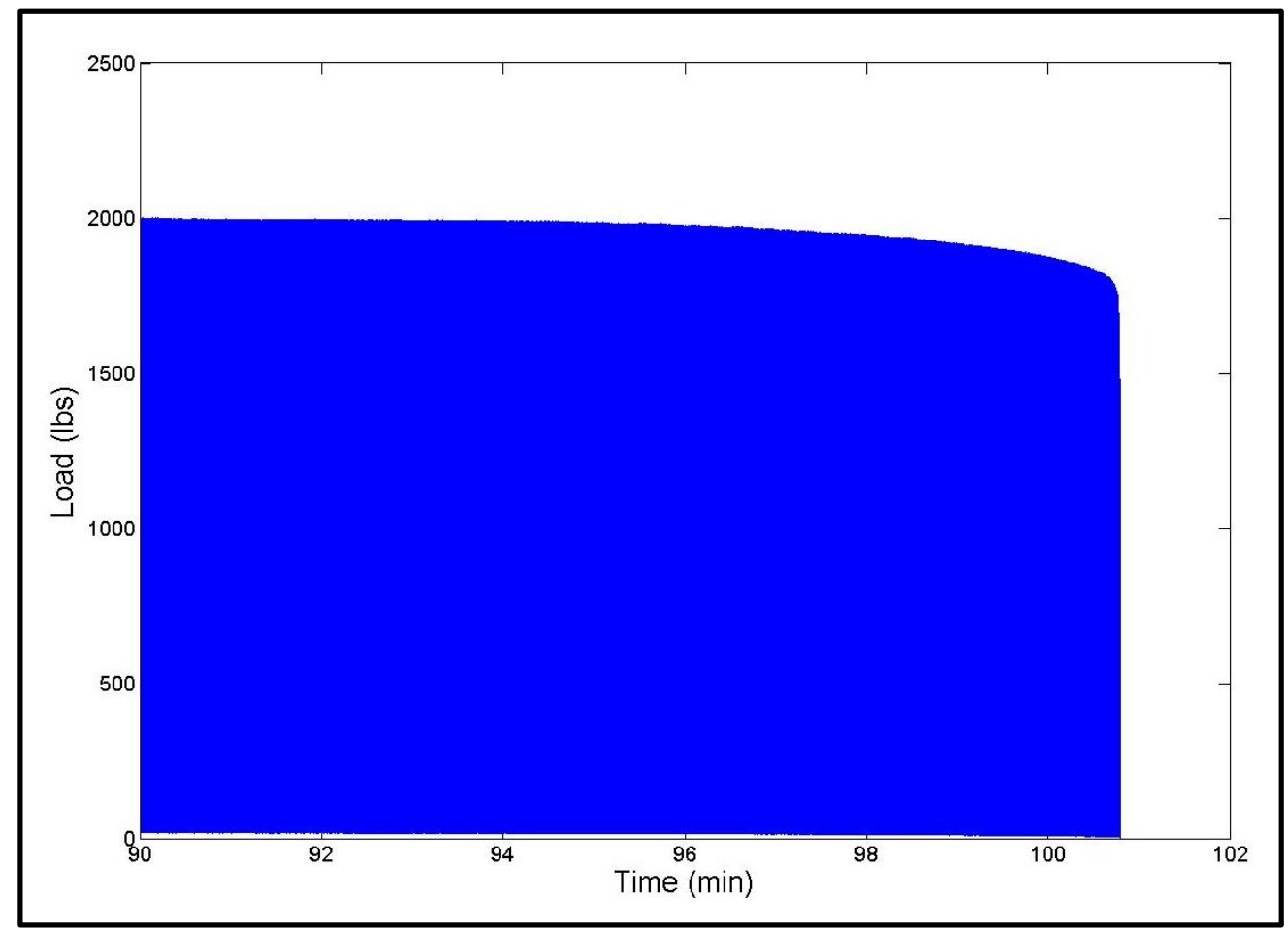

Figure 51. Final minutes of position-controlled fatigue loading for Gear 6 -Tooth 4. 
The presence of a load-drop occurs in every test, but the percentage drop between each cycle is not consistent and cannot, at this time, provide a simple method for test control. In all cases, however, the drop in load is highest in the final few cycles before fracture. Table 12 contains a summary of the load drops for each tooth. The final cycle before immediate failure has a percent difference from the previous cycle of approximately $4 \%$ for Tooth 1 through 3 . Tooth 4 had a $12 \%$ difference on the final cycle. The cycle previous to the final cycle had a percent difference of approximately $1 \%$ for Tooth 1 through 3 while Tooth 4 had a $2 \%$ difference. Besides the last two to three cycles the percent difference from one cycle to another is around or less than $0.5 \%$, but this percent is not consistent among tests at the earliest onset of damage. Although the percent difference from cycle to cycle is not consistent, once the load begins to decrease it decreases every cycle until failure. This is consistent with the understanding that, once initiated, the crack would propagate according to a Paris fatigue law [25]. Figure 52 plots the max load in each cycle for Tooth 1 on gear 6 . Similar plots were constructed for teeth 2 through 4 . Once again there was considerable variability among gear teeth, but there is a consistent load drop with cycles near end-of-life.

Table 12. Last five cycle analysis for Gear 6 fatigue testing.

\begin{tabular}{|c|c|c|c|c|c|c|c|}
\hline \multicolumn{2}{|c|}{ Tooth 1 } & \multicolumn{2}{c|}{ Tooth 2 } & \multicolumn{2}{c|}{ Tooth 3 } & \multicolumn{2}{c|}{ Tooth 4 } \\
\hline $\begin{array}{c}\text { Peak } \\
\text { Load }\end{array}$ & $\begin{array}{c}\% \\
\text { Difference }\end{array}$ & $\begin{array}{c}\text { Peak } \\
\text { Load }\end{array}$ & $\begin{array}{c}\% \\
\text { Difference }\end{array}$ & $\begin{array}{c}\text { Peak } \\
\text { Load }\end{array}$ & $\begin{array}{c}\% \\
\text { Difference }\end{array}$ & $\begin{array}{c}\text { Peak } \\
\text { Load }\end{array}$ & $\begin{array}{c}\% \\
\text { Difference }\end{array}$ \\
\hline 1611 & -0.537 & 2319 & -0.628 & 2310 & -0.382 & 1763 & -0.551 \\
\hline 1600 & -0.701 & 2301 & -0.750 & 2297 & -0.535 & 1753 & -0.606 \\
\hline 1586 & -0.849 & 2280 & -0.928 & 2281 & -0.697 & 1734 & -1.062 \\
\hline 1560 & -1.664 & 2251 & -1.245 & 2254 & -1.217 & 1693 & -2.349 \\
\hline 1494 & -4.265 & 2154 & -4.317 & 2161 & -4.117 & 1482 & -12.489 \\
\hline
\end{tabular}




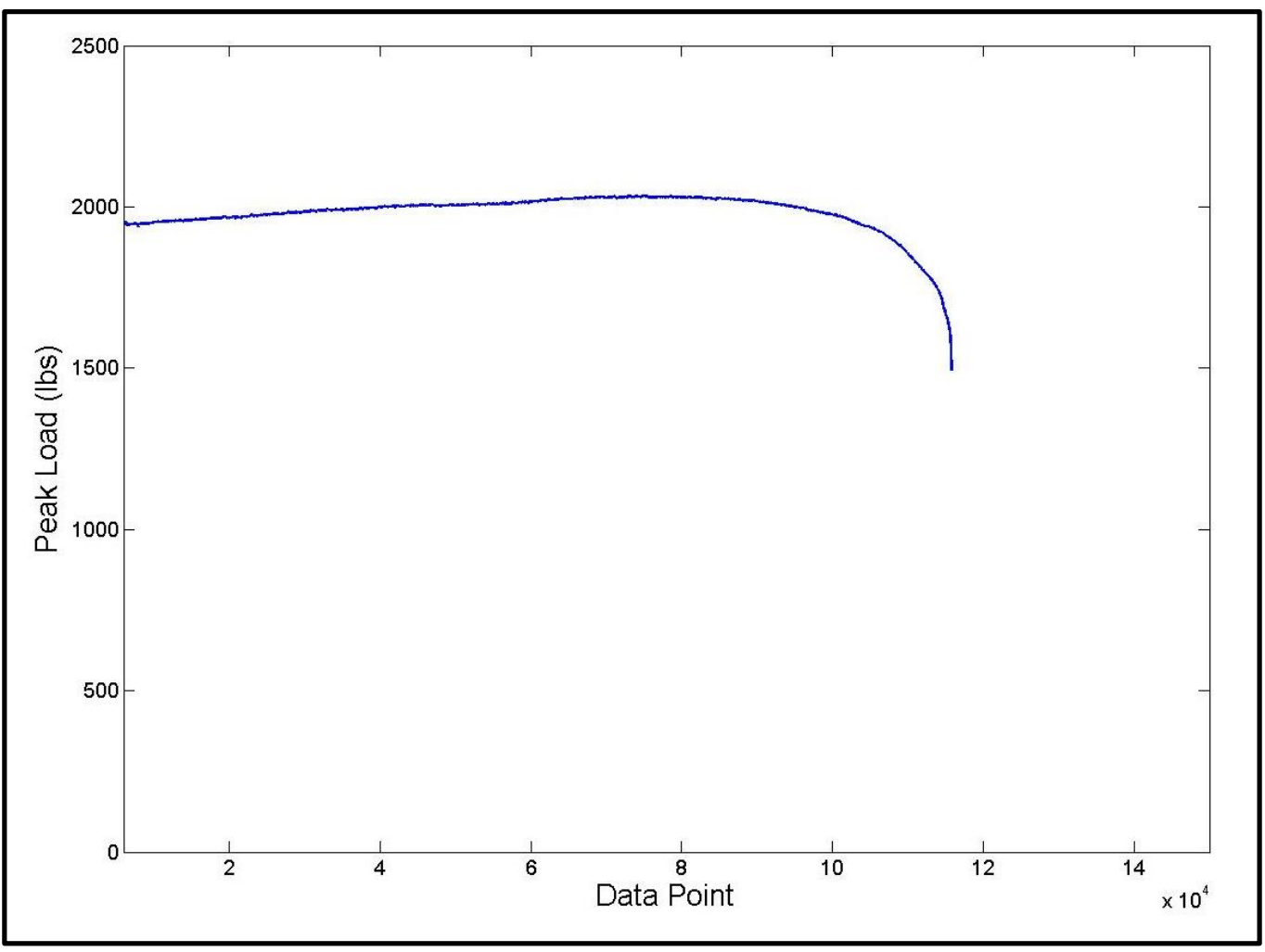

Figure 52. Max load for each cycle of fatigue testing for Gear 6 - Tooth 1.

The drop-off in load with fatigue crack growth can be attributed to a change in gear tooth compliance with crack propagation. Using the cantilever analogy, the cross section at the tooth root is decreasing with crack growth, which changes the moment of inertia of the section. This increases the compliance of the system which, for a fixed end displacement, results in a decrease in load. Once damage due to fatigue loading reaches a critical point, fracture occurs suddenly.

Figure 52 shows an interesting change that was noted in all the materials: a small, yet steady, increase in load occurs over a large portion of the test, climbing to a steady-state peak load, followed by a rapid decrease in load. From the onset of the test until approximately 14 minutes into the test, the max load increases from $1940 \mathrm{lbf}$ to $2030 \mathrm{lbf}$ 
in Figure 52. Eventually the peak load of each cycle reaches a steady maximum of 2030 lbf .The steady max load is maintained for a few minutes and then the drop-off due to fatigue damage begins. One possible explanation is thermal expansion due to frictional heating during the test. For displacement control, since the control in embedded in the actuator far from the part, any thermal expansion of the test parts would necessarily add to the applied load. It is quite reasonable to expect frictional heating during contact fatigue testing especially since no lubricant was placed between the loading anvil and the gear tooth [26]. A complete compilation of all load verses time, position versus time, and peak load plots for Gear 6 under position control fatigue are located in Appendix C, while key test attributes are in summarized in Table 13.

Table 13. Summary of position control fatigue testing for Gear 6.

\begin{tabular}{|c|c|c|c|}
\hline Tooth & $\begin{array}{c}\text { Positon Amplitude } \\
\text { (inch) }\end{array}$ & $\begin{array}{c}\text { Max Load } \\
\text { (Ibf) }\end{array}$ & Cycles to Failure \\
\hline 1 & -0.020 & 2130 & 2245 \\
\hline 2 & -0.018 & 2516 & 3200 \\
\hline 3 & -0.016 & 2540 & 4291 \\
\hline 4 & -0.014 & 2018 & 9042 \\
\hline
\end{tabular}

\subsection{CAPTURE OF TOOTH ROOT FATIGUE CRACK}

Position control fatigue testing was chosen because it offered a damage signature (the decrease in peak load) that could be associated with the presence of a sub-critical fatigue crack. Recall that a key goal of this research was to capture a natural fatigue crack in a spur gear which could then be placed into a gearbox. This was done on Tooth 4 of Gear 4. As described above, we had identified a characteristic load-drop that we associated with fatigue crack propagation. During testing of Tooth 4 on Gear 4, we carefully monitored the load for the onset of the load drop. Once a load drop-off was detected we stopped the test. The gear was removed from the fixture and carefully 
imaged using the SEM, Figure 53. This clearly shows a fatigue crack that supports the notion that fatigue cracks are responsible for the change in load during testing. One of the most difficult aspects of these experiments is knowing when to stop the test to capture a crack at before it goes critical.

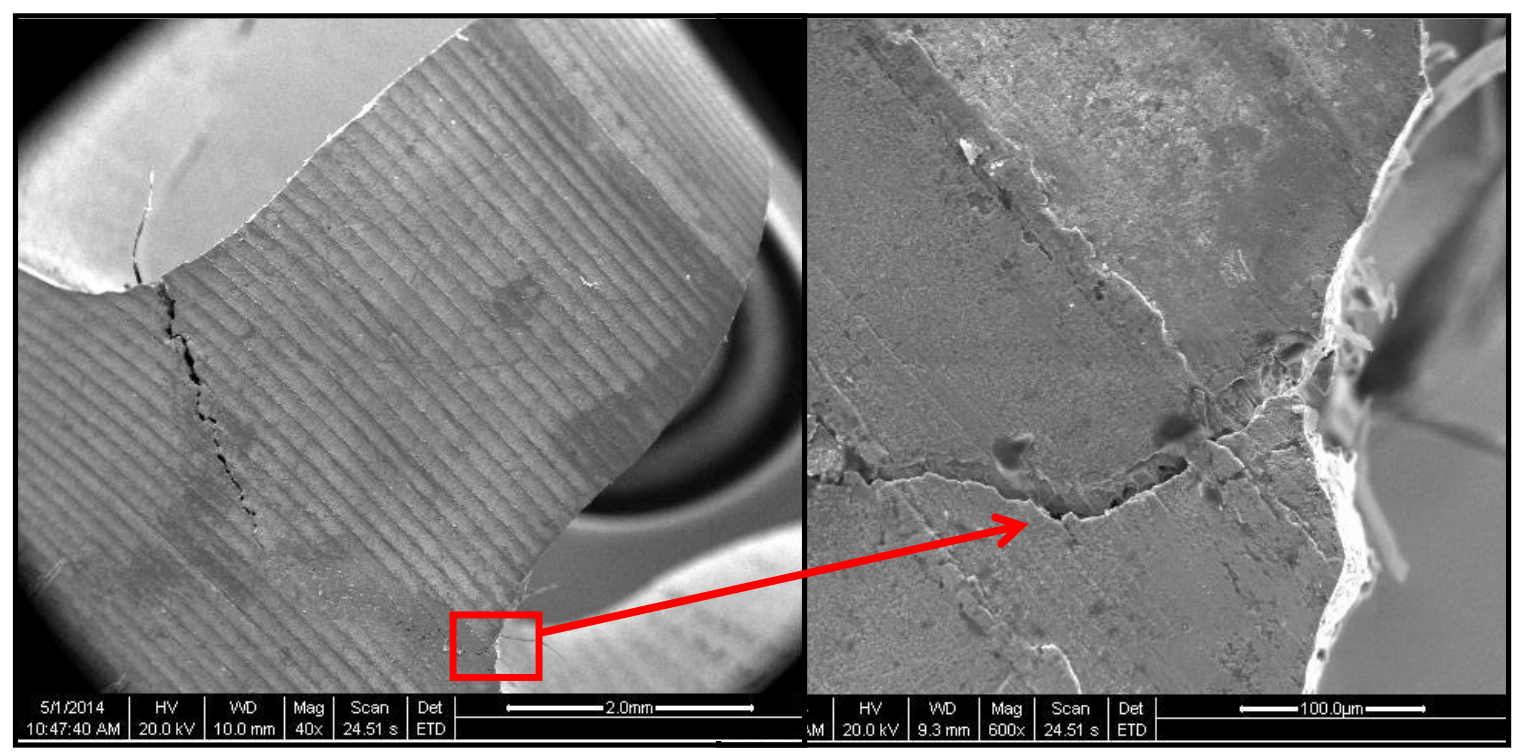

(a)

(b)

Figure 53. (a) Fatigue crack at 20x magnification and (b) 600x magnification.

To assist with crack detection, gears were polished and the USB digital microscope was used to image the tooth root during testing. Tests conducted on Gear 8 - Tooth 1 yielded no visual indications of fatigue cracking during the load drop-off. This was attributed to a lack of contrast, but even after using Dykem layout fluid to enhance contrast we could still see no visual evidence of crack propagation in the microscope video.

For Gear 9 the digital microscope was illuminated with LED lights at the highest setting and the lens adjusted so that a bright glare was seen at the tooth root. The test settings for Gear 9 are summarized in Table 14. 
Table 14. Summary of Gear 9 Instron settings.

\begin{tabular}{|c|c|c|c|c|}
\hline \multirow{2}{*}{$\begin{array}{c}\text { Gear 9 } \\
\text { Tooth \# }\end{array}$} & Position (in) & Load (Ibf) & $\begin{array}{c}\text { Amp } \\
\text { (in) }\end{array}$ & $\begin{array}{c}\text { Max Load } \\
\text { (lbf) }\end{array}$ \\
\hline 1 & -0.004 & -177 & -0.018 & 2200 \\
\hline 2 & -0.002 & -122 & -0.016 & 2100 \\
\hline 3 & -0.004 & -177 & -0.016 & 1950 \\
\hline 4 & -0.007 & -155 & -0.018 & 2150 \\
\hline
\end{tabular}

On Gear 9 - Tooth 2, the microscope camera successfully imaged a fatigue crack from initiation to a length approximately half-way across the width of the gear tooth. When the camera video was synchronized to the load data, we were able to correlate the time at which the load initially began to drop-off to a small dull spot in the glare along the tooth root. This observation was determined to be the initiation site of the fatigue crack. As the video progresses the crack propagated and the tooth load dropped off in accordance with the crack length. In this test, the load began to drop at 675 cycles, and the crack propagated until 1078 cycles, at which time we terminated the test. The max load on the gear tooth the cycle prior to stopping the test was $1897 \mathrm{lbf}$. This load value is $9.66 \%$ lower than the steady max cycle load of $2100 \mathrm{lbf}$. The last 6 minutes of testing data are shown in Figure 54, again demonstrating a distinct load drop with cycles. 


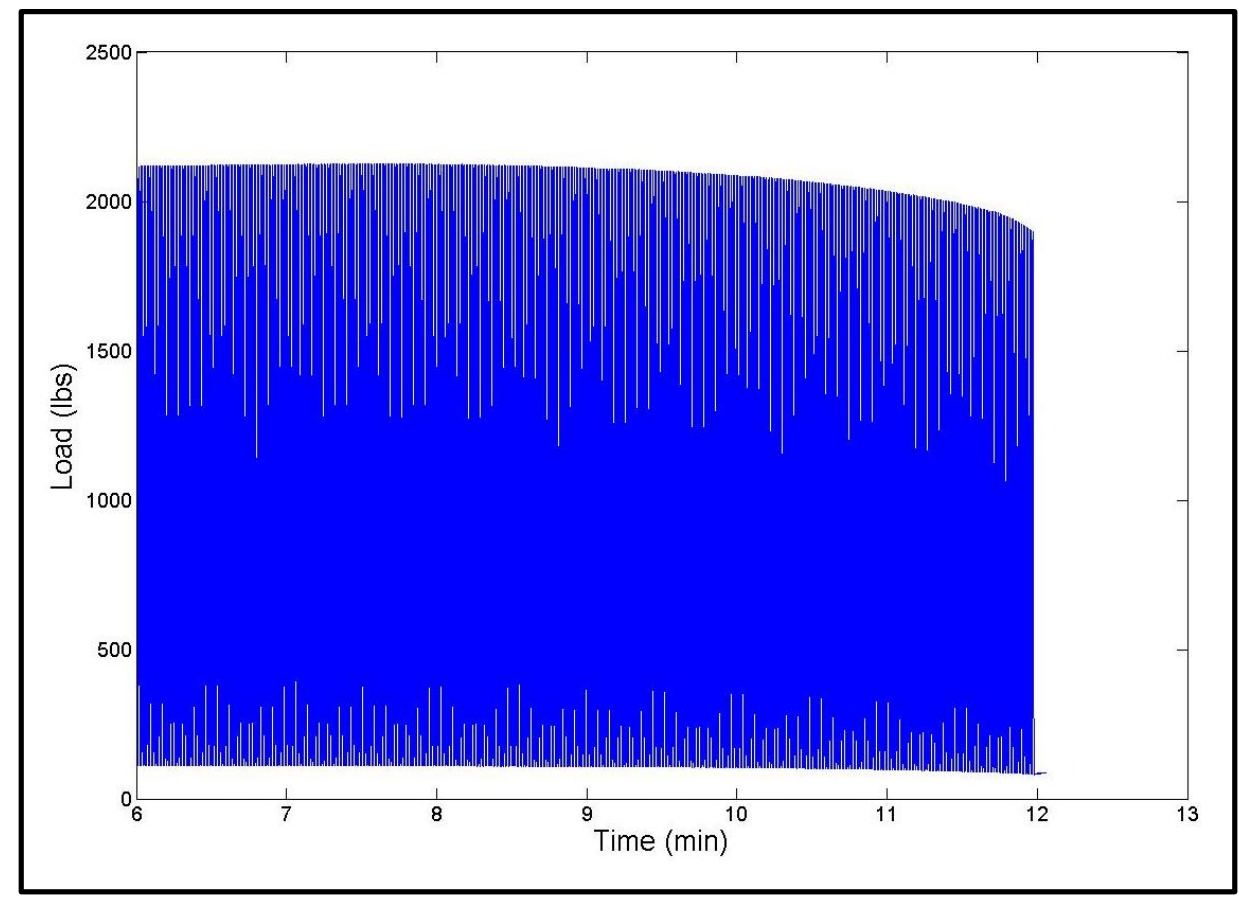

Figure 54. Final 6 minutes of Gear 9 - Tooth 2 crack propagation test.

Additional testing on Tooth 3 was conducted to replicate this result, Figure 55. The LabVIEW plot was watched even more closely and as soon as the steady max cycle load began to decrease the video was immediately viewed and fatigue crack initiation was seen at the tooth root. The glare at the tooth root developed a small dark spot just as in the previous test. The test continued and the crack was allowed to propagate. The test was eventually stopped and the gear was removed and analyzed with the naked eye. In the proper lighting a fatigue crack could be seen at the tooth root. The length of this crack was much shorter than the previous test and was confirmed by the load percent difference. For this test a load percent difference of $5.18 \%$ was achieved, indicating less damage had occurred than on Tooth 2. Damage began at 5962 cycles and the test was terminated at 8212 cycles. This test took much longer to achieve damage results and the damage occurred over a much longer duration of time than the previous test on Tooth 2. Though identical test settings were chosen for each test we note a large variation in fatigue crack initiation amongst gear teeth. 


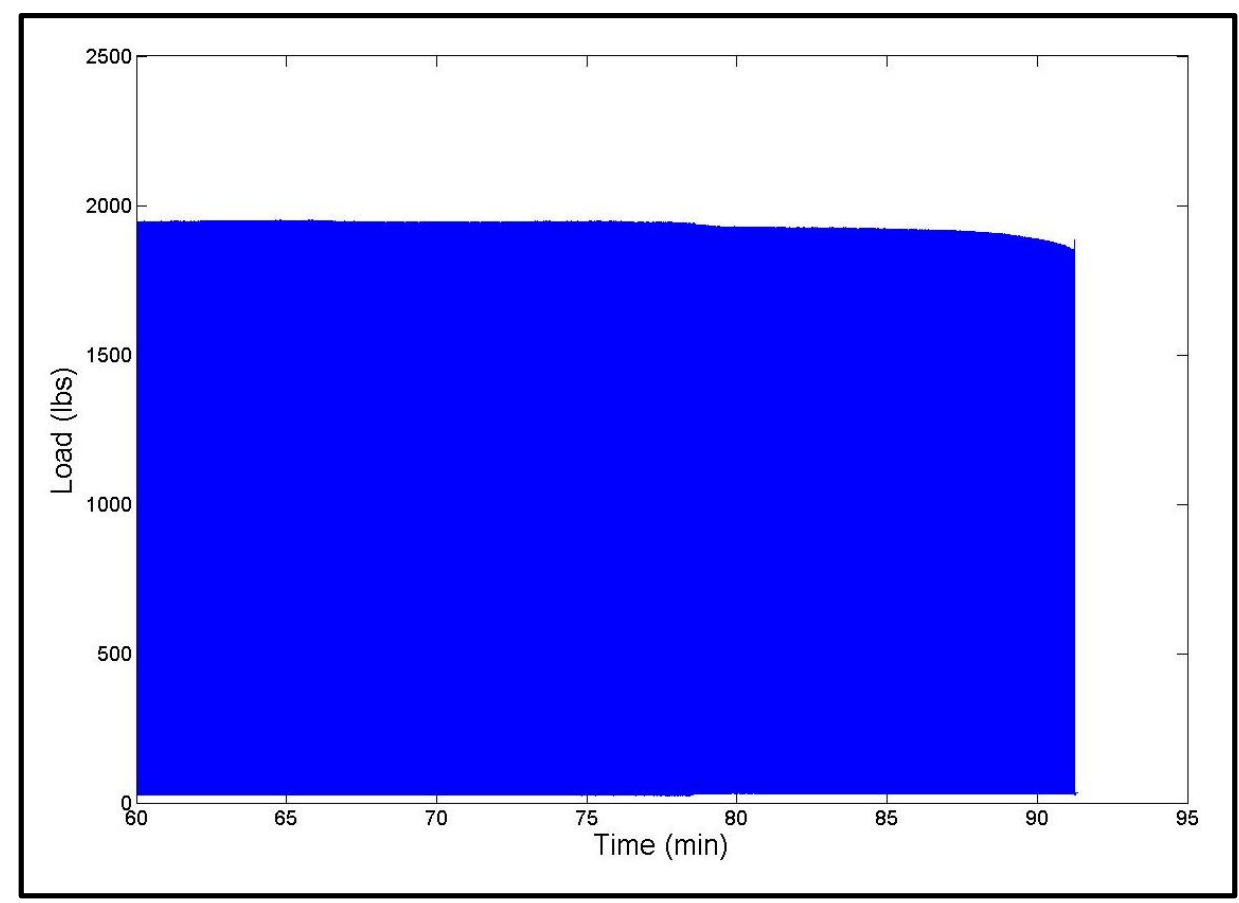

Figure 55. Final 32 minutes of Gear 9 - Tooth 3 crack propagation test.

The goal of the final tooth on Gear 9 was to capture on video the entire process of crack initiation, crack propagation, and complete tooth failure. The same procedure as the previous two tests was followed. After testing, the video recorded by the digital microscope was viewed and analyzed. Once again, crack initiation was visible on video and, as the test progressed, the crack propagated across the tooth until complete failure occurred.

Tooth 2 and Tooth 3 from Gear 9 were analyzed in the SEM to get a detailed image of the crack initiation sites and to measure how far the crack propagated across the tooth thickness. Figure 60 shows an SEM image of the entire crack at 40x magnification, while Figure 61 images the crack at 150x. The crack initiation site, Figure 56 , shows a complex and distributed damage pattern where multiple micro-cracks coalesce into a single, dominant macro-crack. Figure 57 shows a 300x image of the crack tip. Tooth 2 
has a crack length approximately $65 \%$ of the tooth thickness. SEM images of Tooth 3 on Gear 9 are shown in Figures 60 and 61 . We note that this crack is much smaller than that seen in Tooth 2 . This fatigue crack runs to a length roughly $1 \%$ of the tooth thickness. These images positively confirm the presence of the fatigue crack at the tooth and validate the hypothesis that the drop in load, during displacement controlled fatigue testing, is associated with the appearance and propagation of a fatigue crack. It is notable that the load associated with the fatigue crack on Tooth 2 had dropped to roughly $9.66 \%$ of the max, while the load for Tooth 3 had dropped to $5.18 \%$ of the max. These differences in load drop, association with their respective SEM images, shows that the magnitude of the load drop is related to the length of the fatigue crack.

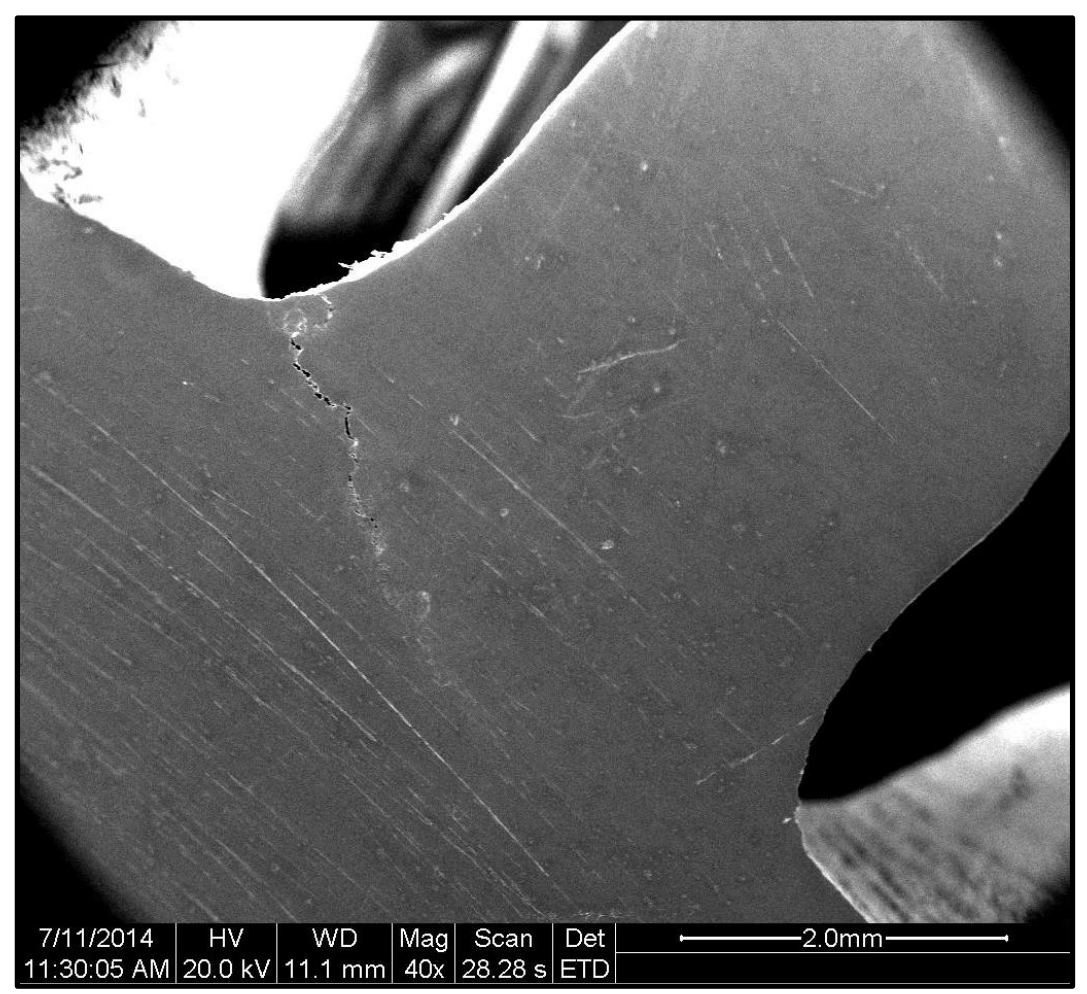

Figure 56. Tooth root crack on Gear 9 -Tooth 2 at 40x mag. 


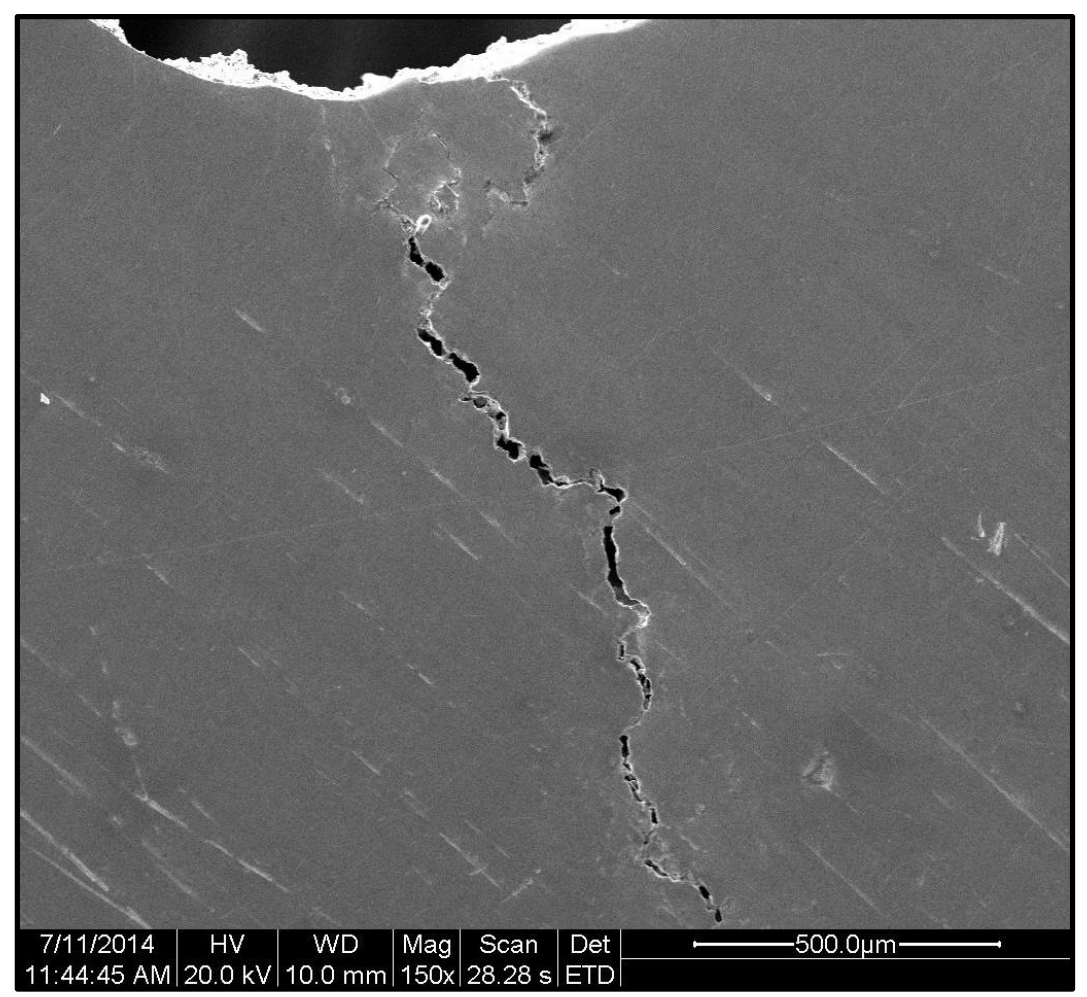

Figure 57. Tooth root crack on Gear 9 -Tooth 2 at 150x mag.

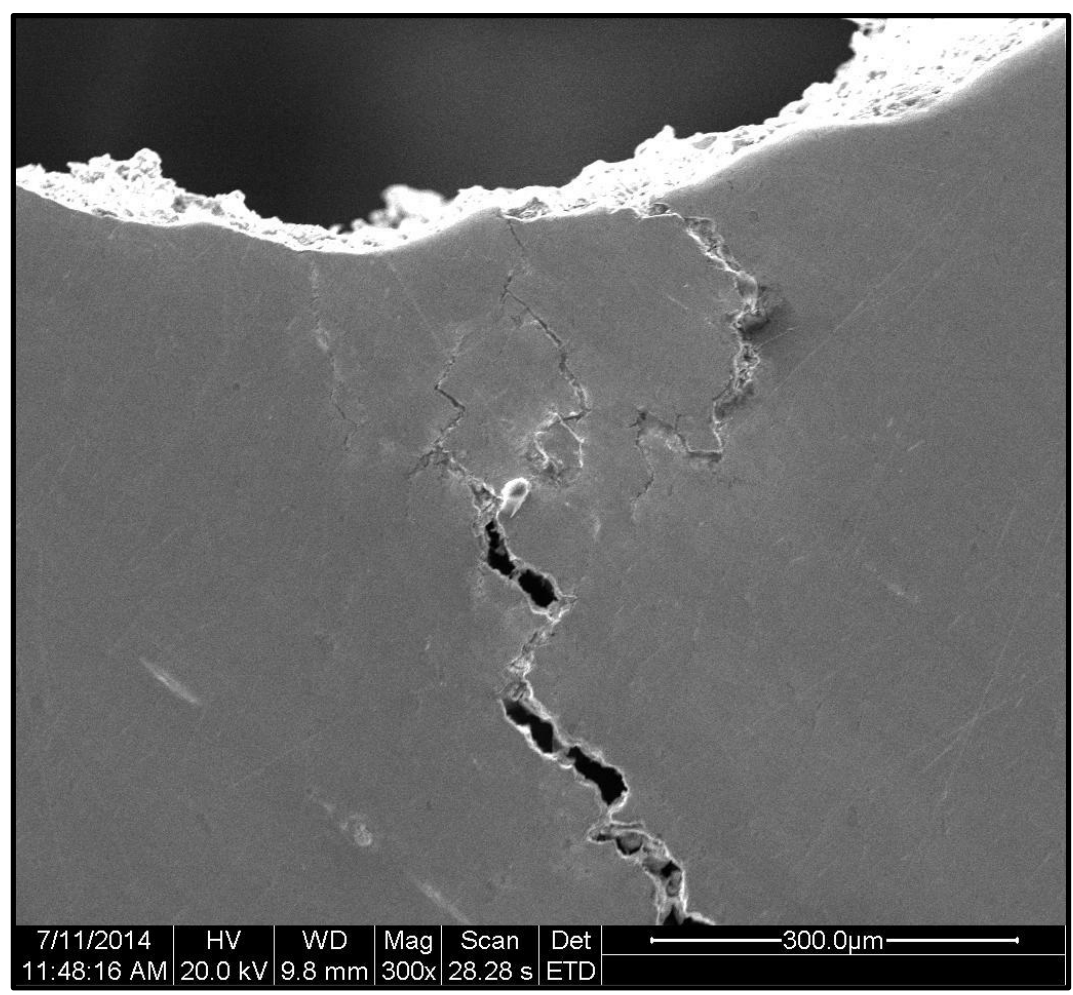

Figure 58. Tooth root crack initiation site on Gear 9 -Tooth 2 at 300x mag. 


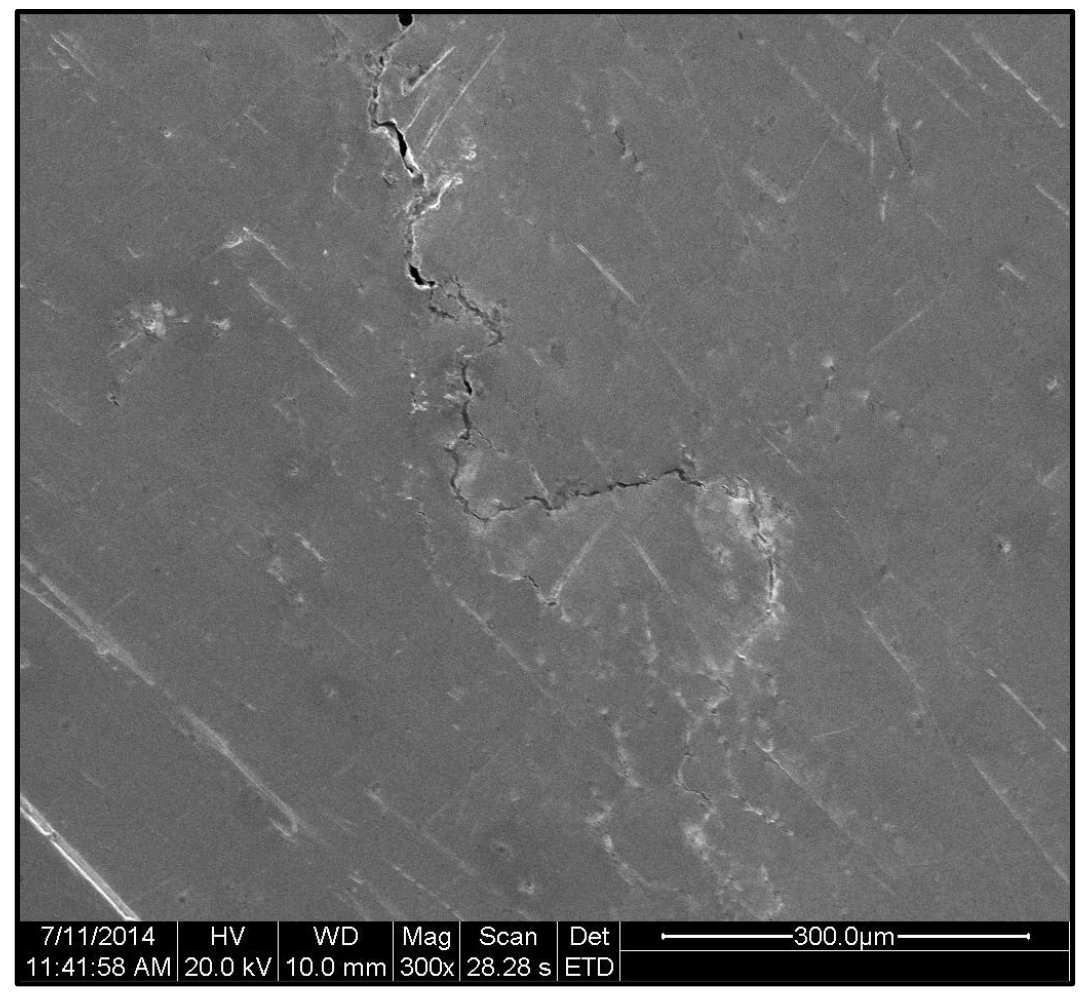

Figure 59. Crack end on Gear 9 -Tooth 2 at 300x mag.

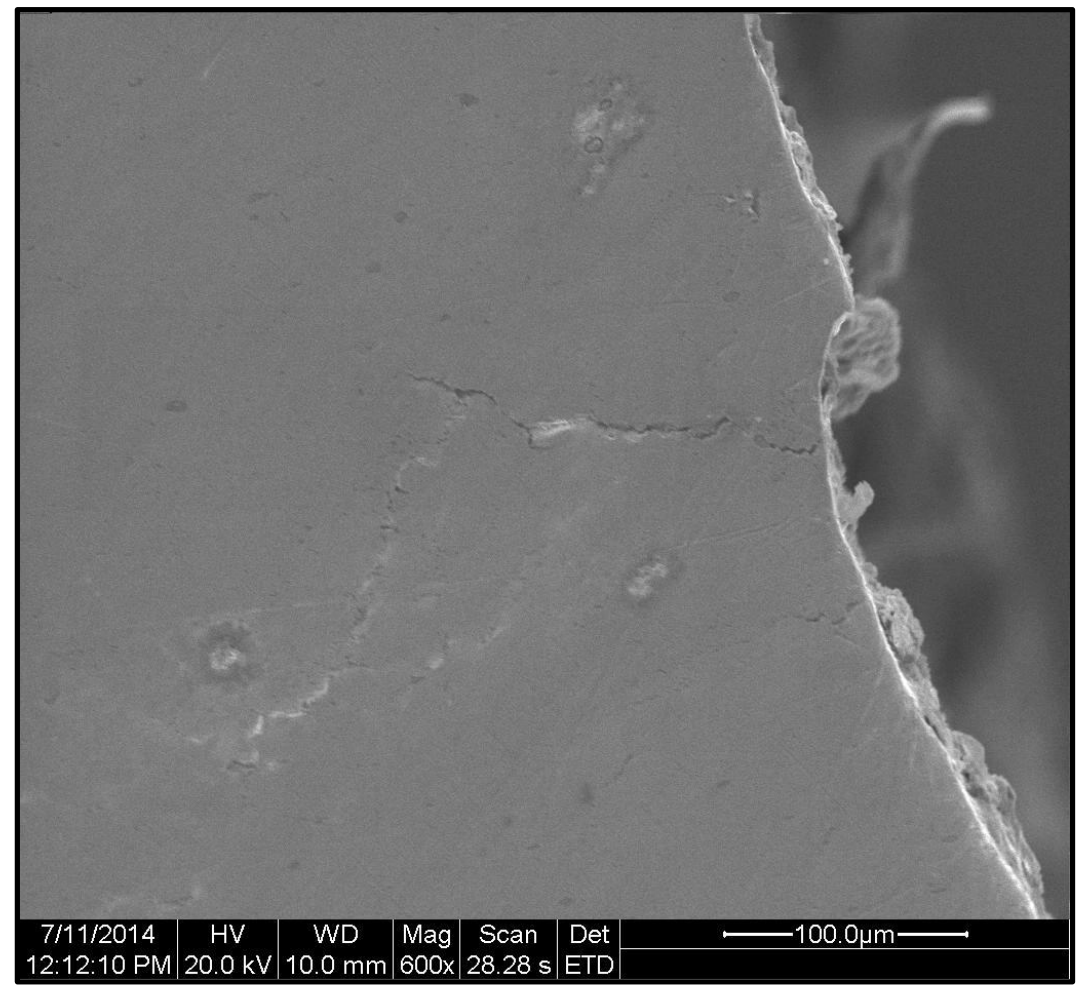

Figure 60. Tooth root crack on Gear $9-$ Tooth 3 at $600 x$ mag. 


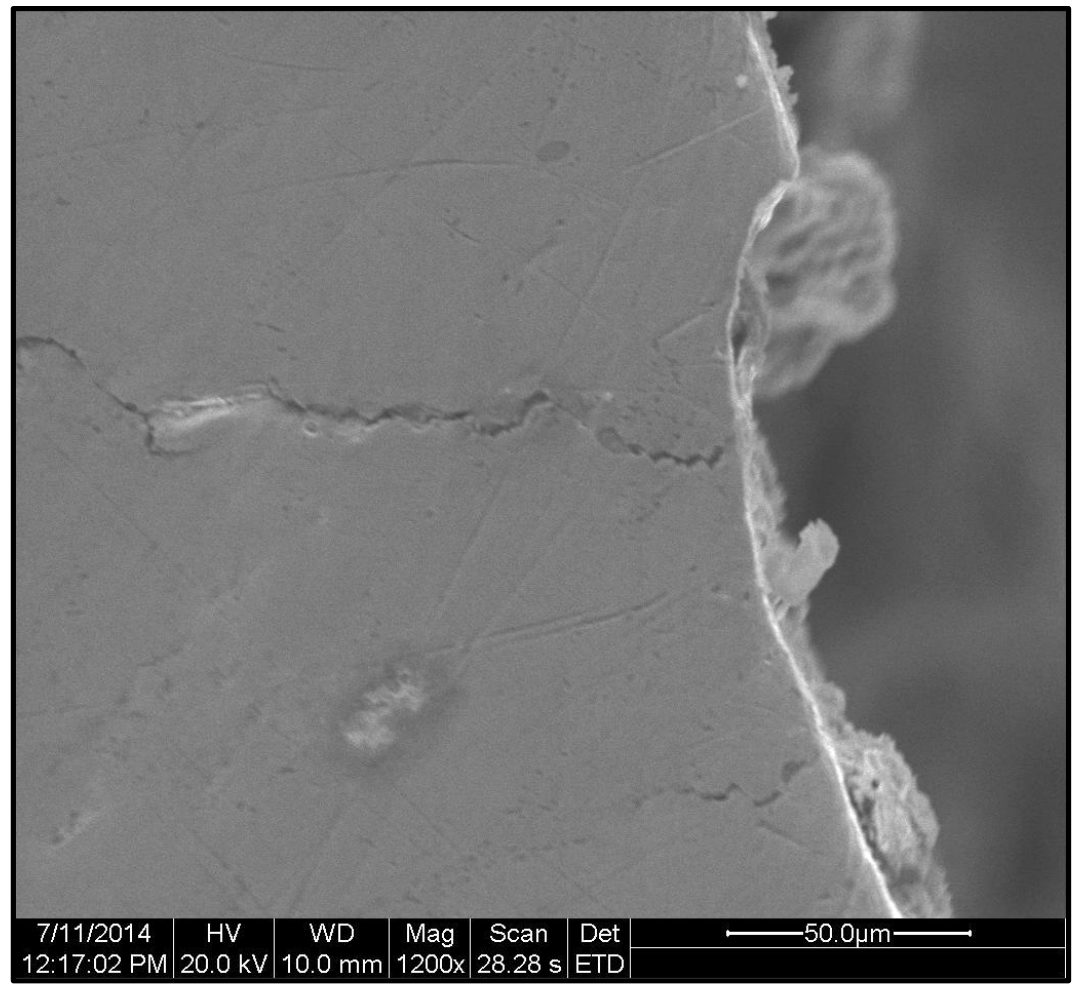

Figure 61. Tooth root crack initiation site on Gear 9 -Tooth 3 at $1200 x$ mag. 


\section{FUTURE WORK}

In the immediate future this research shall continue with current graduate students at Cal Poly. Although a definitive process has been developed and outlined for propagating a fatigue crack in a gear tooth root, some improvements are needed. First off, the lighting is the key to capturing a fatigue crack on the digital microscope. Although the crack was captured on video, better visibility could lead to the analysis of video stills to determine crack length at various times in the test. In addition to this work, the gearbox dynamic simulator needs to be run and an acoustic analysis recorded for the healthy gearbox system using the ADRE 408 data acquisition system. An accelerometer or $\mathrm{AE}$ sensor will be placed on multiple bearing housings and accelerations will be recorded. An FFT analysis of the acceleration acoustic spectra can be compared to the Adams gearbox model to determine the model validity. Next the S1224BS 1 spur gear in the gearbox dynamic simulator will be removed and placed in the fatigue fixture for testing. A fatigue test will be run on a single spur gear tooth and when the onset of damage is present the test will be stopped and the gear removed from the fixture. The damaged spur gear will be placed back into the gearbox and an acoustic analysis collected for the damaged system. Once completed, the gear shall be removed once again and placed back into the fatigue fixture. In the Instron, a ramp load will be applied and the fatigued tooth will be brought to complete failure. In the SEM, the crack initiation site and beach markings associated with the fatigue crack growth can be analyzed. This allows for a final crack size to be measured and then the acoustic signature from the damaged gearbox shall be associated with it. This process will be repeated for gears with various crack lengths. A gearbox with a spur gear that has fatigue crack damage of similar geometry and length will then be modeled in Adams and compared to the actual damaged gearbox acoustic signature. 


\section{CONCLUSION}

The main goal of this study was to develop a practical approach to the detection of early onset of damage in gearbox transmissions. The work done in this thesis was the first step in the process. Research was conducted to develop and understand a detailed computer model of a two-stage fixed axis gearbox. This model was used to simulate the behavior of an experimental gearbox in our vibrations laboratory. A healthy and damaged model was created and compared using an FFT analysis of the gear contact forces and bearing accelerations. The damage studied was a fatigue crack at the root of a single gear on the input shaft. The next step of this study was to produce a repeatable procedure to initiate and propagate a fatigue crack at the tooth root in an actual spur gear. This second goal was accomplished with the development of a custom fatigue fixture in conjunction with an Instron fatigue tester utilizing position control testing.

The healthy and damaged two-stage gearbox computer models were compared using the sideband energy ratio approach. Sideband energy ratio compares the amplitudes of the first six sidebands on each side of the central gear mesh frequency to the amplitude of the gear mesh frequency. An SER value less than 1 yields a healthy system where as a value greater than 1 means damage is present. In both the gear contact force and input bearing translational acceleration FFT plots a significant increase in SER was detected. All examined gear mesh frequency peaks in the healthy model had a SER less than 1. A majority of the gear mesh frequency peaks in the damaged model were greater than 1 and all values increased significantly from the healthy system. This result confirmed that damage was present and the gearbox computer models successfully compared the difference between a healthy and damaged gearbox. 
A damaged spur gear was needed so an actual healthy and damaged gearbox can eventually be compared through experimentation with the gearbox dynamic simulator. A custom fatigue fixture was designed and manufactured for the pinion gear in the actual gearbox. The fatigue crack was initiated by position control fatigue testing which deflects the gear tooth a set amplitude for a number of cycles. Over time the load that the tooth can withstand in bending decreases as damage begins to occur. Once the max load on the gear has dropped by a significant percentage (5-15\%) a crack has initiated and begun to propagate across the tooth face. The use of a scanning electron microscope confirmed the presence a fatigue crack.

Future work shall involve collecting data from the gearbox dynamic simulator and validating the accuracy of the computer model. The healthy input spur gear shall be removed and using the fatigue fixture and Instron, a fatigue crack will be created on a single gear tooth. This damaged gear shall then be put back into the gearbox dynamic simulator and data collected on a damaged system. A comparison between the healthy and damaged gearbox dynamic simulator can then be conducted. Next a comparison between the damaged gearbox dynamic simulator and the damaged gearbox computer model can be conducted. Once the validity and accuracy of the healthy and damaged computer models are confirmed or denied, improvements can be made to emulate the actual gearbox even more.

The end goal of the research in the present study and the work that will come is to get even closer to developing a complete health-monitoring system for gearbox transmissions. This technology can ultimately save cost in the rotorcraft and wind turbine industry and help save lives from preventing mid-air gearbox transmission failures. 


\section{REFERENCES}

[1] Gasparini, G., U. Mariani, C. Gorla Gorla, M. Filippini, and F. Rosa. "Bending Fatigue Tests of Helicopter Case Carburized Gears: Influence of Material, Design and Manufacturing Parameters." GEARTECHNOLOGY Nov/Dec (2009): 6876.www.geartechnology.com. Nov. 2009. Web. 27 Sept. 2013.

[2] Daniewicz, S. R., and D. H. Moore. "Increasing the Bending Fatigue Resistance of Spur Gear Teeth Using a Presetting Process." International Journal of Fatigue 20.7 (1998): 537-42. Print.

[3] Nenadic, Nenad G., Joseph A. Wodenscheck, Michael G. Thurston, and David G. Lewicki. "Seeding Cracks Using a Fatigue Tester for Accelerated Gear Tooth Breaking." Rotating Machinery, Structural Health Monitoring, Shock and Vibration 5 (2011): 349-57. Web. 29 Sept. 2013.

[4] Zakrajsek, James J., and David G. Lewicki. Detecting Gear Tooth Fatigue Cracks in Advance of Complete Fracture. Tech. no. ARL-TR-970. Cleveland: Army Research Laboratory, 1996. Print.

[6] Choy, F. K., D. H. Mugler, and J. Zhou. "Damage Identification of a Gear Transmission Using Vibration Signatures." Journal of Mechanical Design 125.2 (2003): 394-403. Print.

[7] Pullin, Rhys, A. Clarke, M.J. Eaton, Karen M. Holford, S.L. Evans, and J.P. McCory. "Detection of Cracking in Gear Teeth Using Acoustic Emission." Applied Mechanics and Materials 24-25 (2010): 45-50. Scientific.net Materials Science and Engineering. 30 June 2010. Web. 2 Oct. 2013.

[8] Budynas, Richard G., J. Keith. Nisbett, and Joseph Edward. Shigley. Shigley's Mechanical Engineering Design. New York: McGraw-Hill, 2011. Print.

[9] Errichello, Bob, and Jane Muller. "How to Analyze Gear Failures." How to Analyze Gear Failures. Geartech, n.d. Web. 5 Dec. 2013.

[10] K.Gopinath, and M.M.Mayuram. Tooth breakage. Machine Design II Lecture 6 GEAR FAILURE, Indian Institute of Technology Madras. Web. 10 Oct. 2013.

[11] Different Types of Gears. 2006. gearsandstuff.com. Different Types of Gear, 5 Oct. 2013

[12] Lucas, Martin. "Acoustic Emission: The Next Generation of Vibration Techniques."Reliable Plant. N.p., n.d. Web. 2 Nov. 2013.

[13] "ER10K-NFF - ER-K - MB ER Adapter Series Centrik-Lok Ball Bearing Insert." Product. Rexnard Process and Motion Control, 2014. Web. 16 May 2014.

[14] Beardmore, Roy. "Lewis Form Factor." Spur Gears. Roymech, 2 Feb. 2013. Web. 15 Nov. 2013. 
[15] "Adams The Multibody Dynamics Simulation Solution." MSC Software. N.p., n.d. Web. 10 Jan. 2014.

[16] Beardmore, Roy. "Gears- Gearboxes." RoyMech. N.p., 6 Oct. 2012. Web. 30 Aug. 2014. <http://www.roymech.co.uk/Useful_Tables/Drive/Gears_Gearboxes.html>.

[17] Dudley, Darle W., S. P. Radzevich, and Darle W. Dudley. Dudley's Handbook of Practical Gear Design and Manufacture. Boca Raton, FL: CRC, 2012. Print.

[18] Toutountzakis, Tim, Chee Keong Tan, and David Mba. "Application of Acoustic Emission to Seeded Gear Fault Detection." NDT \& E International 38.1 (2005): 27-36. Web.

[19] Eftekharnejad, Babak, and D. Mba. "Seeded Fault Detection on Helical Gears with Acoustic Emission." Applied Acoustics 70.4 (2009): 547-55. Web

[20] "SAE J1619 Single Tooth Gear Bending Fatigue Test." SAE International. California Polytechnic State University, Jan. 1997. Web. 9 Jan. 2014.

[21] "Abaqus 6.12 Abaqus Interface for MSC.ADAMS User;s Manual." Faculty of Mathematics. University of Cambridge, n.d. Web. 15 May 2014.

[22] "Adams/View Help - Adams 2012.1.2." MSC Software, n.d. Web. 20 Mar. 2014. <https://simcompanion.mscsoftware.com/infocenter/index?page=content\&id=DO C10021\&actp=LIST_POPULAR > .

[23] Deep Groove Ball Bearings, Single Row, Stainless Steel." Deep Groove Ball Bearings, Single Row, Stainless Steel. SKF, n.d. Web. 30 Mar. 2014. <http://www.skf .com/group/products/bearings-units-housings/ball-bearings/deepgroove-ball-bearings/single-row-stainless-steel/index.html?prodid=1010470004>.

[24] Hanna, J.; Hatch, C.; Kalb, M.; Weiss, A.; Luo, H. "Detection of Wind Turbine Gear Tooth Defects Using Sideband Energy Ratio ${ }^{\mathrm{TM}}$." China Wind Power 2011;October, 19-21, 2011, Beijing, China. http://www.ge$\mathrm{mcs} . c 0 \mathrm{~m} /$ download/monitoring/SER-Technical-Paper.pdf

[25] "Paris Law." Paris Law. University of Plymouth, n.d. Web. 17 Sept. 2014. <http://www.tech.plym.ac.uk/sme/tutorials/FMTut/Fatigue/FatTheory1.htm>.

[26] Davis, J. R. Gear Materials, Properties, and Manufacture. Materials Park, OH: ASM International, 2005. Print.

[27] Sawatzky, Rene. Vibration Based Planetary Gear Analysis and Damage Detection. Thesis. California Polytechnic State University, 2014. San Luis Obispo: California Polytechnic State U, 2014. Print. 
[28] Wu, X., B. Fang, A. Sommer, and J. Meagher. Frequency-domain Analysis of a Two-stage Planetary Gear with Combined Backlash and Tooth Damage Nonlinearities. Proc. of ASME 2013 International Design Engineering Techincal Conferences \& Computers and Information in Engineering Conference, Oregon, USA, Portland. August 4-7, 2013. Print.

[29] Fang, Brian. CAE Methods on Vibration-based Health Monitoring of Power Transmission Systems. Thesis. California Polytechnic State University, 2013. San Luis Obispo: California Polytechnic State U, 2013. Print. 


\section{APPENDICES}

\section{A. FATIGUE FIXTURE DRAWINGS}

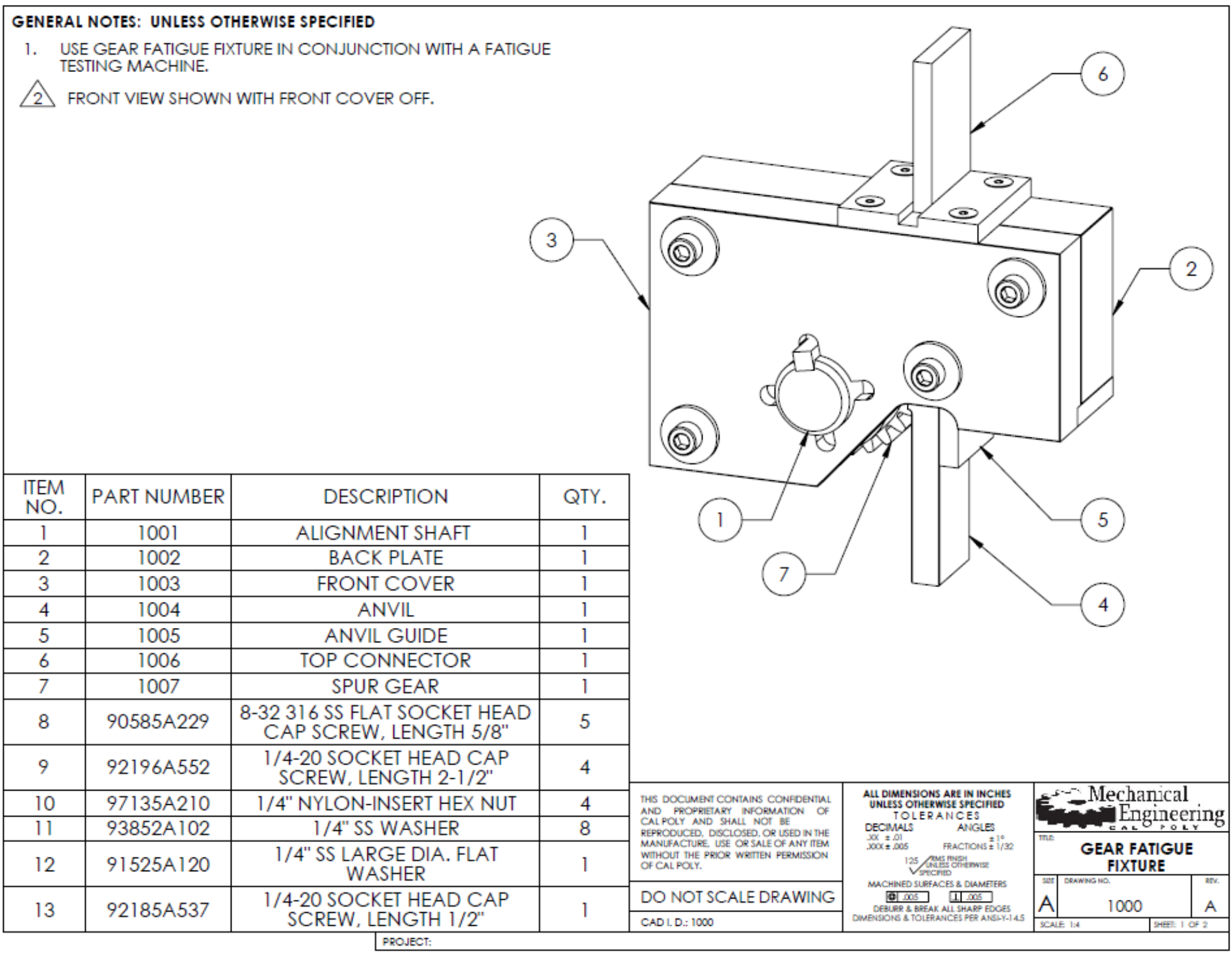




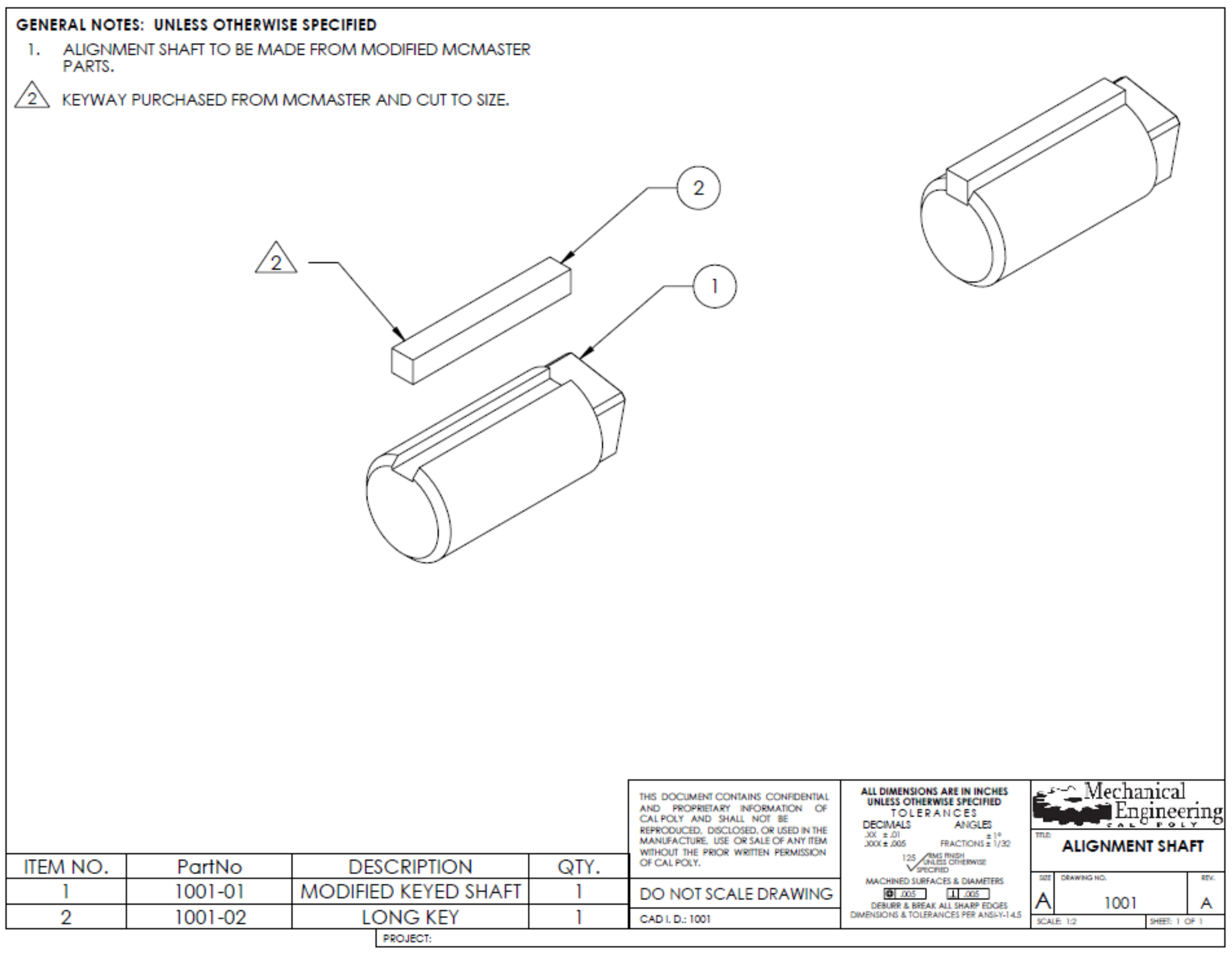




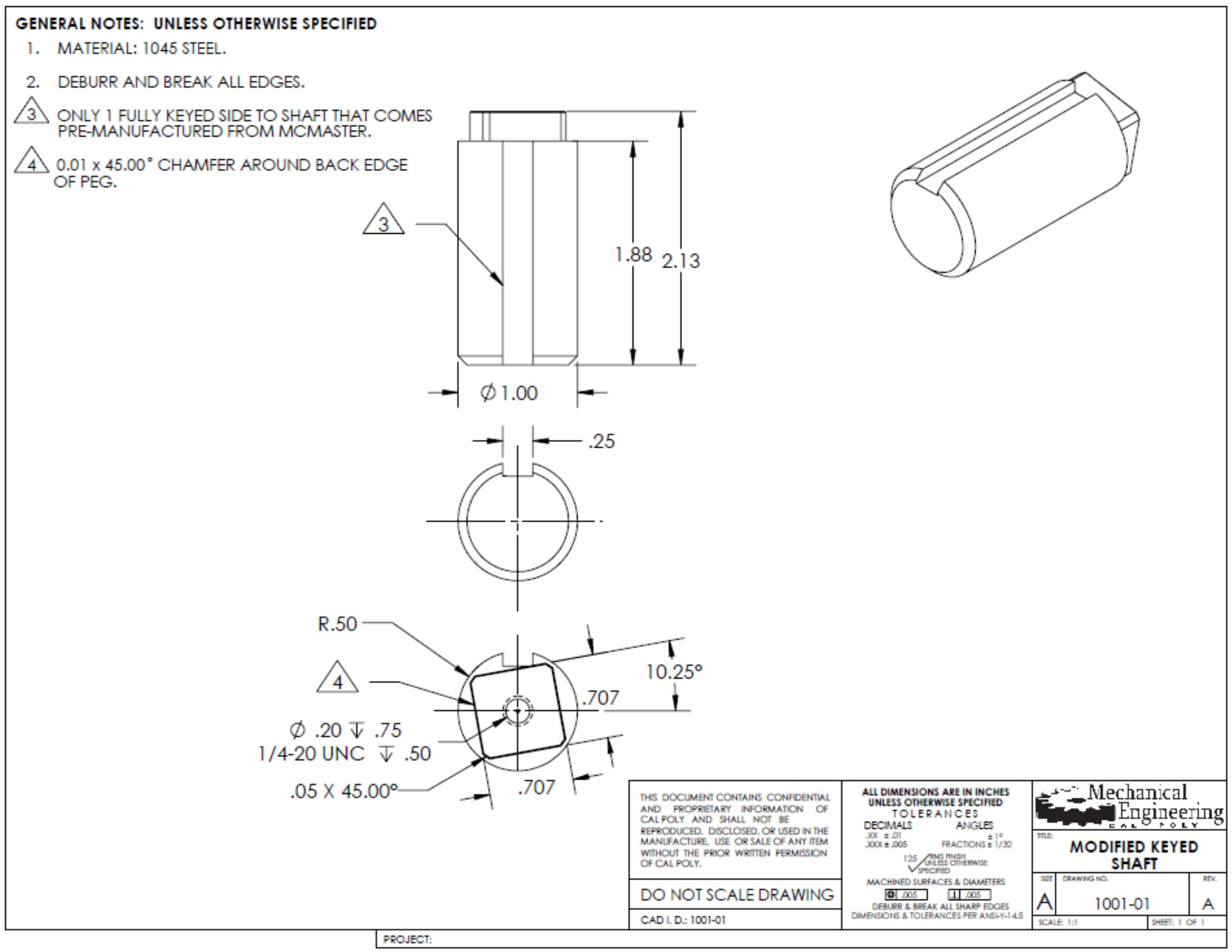




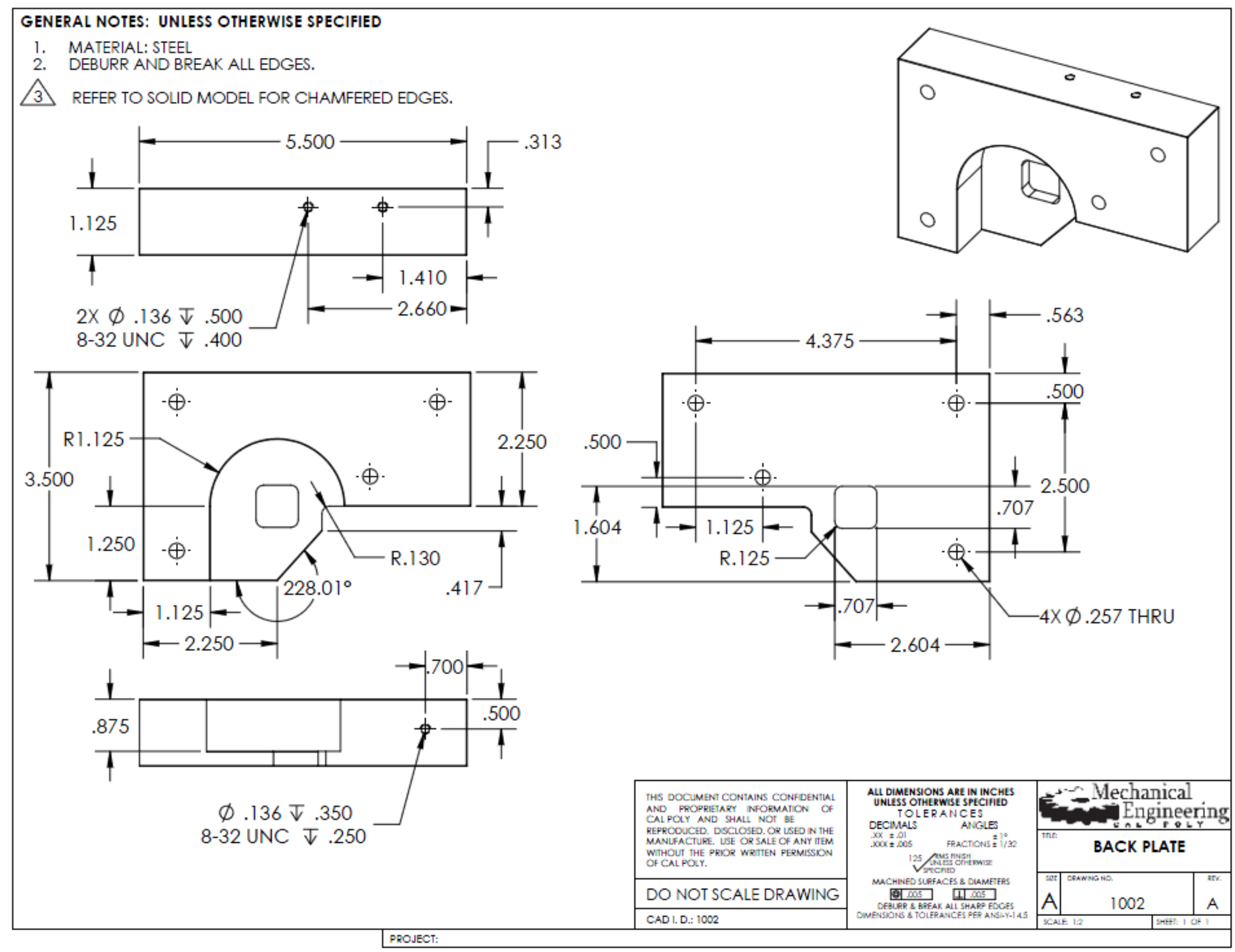




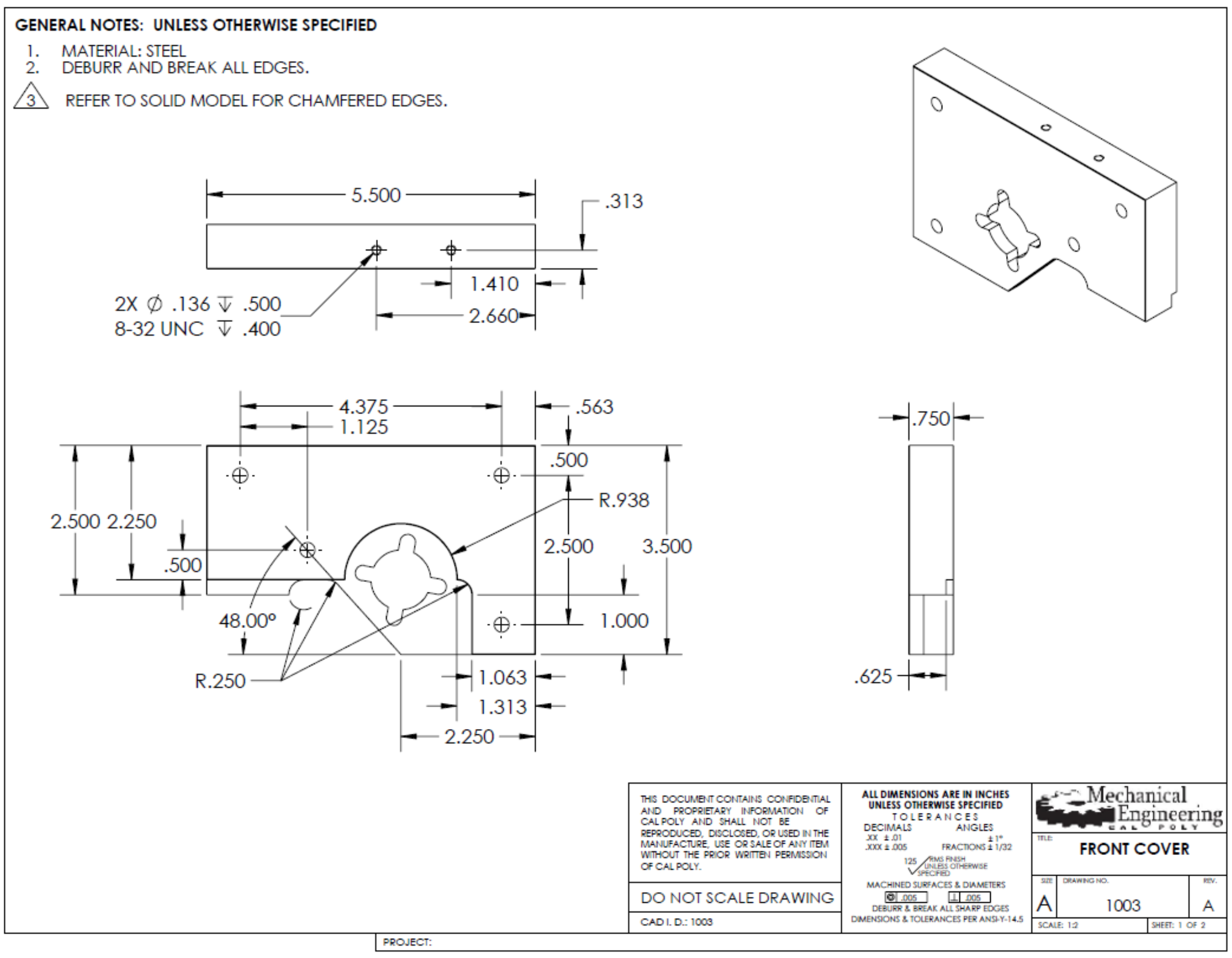




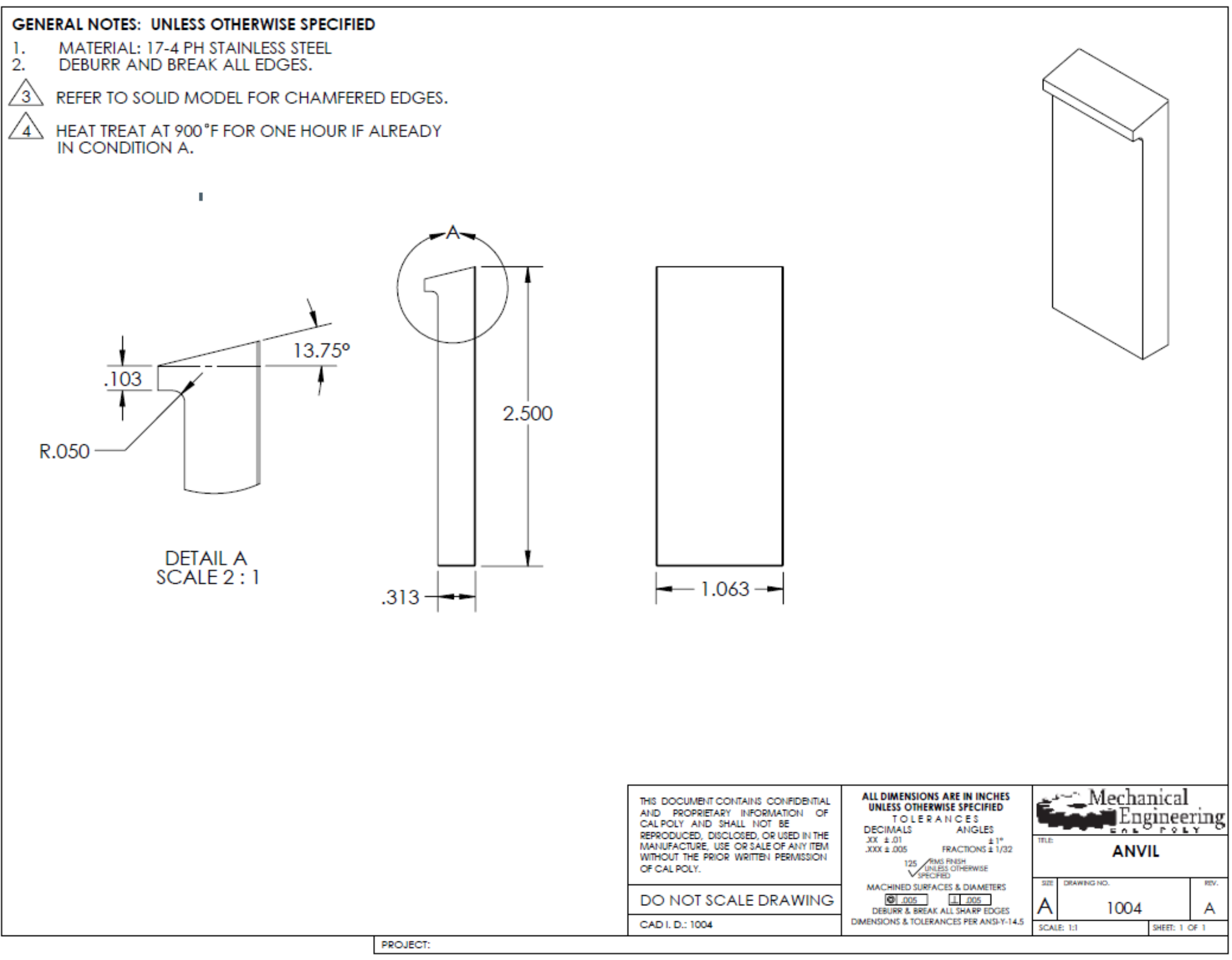




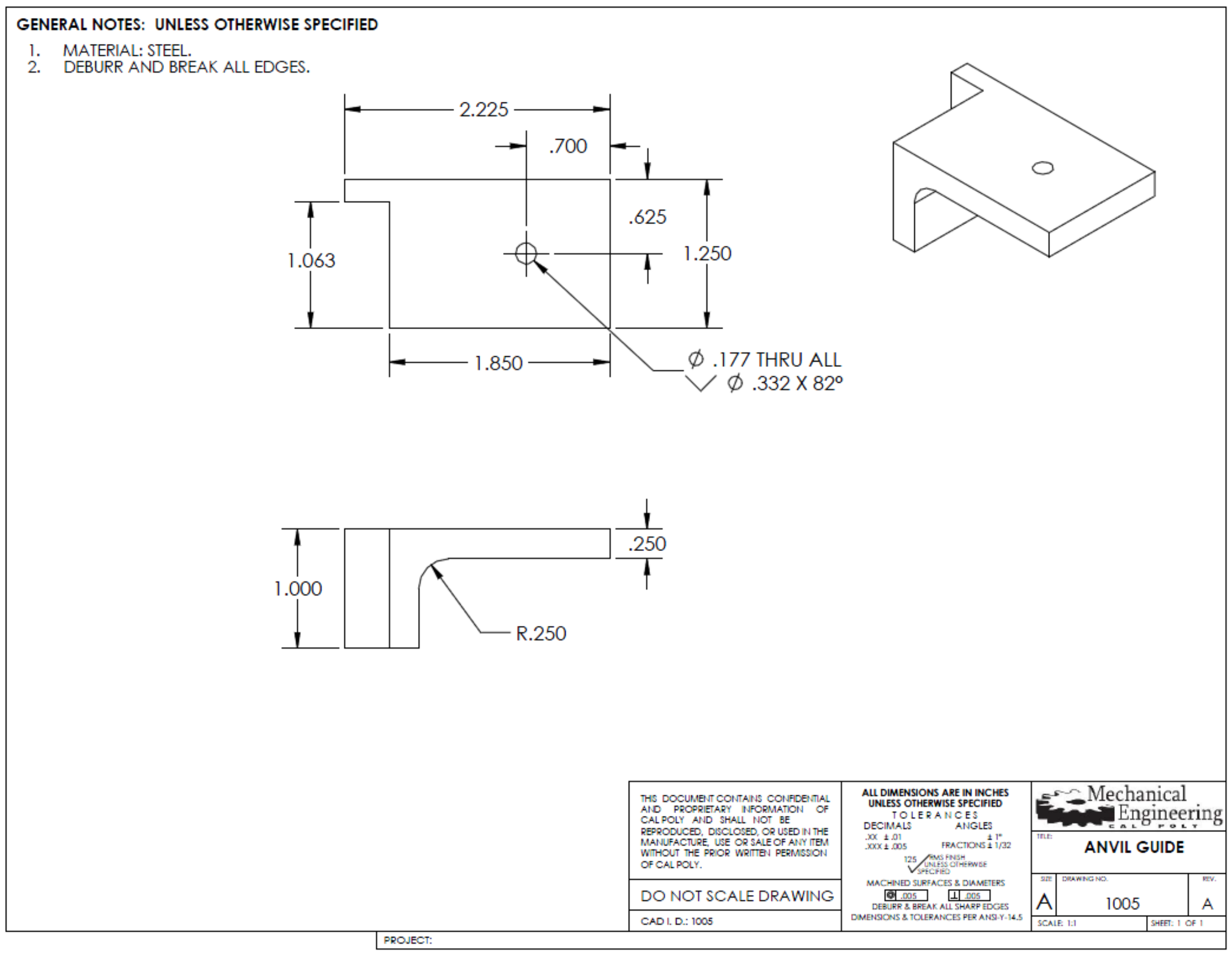




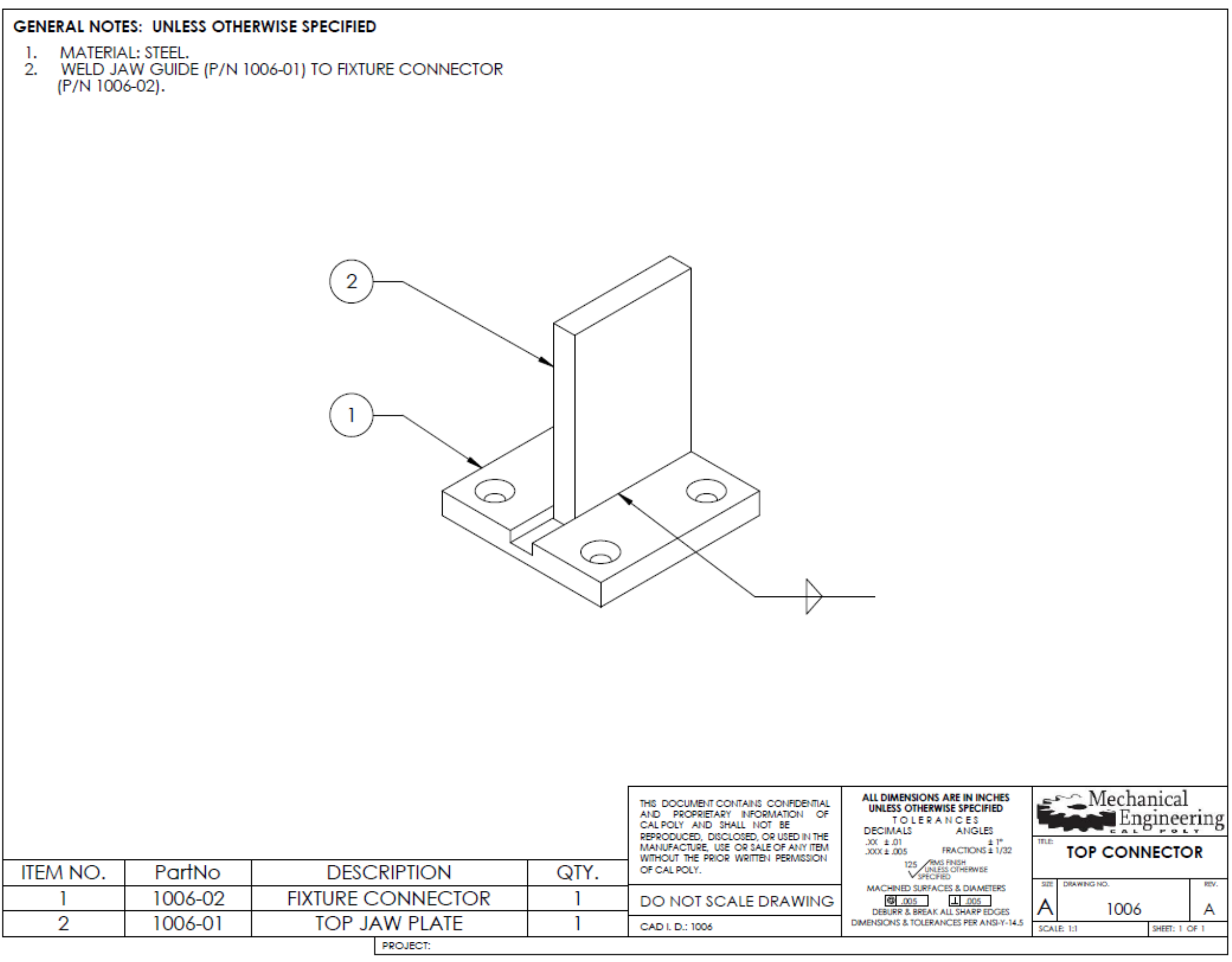




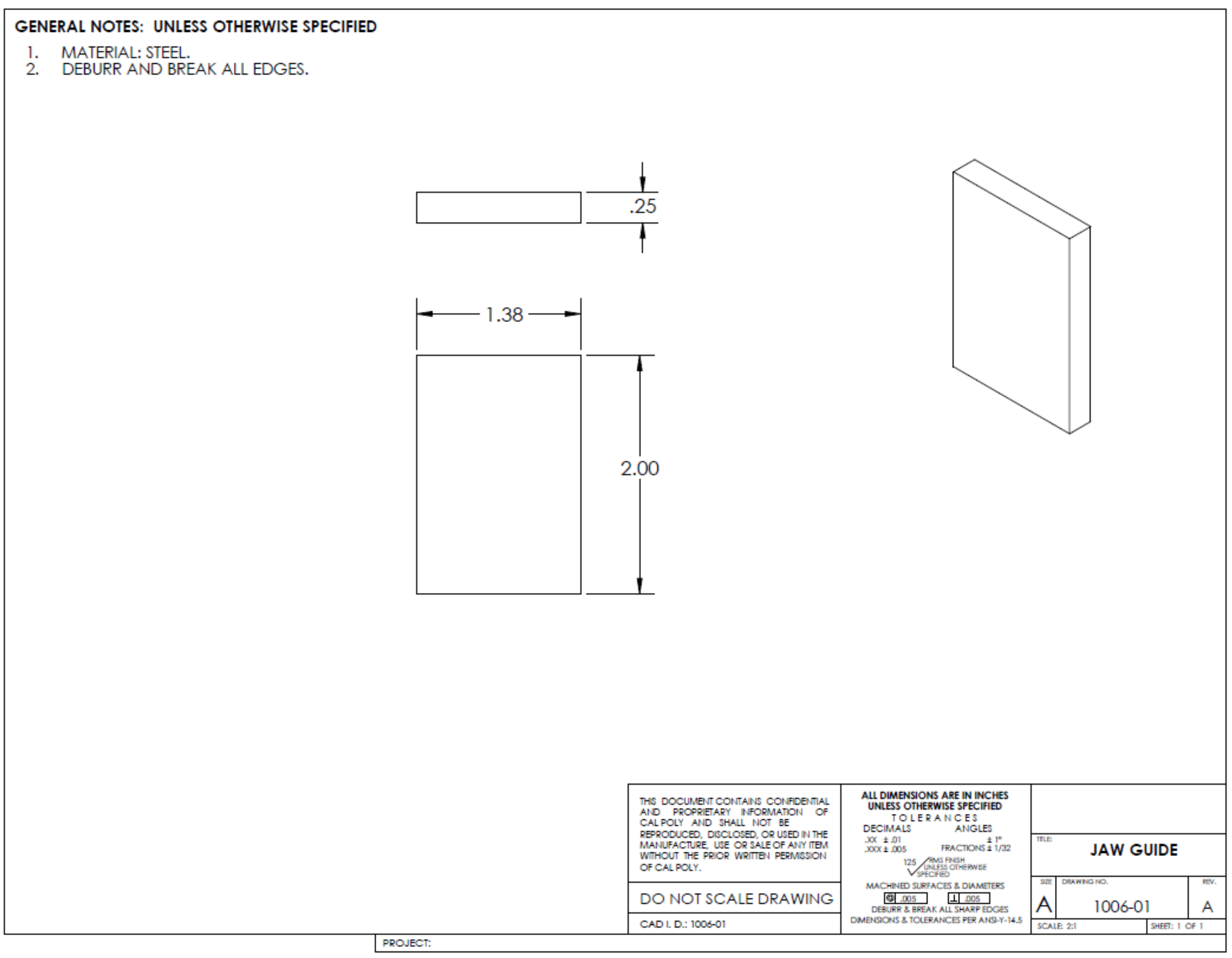




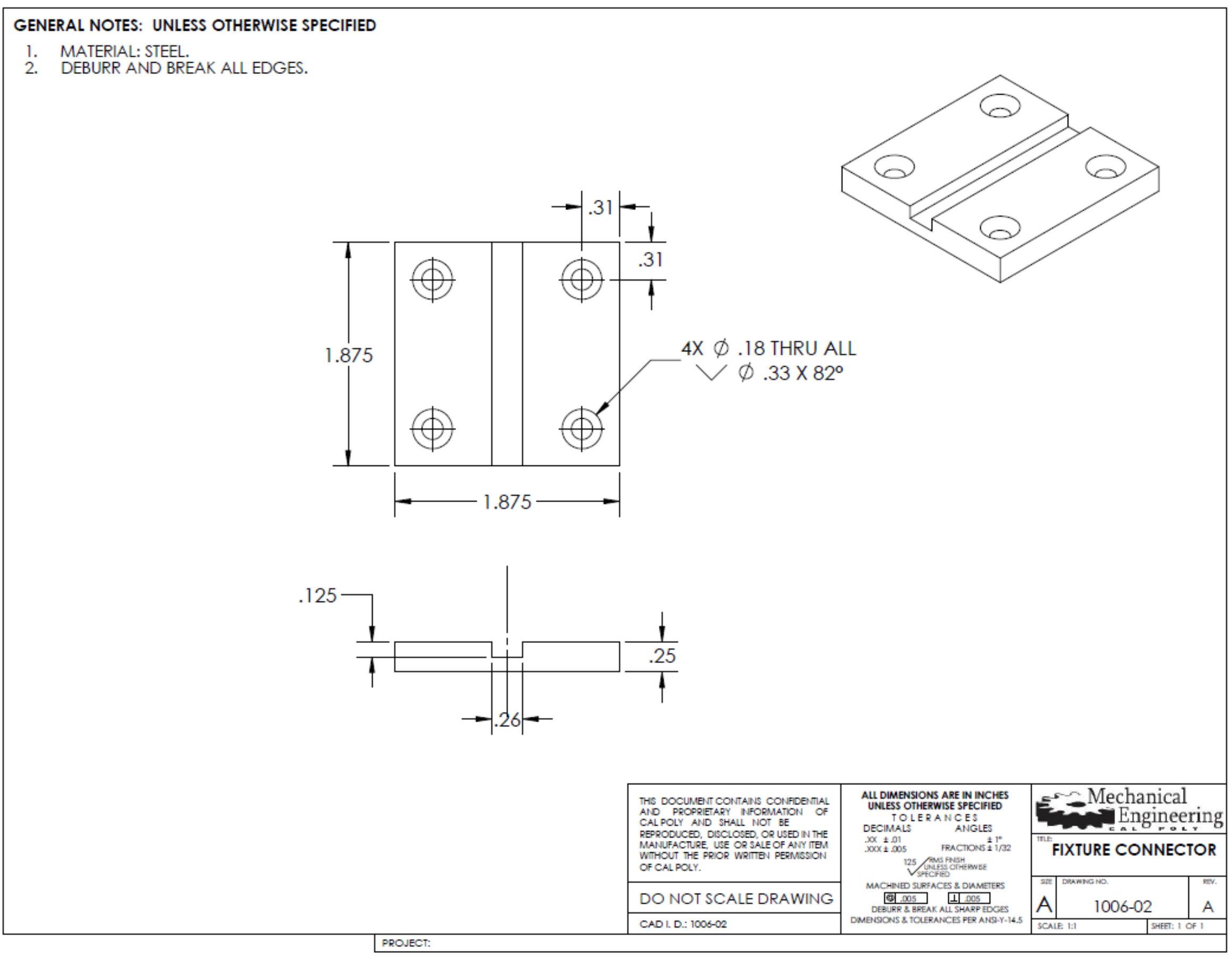




\section{B. MANUFACTURER SPECIFICATIONS}

\section{Martin Spur Gears}

\begin{tabular}{|c|c|c|c|c|}
\hline \multicolumn{5}{|l|}{ Product Detail } \\
\hline$\theta$ & \multicolumn{4}{|c|}{$\begin{array}{l}\text { GEAR SPUR } 141 / 2 \text { DEG STEEL } \\
\text { S1224BS } 1 \\
\text { UPC: } 697950439198 \\
\text { Martin Stock Spur Gears are available in five different styles. Steel Gears are } \\
\text { furnished in plain style and plain style with hub. Cast gears are furnished, plain } \\
\text { with hub, web with lightening holes, and spoke. Cast gears are machined on all } \\
\text { operating surfaces. Martin cast gears are cast with a larger hub to provide } \\
\text { extra strength and to allow for larger bores. Spur gears are stocked in both } 14 \\
1 / 2 \text { and } 20 \text { degree pressure angles. }\end{array}$} \\
\hline Product Specifications & \multicolumn{4}{|l|}{ Misc Info } \\
\hline Material & & Steel & Finished Bore Size & $1.000 \mathrm{in.}$ \\
\hline Diametral Pitch & & 12 & Key Way Size & $.250 \times .125 \mathrm{in}$. \\
\hline Pressure Angle & & $14.500 \mathrm{deg}$. & Set Screw Size & $5 / 16-18$ in. \\
\hline Number of Teeth & & 24 & Set Screw Location & 90 Degrees From Key Way \\
\hline Pitch Diameter & & $2.000 \mathrm{in.}$ & Hub Outside Diameter & 1.750 in. \\
\hline Outside Diameter & & $2.166 \mathrm{in.}$ & Hub Projection & $0.500 \mathrm{in.}$ \\
\hline Bore Type & & Bored To Size & & \\
\hline
\end{tabular}

\section{Product Detail

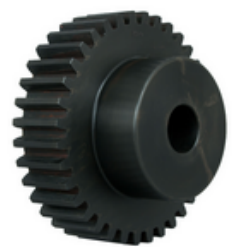 \\ GEAR SPUR 14 1/2 DEG STEEL \\ $\mathbf{S 1 2 6 0}$ \\ UPC: 697950057040 \\ Martin Stock Spur Gears are available in five different styles. Steel Gears are furnished in plain style and plain style with hub. Cast gears are furnished, plain with hub, web with lightening holes, and spoke. Cast gears are machined on all operating surfaces. Martin cast gears are cast with a larger hub to provide extra strength and to allow for larger bores. Spur gears are stocked in both 14 $1 / 2$ and 20 degree pressure angles}

\begin{tabular}{|l|r|l|r|}
\hline Material & Steel & Bore Type & Reborable \\
\hline Diametral Pitch & 12 & Set Screw Size & NONE in. \\
\hline Pressure Angle & $14.500 \mathrm{deg}$. & Set Screw Location & None \\
\hline Number of Teeth & 60 & Hub Outside Diameter & 2.750 in. \\
\hline Pitch Diameter & 5.000 in. & Hub Projection & 0.750 in. \\
\hline Outside Diameter & 5.167 in. & &
\end{tabular}




\begin{tabular}{|c|c|c|c|c|}
\hline \multicolumn{5}{|l|}{ Product Detail } \\
\hline \multicolumn{5}{|c|}{$\begin{array}{l}\text { GEAR SPUR } 141 / 2 \text { DEG STEEL } \\
\text { S1236 } \\
\text { UPC: } 697950056913 \\
\text { Martin Stock Spur Gears are available in five different styles. Steel Gears are } \\
\text { furnished in plain style and plain style with hub. Cast gears are furnished, plain } \\
\text { with hub, web with lightening holes, and spoke. Cast gears are machined on all } \\
\text { operating surfaces. Martin cast gears are cast with a larger hub to provide } \\
\text { extra strength and to allow for larger bores. Spur gears are stocked in both } 14 \\
1 / 2 \text { and } 20 \text { degree pressure angles. }\end{array}$} \\
\hline \multicolumn{5}{|c|}{\begin{tabular}{l|l} 
Product Specifications & Misc Info
\end{tabular}} \\
\hline Material & & Steel & Bore Type & Reborable \\
\hline Diametral Pitch & & 12 & Set Screw Size & NONE in. \\
\hline Pressure Angle & & 14.500 deg. & Set Screw Location & None \\
\hline Number of Teeth & & 36 & Hub Outside Diameter & 2.500 in. \\
\hline Pitch Diameter & & $3.000 \mathrm{in.}$ & Hub Projection & $0.625 \mathrm{in.}$ \\
\hline Outside Diameter & & $3.167 \mathrm{in.}$ & & \\
\hline
\end{tabular}

\begin{tabular}{|c|c|c|c|c|}
\hline \multicolumn{5}{|l|}{ Product Detail } \\
\hline \multicolumn{5}{|c|}{$\begin{array}{l}\text { GEAR SPUR } 141 / 2 \text { DEG STEEL } \\
\text { S1248 } \\
\text { UPC: } 697950056999 \\
\text { Martin Stock Spur Gears are available in five different styles. Steel Gears are } \\
\text { furnished in plain style and plain style with hub. Cast gears are furnished, plain } \\
\text { with hub, web with lightening holes, and spoke. Cast gears are machined on all } \\
\text { operating surfaces. Martin cast gears are cast with a larger hub to provide } \\
\text { extra strength and to allow for larger bores. Spur gears are stocked in both } 14 \\
1 / 2 \text { and } 20 \text { degree pressure angles. }\end{array}$} \\
\hline \multicolumn{5}{|c|}{ Product Specifications Misc Info } \\
\hline Material & & Steel & Bore Type & Reborable \\
\hline Diametral Pitch & & 12 & Set Screw Size & NONE in. \\
\hline Pressure Angle & & 14.500 deg. & Set Screw Location & None \\
\hline Number of Teeth & & 48 & Hub Outside Diameter & $2.500 \mathrm{in.}$ \\
\hline Pitch Diameter & & $4.000 \mathrm{in.}$ & Hub Projection & 0.750 in. \\
\hline Outside Diameter & & 4.166 in. & & \\
\hline
\end{tabular}




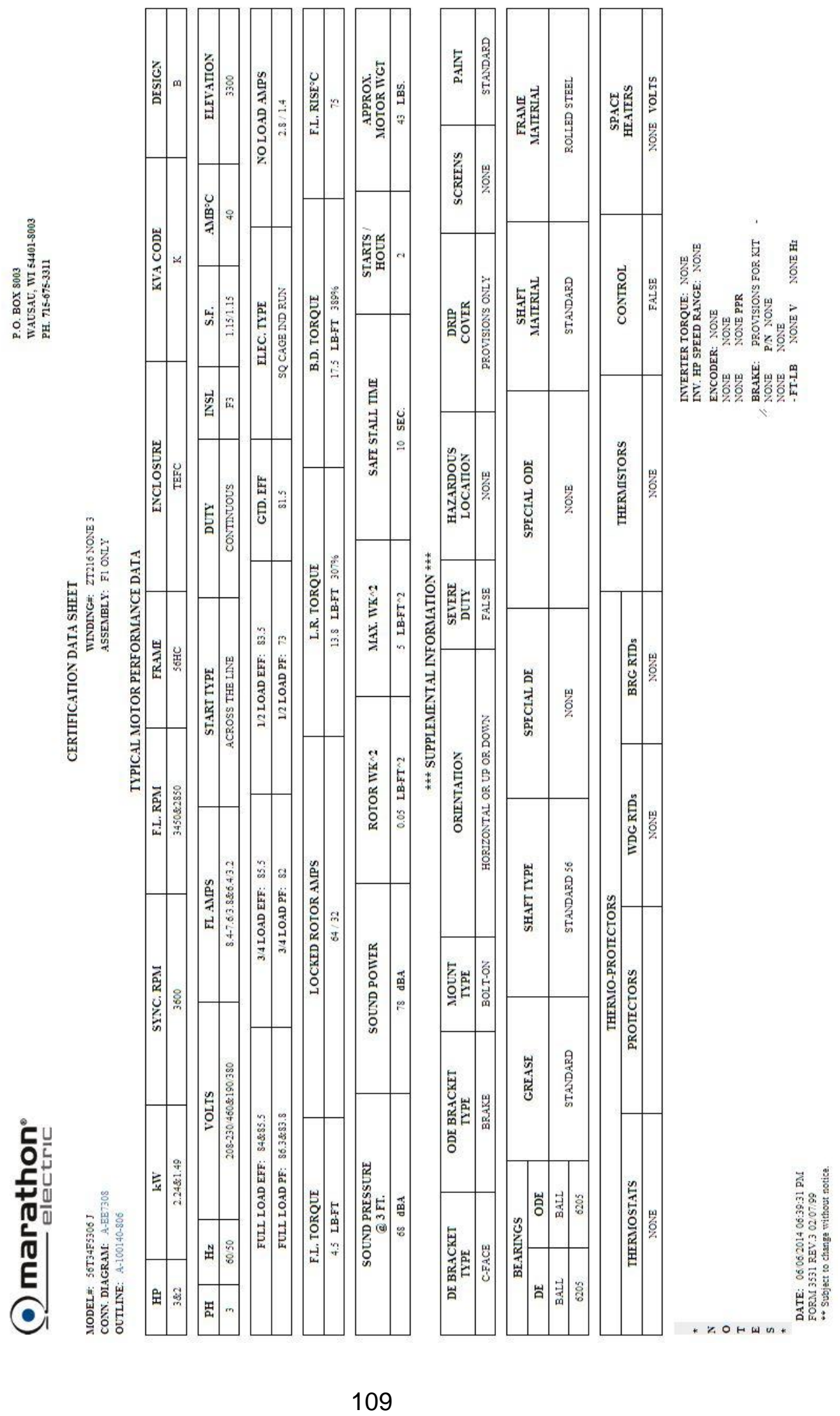




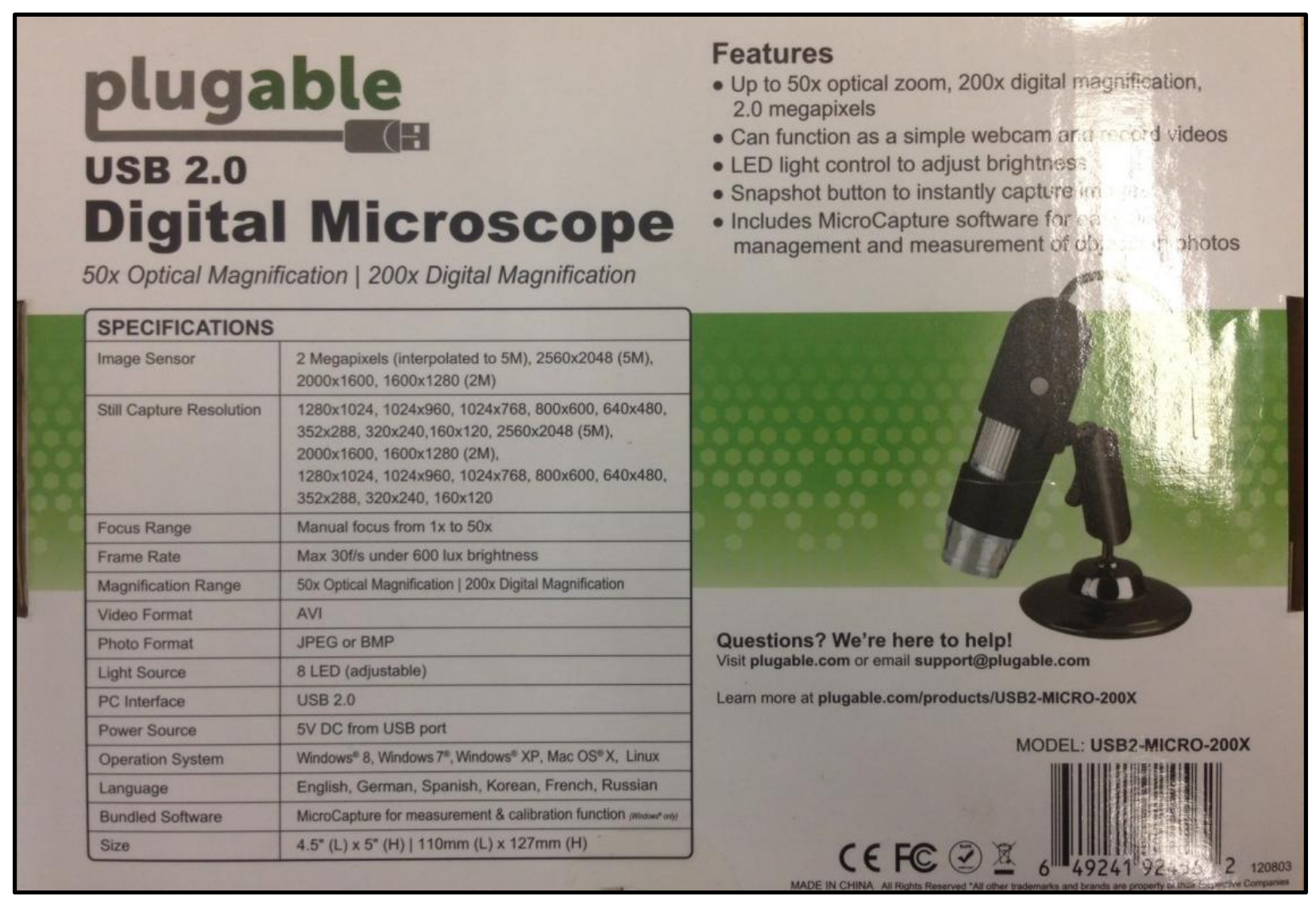




\section{SKF 6004-2Z Bearings}

\section{SICF}

Deep groove ball bearings, single row, for high temperatures

\begin{tabular}{|c|c|c|c|c|c|c|}
\hline \multicolumn{3}{|c|}{ Principal dimensions } & \multirow{2}{*}{$\begin{array}{l}\text { Basic load rating } \\
\text { static } \\
\text { CO }\end{array}$} & \multicolumn{2}{|c|}{ Radial internal clearance } & \multirow[t]{2}{*}{ Designation } \\
\hline d & D & B & & $\min$ & $\max$ & \\
\hline in & & & lbf & $\mu \mathrm{m}$ & & - \\
\hline 0.7874 & 1.6535 & 0.4724 & 1120 & 4409.4488 & 7559.0551 & 6004-2Z/VA208 \\
\hline
\end{tabular}
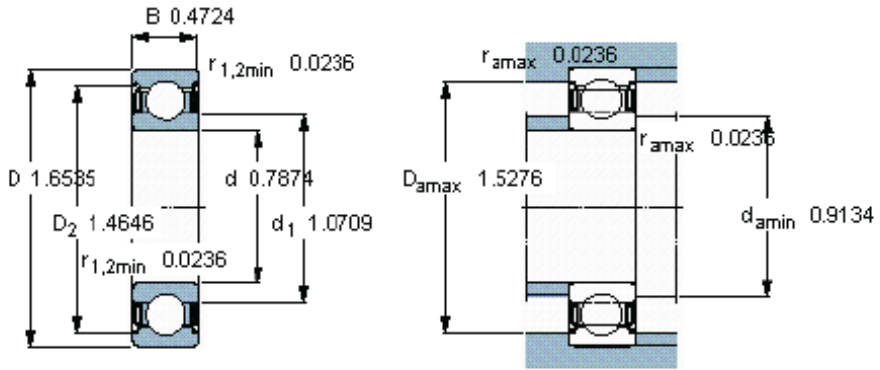

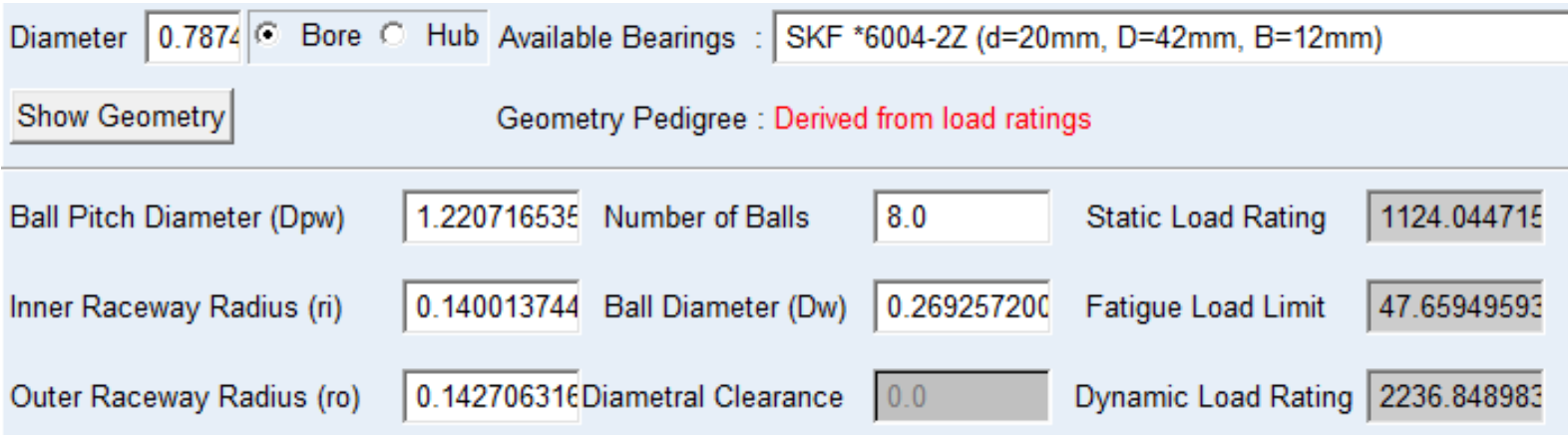




\section{POSITION CONTROL PLOTS AND BEARING ACCELERATION FFT PLOTS}

\section{POSITION CONTROL PLOTS}

Gear 6 - Tooth 1
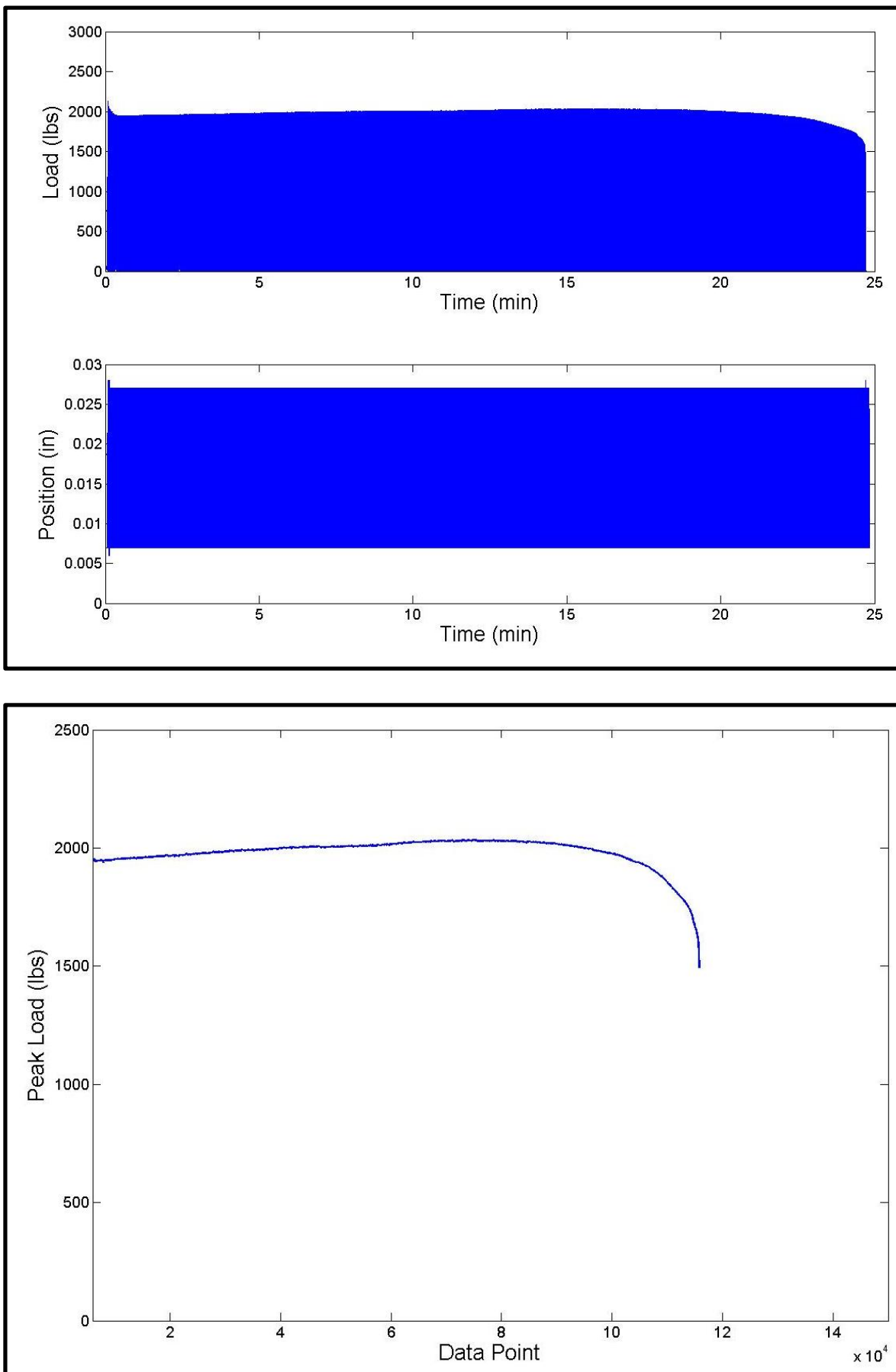

Gear 6 - Tooth 2 

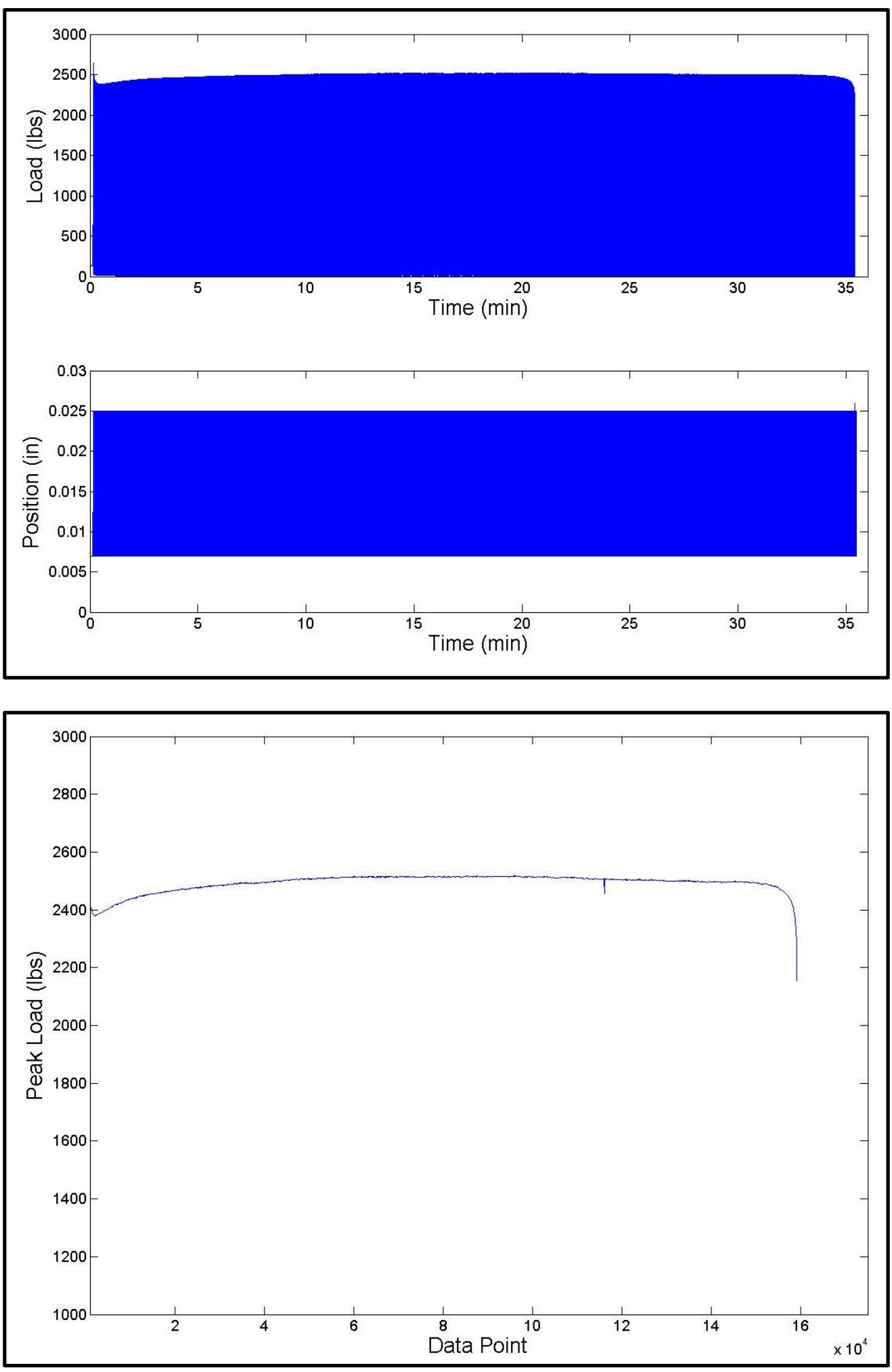

Gear 6 -Tooth 3 

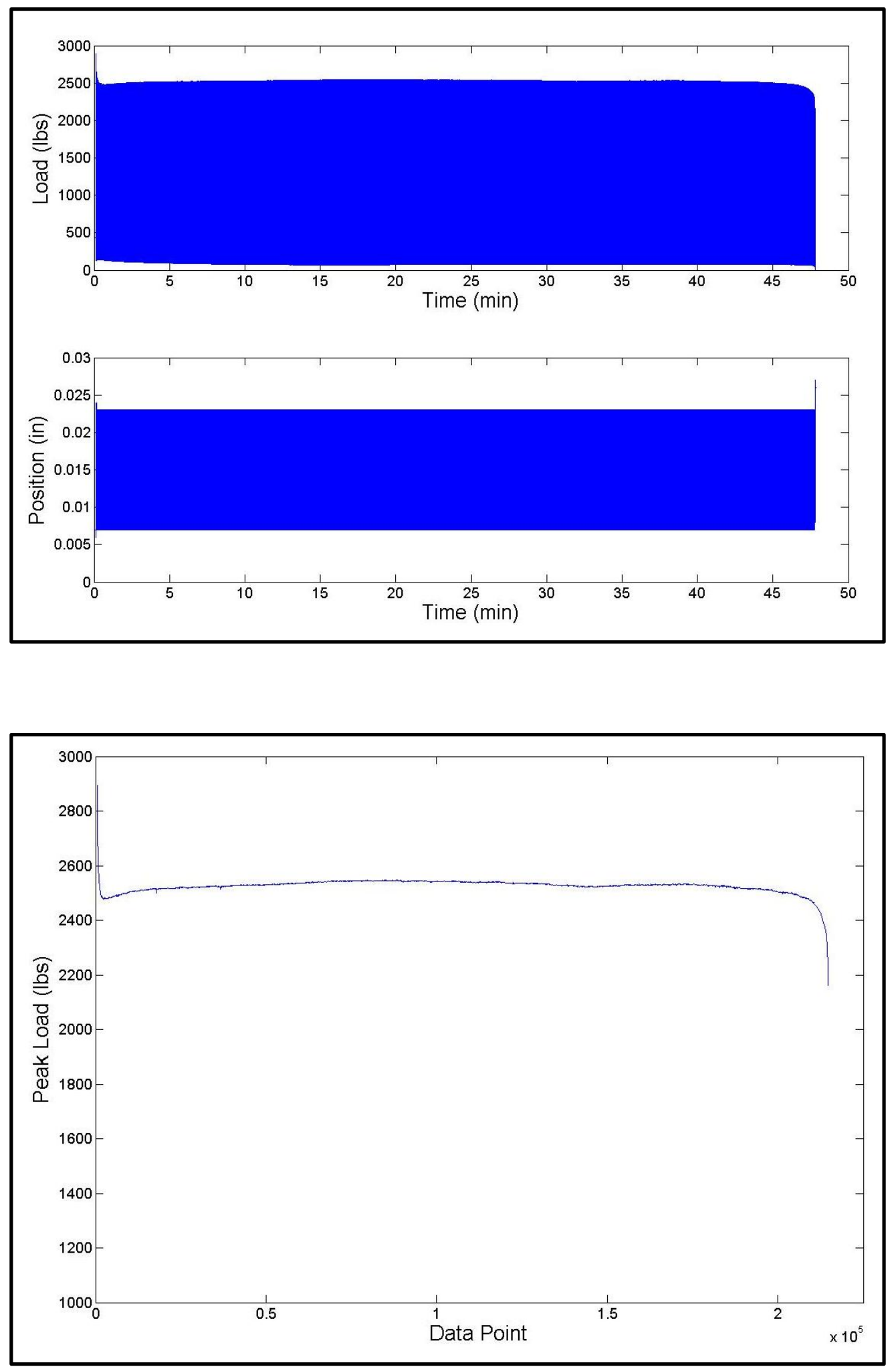

Gear 9 - Tooth 1 

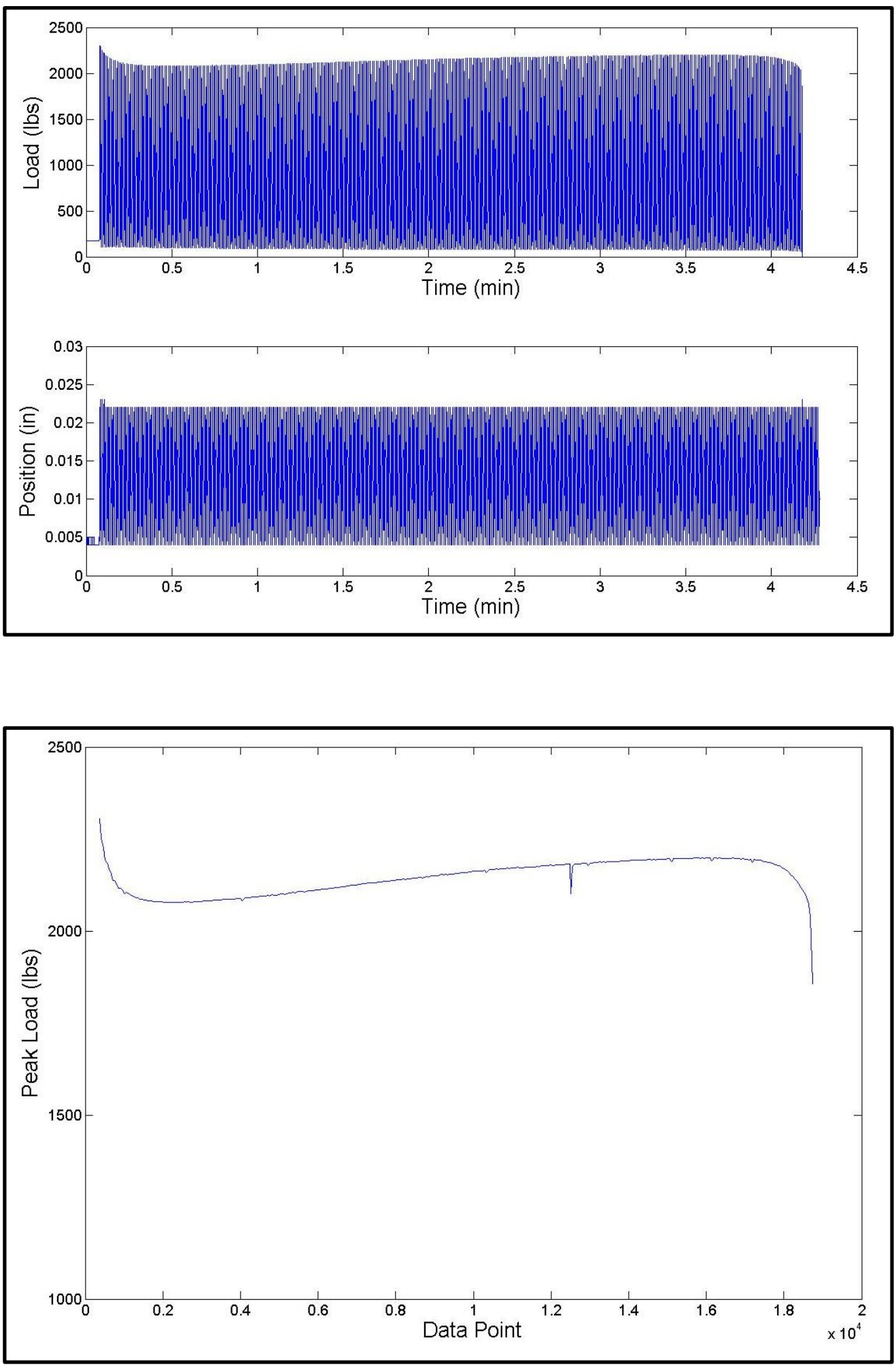

Gear 9 - Tooth 2 

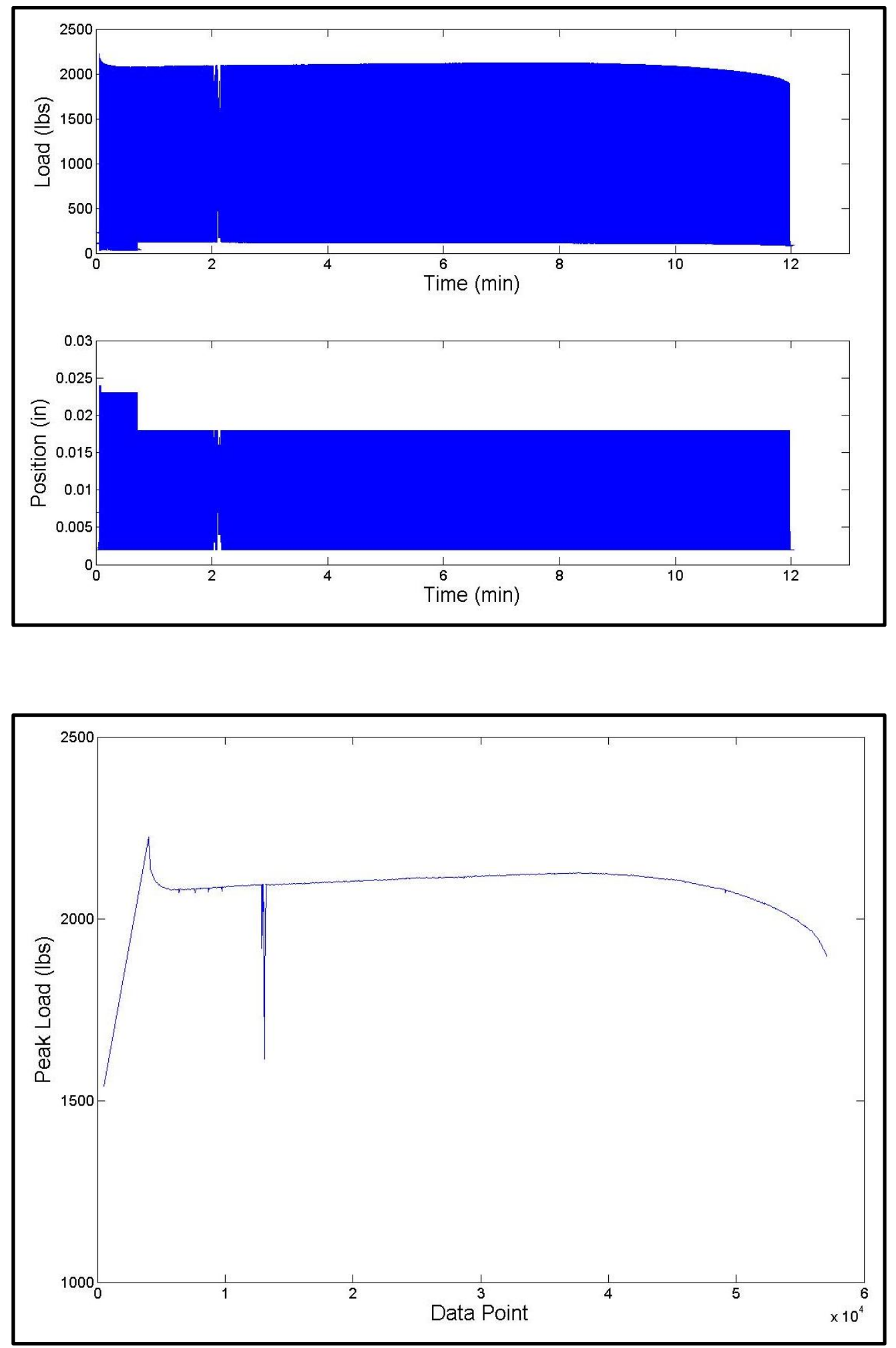

Gear 9 - Tooth 3 

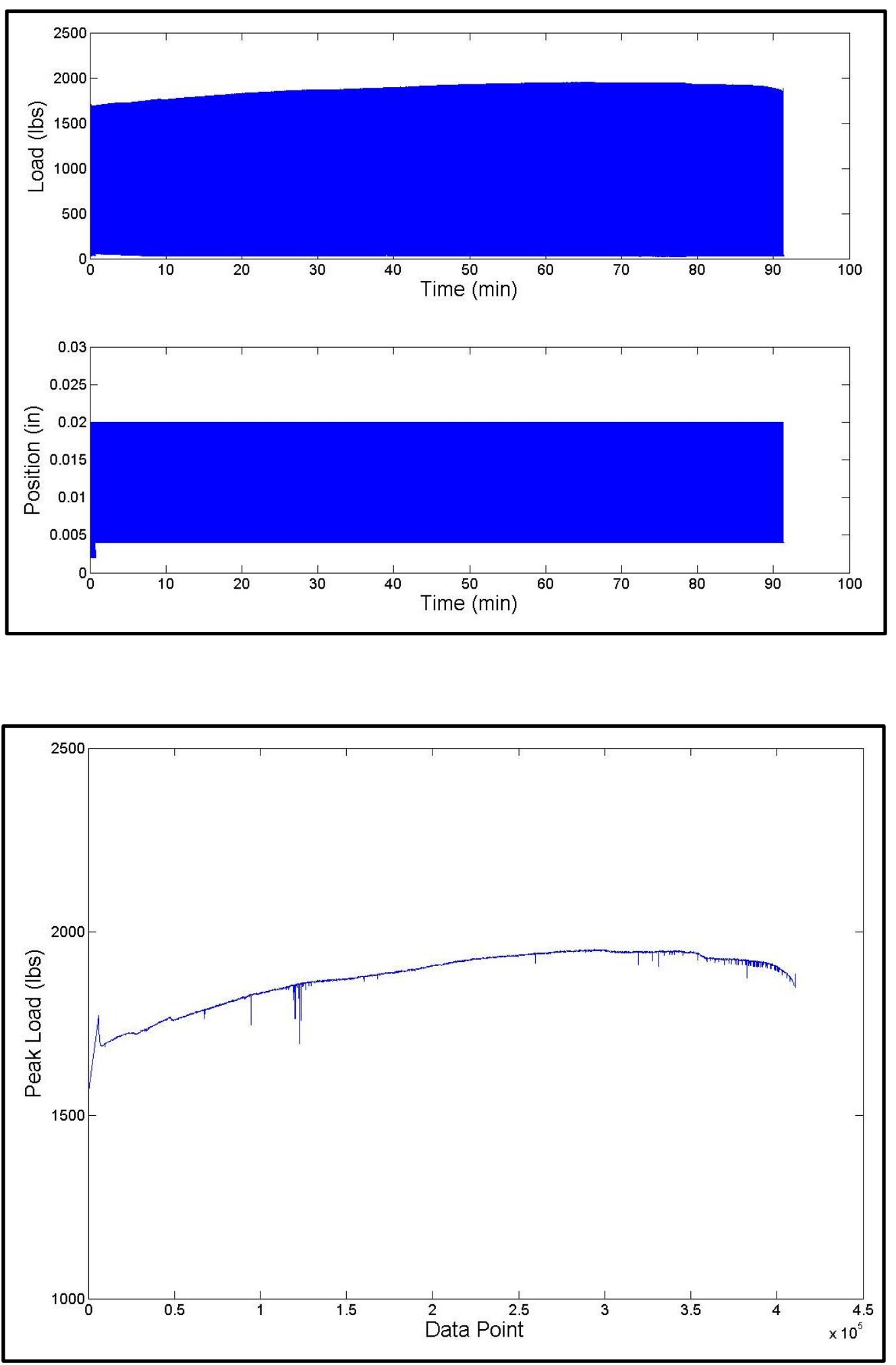

Gear 9 - Tooth 4 

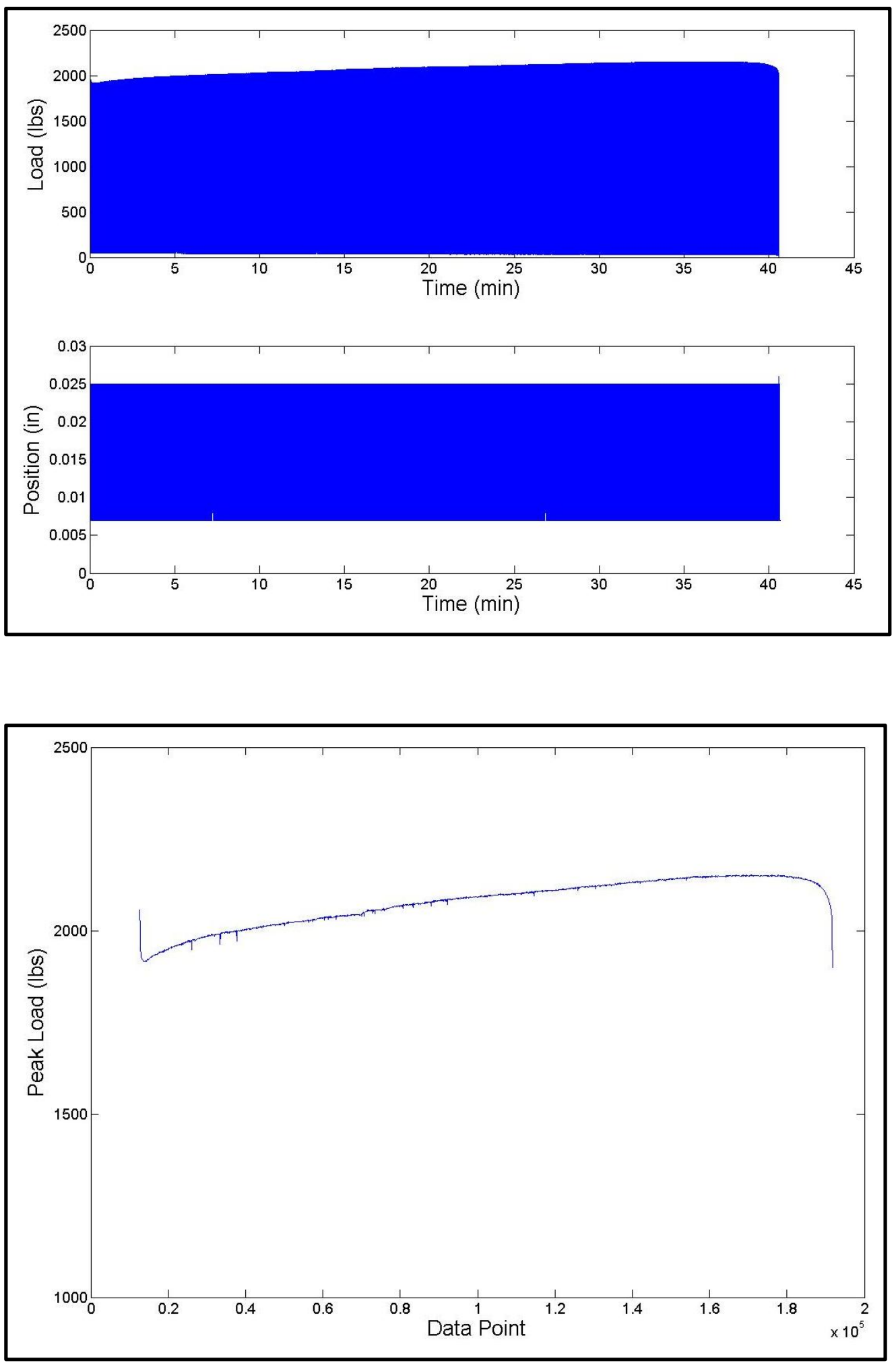

\section{BEARING ACCELERATION AND FFT PLOTS}




\section{BEARING 1}
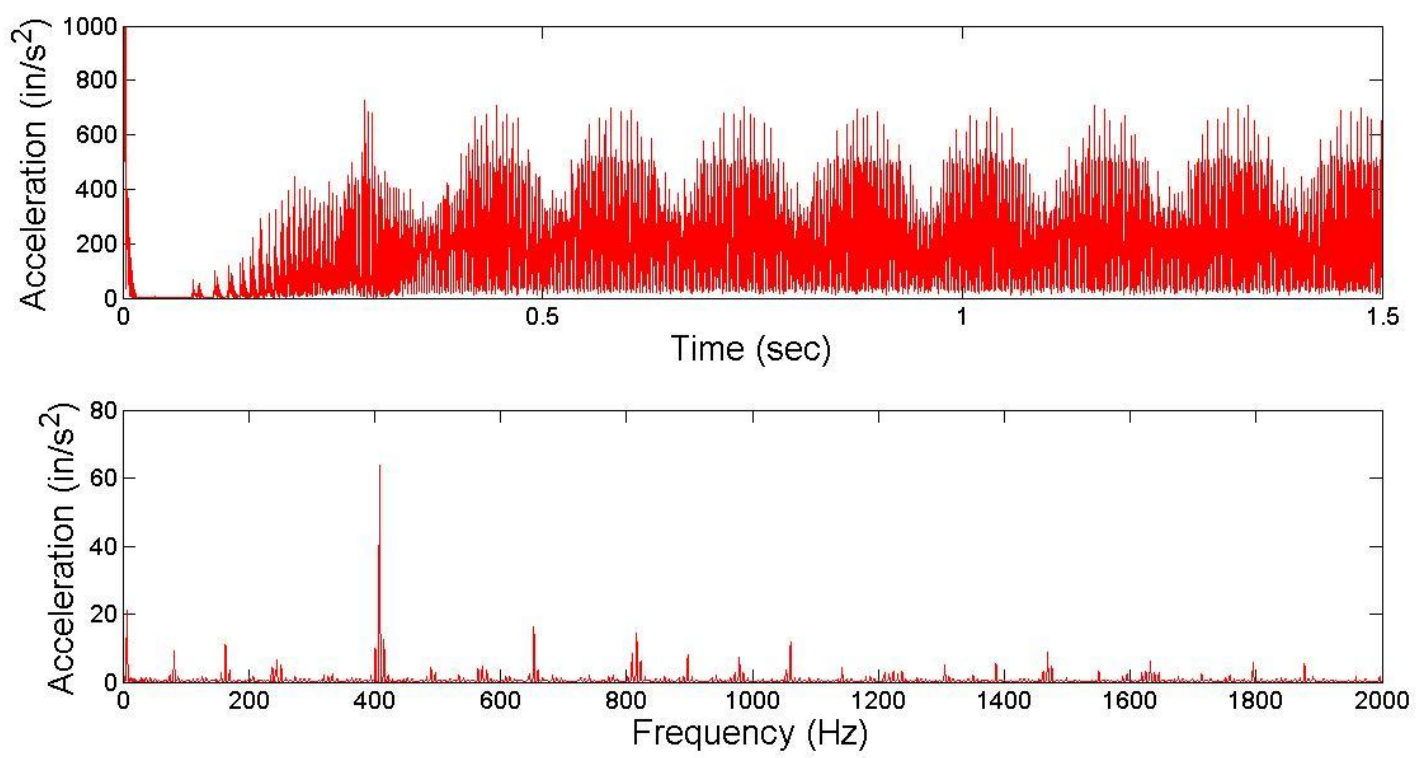

BEARING 2
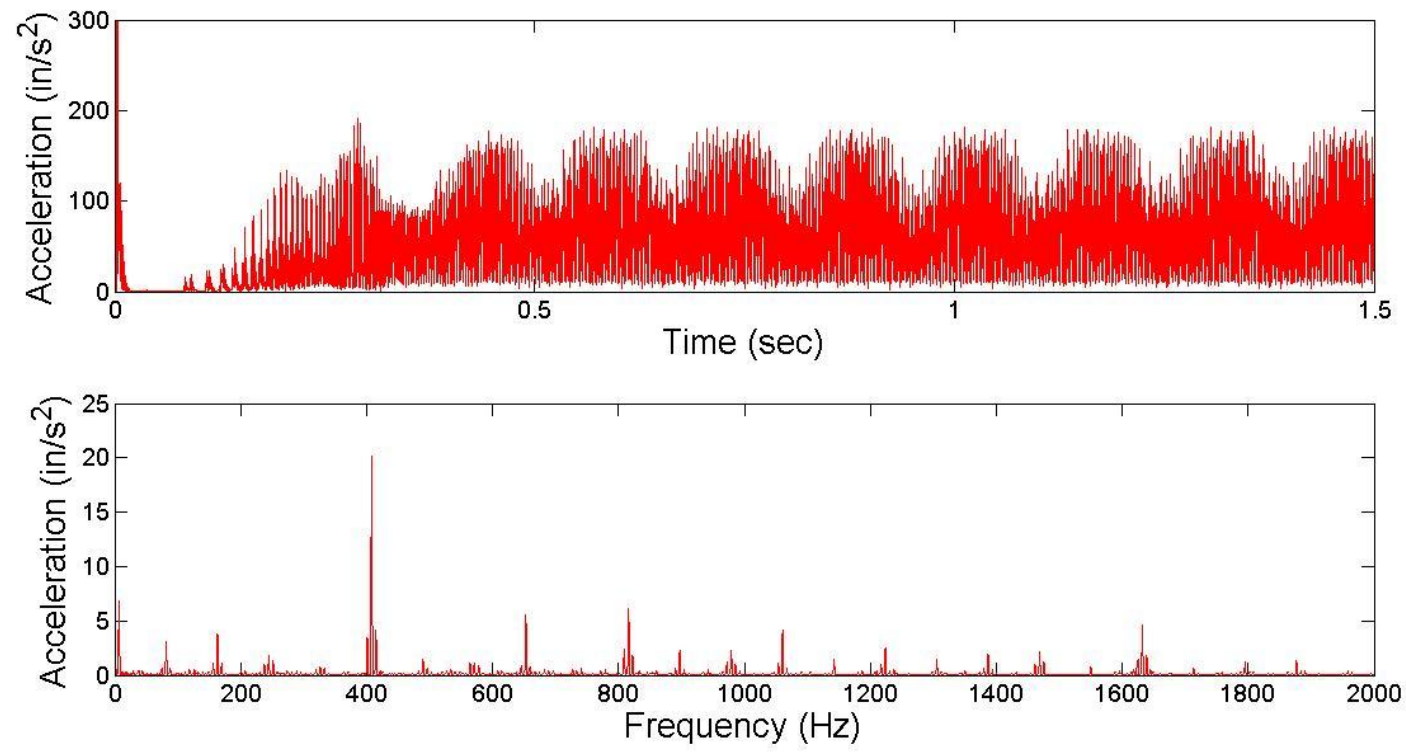

\section{BEARING 3}



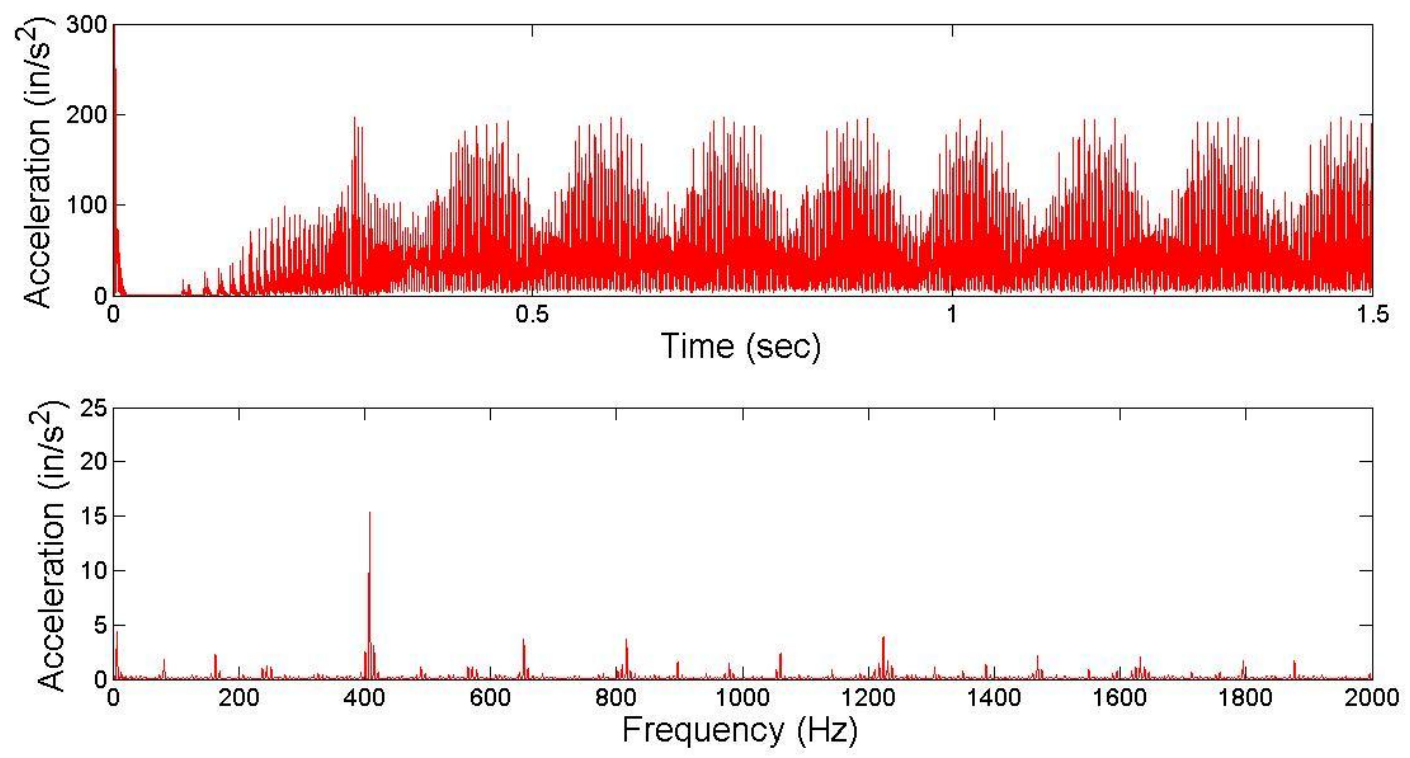

\section{BEARING 4}
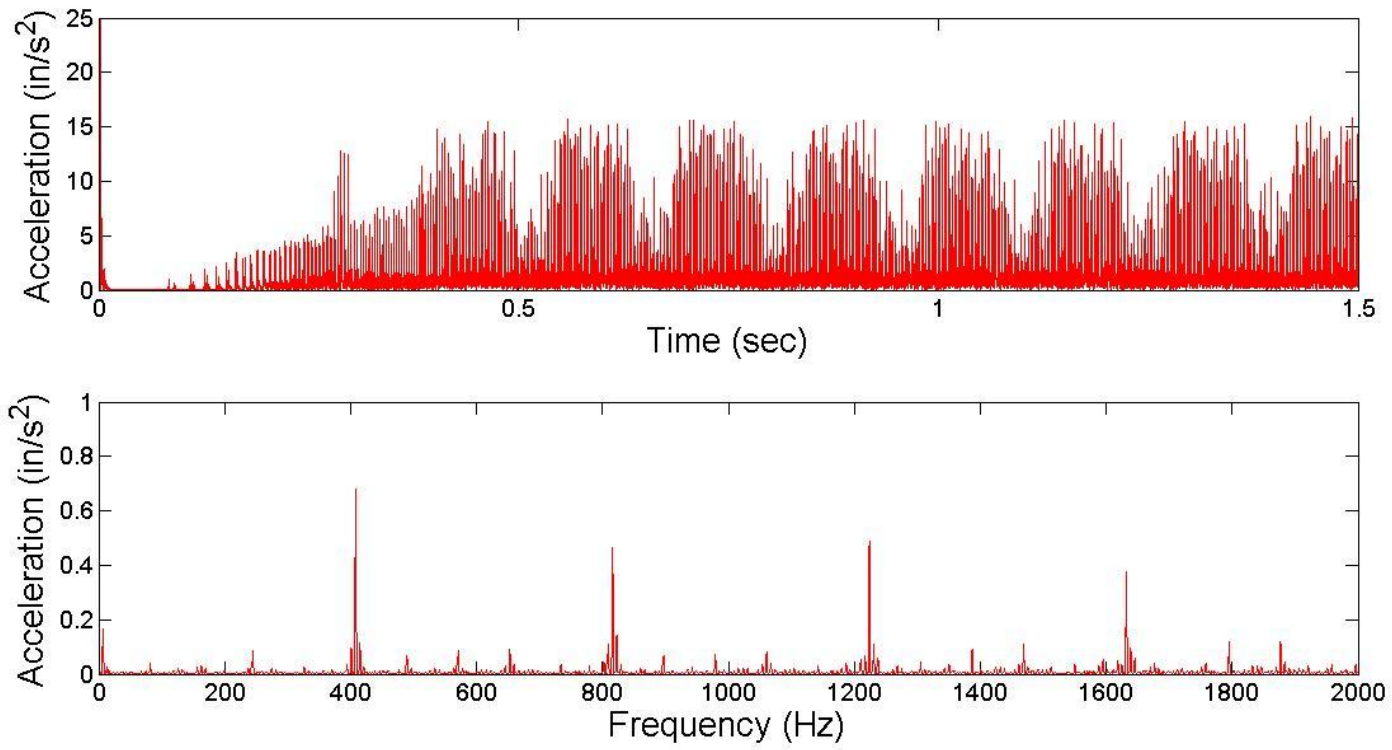

\section{BEARING 5}



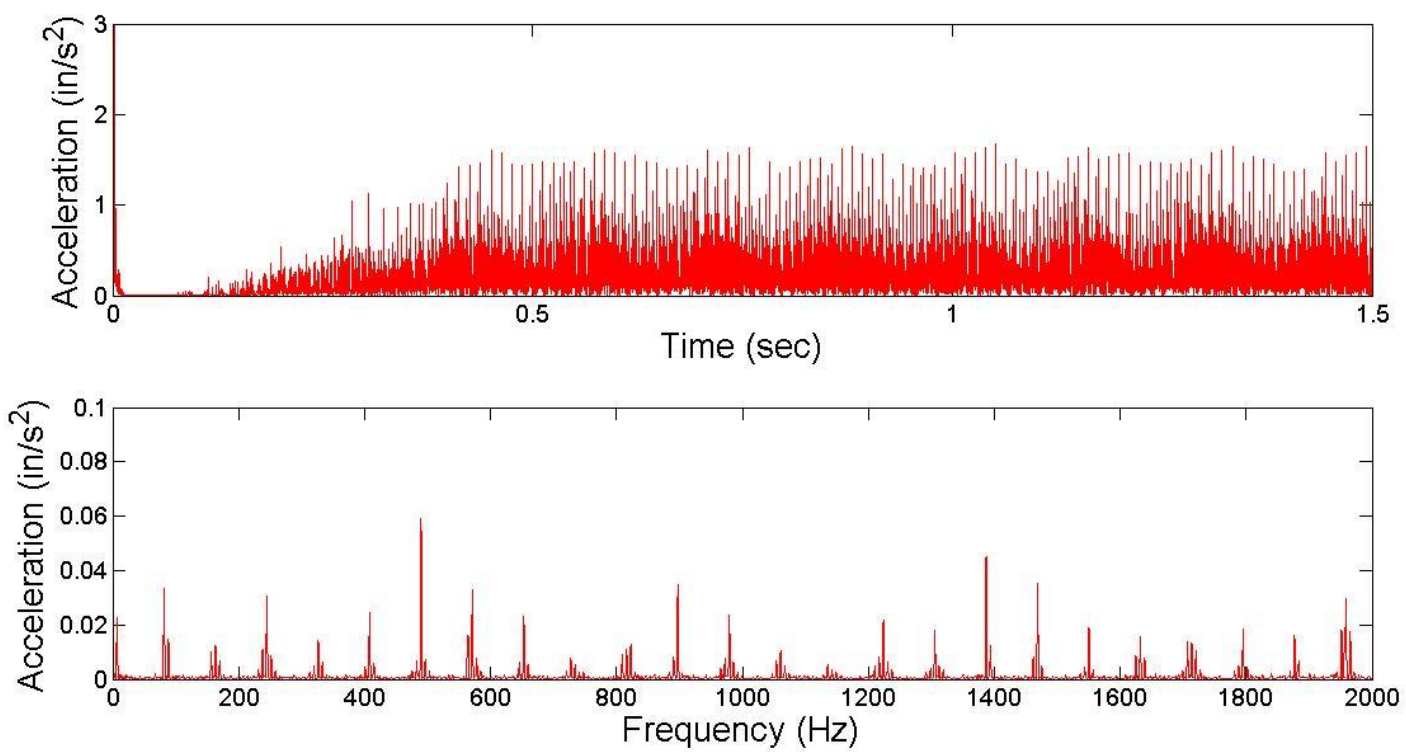

\section{BEARING 6}
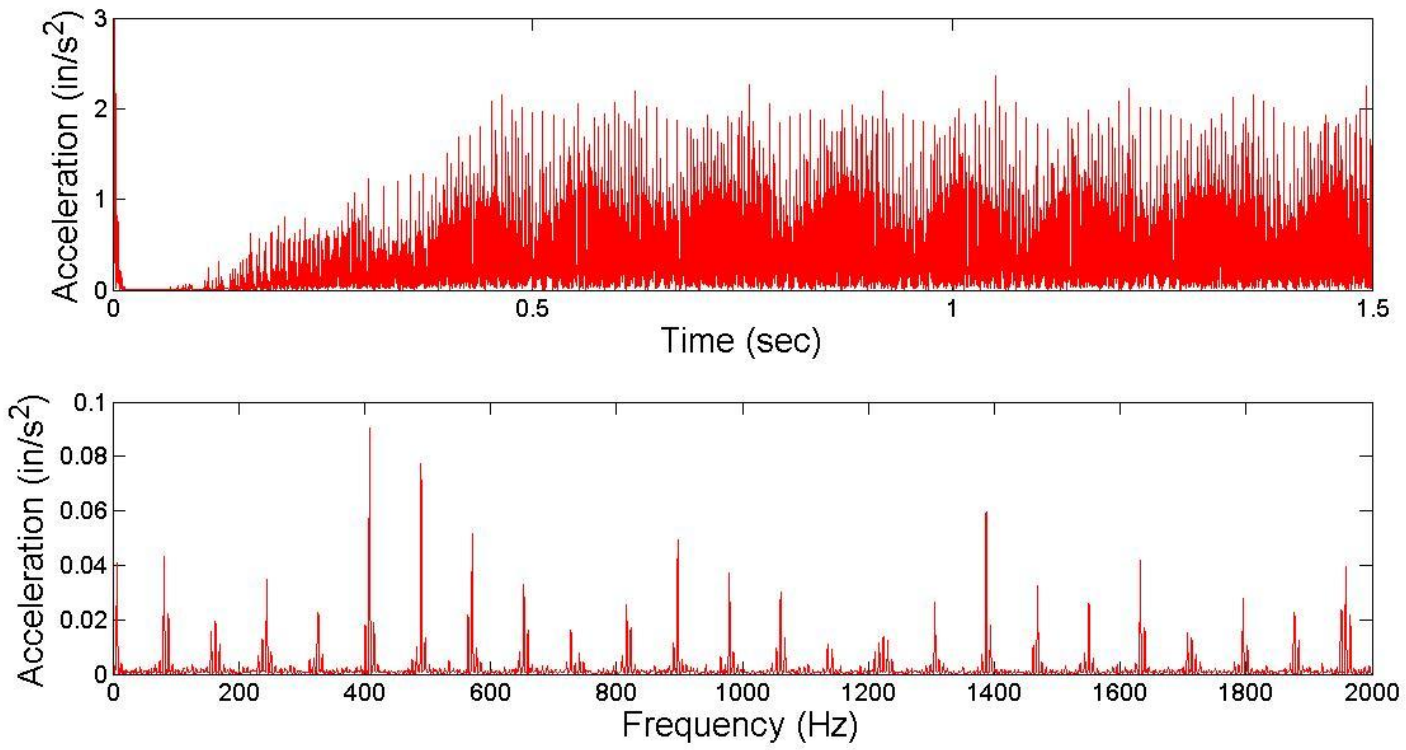


\section{INSTRON FATIGUE TESTING SET-UP/PARAMETERS}

Before any fatigue testing could take place, the Instron fatigue testing machine had to be set-up properly. First the control panel is turned on and system initialization processes takes place. While the controller boots up, the cooling water for the hydraulics are turned on. The top connector of the fatigue fixture is clamped into the top jaw of the Instron and the top crosshead of the Instron is then auto-calibrated so the weight of the fixture is not added to any load measurements. Once the fatigue fixture is secured, the top crosshead is hydraulically raised and the bottom crosshead is then moved to the zero position. This step is done merely for convenience and allows the user to have a good reference for the movement of the bottom crosshead when testing begins. Now the top crosshead is lowered until the bottom of the fatigue fixture is approximately 0.5 inches above the bottom jaw. Next the anvil is slid into place and pushed up against both walls of the anvil guide and the gear tooth face. The bottom jaw is then clamped to the anvil. To prevent any friction between the anvil and the anvil support plate, some tri-flow lubricant is placed between the two surfaces. With the fixture securely fitted, the controller settings for the desired fatigue test can be adjusted.

\section{LOAD CONTROL PARAMETERS}

With load control on the Instron control box selected, the machine will cyclic test to maximum and minimum load values and the position of the bottom crosshead moves to positions that hits these values. First load control is selected and then the waveform is adjusted to half sine, frequency of $1.5 \mathrm{~Hz}$, and an amplitude is set. Since the machine used for this study is almost 30 years old and used by many different students, it was suggested not to run the machine faster than a frequency of $1.5 \mathrm{~Hz}$. The frequency for all tests was set to this value and 5,400 cycles per hour is accomplished. If the gear tooth is to be loaded from $-800 \mathrm{lbf}$ to -2800 Ibf, the amplitude value that should be inserted into the load control menu is $2000 \mathrm{lbf}$. In order for the minimum load value to be reached the load set point must be adjusted. The set point button on the Instron control panel is selected and the set point should be set to the minimum value desired. For this example it would $-800 \mathrm{lbf}$. When this number is entered the Instron will place the spur gear tooth under the set point load. The load values are negative because the gear tooth is loaded in compression in the Instron testing machine. Next the constant amplitude control is set on along with minimum and maximum position limits. The max position is set to 0.01 inches and this prevents the lower crosshead from moving too far downward and hitting the wrong gear tooth with the bottom side of the anvil. The minimum position is set to -0.05 inches and this prevents the anvil from hitting the fatigue fixture if the gear tooth breaks during testing. If either the minimum or maximum position limit is tripped then the test and entire system stops completely so no damage to the fixture or the fatigue testing machine occurs. If needed, an event can be created on the controller and this stops the test once a certain cycle number is reached.

\section{POSITION CONTROL PARAMETERS}

Setting up the Instron for position control is very similar to the load control process. The position button is selected and the waveform is adjusted. The only difference now is that the amplitude refers to the position amplitude of the lower crosshead. The set point now refers to the minimum position desired for the waveform as well. If the desired half sine wave is to have a minimum position of -0.007 and a maximum position of -0.021 inches then the minimum value is entered as the set point and then the amplitude of the waveform should be -0.014 inches in 
order to reach the maximum position. Position limits and events can be used as well. The Instron machine defines the negative position direction as moving upward and since the lower crosshead moves upward from the zero position to load the tooth the negative values are used.

\section{E. INPUT/OUTPUT TORQUE FOR USE IN ADAMS TUTORIAL}

Actual motors electric motors have a torque that is related to the current RPM of the drive shaft. This tutorial explains how to generate this input as a realistic behavior for use in dynamic simulations in MSC Adams.

1. Acquire or generate torque curve data points for a desired electric motor. If a torque curve polynomial is already available skip to step 3.

2. Using the data points crate a polynomial curve fir. This step can be done using Excel or Matlab. In this present study, Matlab was chosen.

a. In the Matlab command window enter the shaft RPM as a column vector $[A]$ and the motor torque as a column vector $[\mathrm{B}]$. Both vectors must be the same size.

$A=[1,2,3,4 \ldots \ldots \ldots \ldots .$.

$B=[5,6,7,8 \ldots \ldots \ldots \ldots .$.

b. Next use the polyfit function and specify an order for the curve fit. Use $6^{\text {th }}$ order or above.

$\mathrm{P}=$ polyfit $(A, B, n)$, where $n$ is the polynomial order

c. Matlab outputs the array $[\mathrm{P}]$ which provides the polynomial coefficients of the curve fit.

3. Next open your current Adams dynamic model.

4. Before the torque can be applied appropriately some measures must first be created in the model.

a. Create a point-to-point measure to calculate the angular velocity of the input pinion gear.

Select point-to-point measureby clicking the

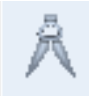
under the design exploration tab.

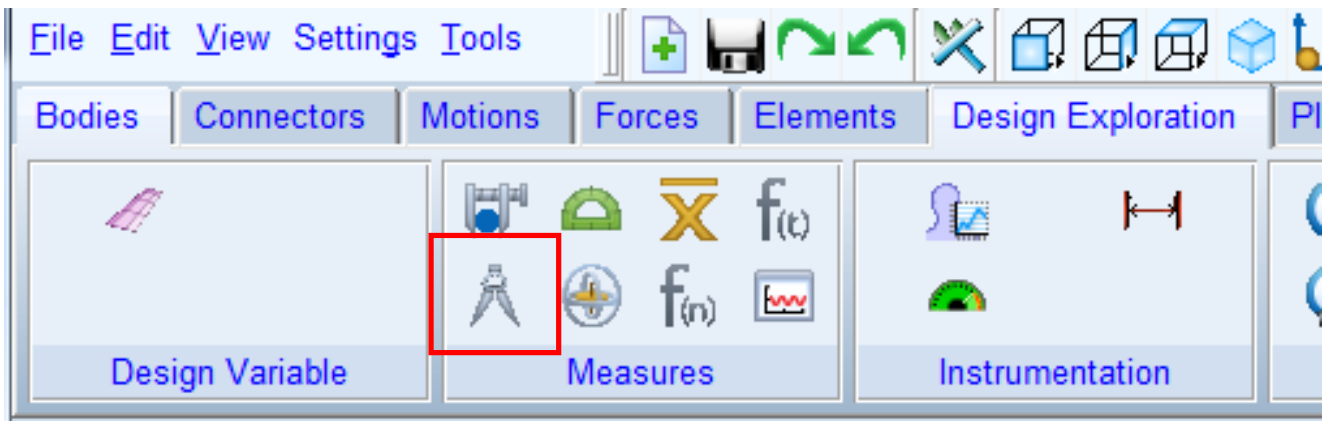

In the next menu, name the measure and then select a marker on the ground for the "To Point" and then select a marker at the pinion gear center as the "From Point". Make sure angular velocity is selected as the "Characteristic" and magnitude is selected as component. 


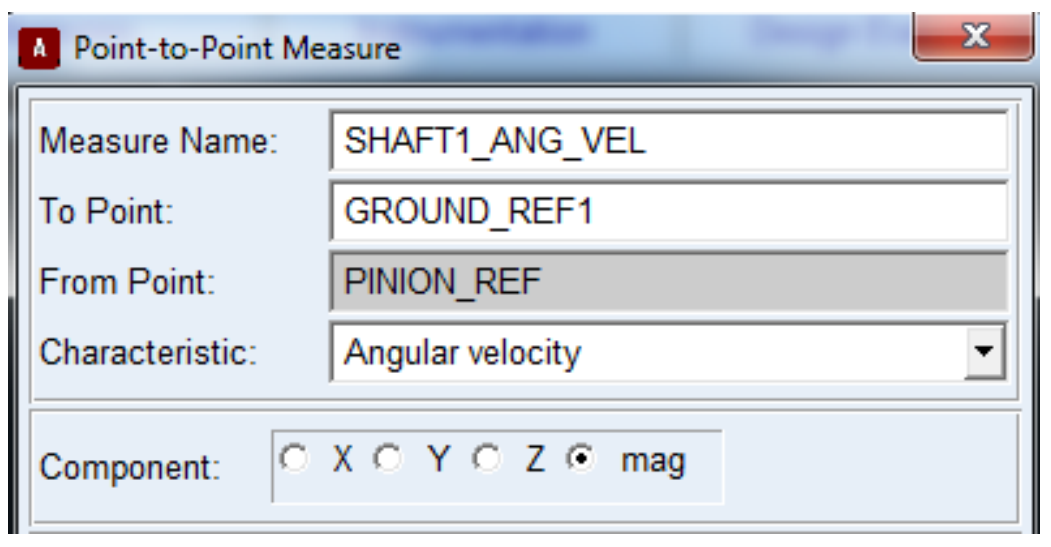

This measure will output the angular velocity in the default angular velocity units, typically $\mathrm{Hz}$.

Next create a function measure by selecting $f_{(t)}$ under the design exploration tab.

In the function builder menu enter the name of the point-to_point measure from the previous step. After entering the point-point meausre name divide the measure by 6 . This measure converts the pinion angular velocity in $\mathrm{Hz}$ to RPM.

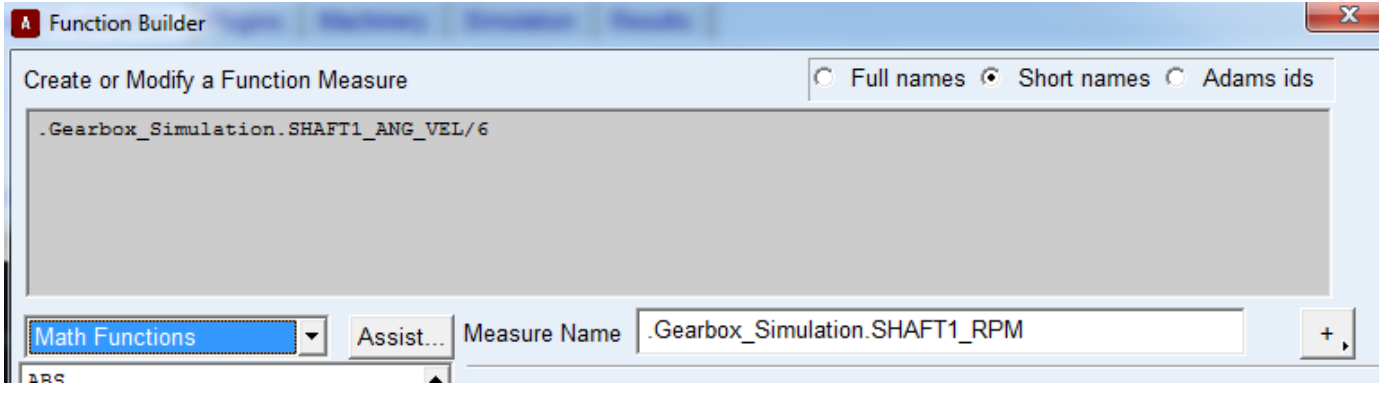

Now insert the torque curve polynomial by selecting function measure once again. In the function builder menu use the POLY function to enter the polynomial curve.

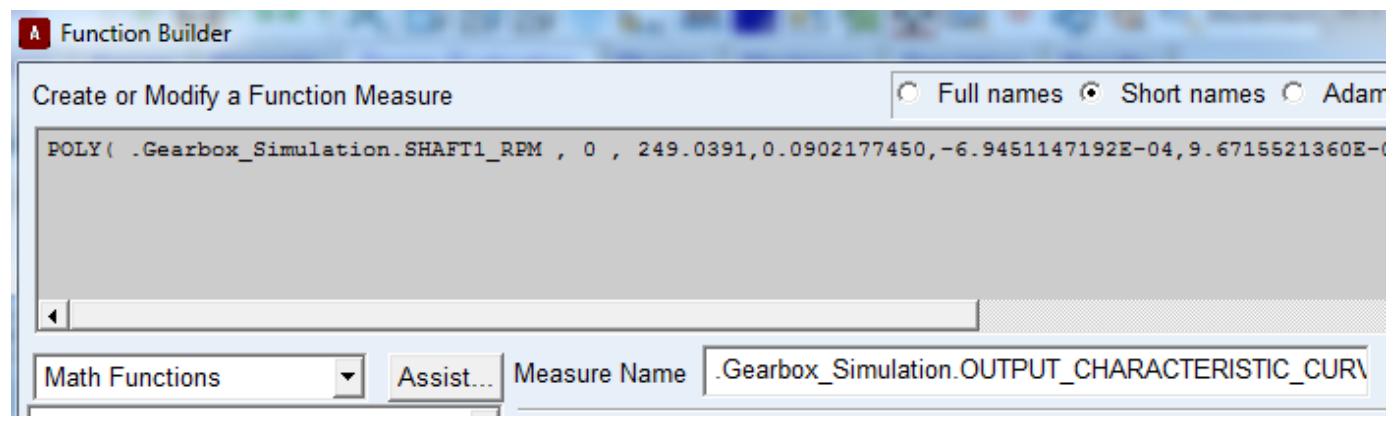

$\operatorname{POLY}(x, x 0, a 0$, a30) 
$x, A$ real variable that specifies the independent variable. $x_{0}$ a real variable that specifies a shift in the polynomial. $a_{0}, a_{1}, \ldots ., a_{30}$, polynomial coefficients

Enter the angular velocity in RPM function measure as the $\mathrm{x}$ variable, 0 as $\mathrm{x} 0$, and then enter the polynomial coefficients of the torque characteristic curve.

5. Now create a torque by selecting

under the forces tab.

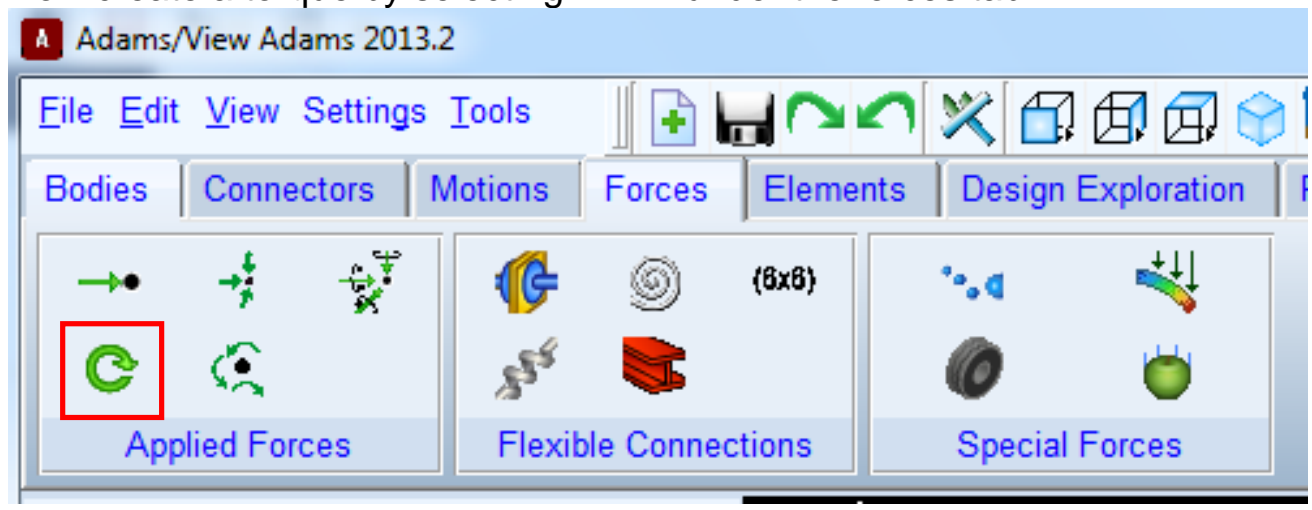

Upon clicking the torque force icon you will be prompted to select the body on which to apply the force. Select the appropriate shaft. Next the location at which the torque will be applied is needed. Select the appropriate marker.

In the torque force menu open the function dialog box.

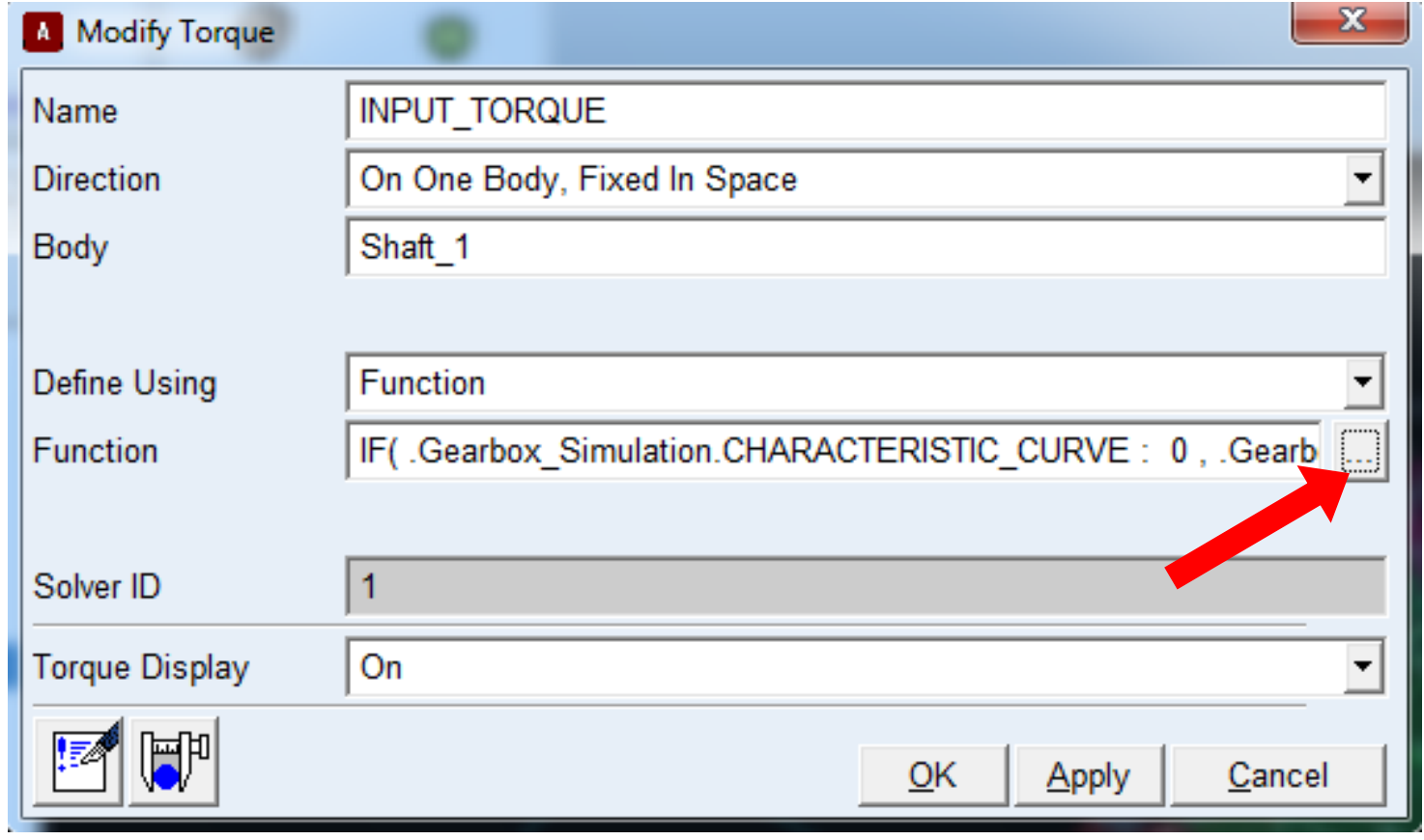

In the function menu enter an IF function. Enter the polynomial characteristic curve function measure in the expression 1, 2, and 4 slot. Enter 0 as expression 2.

IF(expression 1: expression 2, expression3, expression 4) 
If the value of $\exp 1$ is $<0$, IF evaluated using $\exp 2$. If value $\exp 1=0$, IF evaluated using $\exp 3$. If the value of $\exp 1>0$, IF evaluated using $\exp 4$.

The IF function ensures the torque will never export a negative number when used in this manner. This function should be adjusted accordingly if torque is supposed to be negative.

6. Run a quick simulation and check the output torque curve works properly.

\section{F. ABAQUS MNF GENERATION FOR USE IN ADAMS TUTORIAL}

A. Creating the Abaqus Model

1. Create a work directory folder that will house all of the files created in this process.

2. Place part step file/s, provided abaqus .env file, and provided inp files into folder.

3. Open Abaqus 13.2.

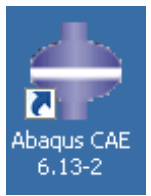

4. Select With Standard/Explicit to start a new model or open an existing model with Open Database.

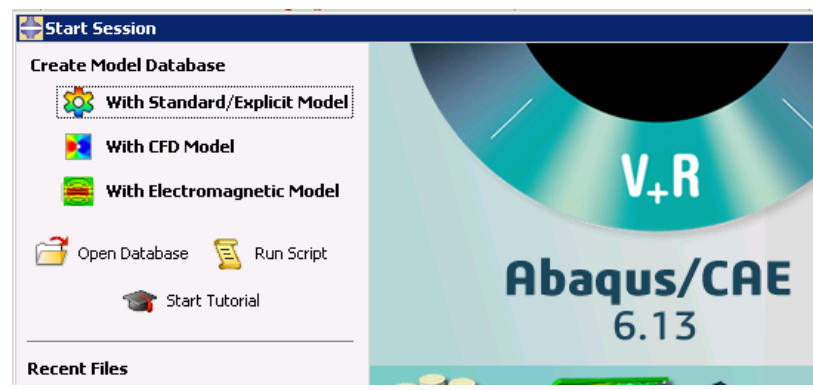

5. Set work directory by clicking File at the top and the selecting Set Work Directory. Select the folder that was created in step 1.

6. Import part step file or create a part in Abaqus.

a. To import right click Part in the model tree and select Import...

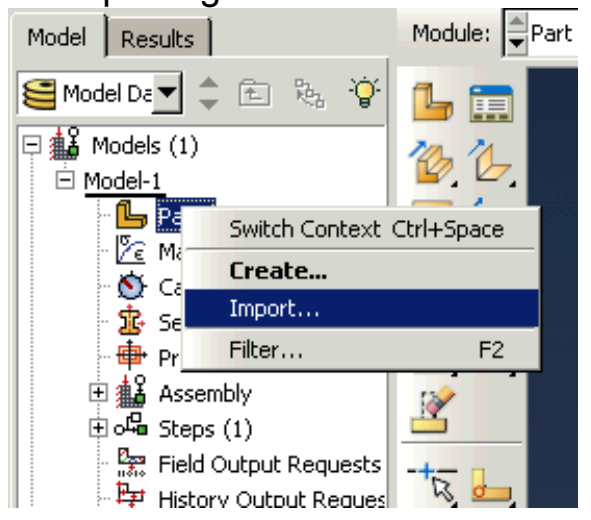


7. Create a material by right clicking Material under the Model tree and select Create...

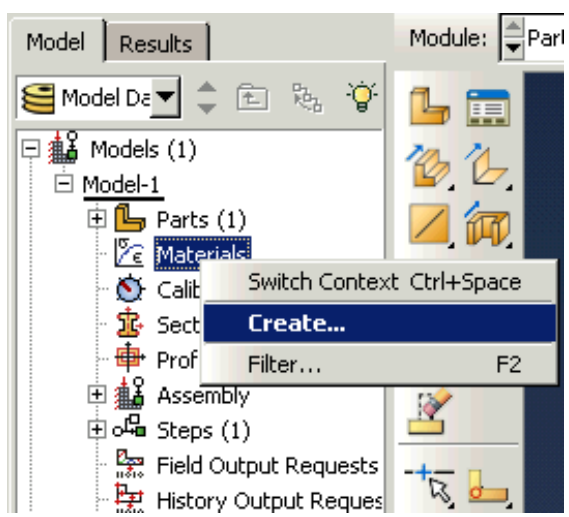

a. Within the Edit material dialog box, click the General tab and select Density. Enter the density of your material. Then select the Mechanical tab and click Elasticity then Elastic. Enter the Young's Modulus and Poisson's Ration of your material.
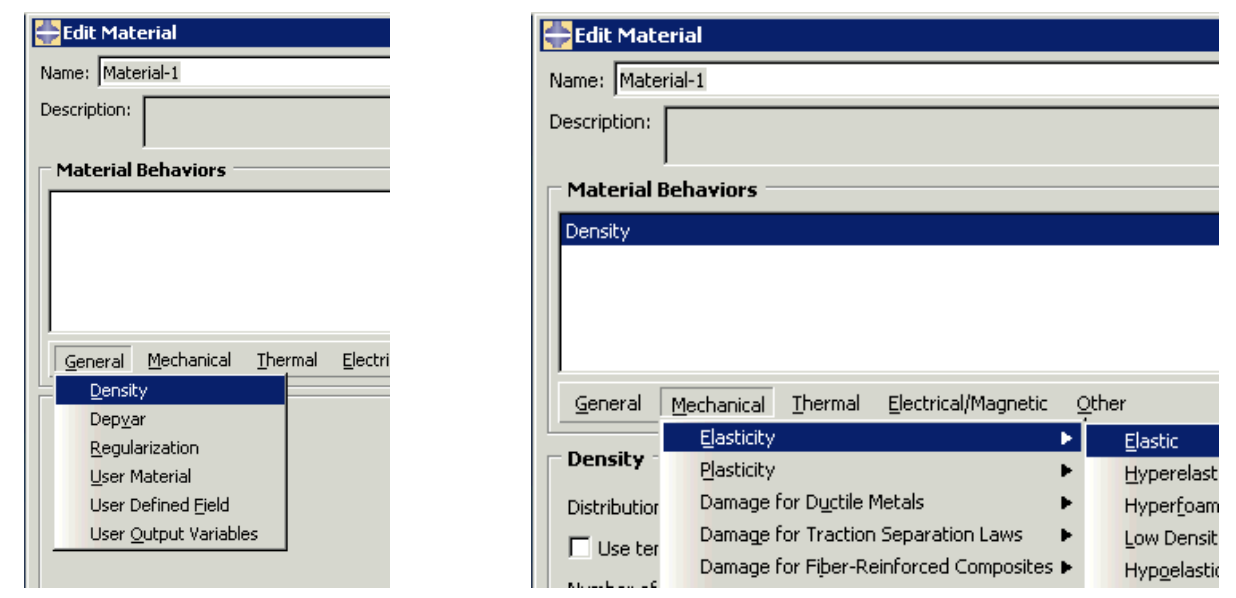

${ }^{*}$ Be careful with units! Abaqus is dimensionless so the units of the numbers you enter must be the same for the entire model. Also use consistent units with Adams otherwise material properties could be defined incorrectly in your Adams Model.

8. Now we create a section and assign our material to this section by double clicking Sections under the model tree.

a. Name the section and click Continue.

b. Select the Material created earlier and Click Ok.

c. In the window next to the model tree, assign the section by clicking select your part and then click the Done button at the bottom.

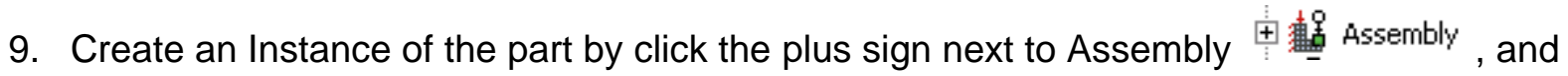
then right clicking Instance and selecting Create... 
a. Click the name of the part you wish to instance in the Create Instance dialog box, and select Ok.

10. Create reference point/s for important node attachment locations. For this tutorial they are the geometric centers of any gears, bearing, or torques that will be applied to the shaft. (This step is merely done for convenience later but is not absolutely necessary)

a. Click Assembly in the model tree and then go to the top menu bar and click Tools then Reference Point. Enter the coordinates $(X, Y, Z)$ of the point in the dialog box at the bottom of the screen.

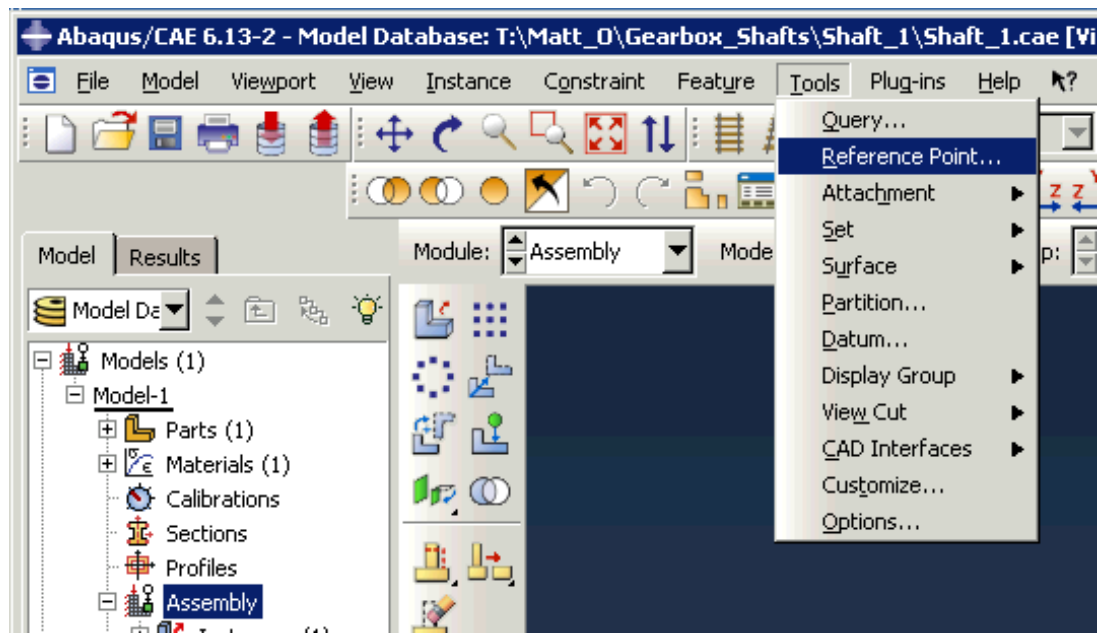

11. Mesh the part by clicking the plus sign next to Part and then click the plus sign next to name of your part. The tree shown below should appear.

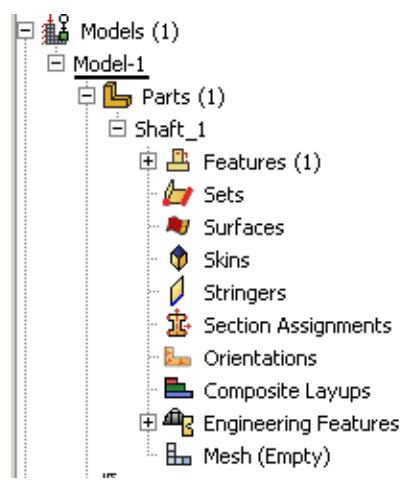

a. Double click Mesh at the bottom of the tree.

b. Click seed at the top of the menu bar and then click Part.

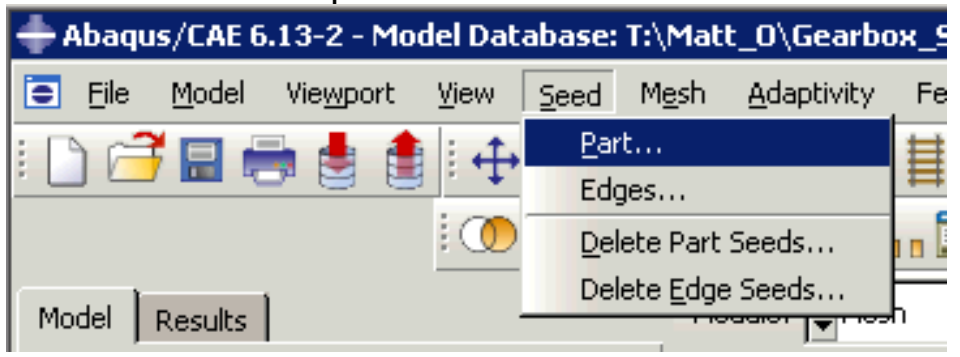


c. Enter a global seed size you wish to have for your mesh in the Approximate global size box, then Ok.

d. Next click Mesh at the top of the menu bar and select Element type. Then select the entire part as the region to be assigned the element type.

e. In the Element Type Dialog box, settings such as the element shape and geometric order can be selected. Click Ok when finished

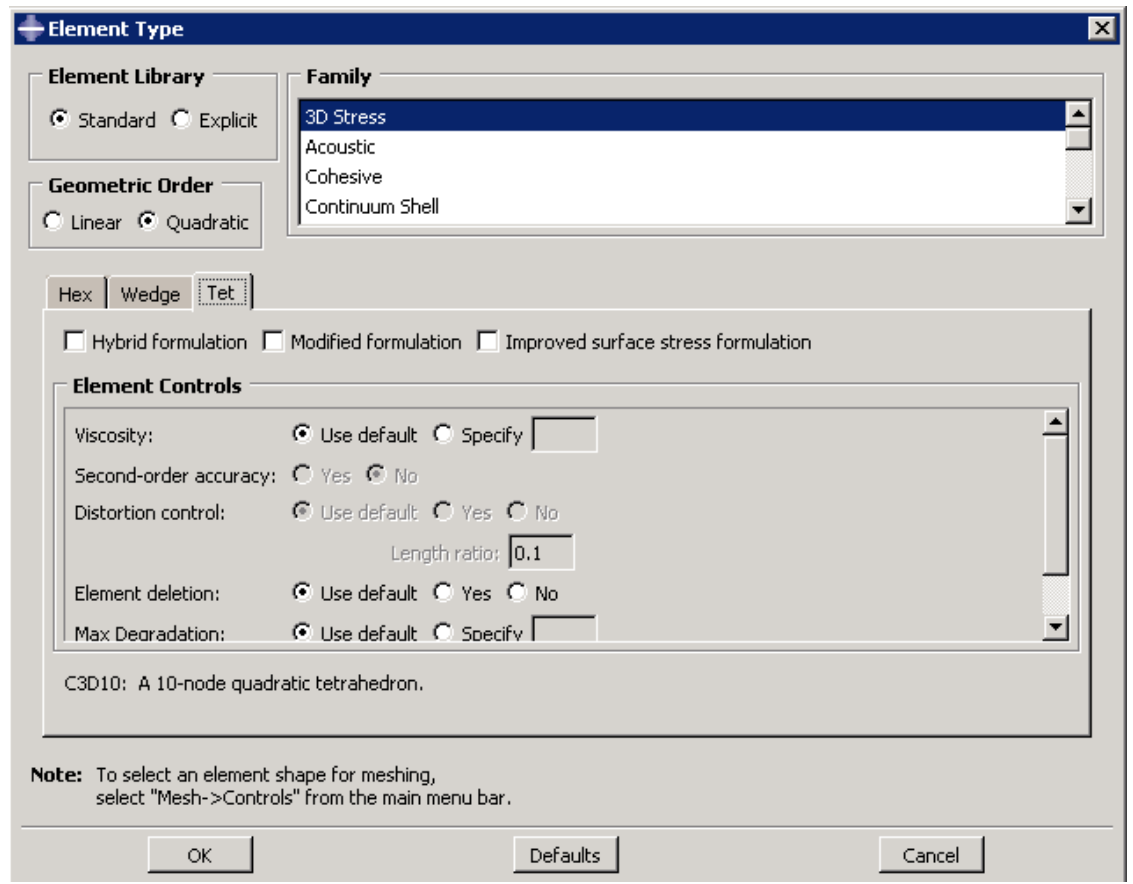

f. Click Mesh once again on the top toolbar then click Part. The part should b e meshed, For example:

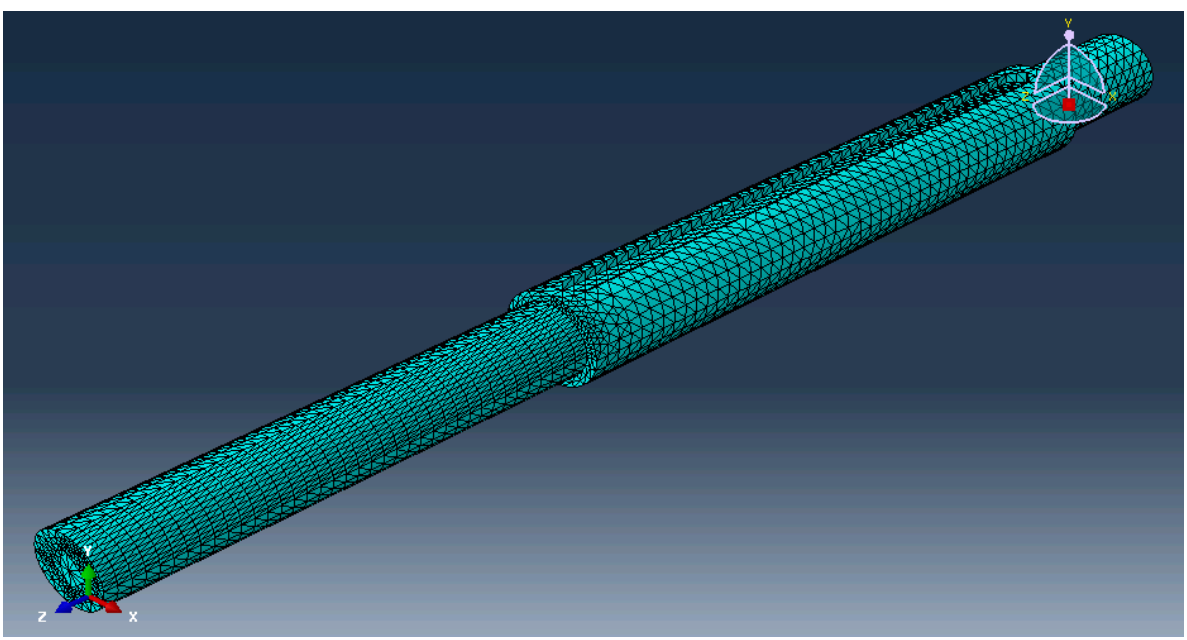

12. Now create node sets for the sections at which a force, a gear, and bearing will eventually be attached in Adams. This is important because these nodes will be used to generate multi-point constraints (MPC). This type of constraint allows the nodes to transmit forces and moments between parts. So for example the nodes where a bearing will be located allows the flexible shaft to transfer forces into a rigid bearing. 
a. Right click Sets under the Assembly tree and then click Create...

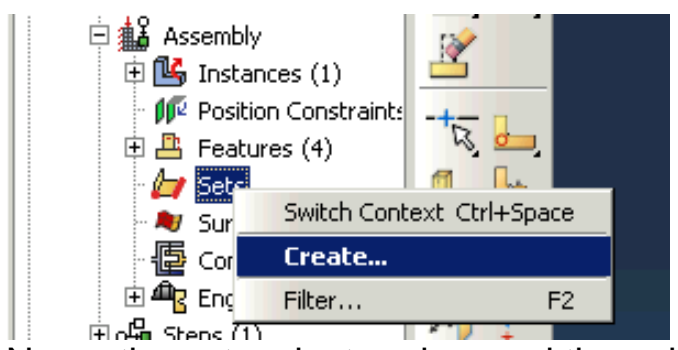

b. Name the set, select nodes, and then click continue.

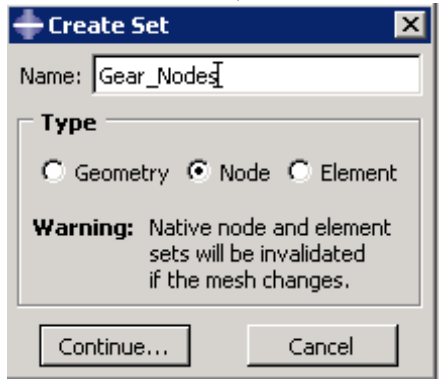

c. Select the nodes that you wish to include, selected nodes are highlighted in red.

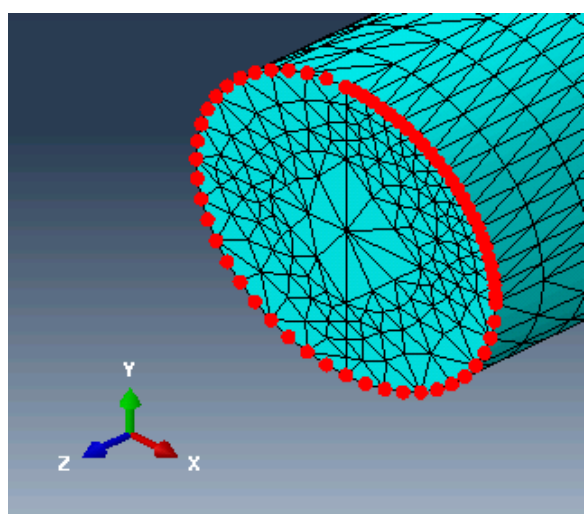

13. Next create a Step by right-clicking Steps under the Model Tree and select Create...

a. Name the step, and under procedure type select Linear perturbation and then highlighting Frequency. The purpose of this step if to give Abaqus a reason to run a simulation. 


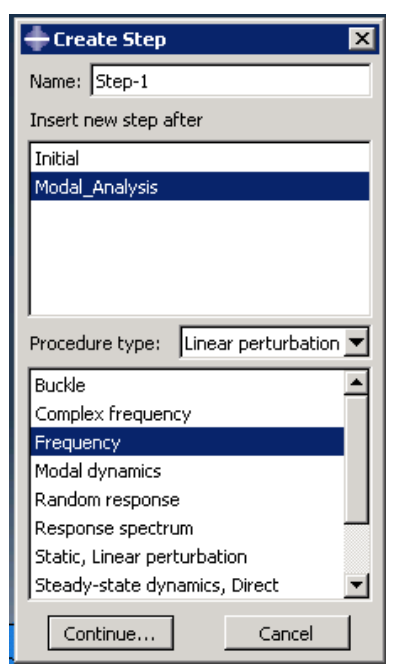

b. The reference points created earlier help detect which nodes you may need. For example if a reference point is at the center location of where the gear is to be placed on the shaft then you have an idea which nodes on the outside surface you should put in a set.

14. Now create a Job by right clicking Job below the Analysis heading under the Model Tree. Click Create..., name the job, select the model, and then click continue.

a. Enter in a brief description if wanted and click Ok.

15. Now click the plus sign next to Jobs in the Model Tree and right-click the job just created.

a. Next click Data Check.

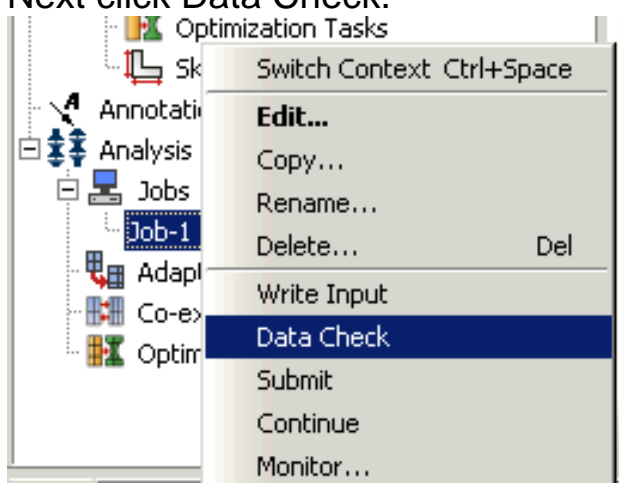

b. In the message window at the bottom of the model should read as follows when completed:

The job input file "Job-1. inp" has been submitted for analysis.

Job Job-1: Analysis Input File Processor completed successfully.

Job Job-1: Abaqus/Standard completed successfully .

Job Job-1 completed successfullv.

\section{B. MNF Generation}

1. Go to the work directory folder and open the Job-1.inp (name of Job) file.

2. In the same folder open the provided beam_nodes.inp file.

3. In the Job-1.inp file select and copy all the node points. Then paste the node information into the beam_nodes.inp file. 
a. Also in the beam_nodes.inp file, enter the locations of your multi-point constraints. The MPC locations are given high node numbers (10000000 etc.) to not interfere with the node code in the part.

b. The beam_nodes.inp should look similar to this:

**

**

** NODE for "Shaft_1"

** Created from: Matt Ostiguy

** Date: 06/13/2014

** Version: V1

$\star *$

** Total Number of nodes: 85660

**

** MPC NODES

**

$x *$

$\begin{array}{llll}10000000, & 0 ., & 0 ., & 6 . \\ 20000000, & 0 ., & 0 ., & 2.25 \\ 30000000, & 0 ., & 0 ., & -5.75 \\ 40000000, & 0 ., & 0 ., & 0 .\end{array}$

**

**

**

** GEOMETRY NODES: 85660

**

**

$1, \quad 0 .,-0.196850389, \quad-6$.

$2,0.196850389, \quad 0 ., \quad-6$.

$3,0.393700778, \quad 0 ., \quad-6$.

$4, \quad 0 .,-0.393700778, \quad-6$.

$5, \quad 0 .,-0.393700778, \quad-4.75$

$6,0.393700778, \quad 0 ., \quad-4.75$

$7,0.196850389, \quad 0 ., \quad-4.75$

$8, \quad 0 .,-0.196850389, \quad-4.75$

$9, \quad 0 ., \quad 0.393700778, \quad-4.75$

$10, \quad 0 ., 0.393700778, \quad-6$.

$11,-0.393700778, \quad 0 ., \quad-6$.

$12,-0.393700778, \quad 0 ., \quad-4.75$

13, $-0.196850389, \quad 0 ., \quad-4.75$

$14,-0.196850389, \quad 0 ., \quad-6$.

$15, \quad 0 ., 0.196850389, \quad-6$.

data continues for multiple pages as there are 85660 total nodes in the part.

4. Follow the same "copy and paste" procedure for the beam_elements.inp file.

a. Example:

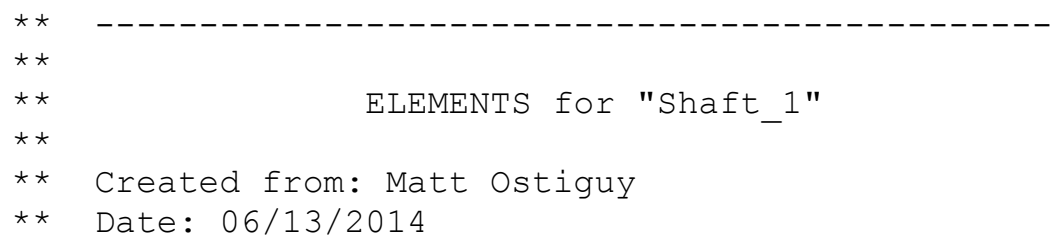




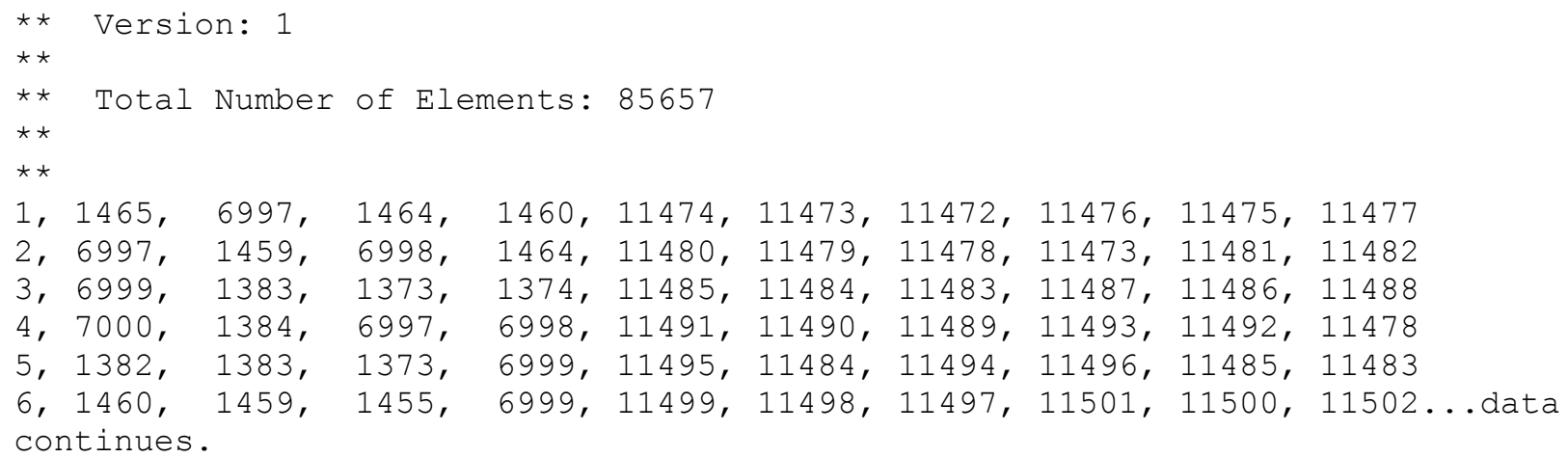

5. Open the provided beam_BC.inp file.

a. Under *Heading, type in the name of the Model you created in Abaqus.

b. In the Node Sets section copy and paste the node sets from the Job_1.inp file. Be sure to copy each node set associated with the node sets created in Abaqus. In this example there is a set for the input torque, both bearing locations, and the gear location.

c. Next associate those node sets with the MPC locations to allow for the creation of MPC constraints. Under *MPC in the MPC Definition section type:

BEAM, "name of node set", "associated MPC node number"

For each node set this must be done. These ties all the nodes in the node set to the MPC point with a BEAM-type multi-point constraint. Look at the beam_BC.inp example as reference.

d. Under the ELEMENT DEFINITION section ensure the element type is the same as the one listed in the Job_1.inp file.

e. Under the MATERIAL DEFINITION section copy and paste the material properties from the Job_1.inp file.

Shortened beam_BC.inp example:

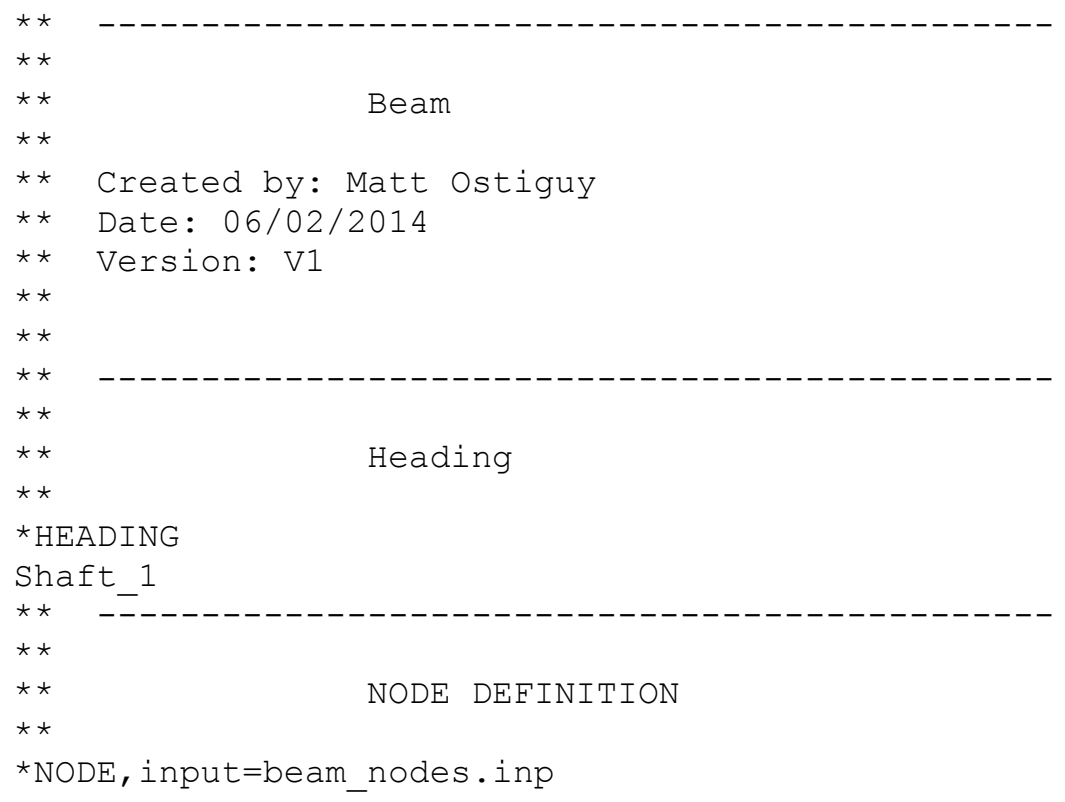


$\star \star \quad$ NODES SETS

$\star \star$

*Nset, nset=Force_Nodes

24, 27, 29, 32, 607, 608, 609, 610, 611, 736, 737, $738, \quad 739, \quad 740, \quad 832, \quad 833 \ldots$

*Nset, nset $=\mathrm{B} 1$ Nodes
490, 491, 492, 493, 494, 639, 640, 641, 642, 643, 684, $685,686,687,688, \quad 704 \ldots$

*Nset, nset $=$ B2 Nodes

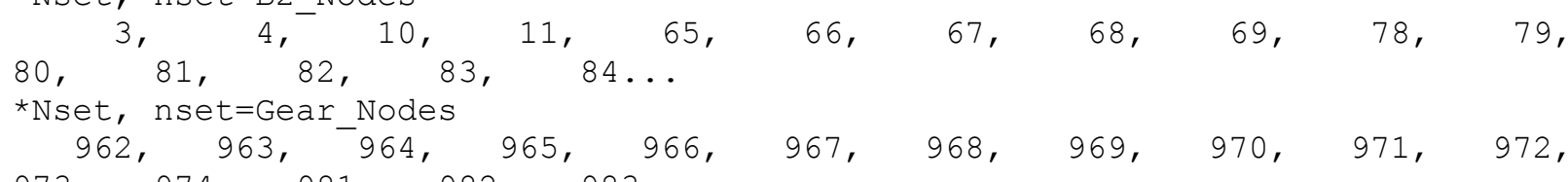
$973,974,981,982,983 \ldots$

$\star \star$

$\star * \quad$ MPC Definiton (Multi-point constraints)

$\star \star$

$\star \mathrm{MPC}$

BEAM, Force_Nodes, 10000000

BEAM, B1_Nōeses, 20000000

BEAM, B2-Nodes, 30000000

BEAM, Geār Nodes, 40000000

$\star \star$

$\star \star$

*NSET, NSET=RETNODES

$10000000,20000000,30000000,40000000$

*

$\star \star$

$\star \star \quad$ ELEMENT DEFINITION

$\star \star$

*ELEMENT, TYPE=C3D10, ELSET=PROP1, INPUT=beam_elements.inp

$\star \star$

$\star \star$

$\star \star$

$\star \star$

$\star \star$

$\star \star$

ELEMENT PROPERTY DEFINITION

*SOLID SECTION, ELSET=PROP1, MATERIAL=STEEL

$\star \star$

$\star \star \quad----------------------------------------$

$\star \star$

$\star \star$

$\star \star$

MATERIAL DEFINITION

*MATERIAL, NAME $=$ STEEL

*ELASTIC

$3.002 e+07,0.29$

* DENSITY

0.281829 ,

$\star \star$

$\star \star$

$\star \star$

$\star \star$

$\star \star$

MODAL ANALYSIS 


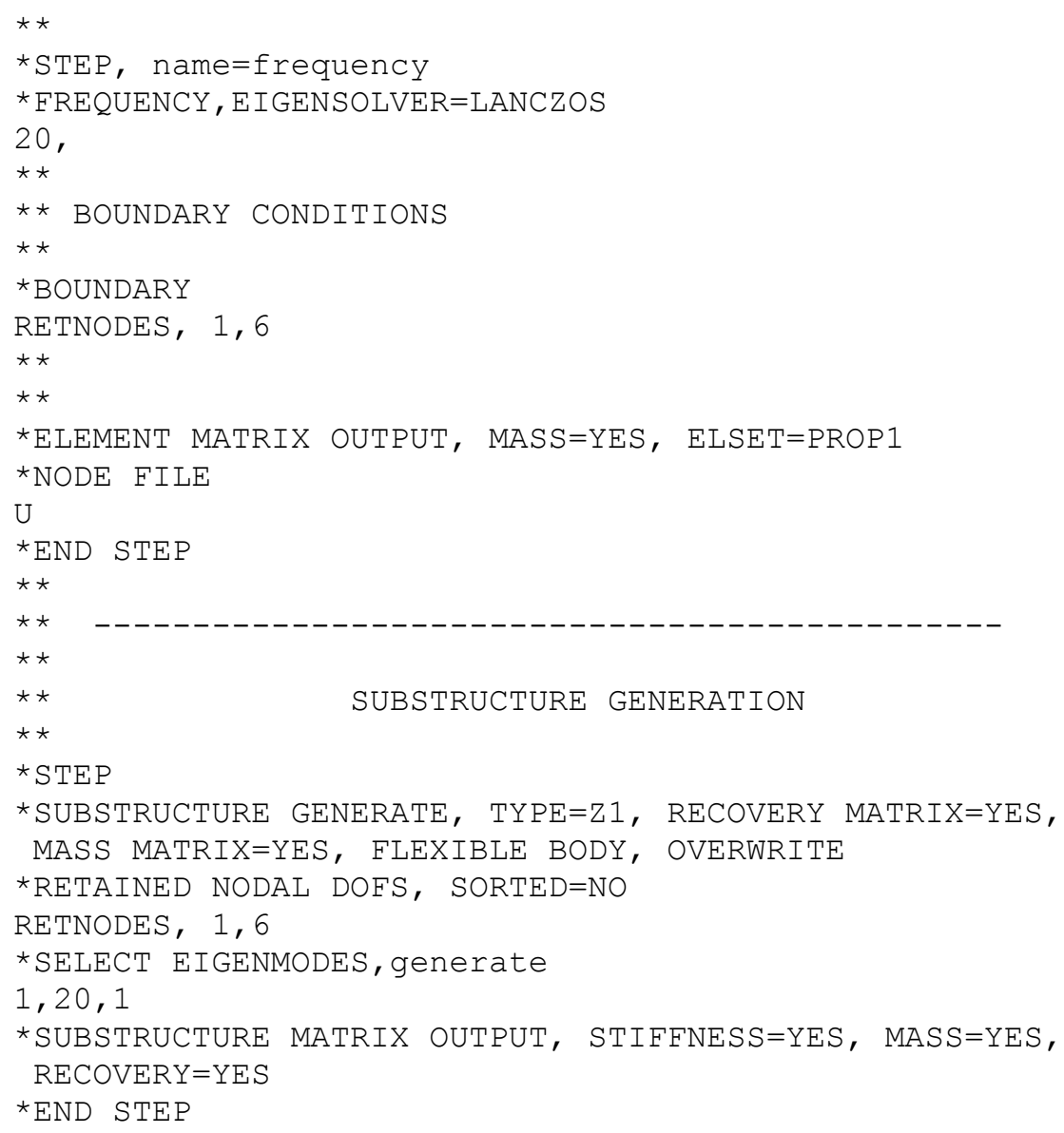

6. Open the Abaqus Command window

a. Enter the folder where your work directory is located.

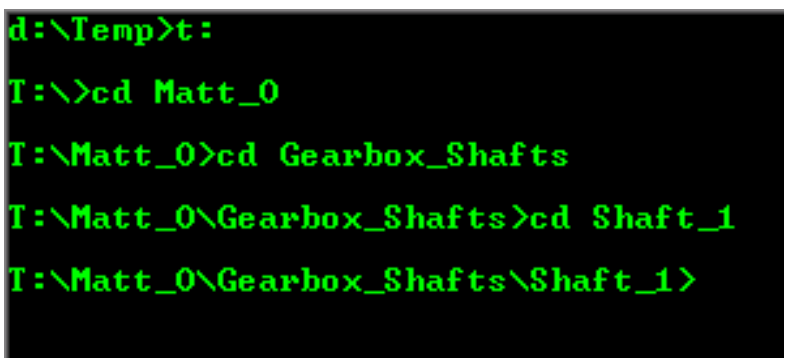

b. Type, abaqus job=beam_BC interactive, and hit enter. The following should happen: 


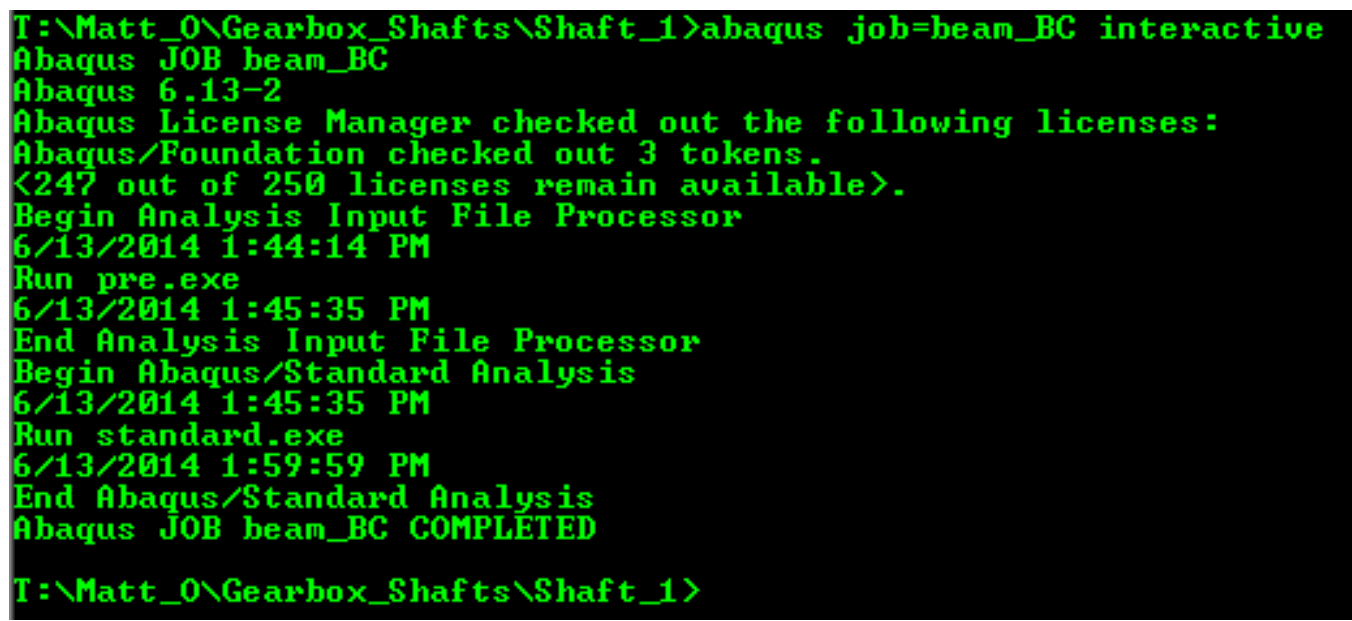

c. Now generate the MNF. Type, abaqus adams job=beam_BC substructure_sim=beam_BC_Z1 units=ips

The following should occur: 


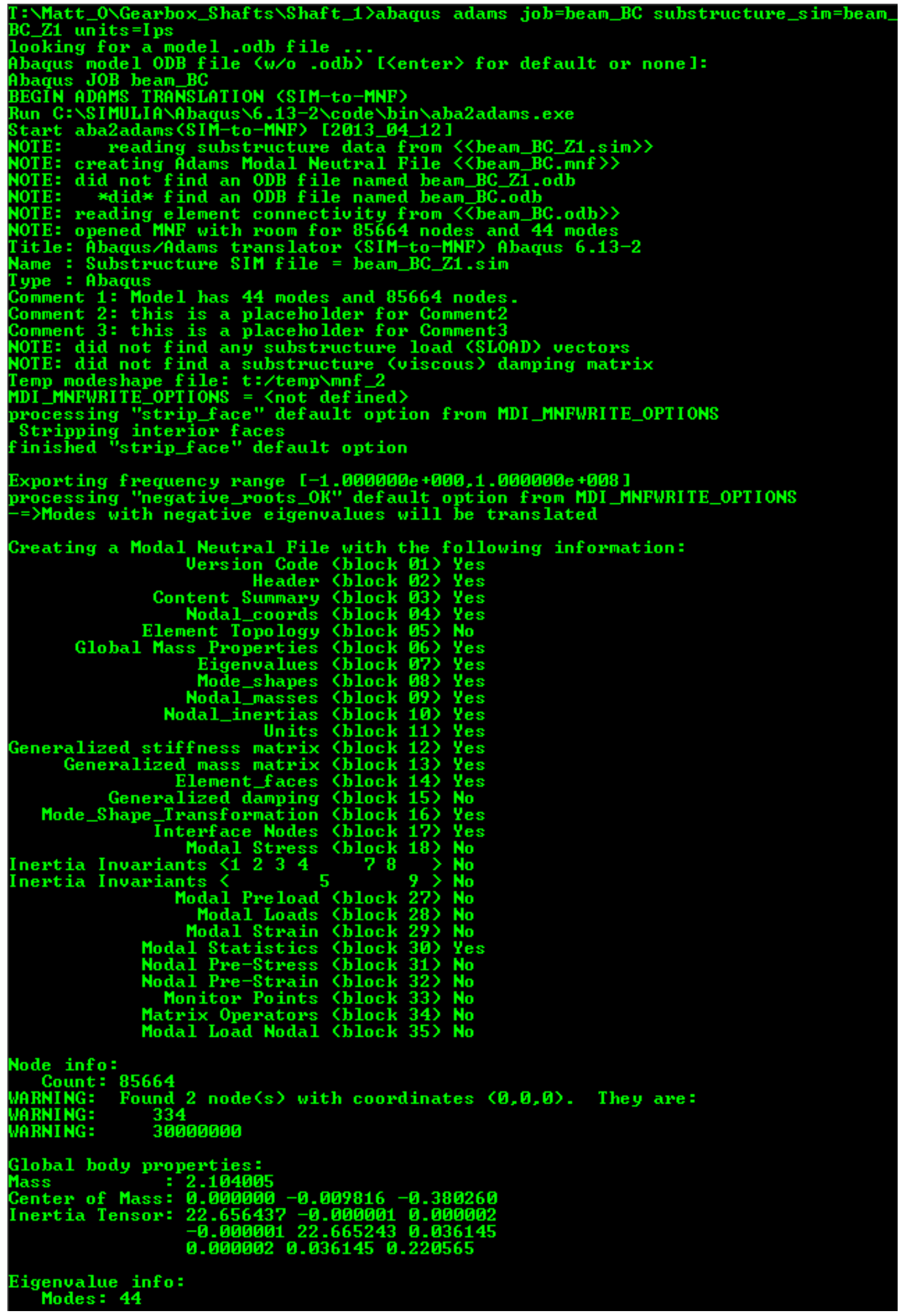




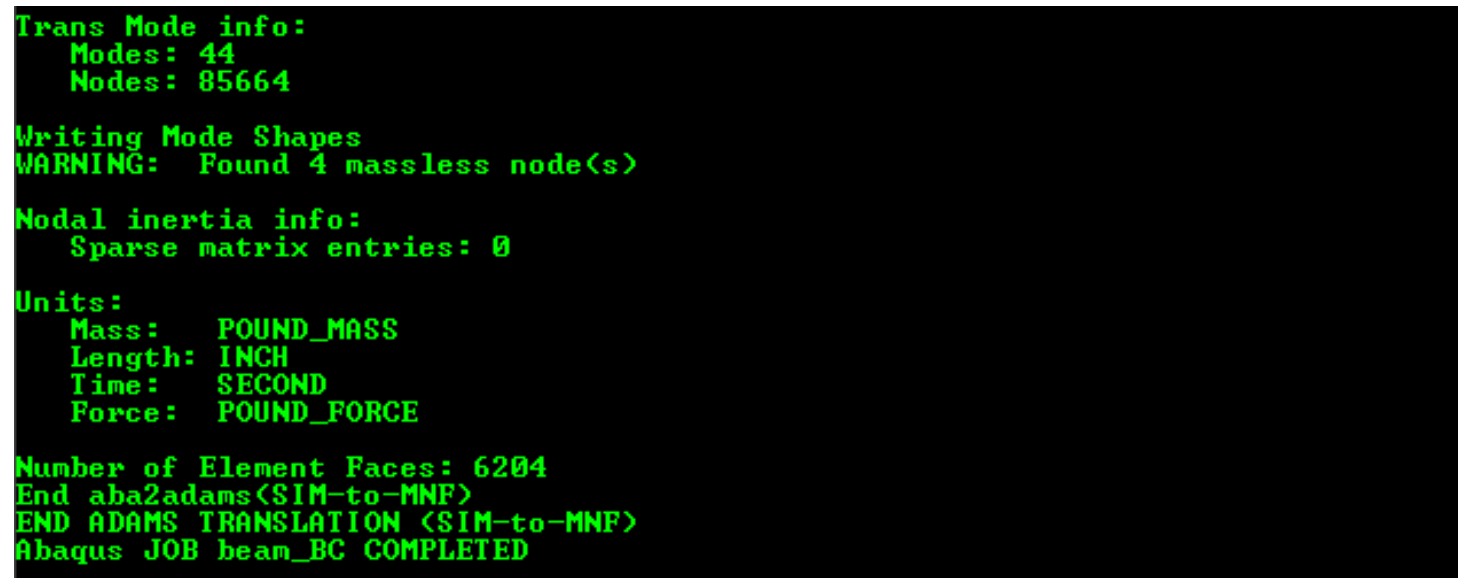

\section{G. MATLAB CODE}

\section{backlash.m Matlab Program}

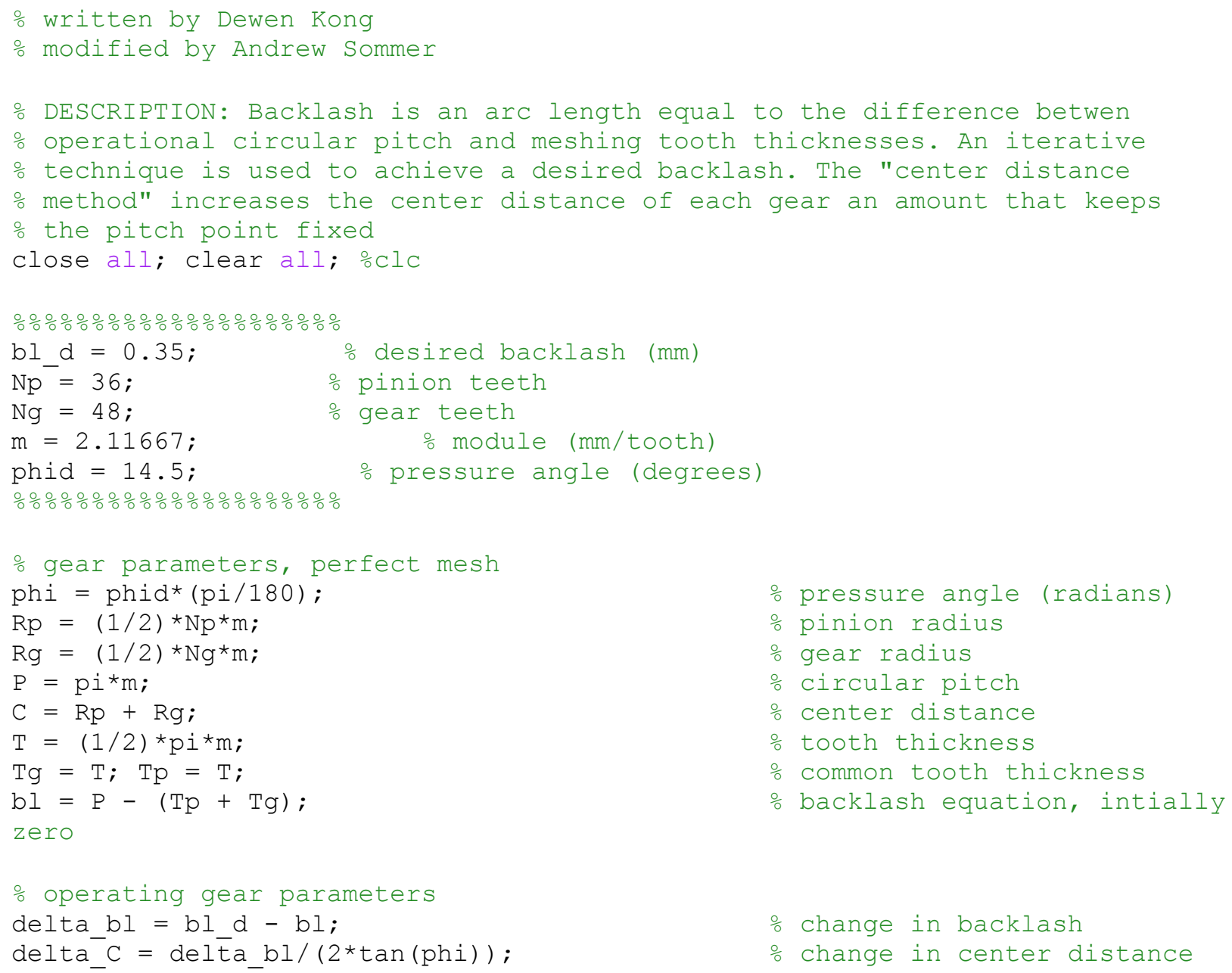




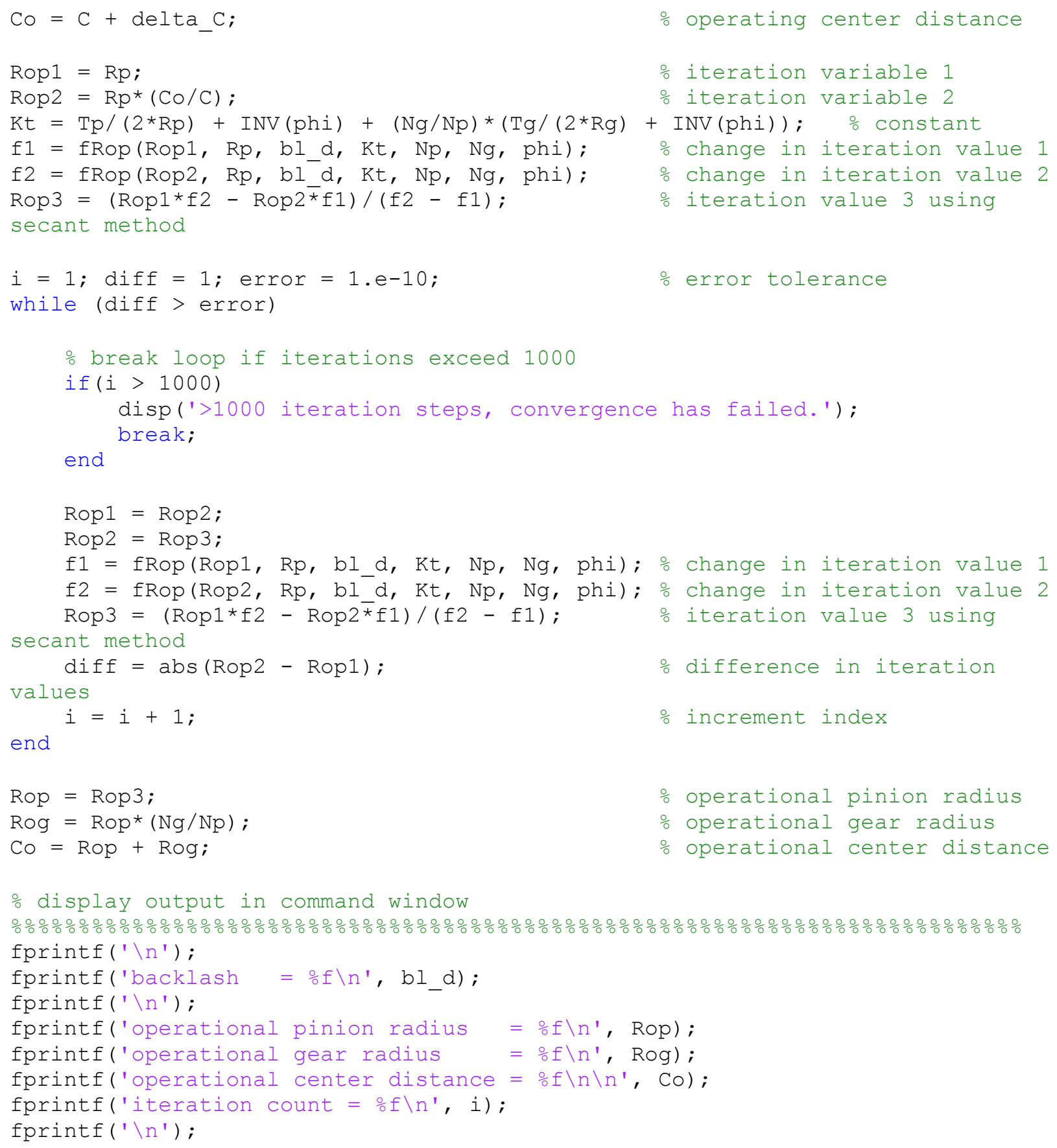

\section{GEAR_EFFICIENCY.m Matlab Program}

\% written by Matthew Ostiguy 5/28/14

\% DESCRIPTION: Calcualte the gear mesh efficiency between a gear pair.

ㅇ Source]

close all; clear all; \%clc 


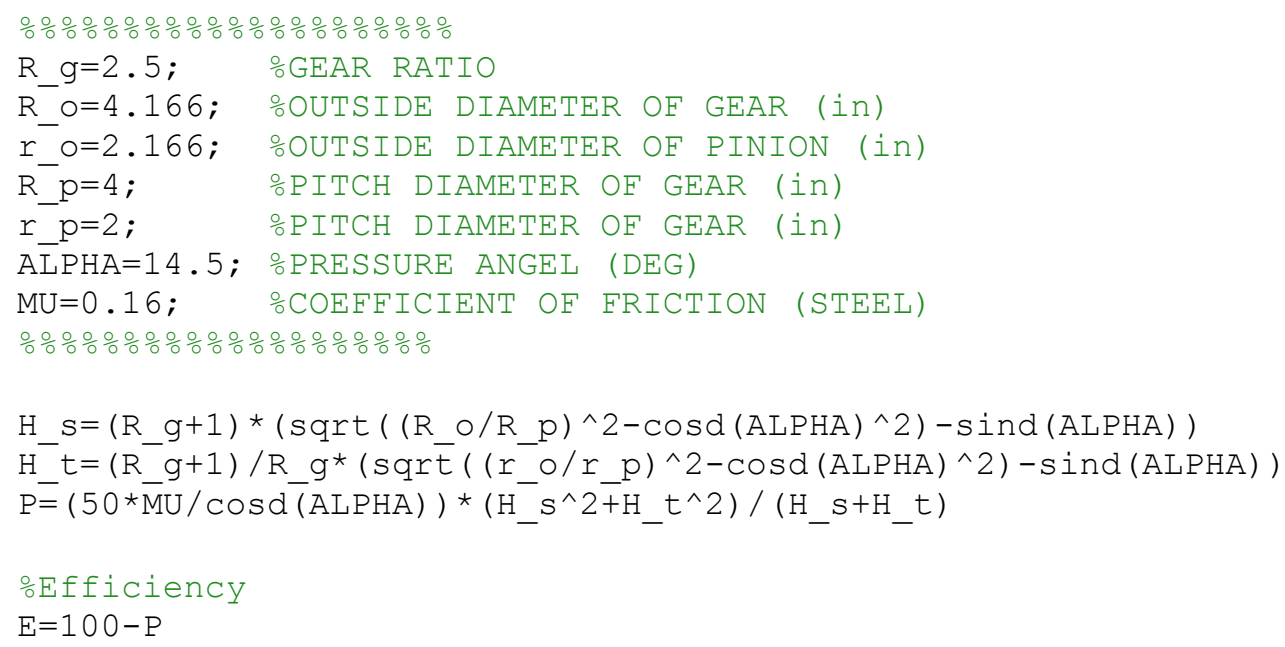




\section{H. EES CODE}

"Transmitted Tooth Load"

$d=2$

omega $=3600$

$\mathrm{V}=\left(\mathrm{pi}^{*} \mathrm{~d}^{*}\right.$ omega $) / 12$

"gear diameter - in"

"operating speed - rpm"

"Pitch-line velocity - ft/min"

$\mathrm{H}=3$

W_t $=33000 *(H / V)$

"motor power - hp"

"Tangential tooth load -lbf"

"Bending Stress - Lewis Bending Eqn

converted to use diametral pitch"

$\mathrm{P}=12$

$\mathrm{Y}=0.302$

$\mathrm{F}=0.75$

sigma_b $=\left(W \_t^{\star} P\right) /\left(F^{\star} Y\right)$

"diametral pitch - teeth/in"

"tooth form factor"

"face width - in"

"Tooth bending stress - psi"

"Fatigue Loading"

S_ut $=102$

$k \_a=a * S \_u t^{\wedge} b$

"Steel ultimate stress - ksi"

$a=1.34$

$b=-0.085$

$k \_b=0.879^{\star} d \_e^{\wedge}\left(-1^{*} 0.107\right)$

$\mathrm{t}=0.1309$

d_e $=0.808^{*}\left(F^{*} t\right)^{\wedge} 0.5$

"Surface Factor"

k_c $=1$

k_d $=1$

k_e $=1$

$k \_f=1$

"Size Factor"

"tooth thickness - in"

"effective diameter"

"Loading Factor"

"Temperature Factor"

"Reliability Factor"

"Miscellaneious Effects"

$S \_e=k \_a^{*} k \_b^{*} k \_c^{*} k \_d^{*} k \_e^{*} k \_f^{*} 0.5^{*} S \_u t$

"Endurance Stregnth"

"Fatigue strength of gear for 10,000 cycles"

$\mathrm{S} \_\mathrm{f}=\mathrm{a} \_2^{*} \mathrm{~N}^{\wedge} \mathrm{b} \_2$

$\mathrm{N}=10000$

f $2=0.85$

a_2 $=\left(f \_2 * S \_u t\right)^{\wedge} 2 / S \_e$

b_2 $=-1 / 3^{\star} \log 10\left(f \_2^{\star} S \_u t / S \_e\right)$

"Calculate testing stress amplitude"

sigma_min $=62$

sigma_a $=($ sigma_max-sigma_min $) / 2$

sigma_m $=($ sigma_max+sigma_min $) / 2$

S_f=sigma_a/(1-sigma_m/S_ut)

"Fatigue Strength - ksi"

"Number of cycles" 
"Case 1: Nominal un-notch tooth"

W_t2 $=\left(\right.$ sigma_max $\left.{ }^{*} F^{*} Y\right) / P^{*} 1000$

"Required tangential load - Ibf"

"Case 2: Notched Tooth"

$\mathrm{K} \mathrm{t}=2.4$

sigma_nom $=$ sigma_max $/ \mathrm{K} \_\mathrm{t}$

W_t3 $=\left(\right.$ sigma_nom $\left.{ }^{\bar{*}} F^{*} Y\right) / P^{\bar{*}} 1000$

"Stress concentration factor" "Nominal Stress - ksi"

"Required tangential load - lbf" 